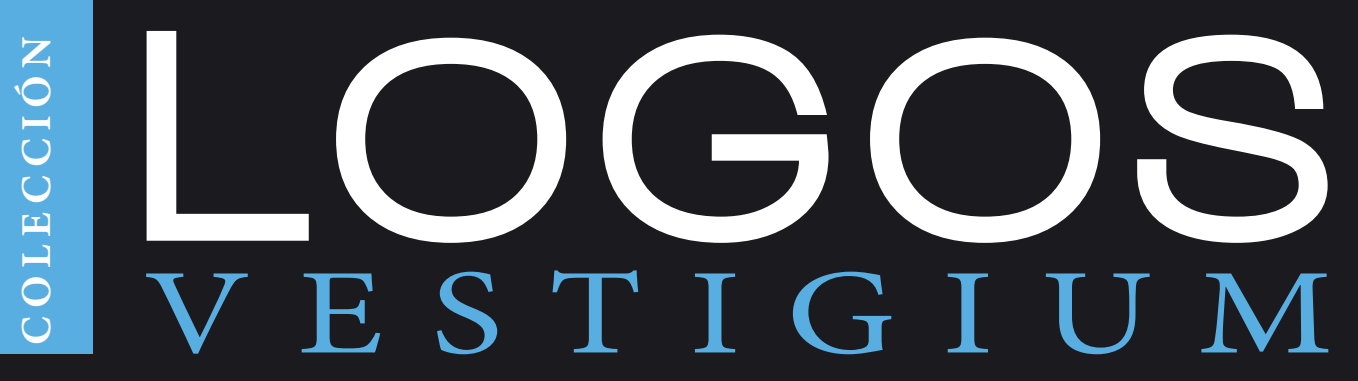

Cultura organizacional y cambio: reflexiones y discusiones desde la psicología organizacional

Juan Javier Vesga R. (ed.), Mónica García-Rubiano (ed.), Eliana Quiroz González, Esther Julla Castaño González, María Constanza Aguilar Bustamante, Verónica Andrade Jaramillo, María Alejandra Gómez Vélez, Carlos Forero-Aponte, Jairo A. Ángel Jaramillo

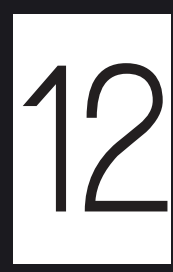




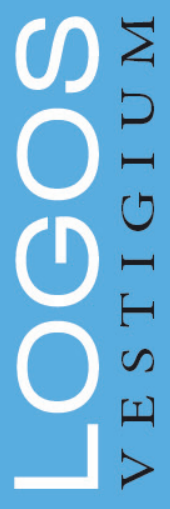

\section{Verónica Andrade Jaramillo}

Doctora en Psicología con énfasis en Psicología del Trabajo y las Organizaciones de la Universidad del Valle, magíster en Psicología con énfasis en Psicología Organizacional y del Trabajo de la Universidad del Valle. Actualmente, docente de la Facultad de Psicología de la Universidad Pontificia Bolivariana de Medellín y coordina el Grupo de Investigación en Psicología, Sujeto, Sociedad y Trabajo.

\section{María Alejandra Gómez Vélez}

Doctora en Psicología, magíster en Ciencias Sociales, especialista en Psicología Organizacional y especialista en Seguridad y Salud en el Trabajo. Actualmente, docente de pregrado y posgrado en la Facultad de Psicología de la Universidad Pontificia Bolivariana, sede Medellín.

\section{Carlos Forero-Aponte}

Magíster en Psicología de la Universidad Católica de Colombia, docente de diversas universidades. Actualmente, vinculado al Consejo Nacional del Servicio Civil. Autor de diversos artículos y capítulos de libros.

\section{Jairo A. Ángel Jaramillo}

Psicólogo de la Universidad Santo Tomás, especialista en Gerencia de Mercadeo de la Universidad del Rosario, magíster en Gestión de la Calidad del convenio Icontec-UsTA y certificado en Educación de Adultos de la Universidad de Calgary (Canadá). Actualmente, docente en la Universidad Santo Tomás en el Programa de Psicología.
Juan Javier Vesga R.

Doctor en Psicología en la línea de Psicología del Trabajo y las Organizaciones, especialista en Gerencia del Talento

Humano. Fue director del Doctorado en Psicología en la Universidad Católica de Colombia y actualmente es decano de la Facultad de Psicología en la Universidad El Bosque. Miembro del Colegio Colombiano de Psicólogos y de la Red Iberoamericana de Psicología de las Organizaciones y del Trabajo (Ripot).

\section{Mónica García-Rubiano}

Doctora de la Universidad de Almería (España), magíster en Psicología y especialista en Psicología de las Organizaciones de la Universidad Católica de Colombia.

Actualmente, coordinadora de la Especialización en Psicología de las Organizaciones y directora del grupo de investigación Europsis.

\section{Eliana Quiroz Gónzalez}

Psicóloga, especialista y magíster en Gerencia del Talento Humano. Docente e investigadora de la Universidad Católica de Pereira. Coordinadora de campos, programas y proyectos del capítulo Eje Cafetero del Colegio Colom-

biano de Psicólogos e integrante del grupo de investigación Comunicación, Educación y Cultura.

\section{Esther Julia Castaño González}

Doctora en Relaciones Internacionales Iberoamericanas de la Universidad Rey Juan Carlos de España, magíster en Educación, Desarrollo Humano de la Universidad de San Buenaventura de Cali, con un máster profesional en Relaciones Internacionales Iberoamericanas y especialista en Comunicación Organizacional de la Universidad Autónoma de Occidente de Cali. Docente de la Universidad Católica de Pereira e integrante grupo de investigación Comunicación, Educación y Cultura.

\section{María Constanza Aguilar Bustamante}

Doctora en Psicología de la Universidad de La Laguna

(Tenerife, España), magíster en Psicología con énfasis en Psicología de las Organizaciones y del Trabajo

(Universidad Católica de Colombia). Representante nacional de Colombia de la Sociedad Interamericana de

Psicología (sIP) 2017-2019. Premio Nacional de Psicología 2016: Promoción y divulgación del conocimiento psicológico, otorgado por el Consejo Directivo Nacional del Colegio Colombiano de Psicólogos (COLPSIC). 


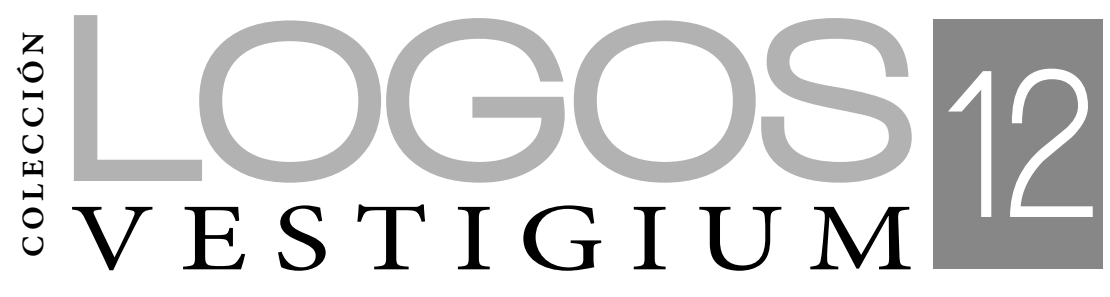

Cultura organizacional
y cambio: reflexiones y discusiones desde la psicología organizacional

\author{
Juan Javier Vesga R. \\ Mónica Garćía-Rubiano
}

Editores académicos 
Quiroz González, Eliana

Cultura organizacional y cambio: reflexiones y discusiones desde la psicología organizacional / Eliana Quiroz González, Esther Julia Castaño González, Verónica Andrade Jaramillo, María Alejandra Gómez Vélez, María Constanza Aguilar, Bustamante, Jairo Ángel Jaramillo, Juan Javier Vesga R., Mónica García-Rubiano, Carlos Forero-Aponte; Juan Javier Vesga R. y Mónica García-Rubiano (editores) - Bogotá: Universidad Católica de Colombia, 2020

186 páginas ; $17 \times 24 \mathrm{~cm}$

ISBN: 978-958-5133-48-8 (impreso)

\section{8-958-5133-49-5 (digital)}

I. Título II. Castaño González, Esther Julia III. Andrade Jaramillo, Verónica IV. Gómez Vélez, María Alejandra V. Aguilar Bustamante, María Constanza VI. Ángel Jaramillo, Jairo VII. Vesga R., Juan Javier VIII. García-Rubiano, Mónica IX. Forero-Aponte, Carlos X. Vesga R., Juan Javier (editor) XI .García-Rubiano, Mónica (editora)

1. Cultura organizacional 2. Comportamiento organizacional

\section{Proceso de arbitraje}

Primer concepto de evaluación:

15 de agosto de 2020

Segundo concepto de evaluación:

25 de agosto de 2020

(C) Universidad Católica de Colombia

(C) Juan Javier Vesga R. (ed.)

(C) Mónica García-Rubiano (ed.)

(C) Eliana Quiroz González

(C) Esther Julia Castaño González

(C) María Constanza Aguilar Bustamante

(C) Verónica Andrade Jaramillo

(C) María Alejandra Gómez Vélez

(C) Carlos Forero-Aponte

(C) Jairo A. Ángel Jaramillo

Primera edición, Bogotá, D.C.

Diciembre de 2020

DiRECCIÓN EDITORIAL

Stella Valbuena García

CoOrdinación Editorial

María Paula Godoy Casasbuenas

CorrecCión DE ESTILO

Alejandra Muñoz

Diseño DE COLECCIÓN

Juanita Isaza

Diagramación

Andrés Mauricio Enciso B.

Publicación digital

Hipertexto Ltda.

www.hipertexto.com.co

Las pruebas citadas en este libro han sido obtenidas de publicaciones electrónicas, tesis de grado y web relacionados. No son ni pretenden ser autoría de los autores que escribieron la presente obra.

\section{Cómo CITAR EN APA}

Impreso

Vesga, J. \& García-Rubiano, M. (Eds.). (2020).

Cultura organizacional y cambio: reflexiones $y$

discusiones desde la psicología organizacional.

Editorial Universidad Católica de Colombia.

Digital

Vesga, J. \& García-Rubiano, M. (Eds.). (2020).

Cultura organizacional y cambio: reflexiones y

discusiones desde la psicología organizacional.

Editorial Universidad Católica de Colombia.

https://doi.org/10.14718/9789585133495.2020

\section{FACUlTAd DE PSICOlOGÍA}

Avenida Caracas \# 46-22

Bogotá, D. C.

psicologia@ucatolica.edu.co

\section{EDITORIAL}

Universidad Católica de Colombia

Av. Caracas $46-72$ piso 5

Bogotá, D. C.

editorial@ucatolica.edu.co

Todos los derechos reservados. Esta publicación no puede ser reproducida ni total ni parcialmente o transmitida por un sistema de recuperación de información, en ninguna forma ni por ningún medio, sin el permiso previo del editor.

Hecho el depósito legal

(C) Derechos reservados

Licencia Creative Commons Atribución-CompartirIgual 4.0

Internacional (CC BY-SA 4.0)

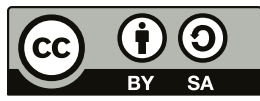


Prólogo 11

INTRODUCCIÓN 15

CAPítulo 1

Las organizaciones del siglo XxI: historia, transformaciones y desafíos.

Capítulo 2

Cultura organizacional: reflexiones sobre el concepto

CApítulo 3

Liderazgo y cultura organizacional

Capítulo 4

Intervenir sobre la cultura organizacional:

¿qué aspectos se pueden considerar?

Capítulo 5

Cambio organizacional: una introducción al concepto .91

Capítulo 6

Aprendizaje organizacional como base de los procesos

de cambio

CAPítulo 7

Gerencia del cambio organizacional

CAPítulo 8

Tendencias de la cultura y cambio organizacional:

estudio de caso 171

REFLEXIONES FINALES 183 


\section{LISTA DE TABLAS}

Capítulo 3

Tabla 1. Teorías clásicas: rasgos, estilos y contingencia .......................... 53

Tabla 2. Enfoques alternativos del liderazgo .......................................... 54

Tabla 3. Enfoques recientes de liderazgo .............................................. 54

Tabla 4. Temas y orientaciones actuales ................................................. 56

Tabla 5. Perspectivas y niveles de la cultura según Molero (2002) .......... 63

Capítulo 6

Tabla 1. Barreras para el aprendizaje en las organizaciones

Tabla 2. Fases del proceso de aprendizaje de Robert Gagné

Capítulo 7

Tabla 1. Cuatro enfoques diferentes para el proceso de cambio

Tabla 2. Cambio de contenido y cambio asociado a tipos

de intervención ideales

Capítulo 8

Tabla 1. Descriptivos de las variables objeto de estudio 176

Tabla 2. Correlación entre las dimensiones de la cultura y la disposición al cambio organizacional

Tabla 3. Correlación entre los tipos de la cultura y la disposición al cambio organizacional 


\section{LISTA DE FIGURAS}

\section{Capítulo 2}

Figura 1. Modelo de niveles de la cultura organizacional de Schein .......42

Figura 2. Modelo de rasgos de la cultura organizacional de Denison .....44

Figura 3. Modelo de tipos de cultura organizacional de Cameron

y Quinn

CApítulo 3

Figura 1. Relación entre cultura organizacional y liderazgo

Capítulo 7

Figura 1. Organización como sistema abierto 129

Figura 2. Manteniendo el statu quo 136

Figura 3. Modelo de los tres pasos de Lewin. 136

Figura 4. Modelo de procesamiento de cambio continuo. 143

Figura 5. Gestión de la transición de Carnall 145

Figura 6. Efecto maratón 146

Figura 7. Los cinco componentes básicos de una organización. 147

Figura 8. Modelo de rendimiento organizacional y cambio 149

Figura 9. Estrategia de negocios y relación con los procesos de gerencia relacionados 150

Figura 10. Matriz de posiciones de cambio 151

Figura 11. Matriz de cambio y estrategia de recursos humanos 153

Figura 12. Modelo integrativo de dinámica organizacional de Kotter .154

Figura 13. Modelo de ocho pasos de Kotter 154

Figura 14. Modelo Anderson y Anderson de cambio 159

Capítulo 8

Figura 1. Cultura organizacional según el modelo de valores en competencias 



\section{GRUPO: EUROPSIS}

\section{LÍNEA DE INVESTIGACIÓN}

Psicología organizacional

\section{PROYECTO:}

Aspectos de la cultura organizacional y su relación con la disposición al cambio organizacional 



\section{Resumen}

Este libro es producto de un proyecto de investigación institucional que busca realizar una contribución teórica y empírica sobre la cultura y el cambio organizacional, variables importantes en la dinámica organizacional.

En este libro se aborda la perspectiva de la cultura organizacional considerando diversos temas que permiten entender su relación con otras variables y a su vez identificar cómo el cambio organizacional es un constructo que tiene un impacto importante en la organización. Por tanto, la aceptación o rechazo de los cambios en las organizaciones va a depender, de alguna manera, de la cultura organizacional que se refleje en la organización. Finalmente, se presenta la relación entre las variables objeto de estudio como un estudio de caso.

Palabras clave: organización, cultura organizacional, cambio organizacional, liderazgo, gerencia del cambio. 


\section{Abstract}

This book is the product of an institutional research project that seeks to carry out a theoretical and empirical contribution on culture and organizational change, variables important in organizational dynamics.

This work addresses the perspective of organizational culture considering various topics that allow understanding their relations with other variables and in turn identifying how the organizational change is a construct that has an important impact on the organization. Therefore, the acceptance or rejection of changes in organizations will depend somehow on the organizational culture that is reflected in the organization. Finally, the connection between the variables under study is presented as a case study.

Keywords: Organization, Organizational culture, Organizational change, Leadership, Change management. 


\section{PRÓLOGO}

Carlos Alberto Gómez Rada

Universidade de São Paulo

Universidad Católica de Colombia

En un mundo en continua turbulencia donde el cambio parece la única constante, donde las formas organizacionales se agitan y transforman a la velocidad de la tecnología, donde los indicadores económicos se deslizan como una montaña rusa e incluso las tendencias políticas y sociales varían al vaivén de los extremismos de izquierda y de derecha, lo único cierto es la incertidumbre, el eclipse permanente de los paradigmas de largo plazo y organizaciones que se cimientan en una metamorfosis infinita.

Bajo tal perspectiva, esta obra presenta una panorámica de la organización de hoy frente a la organización del pasado. En este punto, las autoras Quiroz-González y Castaño-González hacen un recorrido histórico que retrata la evolución de las organizaciones en su interacción con el entorno y las mutaciones estructurales que han desarrollado para responder a esta dinámica.

Dentro de esta misma línea de ideas, los autores García-Rubiano y Forero-Aponte introducen al lector el concepto de cambio organizacional desde una perspectiva holística que conduce a reconocer la complejidad de este fenómeno, los múltiples factores involucrados y el papel trascendental del comportamiento humano en los resultados que se derivan para la organización. Esta disertación es complementada por Ángel-Jaramillo, quien nos presenta una visión ampliada de los retos derivados del cambio organizacional para la gerencia actual y la manera como diversos autores han postulado un conjunto de modelos explicativos que sirven a su vez como una guía de consulta para los lectores interesados en gestionar el cambio. 
El cambio en la organización solo es posible en la medida en que la organización desarrolla la capacidad de aprender y reconstruirse a sí misma, incluso a veces como el ave fénix desde sus propios cimientos o como lo expresan Hammer y Champy (1993), puede reinventarse y redefinir su know how. Sobre este punto, Gómez-Vélez nos adentra en el proceso de aprendizaje organizacional y describe las intrincadas relaciones que al interior de la organización permiten develar su naturaleza.

Pero, si todo en la organización fluye, como diría Heráclito "en un cambio incesante", ¿Cómo se reconoce el ser humano en la organización y la organización en sí misma?; ¿cómo resulta posible hablar de identidad organizacional y generar lo que se denomina imagen corporativa y los símbolos que se desprenden de ella? Para responder a estas preguntas, Vesga-Rodríguez, en primer lugar, introduce a los lectores al concepto de cultura y desde una óptica crítica nos sumerge en el océano oscuro de las definiciones conceptuales, en las que, como ocurre con otros conceptos psicológicos, la acepción de este no suele ser lineal, sino que presenta muchas vertientes y extrapolaciones de una disciplina a otra. En su recorrido, el autor nos lleva a los orígenes del concepto del ethos, su relación y derivación al constructo de la cultura organizacional.

En la siguiente fase de este periplo, los autores de este compendio examinan con profundidad las relaciones del concepto de cultura organizacional con dos variables del comportamiento humano en la organización: el liderazgo y el cambio organizacional. Con respecto a la relación liderazgo-cultura, Aguilar-Bustamante nos presenta una síntesis de los estudios que han mostrado evidencias empíricas de las relaciones entre el tipo de liderazgo y las distintas configuraciones de cultura organizacional.

Por otra parte, García-Rubiano, Vesga-Rodríguez y Forero-Aponte en una descripción sumaria, describen las características y hallazgos principales de una investigación realizada en torno a la relación entre el cambio y la cultura organizacional en una institución de educación superior.

Como parte de esta travesía, Andrade hace un discernimiento de los diferentes factores que se deben considerar para hacer un proceso de intervención en la cultura de una organización, a la luz de los hallazgos reseñados en la literatura científica.

Por todo lo anterior, este volumen resulta un texto de gran interés para todos los lectores académicos, neófitos y expertos, que busquen un libro de consulta rico en evidencias científicas sobre el mundo actual de las organizaciones, sus desafíos sobre cambio y cultura y el aporte de la psicología de las organizaciones y del trabajo en la comprensión, predicción e intervención de estos fenómenos. 
Al final, el conocimiento es un infinito mar de posibilidades que se alimenta del esfuerzo conjunto de mujeres y hombres que desbordan su intelecto para compartirlo con otros y esta obra es un ejemplo de ello.

\section{Referencia}

Hammer, M. y Champy, J. (1993). Reingeniería. Norma. 



\section{INTRODUCCIÓN}

Juan Javier Vesga $R$.

Mónica García-Rubiano

Universidad Católica de Coiombia

Colombia

Este libro es producto del proyecto de investigación "Aspectos de la cultura organizacional y su relación con la disposición al cambio organizacional", llevada a cabo en el marco de la convocatoria interna de investigación realizada por la Universidad Católica de Colombia en 2018 y que convocó además a las universidades Santo Tomás en Bogotá, Pontificia Bolivariana de Medellín y Católica de Pereira.

Cultura organizacional y cambio son dos conceptos claves en la vida de las organizaciones, que aluden a hechos y realidades que estas experimentan en la dinámica cotidiana de su gestión y que sin duda son referentes importantes para la gestión, supervivencia, desarrollo y competitividad, en un ambiente de negocios cada vez más variado y complejo.

En cuanto a la cultura organizacional, tanto las investigaciones como la literatura especializada en el tema han puesto en evidencia su importancia en la ejecución de las estrategias de gestión, en la vida de la organización y en la creación de una identidad corporativa que facilite estados de compromiso y vinculación de los actores laborales con la propia organización.

Por otra parte, en relación con el cambio organizacional, desde la década de 1970, cuando se pone en evidencia la crisis del fordismo y el taylorismo y luego en la década de 1990 con las transformaciones globales políticas y económicas, así como el desarrollo de tecnologías de comunicaciones y de informática, la necesidad de cambio se volvió un requerimiento imprescindible para la supervivencia de las organizaciones, ya sea como mecanismo de adaptación a las rápidas y continuas transformaciones del 
entorno, o como forma de innovar y buscar estar a la vanguardia como estrategia de competitividad en los mercados cada vez más convulsionados.

En este orden de ideas, dos escenarios son posibles para todo tipo de organizaciones: el primero se refiere a que las culturas cambian, pero no con la velocidad que a veces se requiere, o consolidan patrones de comportamiento favorables o desfavorables a los objetivos corporativos; el segundo implica que los líderes organizacionales requieren impulsar el cambio de las culturas de las organizaciones que dirigen, aunque esto no siempre sea posible o no sepan cómo hacerlo. Sin embargo, independientemente de estas posibilidades, cultura organizacional y cambio son temas que nunca pierden vigencia en la dinámica de las organizaciones, y que requieren una atención permanente por parte de quienes las dirigen.

De esta manera, este texto es un esfuerzo por compilar temáticas que, a modo de ver de sus autores, ofrecen ideas que arrojan luz sobre interrogantes referidos a problemáticas asociadas a la gestión del cambio y la cultura organizacional en relación con asuntos como el aprendizaje organizacional y el liderazgo. El primer capítulo constituye una introducción necesaria a modo de marco contextual, sobre las organizaciones actuales, su historia y desafíos. Los capítulos 2, 3 y 4 abordan la primera variable de esta investigación: la cultura organizacional; en ellos se discuten diversos aspectos relacionados con este concepto. En los capítulos 5, 6 y 7 se discute la segunda variable de la investigación, el cambio organizacional. Finalmente, en el capítulo 8 se presentan, a modo de caso, el proceso y los resultados de la investigación realizada. Los autores esperan que los lectores encuentren en estos capítulos no solo respuestas a algunas de sus inquietudes, sino que estas impulsen, además, la formulación de otras preguntas que sirvan de base para una búsqueda continua del conocimiento. 


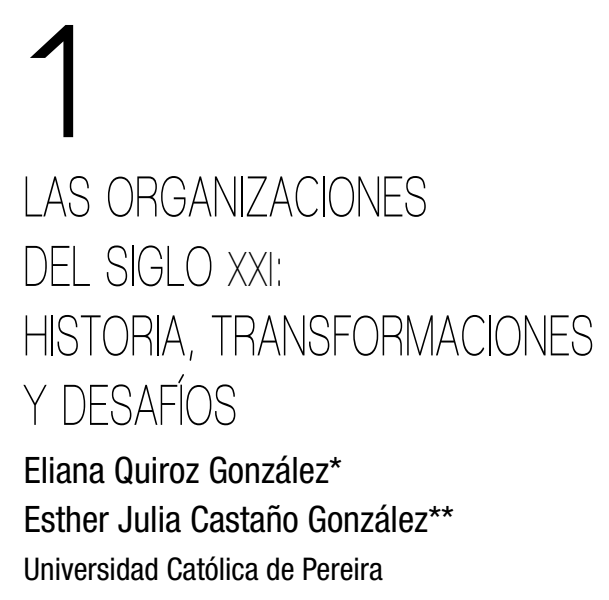

Diversos cambios políticos, económicos, sociales y tecnológicos acontecidos en el mundo desde finales de los años sesenta, junto a crisis como las del petróleo (1973 y 1979), y el caos económico-financiero del sistema estructurado en Bretton-Woods, llevaron a que se cuestionaran los postulados keynesianos y fordistas (Alonso y Fernández, 2006; Jaua, 1997).

Esto trajo consecuencias que marcaron la historia de las organizaciones y las modificaron profundamente. Las nuevas formas de contratación, las organizaciones que coexisten con otras de manera simultánea, el trabajo en red, la flexibilización y la virtualización, son algunos efectos de estas transformaciones y realidades propias de las organizaciones del siglo XXI.

Pese a estos importantes cambios y al constante dinamismo en el que el mundo se encuentra, hoy diversas organizaciones son administradas con modelos obsoletos, creados en una época en la que las condiciones culturales y financieras eran diferentes, por tanto, hay un llamado a actualizar, redefinir, repensar algunos modelos teóricos y prácticas organizacionales, pues ante tanta turbulencia se requieren formas diferentes de hacer las cosas.

Partiendo de este escenario, en el presente capítulo se desarrolla el concepto global de organización, se hace, en retrospectiva, un recorrido por las teorías clásicas que fundaron la administración, se plantean los nuevos retos para el trabajador y se muestra la importancia de las organizaciones saludables, las cuales promueven el bienestar

eliana.quiroz@ucp.edu.co

* https://orcid.org/0000-0001-9061-8864

** https://orcid.org/0000-0003-3240-896X 
de los trabajadores, en un proceso de optimización en el que la cultura y el cambio organizacional son protagonistas.

\section{Concepto de organización: coincidencia en la importancia del factor humano}

Tras las transformaciones acaecidas con la Revolución industrial iniciada en el siglo XVIII, entre ellas, el abandono de viejas legitimaciones y la reconstrucción de una nueva sociedad, que pasa de lo rural y agrario a lo urbano e industrial, con el protagonismo de las máquinas y las grandes factorías, la organización y sus estudios toman fuerza (Chaves, 2004; Livacic, 2009).

Muchas son las conceptualizaciones dadas a la organización a lo largo de la historia, algunas con poca unicidad conceptual, por surgir de diversos lentes epistemológicos, aunque suelen coincidir en que son las personas quienes hacen posible la existencia y la supervivencia de las organizaciones.

Una de las primeras conceptualizaciones sobre la organización remarca la diferencia entre la organización económica y la organización social, reconociendo que, en la económica, se tejen relaciones sociales asociativas, mas no comunales, las cuales están limitadas por especificidades como la estructura, los patrones de interacción entre los trabajadores, las normas y los roles (Weber, 1947).

Posteriormente, la organización fue entendida como una unidad social con un objetivo definido (Etzioni, 1965), dicha unidad o entidad social tiene una configuración racional (Mayntz, 1972) que le permite sostenerse y tener trascendencia en el tiempo (Porter, Lawler y Hackman, 1975).

Las organizaciones son sistemas abiertos en continua transacción con el ambiente (Kahn y Katz, 1989), en el que se llevan a cabo la planeación y coordinación de diversas actividades para llegar al cumplimiento de objetivos (Schein, 1991), dichos objetivos o propósitos comunes se logran a partir de un acuerdo intencional entre las personas que conforman la organización (Robbins y Coulter, 2009).

Las organizaciones como sistemas colectivos deben ser leídas desde una perspectiva política y constructivista (Peiró, 1999). Para Porras (2012), en consonancia con Peiró (1996), la organización está constituida por "fenómenos socio-cognoscitivos construidos, donde dichas construcciones sociocognitivas se configuran como 'juegos de poder"' (p. 11) que son, para este autor, justamente, lo que conforma la esencia de la organización.

Para Blanch (2007), la organización es un “[...] colectivo de personas asociadas para trabajar conjuntamente de cara al logro de objetivos comunes. Constituyen un sistema 
social complejo, estable, integrado, jerarquizado, con estructura de poder, división de roles, delimitación de competencias y definición de objetivos y estrategias" (p. 20).

Estos objetivos y estrategias cambian en la medida en que el entorno y la propia organización se transforma. Por ejemplo, gracias al desarrollo de las nuevas tecnologías, una de las nuevas formas de organización consiste en aquella conformada por una estructura en red, dicha estructura se basa en la existencia de nodos que buscan dar respuesta a problemas específicos (Rivas, 2002). Desde esta óptica, la organización se sostiene a partir de relaciones en constante fluidez (Alonso y Fernández, 2006).

Para Chiavenato (2012) la sociedad se encuentra institucionalizada y compuesta de organizaciones que, además de estar presentes en la vida de todos ya que proveen los satisfactores a las necesidades de los seres humanos, proyectan la cultura en la que están inmersas (Livacic, 2009) y, finalmente, responden a necesidades y problemas de época, sin decir aquí que su presencia sea siempre positiva.

Los seres humanos "nacen, crecen, aprenden, viven, trabajan, se divierten, se relacionan y mueren dentro de organizaciones" (Chiavenato, 2012, p. 2), en otras palabras, la vida de las personas se desarrolla en torno a las organizaciones (Blanch, 2007). Al estar conformadas esencialmente por personas, la comprensión del fenómeno organizacional implica reconocer la naturaleza humana, de forma que las organizaciones sean escenarios para el desarrollo de sus trabajadores (Bächler y Poblete, 2009).

En este sentido, las organizaciones, como sus trabajadores, tienen vida propia (Díez y Atela, 2019). El hecho de que las personas dependan de las organizaciones y que, a su vez, las organizaciones requieran del trabajo de estas, pone en evidencia una relación recíproca, íntima e inseparable que, idealmente, debe ser beneficiosa para ambas partes, por tanto, la organización debe desplegar los recursos suficientes para generar un óptimo desarrollo en sus trabajadores, pero también de sus roles, de las normas y de sus mecanismos de control para, consecuentemente, lograr una gestión administrativa que garantice su supervivencia, su crecimiento y que responda a los resultados esperados (Salanova y Schaufeli, 2009a), según sean sus intereses económicos y productivos.

Para esto, la organización debe encontrar el equilibrio entre los alicientes y las contribuciones de sus trabajadores, puesto que, para que una organización sobreviva “[...] se requiere invertir recursos y energía” (Pfeffer, 1997, p. 8), sobre todo, en adelantar procesos heterogéneos y dinámicos que aporten a la labor que realiza el trabajador y a este como tal, favoreciendo su desempeño laboral y su realización personal, además del establecimiento de relaciones armónicas con sus pares, personal a cargo y superiores (Marchiori, 2011). 
En síntesis, las personas constituyen el activo más importante para una organización (Raya y Panneerselvam, 2013). Sin embargo, para llegar a reconocer la importancia de lo humano en las organizaciones, sus motivaciones, expectativas y emociones, el camino ha sido largo, por lo que vale la pena recorrer algunas teorías que llevaron a esta comprensión de la figura e importancia del trabajador en la organización.

\section{La evolución de la administración: abordaje desde diferentes teorías}

La organización de hoy se torna interconectada y compleja (Martín, Segredo y Perdomo, 2013; Rivera, Carrillo, Forgiony, Nuván y Rozo, 2018), esta, independientemente de su antigüedad, número de empleados, misión o tipo de sistema de producción, requiere ser administrada, actividad que, históricamente, ha sido objeto de estudio.

Es así como en la antigua Mesopotamia se redactan los primeros documentos históricos sobre la acción directiva (Agulló, 1999; Ramírez, 2010); no obstante, Pfeffer (1997) refirió que los estudios de las organizaciones y específicamente de la administración se originan en la ingeniería mecánica y en la ingeniería industrial y se remontan a finales del siglo XIX e inicios del Xx.

En este orden de ideas, fueron clásicos como Taylor, Gantt y Gilbreth con su organización científica del trabajo; Fayol, Urwick, Mooney y Reiley con su propuesta de escuela administrativa y Max Weber con su modelo burocrático quienes, metódicamente, teorizaron sobre la organización y su direccionamiento y aportaron una evolución conceptual devenida de la investigación (Agulló, 1999; Segredo, 2016). Para esta época y bajo estos modelos era fundamental que quien estuviera a cargo de la dirección en una organización se dedicara a aplicar racionalmente técnicas que permitieran la maximización de los beneficios (Grau, 2014).

Además, estos modelos caracterizados por la solidez y la centralización respondían a los problemas que se presentaban propios de la producción en serie, y también a fenómenos sociales desde la racionalización y la modernización. Este periodo fue denominado la "época gloriosa" basada en la idea de progreso de las organizaciones en Norteamérica, la cual se difundía en el mundo con cierto aire ideal (Piore y Sabel, 1990).

Según Vesga (2016) "la gestión empresarial y la administración del trabajo estuvieron definidas sobre las bases del fordismo y el taylorismo" (p. 239), sin embargo, aunque se reconoce su aporte, los postulados de algunos clásicos gozan de una imagen que genera controversia al relacionar sus teorías con conceptos como el de la explotación del trabajador. 
Esto se denota en aseveraciones como la de Saldarriaga (2014) cuando afirma que "desde los postulados de Taylor y Fayol, la administración ha concebido al ser humano, en el mejor de los casos, como una herramienta para el trabajo" (p. 225). En cierta posición de defensa se ha afirmado que Taylor ha sido malinterpretado y que su propósito esencialmente era estudiar cómo, a través del trabajo, el ser humano podría alcanzar un nivel máximo de prosperidad (Agulló, 1999).

Ahora bien, basados en los preceptos de Taylor aparece el fordismo; este movimiento está inspirado en Henry Ford, quien a principios del siglo xx realizó grandes aportes a la administración a partir de la disminución del tiempo de producción, el manejo de la materia prima, el pago a los empleados y el trabajo coordinado, entre otros aspectos como las ideas desde el proteccionismo y la eliminación de los tiempos inútiles de los empleados, lo cual hace que sea considerado un clásico (Rodríguez, 2014).

Entonces, tras los postulados racionalistas, el trabajo se centraba en la productividad, lograda gracias a reglas claras y estrictas, impersonalidad en las decisiones y perfección técnica (Arano Chávez, Escudero Macluf y Delfín Beltrán, 2016), con especial esfuerzo en diagnósticos sobre métodos y movimientos, distribución de funciones, subfunciones y procedimientos, eficiencia, eficacia y evaluación, tanto de los puestos de trabajo como del desempeño.

Sin embargo, estos modelos comienzan a ser altamente cuestionados, ya que sus técnicas mostraron síntomas de crisis, pues parecían fórmulas en extremo mecanizadas en las que el obrero era instrumentalizado y además explotado pues, más que persona, el empleado era una herramienta al servicio de la organización con altas jornadas de trabajo y un sueldo básico muy bajo (Mancheno-Saá, Bermúdez-Santana y PérezBarrionuevo, 2019).

Así que la filosofía racionalista ya no se ajustaba a un mundo cambiante, por lo que se empieza a popularizar el pensamiento humanista a nivel mundial y el interés por la estimulación de los trabajadores en el proceso productivo aportado por los científicos sociales de la época. Por tanto, se tornan importantes las motivaciones de los trabajadores, en esencia, se hace un llamado a la humanización de los escenarios organizacionales.

Entre 1920 y 1966 se acredita el nacimiento y desarrollo de las escuelas y teorías de las relaciones humanas (Pfeffer, 1997), en las que sobresalen nombres relevantes en la historia de la administración como Elton Mayo, Abraham Maslow, Rensis Likert, Douglas McGregor, Chris Argyris y Frederik Hezberg (Agulló, 1999; Ramírez, 2010). 
Con los experimentos de Elton Mayo, el aumento de la productividad se empezó a relacionar con aspectos como la iluminación, e incluso con periodos de descanso más extensos (Mancheno-Saá et al., 2019). Así, la Escuela de las Relaciones Humanas defiende "la existencia de un sujeto humano en la organización", por lo que de allí deviene el discurso propio del talento humano (Saldarriaga, 2014, p. 230).

Un breve ejemplo de esta preponderancia en las personas se encuentra en la teoría Y de McGregor, desde este planteamiento, los trabajadores tenían la capacidad de aportar ideas y sugerencias, tareas que le habían correspondido a la dirección, que ahora comenzaba a ser sustituida o por lo menos apoyada por el equipo (Alonso y Fernández, 2006).

Elton Mayo hizo énfasis en la importancia de la motivación en los procesos organizacionales (Saldarriaga Ríos, 2014), idea que se mantiene vigente, pues postulados recientes indican que la motivación es la que define el comportamiento de las personas en el ambiente laboral (González, Lugo y Saldaña, 2019).

Ahora bien, alrededor de 1970, el mundo postra su mirada hacia la organización japonesa, la cual sustentaba su éxito en un nuevo modelo de relaciones industriales, caracterizado por un trabajador, quien era considerado importante y tratado con exigencia, pero con respeto y tolerancia (Alonso y Fernández, 2006).

Entonces, la empresa japonesa surge como ejemplo ideal para lo que se quería lograr en Occidente, que era, entre otras cosas, la flexibilidad organizacional, el reconocimiento del trabajador desde la figura de gestor de la producción (Arteaga, 2011), el compromiso de los directivos y su identificación con la organización y el equilibrio entre lo económico y los objetivos de las instituciones. A pesar de la fortaleza de este planteamiento, Japón deja de ser ejemplo, tras diferentes prácticas sustentadas en el capitalismo, en las que Estados Unidos es protagonista.

Vesga (2017) refiere cómo en los setenta, los modelos administrativos se caracterizaban por su rigidez, sin embargo, a causa de la aguda recesión económica y de la deflación que se vivía, en un intento de las organizaciones por sobrevivir, se incita al desarrollo tecnológico, la automatización, las alianzas estratégicas, la capacitación del trabajador y a procesos de transmisión cultural en pro de "sumar voluntades para la reducción de costos y la mejora continua” (Hernández, 2019, p. 30), entre otras medidas.

Estas transformaciones llevaron a cambios en la institucionalización del trabajo, pues ya no estaba solo vinculada a las nociones de solidez, estabilidad, desarrollo de carrera dentro de una organización y relaciones laborales en el marco de la seguridad 
(Vesga, 2016), sino que se transitó de una lógica de la producción en serie, en la que se minimizaban los riesgos a partir de la planificación de la producción, a una lógica de lo efímero, lo líquido, lo volátil. Así pues, en los años noventa del siglo xx se populariza la globalización y todo lo que ello implica, lo que da paso al vertiginoso siglo XXI, al que las organizaciones deben adaptarse.

Se trata de "un contexto donde resulta inocultable el aumento de la productividad vinculado a la incorporación de robots, de nuevos dispositivos electrónicos y a la propagación de la informática por todo el espacio productivo" (Hernández, 2019, p. 35), lo que da lugar para el requerimiento de más atención al trabajador, al desarrollo de sus competencias, pero también al cuidado de sus necesidades, sobre todo de las emocionales.

\section{La organización del siglo XXI y sus implicaciones para los trabajadores}

Tras el libre canje y la desregulación de los mercados, la popularización de la globalización y su ritmo vertiginoso, exceso de oferta, clientes más exigentes y la creación y desarrollo de las nuevas tecnologías de la información, las organizaciones, con problemas más complejos, se transformaron de manera profunda.

Ya en los noventa se deja atrás la economía caracterizada por la acumulación de capital, para tener que adaptarse a una nueva realidad impuesta por una economía global (Castells, 1997), caracterizada por "ruptura de fronteras, facilidad de comunicación, desplazamiento entre países, libertad de mercado y competencia colosal" (Zúñiga, 2012, p. 323), lo que ha producido variaciones en todos los ámbitos, incluidos el sistema jurídico, las relaciones de producción y las organizaciones sociales nacionales, por mencionar algunas (Zúñiga, 2012).

Estas condiciones de la economía global han permeado las prácticas gerenciales, y a su vez, la manera en que las personas se relacionan con sus equipos de trabajo, sus superiores y en general, con el mundo del trabajo, concepto complejo y multifacético (Albanesi, 2015), cuya teorización y sentido no son hegemónicos (Weisz, 2016). Estos cambios han posibilitado mutaciones significativas en la subjetividad de los trabajadores, ligadas a un desarrollo histórico, adscrito a un lugar y a un tiempo específico (Pineda, 2017).

$\mathrm{Y}$ es justamente por esto que se entiende que para algunas personas el trabajo genera placer, pero para otras sufrimiento, resaltando aquí una confrontación entre la obligación y el sacrificio contra el crecimiento y el desarrollo personal que puede generar 
el trabajo (Weisz, 2016). Siendo el trabajo vital para las personas “[...] reducirlo solo a la expresión de la urgencia por la sobrevivencia es un retroceso en el avance de la racionalidad humana y de su proceso mismo de humanización" (Gómez, 2014, p. 115).

Sin embargo, y a pesar de lo negativo o positivo que pueda ser, alrededor del trabajo se configuran dimensiones que lo posicionan como una actividad propia de la condición humana, que les permite a las personas potenciar sus habilidades, aprender, tejer nuevas relaciones sociales y trascender, es por esto que, el trabajo “... además de un valor económico, posee un valor social, cultural y simbólico” (Albanesi, 2015, p. 401).

En este entorno social aparece el desempleo como una realidad constante (Albanesi, 2015), la precariedad y la informalidad (Pineda, 2017). La actualidad laboral está caracterizada por un exceso de trabajo, ya sea por hiperpresencialidad o por multiocupación, la cual responde, en muchas ocasiones, a los bajos salarios que se reciben (Weisz, 2016), lo que impulsa a que muchas personas tengan más de un empleo.

Esta multiocupación se explica, entre otras cosas, por la necesidad consumista de la sociedad, que invita a que los individuos adquieran deudas a largo plazo, consuman una variada y sofisticada gama de servicios y productos, a veces innecesarios, lo que "[...] representa una transformación en las configuraciones de las relaciones capitalistas y laborales, pues la acumulación de deuda de la clase trabajadora, en especial, la deuda sobre los ingresos salariales es lo que permite garantizar la continuidad del sistema" (Pineda, 2017, p. 19).

Las organizaciones actuales buscan respuestas rápidas, en las que el trabajador, en medio de las exigencias propias de su rol, debe sobrellevar las contingencias que aparecen en el camino (Bauman, 2004); así, el trabajador debe estar preparado para ello, en ocasiones, restando tiempo para la reflexión, la crítica y la construcción desde el raciocinio (Andrade, 2014).

Otra condición de las organizaciones de este siglo es la tendencia a la individualización. Esto ha llevado a que la conciencia colectiva sea reemplazada por una multiplicidad de proyectos individualistas (Pineda, 2017); los trabajadores, en este momento, se caracterizan por el debilitamiento de la creencia en soluciones colectivas.

Los vínculos se debilitan, se tornan frágiles, dificultando la creación de lazos fuertes entre las personas, lo que, además, aumenta la soledad, el aislamiento y la incertidumbre, se incrementa el individualismo y la necesidad imperante de construir ideas, proyectos y resistencias compartidas (Weisz, 2016).

Todo lo anterior ha transformado la noción de empleabilidad, dado que ya no es la organización la responsable de brindar oportunidades a los trabajadores para que ellos tengan, por ejemplo, acceso a un desarrollo de carrera, sino que son estos mismos, 
los trabajadores, quienes deben desarrollarla a partir de sus capacidades, tanto para encontrar empleo como para crecer en él (Pineda, 2017). Los trabajadores son ahora los responsables de las condiciones bajo las cuales se inauguran y se mantienen en el mundo laboral.

Esta responsabilidad, que se le entrega a la clase trabajadora, también implica que sean los trabajadores los que deban desarrollar competencias para sortear y enfrentar las demandas del trabajo y la incertidumbre que generan las nuevas formas de contratación y las relaciones laborales efímeras que ofrecen las organizaciones, por tanto, el trabajador es responsable de su empleabilidad, por lo que debe capacitarse constantemente para ser competitivo en un mercado laboral (Pineda, 2017) que propone, entre otras cosas, dos grandes fenómenos a saber: la virtualización y la flexibilización laboral, los cuales, se tornan aquí, dimensiones de obligatoria mención.

\section{Virtualización y flexibilidad laboral}

La virtualización permite una desterritorialización del lugar de trabajo, pues el trabajador está conectado todo el tiempo desde diversos lugares (Weisz, 2016), incluyendo escenarios como el de su casa, el tiempo que invierte con la familia, en el descanso o en actividades de ocio.

En esencia, la virtualización tiene una estrecha relación con el desarrollo de las nuevas tecnologías que han desplazado el lugar central que ocupaba el ser humano en la ejecución del trabajo, al reemplazar la mano de obra por la máquina (Andrade, 2014). Los avances tecnológicos han permitido la reestructuración de la organización laboral, debilitando la necesidad de mano de obra, en particular de trabajadores no calificados (Albanesi, 2015).

Cabe mencionar que la interconexión, desde sus nuevas modalidades, va alejando al trabajador de los otros, estas dinámicas relacionales impulsan a que cada vez sea menor la presencialidad. En este tipo de empleos de corte virtual no es necesario un espacio físico determinado por la organización para ejercer las labores, además, es el trabajador quien termina asumiendo algunos costos como los referidos al consumo de los servicios públicos (Andrade, 2014).

Claramente la organización, desde la virtualidad, reduce la posibilidad física del encuentro con el otro. No obstante, estas organizaciones siempre van a requerir de la creatividad y de los conocimientos del ser humano, los cuales les permiten construir y consolidar la elaboración o prestación de los bienes y/o servicios que ofertan.

En este sentido, Rentería (2008) afirma que se debe tener en cuenta el impacto de la transformación de tiempo y espacio en la construcción de la virtualidad, la cual no 
puede desplazar al ser humano, pues hay lugares en los que las máquinas no pueden actuar. Por ejemplo, "la creación de mundos virtuales requiere de sistemas simbólicos creados por personas para personas" (p. 76).

Por otro lado, se presenta el fenómeno de la flexibilización laboral y la necesidad de su comprensión e implementación dentro de la nueva organización. La flexibilización laboral surge con la globalización (Gómez, 2014). La idea es renunciar a viejos hábitos y adaptarse a nuevas circunstancias (Chávez-Ramírez, 2001), es decir, disminuir o retirar la rigidez en lo laboral y legislativo, para que el trabajo se adapte, como convenga, al sistema productivo (Gómez, 2014).

Esta flexibilidad puede ser salarial, de la jornada laboral y de las funciones que el trabajador desempeña (López, 2005), así, la flexibilidad involucra aspectos en la organización del trabajo, la movilidad de la mano de obra y la formación del capital humano, entre otros, es decir, se da en diferentes casos y para cubrir diferentes necesidades (Chávez-Ramírez, 2001).

Específicamente, la flexibilización de las relaciones laborales es una estrategia utilizada para el mejoramiento del desempeño empresarial y el posicionamiento económico de las naciones, por tanto, se trata de una nueva forma de gestión. Sin embargo, y aunque representa mayor competitividad para la organización al promover la eficacia económica, para el trabajador significa una seria disminución de sus condiciones y derechos laborales, en especial de la estabilidad y de los beneficios que esta trae (López, 2005); de esta manera, la flexibilidad se convierte en un camino para reducir los derechos de la clase asalariada, pues facilita los términos para la culminación del vínculo laboral y el deterioro de las condiciones que generan estabilidad (Zúñiga, 2012).

Bajo el lente de la flexibilización laboral, aparecen los outsourcing, el teletrabajo, las contrataciones temporales y ocasionales, la contratación por medio de precooperativas de trabajo asociado, los contratos de prestación de servicios, entre otros. Cabe anotar que en una sola organización pueden coexistir diversas formas de contratación, lo cual afecta de nuevo los derechos de los trabajadores de innumerables maneras.

Estas nuevas formas de contratación, tanto en las organizaciones públicas como en las privadas, ofrecen modos de vinculación y de trabajo caracterizados por la fragmentación y la incertidumbre, las cuales, para Antunes (2000), son polivalentes, parciales, algunas precarias e incluso marginales. Específicamente para el contexto cercano "flexibilizar en América Latina significa reducir aún más los ya mínimos estándares laborales” (López, 2005, p. 47). 
A pesar de esto, los actuales entornos labores exigen a las organizaciones que implementen mecanismos de flexibilidad y dinamismo para ajustarse rápidamente a los constantes cambios que impactan el desarrollo y el progreso organizacional (Marchiori, 2011). Sin embargo, en esta exigencia, para Zúñiga (2012), la flexibilización no ha dado los frutos que se esperaban e insiste en que "[...] no se ha logrado combinar la flexibilidad implementada por la empresa con la seguridad y el progreso de los trabajadores en el marco de un diálogo necesario entre Gobierno, empleadores y trabajadores" (p. 324).

La flexibilización, tal como se vive hoy, ha generado diferentes efectos como el subempleo, la intensificación del trabajo (Blanch, 2007) y la frustración en la clase trabajadora, pues precariza el trabajo, genera relaciones de inequidad, produce sufrimiento en los trabajadores y, por tanto, va en contravía del denominado trabajo decente (Gómez, 2014).

Claramente, el dinamismo del entorno mundial hace que las organizaciones deban ser flexibles para adaptarse a los cambios (Agulló, 1999), pero la flexibilización no puede ser una excusa para crear nuevas formas de sometimiento del otro, para minimizar sus derechos y reducir la calidad de vida laboral, por el contrario, debería ser una oportunidad para el fomento de la motivación y para la consolidación de prácticas flexibles que, nacidas en el seno de la organización, se desplieguen a todos sus trabajadores, procurando su bienestar.

\section{Organizaciones saludables: una propuesta de cara al bienestar}

Reconociendo que las organizaciones influyen en el bienestar de los trabajadores (Raya y Panneerselvam, 2013), se resalta la necesidad que existe en el mundo, de aprender a trazar escenarios que, en vez de ir en detrimento de la salud, generen confort desde el puesto del trabajo, su diseño y ergonomía, hasta la calidad en las condiciones contractuales y relacionales.

Lo anterior representa un desafío, pues como se ha mencionado a lo largo de este capítulo, hoy algunas organizaciones suelen ofrecer condiciones precarias de trabajo. $\mathrm{Al}$ respecto, Ramos y Peiró (2014) señalan que, en tiempo de crisis económica y de condiciones adversas, es urgente buscar estrategias que fomenten la calidad de vida laboral y el fortalecimiento de organizaciones inclusivas, productivas y saludables.

Este desafío requiere una transición en la comprensión del espacio donde se desarrolla el trabajo, pues debe entenderse, no como el escenario donde existe un intercambio productivo, sino como un espacio de vida (Salanova, Llorens y Martínez, 2016) 
en el que las personas desarrollan sus habilidades, fortalecen lazos afectivos y crecen en términos personales y ocupaciones.

Una persona saludable se caracteriza por responder mejor a los cambios, ser resiliente y tener una vida productiva, pues bien, algo similar ocurre con las organizaciones (Raya y Panneerselvam, 2013). Específicamente, la palabra saludable les entrega a las organizaciones "... un nuevo matiz centrado en el cuidado de la salud tanto de los empleados, como de la misma organización en su conjunto" (Salanova y Schaufeli, 2009a, p. 273). Por tanto, la salud de los trabajadores se convierte en un elemento estratégico en términos corporativos.

Desde algunos postulados se diferencian los sistemas de trabajo saludables, de aquellos no saludables (DeJoy, Wilson, Vandenberg, McGrath-Higgins y Griffin-Blake, 2010) o entre las organizaciones saludables y las tóxicas (Salanova, Llorens y Martínez, 2019), coincidiendo en que, estos entornos saludables conllevan múltiples beneficios, dado que se reduce la rotación del personal y el absentismo (DeJoy y Wilson, 2003), se maximiza el bienestar de los trabajadores y la productividad de la organización (DeJoy y Wilson, 2003).

Lo anterior permite afirmar que, cuando el trabajador tiene salud y bienestar, esto tiene un efecto positivo en la salud financiera, el rendimiento y la rentabilidad de la organización (Cooper y Cartwright, 1994; Raya y Panneerselvam, 2013). Para Raya y Panneerselvam (2013) una organización saludable "es aquella que integra estratégicamente el bienestar de los empleados en sus objetivos comerciales y lo refuerza a través de prácticas establecidas" (p. 91), dichas prácticas están dirigidas al liderazgo de apoyo y a la cultura organizacional con un foco en el aprendizaje, también a la calidad del trabajo y a la gestión amigable de los recursos humanos.

Por su parte, Salanova, Llorens y Martínez (2019) consideran que, una organización positiva es, en esencia, una organización saludable y resiliente, a lo que le han dado el nombre HERO, por su sigla en inglés (HEalthy \& Resilient Organization). De forma más detallada, una HERo es "aquella que lleva a cabo acciones sistemáticas, planificadas y proactivas, para mejorar los procesos y resultados tanto de empleados como de la organización como un todo" (Salanova, Llorens y Martínez, 2019, p. 86). Las HERO también se caracterizan por su resiliencia, puesto que, en situaciones adversas y de crisis, logran mantener el equilibrio, adaptarse y salir fortalecidas (Salanova, Llorens, Cifre y Martínez, 2012).

Como modelo heurístico, las HERo tienen tres grandes componentes: 1) recursos y prácticas organizacionales saludables, 2) empleados saludables y 3 ) resultados organizacionales saludables (Salanova et al., 2012). A continuación, se esboza cada uno. 
1) Recursos y prácticas organizacionales saludables:

Para DeJoy y Wilson (2003) promover sistemas de trabajo saludables implica entrar en la estructura de la organización, pues no es posible promover la salud de los trabajadores, sin antes revisar las características propias del trabajo y la organización. En este sentido, este primer componente del modelo está relacionado con el despliegue e implementación de actividades que contribuyen a la salud integral, para ello, algunos recursos que generan impacto en los procesos organizacionales son la autonomía, las características retadoras del trabajo, la claridad de las tareas y del rol, la retroalimentación, el trabajo en equipo, la confianza organizacional, la adecuada supervisión y la justicia organizacional (Salanova et al., 2019).

Por su parte, las prácticas organizacionales saludables están orientadas a la comunicación e información organizacional, el desarrollo de habilidades, el desarrollo de carrera, la conciliación familia-trabajo, la prevención del acoso laboral y la equidad (Acosta, Torrente, Llorens y Salanova, 2013).

2) Empleados saludables:

Los empleados saludables se caracterizan, entre otras cosas, por sus creencias de eficacia, engagement y optimismo (Salanova et al., 2019), estos atributos psicológicos se convierten en recursos personales importantes y potentes para los empleados. Estudios recientes han señalado que la autoeficacia media la relación entre la perspectiva futura del tiempo y la satisfacción laboral (Cernas-Ortiz, Mercado-Salgado y Davis, 2018), además tiene un potencial predictivo respecto a la satisfacción con el trabajo (Vieira y Theotonio, 2018).

El engagement media la relación entre la autoeficacia y el compromiso organizacional afectivo (Orgambídez, Borrego y Vázquez-Aguado, 2019), así mismo, tiene un rol mediador entre los recursos organizacionales saludables y el desempeño laboral (Gil, Llorens y Salanova, 2020). Por su parte, el optimismo es un promotor del bienestar de los individuos (Vera-Villarroel et al., 2016), facilita el logro de objetivos y se asocia al bienestar físico y psicológico (Solberg, 2016).

3) Resultados organizacionales saludables:

Las organizaciones saludables presentan importantes resultados económicos, comerciales y sociales, tienen un excelente rendimiento de los equipos de trabajo, fomentan la calidad y cuentan con un fuerte compromiso con la comunidad (DeJoy et al., 2010; Salanova y Schaufeli, 2009b). Lo anterior repercute en un alto desempeño laboral, en calidad del servicio y en satisfacción del cliente, entre otras cosas, con la responsabilidad social empresarial (Salanova et al., 2019). 
Como se observa, las organizaciones que optimizan sus recursos y desarrollan prácticas organizacionales saludables favorecen la presencia de empleados saludables, esto, a su vez, permite resultados organizacionales excelentes (Salanova et al., 2016), por tanto, es un modelo en el que las diferentes partes se ven beneficiadas. Teniendo en cuenta que hoy el reto de las organizaciones es valorar y fortalecer el potencial humano (Serrate-Alfonso, Portuondo-Vélez, Sánchez-Puigbert y Suárez-Ojeda, 2014), el modelo HERO puede brindar herramientas importantes para que las organizaciones cumplan este propósito fundamental.

\section{Conclusiones}

En este capítulo se ha presentado un abordaje histórico de las organizaciones, las formas que se han propuesto para administrarlas y las implicaciones que esto tiene en el mundo laboral. El trabajo, sus formas, vías y significados han cambiado de manera importante en las últimas décadas. Estas transformaciones tienen de base una lectura política, económica y social, que ha desencadenado nuevas maneras de asumir a los trabajadores.

La informalidad, la precariedad y la inestabilidad no son condiciones novedosas del capitalismo, sino que son condiciones propias y clásicas del trabajo, siempre que este se encuentre condicionado a mercados autorregulados, de esta forma, desde la óptica del capitalismo, la desigualdad salarial, por ejemplo, no es un asunto nuevo, en cambio sí lo es la desprotección social de los trabajadores y la degradación de las condiciones del trabajo (Albanesi, 2015), las cuales se presentaron en este capítulo, al caracterizar fenómenos como la virtualización y la flexibilización laboral.

Ahora bien, existen tres grandes dificultades al intentar comprender las dinámicas relacionales en las organizaciones del siglo xxı. La primera consiste en utilizar modelos teóricos creados en épocas disímiles a las actuales, en que las características y las estructuras de las organizaciones respondían a una realidad diferente a la de los nuevos trabajadores en la actualidad.

La segunda implica la existencia de una brecha, una distancia entre lo que proponen los académicos y lo que venden algunos consultores empresariales, soportadas en ocasiones, en lo que Alonso y Fernández (2006) denominan una "pseudofilosofía managerial", es decir, basan sus intervenciones en prácticas no sustentadas en la evidencia y, por tanto, los resultados no son los esperados.

De manera lamentable, muchos de estos postulados terminan por convertirse en las llamadas "modas de gestión". De forma que debe existir una comunión, un diálogo permanente entre investigadores organizacionales, empresarios y entes 
gubernamentales, dicha comunión permitiría una gestión del conocimiento propia de las disciplinas científicas con las prácticas gerenciales de organizaciones versátiles, en las que el trabajador sea reconocido como persona y no como una máquina en un entorno instrumental que lo cosifica.

La tercera dificultad radica en el uso de modelos teóricos y prácticas de intervención, creadas y desplegadas en otras regiones del mundo. En este sentido, algunos autores hacen énfasis en la necesidad de generar investigación en el marco de los estudios decoloniales (Rodríguez, Mandiola, Pulido Martínez y Giraldo Tamayo, 2019).

Por tanto, esta también es una invitación para pensar la perspectiva decolonial del conocimiento en el estudio del management, las organizaciones y las realidades laborales en países latinoamericanos, en que las características culturales propias no coinciden con los marcos comprensivos y saberes hegemónicos (Vera Ruiz, Llanco Gonzales y Guevara Rojas, 2019).

La psicología y otras ciencias afines a los estudios organizacionales tienen, por ende, un llamado a generar y transformar postulados teóricos y prácticas organizacionales que incidan en la salud de los trabajadores latinoamericanos, es decir, una intervención psicosocial situada en los contextos regionales.

Finalmente, es necesario reconocer en los trabajadores sus particularidades, valorar integralmente a las personas en el trabajo (Saldarriaga, 2014) y asumir que los cambios por los que atraviesan las organizaciones están ocurriendo a un ritmo acelerado (Scott, 2005). Para sortear estos cambios, las organizaciones deben generar procesos planificados de aprendizaje organizacional y de gestión del conocimiento (Olis Barreto, Reyes Ortiz y Fiorino, 2019).

Sumado a lo anterior, urge mayor presencia y permanencia de organizaciones saludables (Salanova, Llorens, Cifre y Martínez, 2012), que dispongan de escenarios óptimos para el cambio, con una cultura que promueva el aprendizaje continuo y la innovación en sus estrategias, prácticas y procedimientos.

\section{Referencias}

Acosta, H., Torrente, P., Llorens, S. y Salanova, M. (2013). Prácticas organizacionales saludables: Un análisis exploratorio de su impacto relativo sobre el engagement con el trabajo. Revista Peruana de Psicología y Trabajo Social, 2(1), 107-120.

Agulló, C. (1999). Cambios significativos en el mundo empresarial. Economía Industrial, (330), 11-18. 
Albanesi, R. (2015). Historia reciente del trabajo y los trabajadores. Apuntes sobre lo tradicional y lo nuevo, lo que cambia y permanece en el mundo del trabajo. Trabajo y Sociedad (25), 387-403.

Alonso, L. y Fernández, C. (2006). El imaginario managerial: el discurso de la fluidez en la sociedad económica. Política y Sociedad, 43(2), 127-151. https://doi.org/10.5209/ POSO.23704

Andrade, V. (2014). Cambios en las relaciones de trabajo: paradojas y consecuencias en el actual mundo del trabajo. Diversitas-Perspectivas en Psicología, 10(2), 337-351. https:// doi.org/10.15332/s1794-9998.2014.0002.10

Antunes, R. (2000). La centralidad del trabajo hoy. Papeles de Población (25), 83-96.

Arano, R., Escudero, J.y Delfín, L. (2016). El origen del clima organizacional, desde una perspectiva de las escuelas de la administración: una aproximación. Instituto de Investigaciones y Estudios de las Ciencias Administrativas de la Universidad Veracruzana, 9-14. www.uv.mx/iiesca/files/2016/11/02CA201601.pdf

Arteaga, A. (2011). Cambios en la organización del trabajo y su impacto en la fuerza laboral: de mano de obra a gestor de la producción. Estudio de caso en la industria automotriz en México [tesis inédita de doctorado Universidad Autónoma Metropolitana Iztapalapa].

Bächler, R. y Poblete, O. (2009). El trasfondo humano de las organizaciones. Mapa comprensivo para su intervención. Administración y Organizaciones, 39-53.

Bauman, Z. (2004). Modernidad líquida. Fondo de Cultura Económica.

Blanch, J. M. (2007). Psicología social del trabajo. En Tratado de psicología social. Perspectivas socioculturales. Anthropos.

Castells, M. (1997). La era de la información: economía, sociedad y cultura. Volumen 1: La sociedad en red. Alianza. https://cataleg.uoc.edu/record=b1012683 S1*cat

Cernas-Ortiz, D. A., Mercado- Salgado, P. y Davis, M. A. (2018). Perspectiva futura de tiempo, satisfacción laboral y compromiso organizacional: el efecto mediador de la autoeficacia, la esperanza y la vitalidad. Journal of Work and Organizational Psychology, 34(1), 1-9. https://doi.org/10.5093/jwop2018a1

Chaves, J. (2004). Desarrollo tecnológico en la primera Revolución industrial. Norba. Revista de Historia, 17, 93-109.

Chávez-Ramírez, P. (2001). Flexibilidad en el mercado laboral: orígenes y concepto. Aportes: Revista de la Facultad de Economía, 6(17), 57-74. https://www.redalyc.org/ pdf/376/37661703.pdf

Chiavenato, I. (2012). Introducción a la teoría general de la administración. McGraw-Hill.

Cooper, C. y Cartwright, S. (1994). Healthy Mind; Healthy Organization-A Proactive Approach to Occupational Stress. Human Relations, 47(4), 455-471. https://doi. org/10.1177/001872679404700405 
DeJoy, D. y Wilson, M. (2003). Organizational health promotion: Broadening the horizon of workplace health promotion. American Journal of Health Promotion, 17(5), 337-341. https://doi.org/10.4278/0890-1171-17.5.337

DeJoy, D., Wilson, M., Vandenberg, R., McGrath-Higgins, A.yGriffin-Blake, S.(2010). Assessing the impact of healthy work organization intervention. Journal of Occupational and Organizational Psychology, 83(1), 139-165. https://doi.org/10.1348/096317908X398773

Díez, F. y Atela, P. (2019). Del talento individual al colectivo: el gran desafío para el éxito de las organizaciones en el siglo xxi. Espacios, 40(11), 16. https://www.revistaespacios.com/ a19v40n11/a19v40n11p16.pdf

Etzioni, I. (1965). Organizaciones modernas. Uteha.

Gil, E., Llorens, S. y Salanova, M. (2020). Employees' Physical Exercise, Resources, Engagement, and Performance: A Cross-sectional Study from HERo Model. Journal of Work and Organizational Psychology, 1-9.

Gómez, M. (2014). Sobre la flexibilidad laboral en Colombia y la precarización del empleo. Diversitas-Perspectivas en Psicología, 10(1), 103-116.

González, M., Lugo de los Santos, J. y Saldaña, S. (2019). La importancia de la motivación laboral de los docentes de la Facultad de Contaduría Pública y Administración de la unidad Cadereyta. VinculaTégica, 1290-1300.

Grau, C. (2014). Editorial. El beneficio como objetivo clásico de la empresa. Sapienza Organizacional, 1(1), 5-8. https://www.redalyc.org/articulo.oa?id=5530/553056603002

Hernández, M. (2019). La formación entre líneas. La centralidad del vínculo productividad-subjetividad en las estrategias de formación de la fuerza de trabajo. Universidad de Buenos Aires.

Jaua, E. (1997). Del fordismo a la flexibilidad laboral: supuestos, crisis y realidades de la regulación social. Economía y Ciencias Sociales, 3(2), 1-47. http://www.red-vertice.com/fep/ textos/Teoria1.pdf

Kahn, R. y Katz, D. (1989). Psicología social de las organizaciones (segunda edición). Trillas.

Livacic, C. (2009). Evolución de las organizaciones: un mundo en cambio. Revista de Estudios Politécnicos, 7(12), 177-191.

López, D. (2005). Mitos y realidades del mercado laboral chileno. En J. López (ed.), Mitos, alcances y perspectivas de la flexibilización laboral: un debate permanente. Graphos.

Mancheno-Saá, M. J., Bermúdez-Santana, D. y Pérez-Barrionuevo, A. (2019). De la teoría científica a la de criticabilidad autoorganizada: un entorno que exige cambios sustanciales en la administración. Revista Científica Fomento de la Investigación y Publicación en Ciencias Administrativas, Económicas y Contables (FIPCAEC), 4(2), 595-612.

Marchiori, M. (2011). Comunicación interna: una visión más amplia en el contexto de las organizaciones. Ciencias de la Información, 42(2), 49-54. http://www.redalyc.org/articulo. oa?id=181422294008\%0ACómo 
Martín, X., Segredo Pérez, A. M. y Perdomo, I. (2013). Capital humano, gestión académica y desarrollo organizacional. Revista Cubana de Educación Médica Superior, 27(3), 288-295.

Mayntz, R. (1972). Sociología de la organización. Alianza.

Olis, I., Reyes, G. y Fiorino, V. (2019). Condicionantes económicas y sociales para las organizaciones en Latinoamérica: estrategia y desarrollo. Opción. Revista de Ciencias Humanas y Sociales, 89(2), 1440-1469. https://doi.org/10.1017/CBO9781107415324.004

Orgambídez, A., Borrego y. y Vázquez-Aguado, O. (2019). Self-efficacy and organizational commitment among Spanish nurses: The role of work engagement. International Nursing Review, 1-8. https://doi.org/10.1111/inr.12526

Peiró, J. (1999). El modelo "Amigo": marco contextualizador del desarrollo y la gestión de recursos humanos en las organizaciones. Papeles del Psicólogo, 72.

Pfeffer, J. (1997). Nuevos rumbos en la teoría de la organización. Problemas y posibilidades. Oxford.

Pineda, S. (2017). Las metamorfosis en el mundo del trabajo. Revista Académica Eco, 16, $15-24$.

Piore, M. y Sabel, C. (1990). La segunda ruptura industrial. Alianza.

Porras, N. (2012). La realidad organizacional: desde la perspectiva psicosocial. Revista Iberoamericana de Psicología: Ciencia y Tecnología, 5(1), 7-18. https://doi. org/10.33881/2027-1786.rip.\%x

Porter, L., Lawler, E. y Hackman, R. (1975). Behavior in organizations. McGraw-Hill.

Ramírez, C. (2010). Fundamentos de administración (tercera edición). ECoE Editores.

Ramos, J. y Peiró, J. M. (2014). La psicología del trabajo y las organizaciones en tiempos de crisis económica (2. ${ }^{a}$ parte). Papeles del Psicólogo, 35(2), 81-82. http://www.papelesdelpsicologo.es/pdf/1165.pdf\#page $=45$

Raya, R. y Panneerselvam, S. (2013). The healthy organization construct: A review and research agenda. Indian Journal of Occupational and Environmental Medicine, 17(3), 8993. https://doi.org/10.4103/0019-5278.130835

Rentería, E. (2008). Nuevas realidades organizacionales y del mundo del trabajo: implicaciones para la construcción de la identidad o del sujeto. Informes Psicológicos, 10(10), 65-80.

Rivas, L. (2002). Nuevas formas de organización. Estudios Gerenciales, 13-45. http://www. scielo.org.co/scielo.php?script=sci_arttext\&pid=S0123-59232002000100001\&ln$\mathrm{g}=\mathrm{en} \& \mathrm{nrm}=\mathrm{iso} \& \operatorname{lng}=\mathrm{es}$

Rivera, D., Carrillo, Sandra Milena Forgiony, J., Nuván, I. y Rozo, A. (2018). Cultura organizacional, retos y desafíos para las organizaciones saludables. Espacios, 39(22), 1-27. http:// www.revistaespacios.com/a18v39n22/a18v39n22p27.pdf

Robbins, S. y Coulter, M. (2009). Administración (décima edición). Pearson. 
Rodríguez, F. (2014). Incidencia y vigencia del taylorismo y fordismo en la producción industrial moderna. In Vestigium Ire, 4(1). revistas.ustatunja.edu.co/index.php/ivestigium/ article/view/178

Rodríguez, J., Mandiola, M., Pulido, H. y Giraldo, A. (2019). Estudios descoloniales del management y las organizaciones: avances, desafíos y prospectos. Cuadernos de Administración, 32(58), 1-4. https://doi.org/10.11144/Javeriana.cao32-58.edmo

Salanova, M., Llorens, S., Cifre, E. y Martínez, I. (2012). We need a hero! Toward a validation of the Healthy and Resilient Organization (HERo) Model. Group and Organization Management, 37(6), 785-822. https://doi.org/10.1177/1059601112470405

Salanova, M., Llorens, S. y Martínez, I. (2016). Aportaciones desde la psicología organizacional positiva para desarrollar organizaciones saludables y resilientes. Papeles del Psicólogo, 37(3), 177-184.

Salanova, M., Llorens, S. y Martínez, I. (2019). Organizaciones saludables. Una mirada desde la psicología positiva. Aranzadi.

Salanova, M. y Schaufeli, W. (2009a). El engagement en el trabajo cuando el trabajo se convierte en pasión. Alianza.

Salanova, M. y Schaufeli, W. (2009b). Un paso más allá: trabajadores engaged y organizaciones saludables. En El engagement en el trabajo cuando el trabajo se convierte en pasión. Alianza. http://www.want.uji.es/wp-content/uploads/2017/11/2009_SalanovaSchaufeli.pdf

Saldarriaga, J. (2014). La concepción del sujeto en la administración: una mirada desde la gestión humana. Revista El Ágora USB, 14(1), 223-237. https://nbn-resolving.org/ urn:nbn:de:0168-ssoar-423182\%0ANutzungsbedingungen:

Schein, E. (1991). La psicología de la organización (tercera edición). Prentice Hall.

Scott, R. (2005). Organizaciones: características duraderas y cambiantes. Gestión y Política Pública, 14(3), 439-463. http://www.redalyc.org/articulo.oa?id=13314302\%0ACómo

Segredo, A. (2016). Aproximación teórica a la evolución, teorías, enfoques y características que han sustentado el desarrollo de las organizaciones. Revista Cubana de Salud Pública, 42(4), 585-595.

Serrate-Alfonso, A., Portuondo-Vélez, Á., Sánchez-Puigbert, N. y Suárez-Ojeda, R. (2014). Evaluación de la cultura organizacional y su incidencia en la efectividad grupal. Ingeniería Industrial, 35(1), 2-12. http://www.redalyc.org/articulo.oa?id=360433596002 \%0ACómo

Solberg, L. (2016). Optimism, pessimism, and stress. En Stress: Concepts and cognition, emotion, and behavior. Academic P, 405-411. Elsevier Inc. https://doi.org/10.1016/ B978-0-12-800951-2.00052-2

Vera-Villarroel, P., Celis-Atenas, K., Urzúa, A., Silva, J., Contreras, D. y Lillo, S. (2016). Los afectos como mediadores de la relación optimismo y bienestar. Revista Argentina de Clínica Psicológica, 25(2), 195-202. http://www.redalyc.org/articulo. oa?id=281946990010\%0ACómo 
Vera, Á., Llanco, C. y Guevara, L. (2019). Desafiando la formación de psicólogos organizacionales desde una perspectiva de aprendizajes situados en el ámbito microempresarial peruano. Cuadernos de Administración, 32(58). https://doi.org/https://doi.org/10.11144/ Javeriana.cao32-58.dfpo

Vesga, J. (2016). Retos para la Рот derivados de las transformaciones en la institucionalización del trabajo. En Psicología de las organizaciones y del trabajo. Apuestas de investigación II. Editorial B.

Vesga, J. (2017). Articulación de repertorios teóricos y transformaciones del trabajo. Equidad y Desarrollo, (29), 13-25. https://doi.org/10.19052/ed.4195

Vieira, D. y Theotonio, M. (2018). Autoeficácia e sucesso na transição para o trabalho: Um estudo longitudinal. Revista Brasileira de Orientação Profissional, 19(1), 31-39.

Weber, M. (1947). The theory of social and economic organization. The Free Press.

Weisz, B. (2016). Diversificación y fragmentación del mundo del trabajo en la hipermodernidad. Psicología, Conocimiento y Sociedad, 6(2), 7-28.

Zúñiga, M. (2012). Flexibilización laboral y ética empresarial. Revista de Derecho (37), 321-349. http://search.ebscohost.com/login.aspx?direct=true\&db=fua\&AN=89639380\&lang= es\&site=ehost-live 


\section{2 \\ CULTURA ORGANIZACIONAL: \\ REFLEXIONES SOBRE EL \\ CONCEPTO \\ Juan Javier Vesga R. * \\ Universidad Católica de Colombia}

La cultura organizacional es un concepto central en la gestión de las organizaciones en la actualidad, pues tanto directivos empresariales en diversas compañías, como académicos e investigadores, no dudan en concebirlo como elemento clave en el momento de gestionar y direccionar el rumbo de las organizaciones o de comprender aspectos de su funcionamiento y del comportamiento organizacional.

No obstante esta centralidad y vigencia del concepto, no es fácil establecer una definición unificada, ya que en la actualidad "prevalece una ausencia de consenso sobre su definición" (Vesga, 2013, p. 94) y las discusiones y debates sobre su concepción se fundamentan en las diferencias entre los paradigmas asumidos al estudiar la cultura como hecho social, lo cual lleva a diferencias tanto en su conceptualización como en las metodologías para su investigación (Gómez, Sánchez y Alonso, 2008).

Aunque el hecho de que la cultura en las organizaciones existe desde la aparición de la empresa moderna como producto de la Revolución Industrial, su conceptualización en el campo de los estudios organizacionales emerge a principios de la década de 1970 (Allaire y Firsirotu, 1984; Barale y Santos, 2017; Carr y Beaver, 2002); sin embargo, es necesario entender que este no es un concepto aislado, sino que se inserta en el concepto más amplio de cultura visto de manera general, el cual proviene de las disciplinas de la antropología y la sociología en las que este ha sido ampliamente estudiado como una manera de describir y entender diferencias, particularmente en valores esenciales que caracterizan colectivos sociales (Schneider y Barbera, 2014), por lo que antes de discutir el concepto más específico de cultura organizacional se abordará inicialmente el de cultura en sentido general.

jjvesga@ucatolica.edu.co

* https://orcid.org/0000-0003-2382-5104 


\title{
El concepto de cultura
}

De acuerdo con el Diccionario Oxford (2018), el término que hoy se conoce como cultura significaba en el inglés medieval un pedazo de tierra cultivado o la acción de cultivar el suelo; a principios del siglo xvi surge para este término el sentido de "cultivar la mente, las facultades o las maneras"; finalmente, una acepción más cercana al término tal como se conoce en la actualidad, con el sentido de manifestaciones de logros intelectuales del ser humano consideradas colectivamente, data de principios del siglo XIX.

Una de las primeras definiciones de cultura aplicada al estudio de las sociedades la proporcionó el antropólogo británico Edward B. Tylor, quien en 1871 definió la cultura como "ese todo complejo que incluye conocimiento, creencia, arte, moral, ley, costumbre y cualquier otra capacidad y hábitos adquiridos por el hombre como miembro de la sociedad" (Tylor, 1920, p. 1). Esta definición proporciona una visión amplia del concepto que involucra diversas y variadas actividades del ser humano en la construcción de colectivos sociales, actividades que tienen la particularidad de ser adquiridas y transmitidas a los miembros de un colectivo en su evolución histórica como sociedades.

Por su parte, para Geertz (2003), la cultura

\begin{abstract}
denota un esquema históricamente transmitido de significaciones representadas en símbolos, un sistema de concepciones heredadas y expresadas en formas simbólicas por medios con los cuales los hombres comunican, perpetúan y desarrollan su conocimiento y sus actitudes frente a la vida. (p. 88)
\end{abstract}

En este sentido, un aspecto central en la constitución de una cultura es el conjunto de significaciones que toman sentido para un colectivo social en particular y que se transmite a través de diversas generaciones.

Igualmente, en la perspectiva de Geertz, la cultura emerge a partir de las respuestas que los miembros de una sociedad, principalmente de manera colectiva, dan a las exigencias que les plantea la existencia cotidiana, generando lo que este autor denomina "actitudes frente a la vida"; de esta manera, y como también en el mismo sentido lo anota Schein (2004), la cultura se forma como un patrón de supuestos básicos compartidos resultantes de procesos de aprendizaje de los miembros de una colectividad sobre el modo de resolver problemas de adaptación a demandas del entorno, cuyas estrategias tuvieron éxito en el pasado y que se van incorporando paulatinamente como prácticas cotidianas. 
Es necesario resaltar el señalamiento que hace Geertz (2003) sobre la importancia que tiene la cultura en la construcción de conocimiento colectivo y en el mantenimiento de este en el desarrollo de las sociedades. Como lo ha propuesto Popper (1993) en su tesis de los mundos 1, 2 y 3, los productos de la mente humana se van consolidando como "mundo" de conocimiento que llega a tener una existencia que pervive a lo largo del tiempo, y elementos constitutivos de la cultura como historias, mitos y herramientas, hacen parte de este mundo.

La cultura se construye socialmente y se mantiene a lo largo del tiempo, pero evoluciona en la medida en que la sociedad en la que se instaura evoluciona también. La cultura es activa, dinámica y pública y está constituida principalmente por significados construidos socialmente (Geertz, 2003).

\section{El concepto de cultura organizacional}

En el ámbito de las organizaciones el interés por el estudio de la cultura empieza a tener importancia a partir del auge de Japón como potencia mundial en el campo de los negocios (Morgan, 1998), más específicamente a comienzos de los años ochenta del siglo xx, cuando la literatura sobre gestión de las organizaciones vuelca sus intereses al éxito de las empresas japonesas, lo que pone en evidencia el impacto de la cultura en la gestión y desempeño organizacional (Denison, 1996; Gómez, Sánchez y Alonso, 2008).

Sin embargo, la primera conceptualización sobre la cultura organizacional es hecha por Andrew Pettigrew en 1979 en su artículo "On Studying Organizational Cultures", en el cual el autor analiza la cultura como un aspecto constitutivo de la vida y proceso evolutivo de las organizaciones a través de su pasado, presente y futuro. En su artículo, el autor define la cultura como "el sistema de significados aceptados pública y colectivamente que operan para un determinado grupo en un momento dado" (Pettigrew, 1979, p. 574).

El elemento central en la definición de Pettigrew es el sistema de significados, el cual se constituye en el común denominador de la variedad de concepciones y perspectivas desde las cuales se ha definido la cultura organizacional. Esta ha sido estudiada y conceptualizada por diversos autores y aunque se presentan elementos comunes a las definiciones, especialmente el relacionado con los significados compartidos, prevalece en la literatura una falta de consenso (Vesga, 2013). A continuación, se revisan brevemente definiciones desde las perspectivas psicológica, sociológica y de la administración. 
En la perspectiva psicológica, Schein (2004) define la cultura organizacional como,

\begin{abstract}
[...] un patrón de supuestos básicos compartidos que fueron aprendidos por un grupo en la medida en que resolvieron problemas de adaptación externa e integración interna, que ha funcionado lo suficientemente bien para ser considerado válido, $\mathrm{y}$, por consiguiente, ser enseñado a los nuevos miembros como la manera correcta de percibir, pensar y sentir en relación con esos problemas. (p. 17)
\end{abstract}

Varios elementos pueden destacarse en esta definición. Primero, ella refiere la cultura organizacional conformada por "un patrón de suposiciones básicas compartidas", lo cual implica la formación de esquemas cognitivos constituidos por supuestos subyacentes, es decir, implícitos, que guían decisiones y actuaciones de un grupo determinado, con la característica particular de ser compartidos por todos los miembros del colectivo social. Para ser compartidos deben ser comunicados, por lo que los procesos de interacción entre los miembros del grupo en torno a las discusiones sobre los supuestos para llegar a consensos sobre estos, son claves en el momento de construir colectivamente tales esquemas mentales.

Segundo, como lo expresa Schein (2004), tanto organizaciones como grupos, sin importar su tamaño, deben lidiar con dos retos primordiales: "(1) supervivencia, crecimiento y adaptación a su entorno; e (2) integración interna que permita funcionar diariamente y la habilidad para adaptarse y aprender" (p. 18). Estas necesidades fundamentales de los colectivos sociales implican esfuerzos de sus miembros por enfrentar las demandas del entorno, así como la realización de acciones dirigidas a evitar su fragmentación que puede llevar a la disolución. Como consecuencia de este proceder se logran aprendizajes sobre las mejores estrategias que han producido resultados positivos en el pasado para incorporarlas como pautas de comportamiento en el presente y hacia el futuro.

Tercero, estos aprendizajes no son exclusivos de los integrantes que los adquirieron en un momento determinado, sino que son enseñados a los nuevos miembros que se incorporan a la vida y funcionamiento del grupo u organización a través de procesos de socialización. Este tipo de socialización es denominada socialización secundaria, la cual se define como "cualquier proceso posterior que induce al individuo ya socializado a nuevos sectores del mundo objetivo de su sociedad" (Berger y Luckmann, 1995, p. 166) como es el caso la incorporación de nuevos integrantes a grupos de trabajo u organizaciones.

Desde la perspectiva sociológica, Méndez (2006) define este concepto de la siguiente manera: "Cultura organizacional es la conciencia colectiva que se expresa en el sistema de significados compartidos por los miembros de la organización que los 
identifica y diferencia de otros institucionalizando y estandarizando sus conductas sociales" (p. 91). El autor afirma que su definición se sitúa en el marco de la teoría sociológica aplicada a las organizaciones, particularmente desde los lineamientos e ideas de Durkheim y Parsons.

Cabe destacar un aspecto central de esta definición con relación al concepto de conciencia colectiva, el cual el autor toma de Durkheim (2008), para quien este fenómeno describe el carácter de una sociedad y es diferente de las conciencias individuales. Para este autor, lo que compone la dinámica de la vida social no puede ser explicado desde factores netamente psicológicos, los cuales constituyen conciencias individuales, sino que, "lo que las representaciones colectivas traducen es la manera en la cual el grupo piensa en sus relaciones con los objetos que lo afectan” (p. 23).

Para Méndez (2006), la cultura organizacional es conciencia colectiva en el sentido de que se manifiesta en "un sistema de significados compartidos" (p. 81). De acuerdo con este autor, este sistema de significados constituidos como conciencia colectiva se forma como producto del aprendizaje social a partir de procesos de socialización y facilita a los miembros de la organización comprender su entorno laboral y adaptarse a las demandas de este.

En cuanto a la perspectiva de la administración, para Serna (2008) "la cultura de una institución incluye los valores, creencias y comportamientos que se consolidan y comparten durante la vida empresarial" (p. 133). En esta perspectiva, uno de los elementos fundamentales de la cultura en las organizaciones son los valores corporativos, los cuales se supone que deben ser compartidos por los miembros de una organización. Estos valores forman parte de la filosofía de gestión de las organizaciones y generalmente son definidos por los líderes en el nivel de la alta dirección; como lo afirma Serna (2008): "las compañías tienen que establecer el marco axiológico que defina el comportamiento de los individuos en la institución” (p. 135).

Una vez definidos los valores corporativos, las organizaciones desarrollan diversos mecanismos para lograr el propósito de que estos se compartan colectivamente y que cada miembro de la organización los incorpore en su actuar en la organización, y alinee su conducta en el trabajo con dichos valores. De acuerdo con Serna (2008), para institucionalizar los valores en las organizaciones,

[...] los empresarios deberán establecer programas de mercadeo corporativo interno

[...] [y] los programas de inducción deben ser diseñados para incluir la axiología corporativa en el entendimiento y la incorporación de los valores de la organización y su aplicación en la vida diaria de la empresa. (pp. 135-136) 
Aparte de las perspectivas desde las cuales se ha conceptualizado y definido la cultura organizacional, también se han propuesto modelos que sintetizan en una estructura determinada los componentes de esta, pues es claro que la cultura organizacional es un concepto multidimensional, en línea con lo propuesto por Law, Wong y Mobley (1998), un concepto multidimensional "consiste de un número de atributos o dimensiones interrelacionados y existe en dominios multidimensionales" (p. 741); en este mismo sentido, la cultura organizacional se ha propuesto como concepto constituido por un conjunto de factores o dimensiones, lo cual es mostrado en diversos modelos teóricos. Estos modelos permiten, además de comprender la forma como se estructura una cultura organizacional, servir de soporte teórico que guía el desarrollo de instrumentos de evaluación para comprender y estudiar la cultura en las organizaciones. A continuación, se presentan tres de los más importantes modelos.

\section{Modelos de "cultura organizacional"}

\section{El modelo de Schein}

Para este autor, la cultura organizacional está constituida por tres niveles, en el sentido de que estos van desde una cota superficial a una más profunda. Tales niveles constituyen aspectos de la cultura organizacional que tienen diferentes niveles de manifestación en un continuo de objetividad-subjetividad. Estos niveles son: a) artefactos observables, b) valores y c) presunciones básicas subyacentes (Schein, 1990). Estos niveles se representan en la figura 1 .

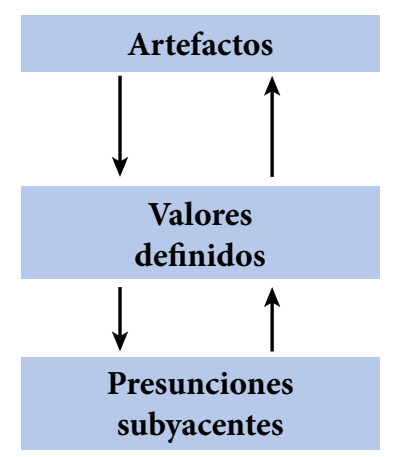

Estructura y procesos organizacionales visibles

Estrategias, metas, filosofías

Inconscientes, debidas a las creencias, percepciones, pensamientos y sentimientos

Figura 1. Modelo de niveles de la cultura organizacional de Schein

Fuente: Schein (2004, p. 26) 
Los artefactos comprenden los procesos y estructura visible de la organización. Esta categoría incluye todos aquellos aspectos fácilmente observables de la organización, desde el diseño físico de las instalaciones, el vestuario de sus miembros, la manera en que las personas interaccionan, colores y olores del lugar, hasta los aspectos de registro más permanentes, como los documentos oficiales, los productos y los informes anuales (Schein, 1990).

El segundo nivel corresponde a los valores, normas e ideologías enunciados por la organización a los que se adhieren sus miembros y, en general, la filosofía de gestión establecida por la alta dirección que guía el comportamiento y formas de vínculo e identificación de los miembros con la organización. Estos valores y creencias manifiestas son compartidas y validadas socialmente en la vida cotidiana de la organización y representan también los límites de lo ético en el desempeño individual y colectivo (Schein, 1990; 2004).

Finalmente, el tercer nivel comprende las presunciones o supuestos subyacentes, los cuales son menos evidentes y conscientes. Estos aspectos tienen gran influencia en la manera como los miembros de una organización perciben, piensan y sienten con respecto a la representación que tienen de ella (Schein, 1990). Este autor manifiesta que los supuestos subyacentes se asimilan al concepto de "teorías en uso" o "teorías de acción" (Argyris, 1985), que constituyen los supuestos implícitos que realmente guían el comportamiento y dicen a los miembros de un grupo cómo pensar y sentir acerca de las dinámicas organizacionales (Schein, 2004).

\section{El modelo de Denison}

El modelo de Denison (Denison y Mishra, 1995) es de particular interés para teóricos y consultores organizacionales, ya que este ha sido diseñado y creado dentro de ambientes empresariales, mientras que otros se han configurado en ambientes académicos (Denison y Neale, 1999).

En la perspectiva de este modelo,

la cultura organizacional se refiere a los valores, creencias y principios subyacentes que sirven de base para el sistema de gestión de una organización, así como el conjunto de prácticas de gestión y comportamientos que ejemplifican y refuerzan esos principios básicos. (Denison y Neale, 1999, p. 4)

El modelo se presenta en la figura 2. 


\begin{tabular}{|c|c|c|}
\hline \multirow{5}{*}{$\begin{array}{r}\text { Orientación } \\
\text { externa } \\
\text { Integración } \\
\text { interna }\end{array}$} & Adaptabilidad & Misión \\
\hline & Implicación & Consistencia \\
\hline & Cambio & Estabilidad \\
\hline & $\mathrm{y}$ & $\mathrm{y}$ \\
\hline & flexibilidad & dirección \\
\hline
\end{tabular}

Figura 2. Modelo de rasgos de la cultura organizacional de Denison Fuente: Denison y Mishra (1995, p. 216)

En esta perspectiva, la cultura organizacional está conformada por cuatro rasgos principales: adaptabilidad, implicación, consistencia y misión. Los dos primeros son rasgos relacionados con flexibilidad, apertura y respuesta a las demandas del entorno, y son fuertes predictores de crecimiento. Los dos últimas se relacionan con integración, dirección y visión, y son mejores predictores de rentabilidad (Denison y Mishra, 1995).

La adaptabilidad implica la capacidad de entender el mercado y el contexto, la implicación hace referencia a alineación y comprometimiento de la fuerza de trabajo, así como el desarrollo de sus capacidades, la consistencia comprende el equilibrio y articulación entre valores, sistemas y procesos y la misión se refiere a la definición del horizonte al cual dirigirse (Denison y Neale, 1999).

\section{El modelo de Cameron y Quinn}

Uno de los modelos para el estudio de la cultura organizacional de mayor importancia en la actualidad, y que ha sido usado en distintas investigaciones por diversos autores, es el propuesto por Cameron y Quinn (2006). Este es uno de los más ampliamente usados y de mayor influencia en el área de la investigación en cultura organizacional, ya que, en comparación con otros modelos, ha demostrado altos niveles de validez y confiabilidad (Yu y Wu, 2009).

El modelo se basa en la estructura de valores en competencia y se deriva de la investigación inicial que hacen Quinn y Rohrbaugh (1983), quienes proponen esta estructura para el análisis y la efectividad organizacional, a partir de ordenar mediante técnicas multivariadas, los criterios que teóricos e investigadores organizacionales usan para evaluar el desempeño de las organizaciones. Posteriormente, el modelo es 
aplicado para el estudio de la cultura organizacional, junto con el diseño de un instrumento que permite este propósito, denominado Organizational Culture Assessment Instrument (OCAI) (Cameron y Quinn, 2006).

Para estos autores, "la cultura se refiere a los aspectos implícitos y a menudo indiscernibles de las organizaciones [...], incluye valores centrales e interpretaciones consensuadas acerca de cómo son las cosas" (Cameron y Quinn, 2006, p. 147). Su modelo propone la existencia unos "valores en competencia" en el funcionamiento de las organizaciones (flexibilidad y discreción vs. estabilidad y control en el eje vertical, y énfasis interno e integración vs. énfasis externo y diferenciación en el eje horizontal) que originan cuatro tipos de cultura: clan, adhocrática, de mercadeo y jerárquica (véase la figura 3 ).

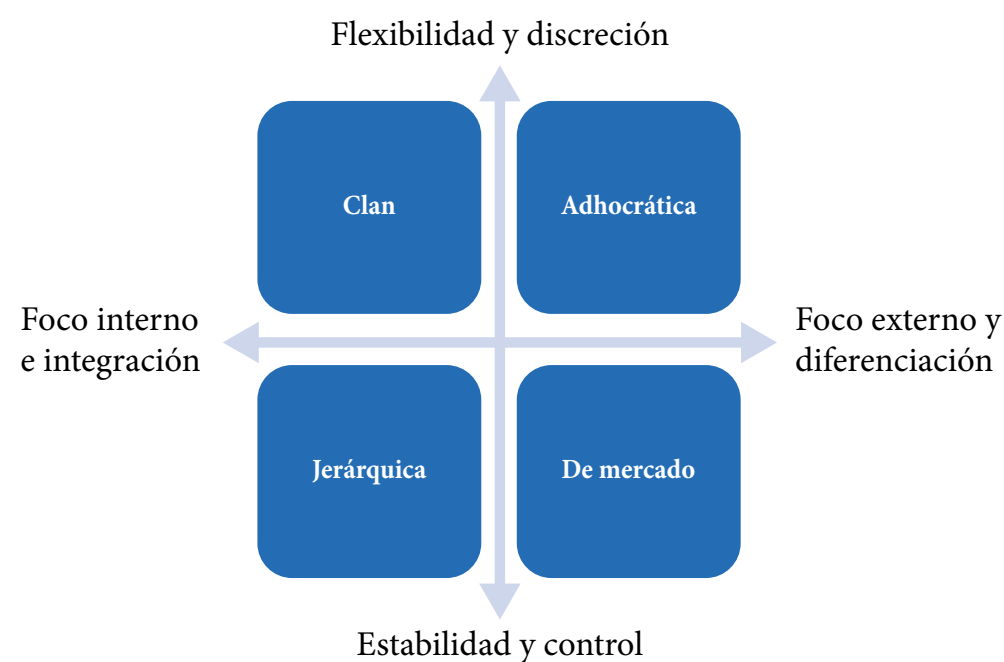

Figura 3. Modelo de tipos de cultura organizacional de Cameron y Quinn

Fuente: Cameron y Quinn (2006, p. 35)

La cultura "clan" se denomina así por su similaridad con una familia. En este tipo de cultura prevalecen el trabajo en equipo, el apoyo y orientación de los líderes, quienes actúan como mentores, prevaleciendo la lealtad y la tradición. En la cultura adhocrática, la organización se concibe como dinámica, cambiante y altamente flexible, innovadora y de avanzada. La cultura de mercadeo está orientada hacia los resultados, y son altamente competitivas, con líderes muy exigentes. Finalmente, la cultura jerárquica mantiene una estructura rígida, con políticas y reglas claramente establecidas, siendo muy importante el cumplimiento estricto de las normas y el orden jerárquico (Cameron y Quinn, 2006). 


\section{Conclusiones}

La cultura organizacional ha sido entendida por diversos estudiosos, académicos, investigadores y líderes empresariales, como un aspecto fundamental del éxito de las organizaciones; es, en esencia, uno de los factores más importantes en la gestión y desempeño de las organizaciones (Cameron y Quinn, 2006; Serna, 2008).

Pero la cultura, por sí misma, no puede producir los efectos requeridos en el compromiso, identidad organizacional o logro de objetivos corporativos, pues para que esto ocurra, las características de la cultura deberán coincidir con las características de los modelos o sistemas de gestión (Serna, 2008). Si esto no ocurre y las brechas entre uno y otro aspecto son importantes, deberán iniciarse procesos de cambio en la cultura, en la estrategia o en ambos factores, para reducir las brechas y facilitar el adecuado fluir de la dinámica organizacional en función de los objetivos establecidos, lo cual requiere de un diagnóstico o caracterización de la cultura organizacional, hecho que puede y debe llevarse a cabo con base en algún modelo teórico que oriente este proceso.

\section{Referencias}

Allaire, Y. y Firsirotu, M. (1984). Theories of organizational culture. Organization Studies, 5(3), 193-226. doi:10.1177/017084068400500301

Argyris, C. (1985). Interventions for improving leadership effectiveness. Journal of Management Development, 4(5), 30-50. doi:10.1108/eb051596

Barale, R. y Santos, B. (2017). Cultura organizacional: Revisão sistemática da literatura. Revista Psicologia: Organizações e Trabalho, 17(2), 129-136. doi:10.17652/rpot/2017.2.12854

Berger, P. y Luckmann, T. (1995). La construcción social de la realidad. Amorrortu.

Cameron, K. y Quinn, R. (2006). Diagnosing and changing organizational culture. Jossey-Bass.

Carr, P. y Beaver, G. (2002). The enterprise culture: Understanding a misunderstood concept. Strategic Change (11), 105-113. doi:10.1002/jsc.579

Denison, D. (1996). What is the difference between organizational culture and organizational climate? A native's point of view on a decade of paradigm wars. Academy of Management Review, 21(3), 619-654.

Denison, D. y Mishra, A. (1995). Toward a theory of organizational culture and effectiveness. Organization Science, 6(2), 204-223.

Denison, D. y Neale, W. (1999). Denison organizational culture survey. http://www.denisonconsulting.com/Docs/DOCS_A-Z/DOCS_Facilitator_Guide.Pdf

Durkheim, É. (2008). Las reglas del método sociológico. Losada.

English Oxford Dictionary. (2018). Oxford Dictionaries. https://en.oxforddictionaries.com/ 
Geertz, C. (2003). La interpretación de las culturas. Gedisa.

Gómez, A. M., Sánchez, J. C. y Alonso, E. (2008). Cultura organizacional. En F. J. Palací, Psicología de la organización (pp. 217-244). Pearson.

Law, K., Wong, C.-S. y Mobley, W. (1998). Toward a taxonomy of multidimensional constructs. Academy of Management Fleview, 23(4), 741-755.

Méndez, C. E. (2006). Transformación cultural en las organizaciones. Un modelo para la gestión del cambio. Limusa.

Morgan, G. (1998). Imágenes de la organización. Alfaomega.

Pettigrew, A. M. (1979). On studying organizational cultures. Administrative Science Quarterly, 24(4), 570-581.

Popper, K. R. (1993). Los mundos 1, 2 y 3. En K. R. Popper y J. C. Eccles, El Yo y su cerebro (2. ${ }^{\mathrm{a}}$ ed., pp. 41-57). Labor.

Quinn, R. y Rohrbaugh, J. (1983). A spatial model of effectiveness criteria: Towards a competing values approach to organizational analysis. Management Science, 29(3), 363-377.

Schein, E. (1990). Organizational culture. American Psychologist, 45(2), 109-119.

Schein, E. (2004). Organizational culture and leadership (3. ${ }^{a}$ ed.). Jossey-Bass.

Schneider, B. y Barbera, K. M. (2014). Introduction: The Oxford Handbook of Organizational Climate and Culture. En B. Schneider y K. M. Barbera (eds.), The Oxford Handbook of Organizational Climate and Culture (pp. 3-20). Oxford.

Serna, H. (2008). Gerencia estratégica (10 ed.). 3R.

Tylor, E. B. (1920). Primitive culture. Researches into the development of mythology, philosophy, religion, language, art, and custom (6. ${ }^{\mathrm{a}}$ ed., vol. 1). John Murray.

Vesga, J. J. (2013). Cultura organizacional y sistemas de gestión de la calidad: una relación clave en la gestión de instituciones de educación superior. Guillermo de Okham, 11(2), 89-100.

Yu, T. y Wu, N. (2009). A review of study on the competing values framework. International Journal of Business and Management, 4(7), 37-42. 



\section{3

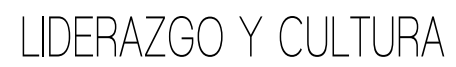 ORGANIZACIONAL}

María Constanza Aguilar Bustamante*

Universidad Santo Tomás

El liderazgo y la cultura organizacional son temas que despiertan un gran interés en el mundo de las empresas. La relación que se aborda en este trabajo es desde la perspectiva de algunos autores: son los líderes los que determinan y conforman la cultura organizacional (Bass, 1985; 1990; 1999; Contreras, Barbosa y Piñeros, 2016; Contreras, Barbosa, Juárez y Uribe, 2010; Moss, 2010; Ogliastri, 1999). Lo que deja en evidencia la literatura científica, por ejemplo, en los estudios transculturales e internacionales, es una importante relación entre la cultura organizacional y los estilos de liderazgo (Anastácio Barata y Martí Ripoll, 2015; Contreras, Barbosa y Piñeros, 2016; Gil y Martí, 2011; Hanges y Dickson, 2004; Dorfman y Hanges, 2004). A continuación, se presenta una síntesis sobre el recorrido histórico de ambos temas, sus desarrollos y avances.

\section{Liderazgo y líderes}

Autores como Bligh y Meindl (2005) y Glynn y DeJordy (2010) han llevado a cabo estudios sobre los líderes y el liderazgo, las variables asociadas a él; modelos teóricos y conceptuales, métodos y técnicas que se encuentran en función de las propuestas teóricas existentes, y ponen en evidencian que su desarrollo teórico aún está en proceso, que la mayor cantidad de investigación se concentra en Estados Unidos, y que frente a los conceptos de liderazgo y los líderes existe una interminable lista de términos referidos a ellos, y cuando se revisan sus definiciones siguen sin estar suficientemente claros.

Revisar la literatura científica sobre el liderazgo lleva a investigar etapas y enfoques por los que ha transitado y las dimensiones y temas que incluye; Francisco Gil (2008) afirma que

mariaaguilar@usantotomas.edu.co

* https://orcid.org/0000-0003-2990-9667 
el entusiasmo, específicamente de los académicos por este tema tiene "un movimiento pendular que va de momentos de entusiasmo a grandes desilusiones" (p. 295).

\section{Desarrollo histórico del liderazgo}

Autores como Bass (1990), Yukl (2002), Gil y García Sáiz (1993), Gil et al. (2011), entre otros, definen el concepto de liderazgo como un proceso grupal, un rasgo de personalidad, una forma de inducir al compromiso, llevar a cabo un ejercicio de influencia, comportamientos y estrategias para persuadir a otros, presentar una relación de poder, un instrumento para alcanzar metas, un efecto de la continua interacción, tener un rol diferenciado, un rol de poder asignado (como cuando se es jefe y se tienen personas a cargo), y todas las posibles combinaciones de las anteriores.

A continuación, se presenta un breve recorrido cronológico, y algunos conceptos que se encuentran asociados al liderazgo.

De acuerdo con Peiró (1995), los inicios de la investigación empírica en liderazgo aparecieron con Kurt Lewin en 1940, cuando él y algunos de sus discípulos trabajaban en el tema. En esta primera etapa prevalecieron los estudios del enfoque de rasgos, en los que el tema central se refiere a que los líderes nacen, y el liderazgo es una habilidad innata (Bryman, 1996).

Luego, en los años cincuenta, comienzan a asociarse una gran cantidad de conceptos al liderazgo, específicamente sobre los estilos de liderazgo, algunos de ellos son: liderazgo funcional, liderazgo sin líder, liderazgo burocrático, carismático, democrático, autocrático, laissez, entre muchos otros; Peiró (1995) pone en evidencia que a pesar de la variedad no hay consenso sobre su definición ni forma de estudiarlo. Según Bryman (1996), la característica principal de estos estudios puede resumirse en la pregunta que muchos trabajos intentaron responder sobre qué hacen y cómo son los líderes.

En la década de los setenta y principios de los ochenta, sobresale la obra de Stogdill (1974) quien publicó un handbook sobre el liderazgo. Este autor llevó a cabo una revisión durante cuatro décadas, sobre "todo" lo que se había publicado alrededor del liderazgo, mostrando, luego igual que Peiró (1995), unas décadas más tarde, que aún no se cuenta con una comprensión integrada al liderazgo.

En estos años surge el enfoque de contingencia, con un concepto nuevo: la eficacia del liderazgo está afectada y determinada por el contexto y la situación (Bryman, 1996). Al detallar la cronología durante las décadas de los ochenta y noventa, según Glynn y Dejordy (2010), nacen dos propuestas teóricas: 1) las teorías comportamentales y 2) las teorías contingenciales, que son las que dominan las publicaciones; después de estas décadas no existen perspectivas teóricas dominantes. Sin embargo, después de los años 
ochenta surgen trabajos sobre un nuevo liderazgo: el liderazgo transformacional y carismático, es decir que los líderes deben desarrollar una visión estratégica, han de inspirar lealtad en sus seguidores y, además, se deben implicar emocionalmente (Bryman, 1996).

En los noventa y siguientes se desarrollan tendencias actuales sobre el liderazgo y sus perspectivas asociadas al estudio de otros procesos psicológicos a nivel individual, grupal y organizacional. Algunas de ellas son bienestar, calidad de vida, comunicación, grupos y equipos de trabajo, los aspectos éticos del liderazgo, liderazgo por e-learning, liderazgo como fenómeno grupal, liderazgo como proceso, líder como sujeto, los seguidores, la situación, entre otras; incluyendo el factor cultural como uno de sus elementos fundamentales, teniendo en cuenta los procesos de globalización que se dan en el mundo (Contreras, Barbosa y Piñeros, 2016; Molero y Morales, 2011; Sabucedo y Morales, 2015).

Por otro lado, Aguilar y Correa (2017); Antonakis, Cianciolo y Stemberg (2004); Contreras (2008); García, Aguilar, Payan y Forero (2016); Molero (2011); Gil y Alcover (2008); Sabucedo y Morales (2015), demostraron, luego de llevar a cabo análisis bibliométricos y revisiones sistemáticas, una gran diversidad de formas de investigar en el liderazgo en el marco de la psicología social y de las organizaciones; estos autores muestran que la investigación sobre el liderazgo está en fase de desarrollo y se encuentra una gran heterogeneidad en estudios cuantitativos, cualitativos y esto puede dificultar la manera como se presentan y dan a conocer los resultados de las investigaciones por parte de las comunidades académicas.

Los estudios de liderazgo que utilizan metodologías cuantitativas usan principalmente cuestionarios, por ejemplo, Bass y su equipo, han estudiado el liderazgo transformacional (Bass, 1985; 1990; 1999; Bass y Avolio, 1994). La mayoría de los cuestionarios son de dos tipos: a) dirigido a los líderes (y se hace de forma autoadministrada), y b) dirigido a los empleados o colaboradores (quienes evalúan las características de su líder). Los ítems corresponden a un modelo teórico que respalda y hace énfasis en determinadas dimensiones, características o variables que permiten medir el liderazgo. Más adelante se presentan los desarrollos históricos del liderazgo.

La investigación del liderazgo a través de experimentos no es muy usual, dada la rigurosidad del diseño de la situación controlada y la manipulación de las variables que el investigador debe tener. Un ejemplo de esto en un contexto real es Lewin, Litpit y White (1939), citados por Peiró (1995), quienes llevaron a cabo un experimento de campo, utilizando muestras de estudiantes. Esto, hoy por hoy, es muy difícil de replicar teniendo en cuenta las exigencias éticas.

Los estudios cualitativos en el liderazgo han usado estrategias como observación participante y entrevistas en profundidad que, de acuerdo con Schilling (2007), es la que más se usa. 
Molero y Morales (2011) y Molero (2011) muestran que los estudios cuantitativos y cualitativos que se conocen sobre el liderazgo y se llevan a cabo desde una perspectiva científica, intentan estudiar el comportamiento del líder, los seguidores y la situación. Cada metodología tiene puntos a favor y en contra, y como el liderazgo es tan complejo, necesita que se integren y complementen; la rigurosidad de ambas metodologías permite replicar y validar investigaciones para contrastar la información que se encuentra en la evidencia publicada.

Ahora bien, pero, ¿qué es el liderazgo? Se presentan dos definiciones, de las muchas encontradas en la literatura, pero estas dos son de autores que han sido importantes en el desarrollo del estudio y las propuestas teóricas del liderazgo, Bass (1990) y Yukl (2002). Bass (1990) define el liderazgo:

[...] como un proceso de interacción entre dos o más personas que normalmente implica estructurar o reestructurar la situación, percepciones y expectativas; el líder es un agente de cambio (influye más en las conductas de otros, que estos sobre él), y el liderazgo tiene lugar cuando un miembro del grupo modifica la motivación o competencias de los miembros del grupo. (pp. 20-21)

Yukl (2002) define el liderazgo como:

[...] el proceso de influir en otros para que entiendan y estén de acuerdo acerca de las necesidades que se deben atender y cómo hacerlo de forma efectiva, y el proceso de facilitar esfuerzos individuales y colectivos para alcanzar objetivos compartidos. (p. 7)

No se olvide que cuando se estudia el liderazgo son tres los elementos que se deben identificar: el líder, los seguidores y el contexto (Aguilar y Correa, 2017). Para finalizar este apartado se presentan cuatro clasificaciones sobre los desarrollos y las aproximaciones teóricas al estudio del liderazgo de acuerdo con Gil (2008):

- Las teorías clásicas de rasgos, estilos de liderazgo y contingencias/situacionales;

- los enfoques alterativos, con una gran influencia el modelo médico;

- los enfoques recientes, con sólidas bases en lo estratégico, carismático, transformacional, transaccional; $y$

- las orientaciones actuales en la dirección y el liderazgo.

Aguilar (2017) y Gil (2008) presentan un resumen de estas clasificaciones, se sintetizan sus autores, principios, aportes y críticas al desarrollo del liderazgo. 
Tabla 1. Teorías clásicas: rasgos, estilos y contingencia

\begin{tabular}{|c|c|}
\hline \multirow{2}{*}{$\begin{array}{l}\text { El liderazgo } \\
\text { como rasgo de } \\
\text { personalidad }\end{array}$} & $\begin{array}{l}\text { - Rasgos personales estables que definen a los líderes. } \\
\text { - Carácter innato de ese rasgo. } \\
\text { - Los líderes nacen. }\end{array}$ \\
\hline & $\begin{array}{l}\text { - Críticas (Yukl y Van Fleet, 1992) no se demostró que un conjunto de rasgos relevantes sea } \\
\text { universal. } \\
\text { - Relación entre rasgo y éxito es escasa e inconsistente. }\end{array}$ \\
\hline \multirow[t]{2}{*}{$\begin{array}{l}\text { El liderazgo } \\
\text { como conducta }\end{array}$} & $\begin{array}{l}\text { - Importante cómo se comporta el líder. } \\
\text { - Cuáles son sus conductas y estilos de comportamiento. } \\
\text { - Las conductas son responsables de la eficacia del liderazgo y pueden aprenderse. } \\
\text { - Dos grandes programas de investigación: } \\
\text { - Estudios de la Universidad de Ohio (Hemphill, Flleishman, Stodgill, Shartle y Pepinsky, } 1962 \\
\text { citados por Peiró, 1995), identificar dimensiones para caracterizar los principales factores en } \\
\text { la conducta de los líderes. } \\
\text { - Estudios de la Universidad de Míchigan (Kahn y Katz, 1978), líderes centrados en los } \\
\text { empleados y líderes centrados en la producción. }\end{array}$ \\
\hline & $\begin{array}{l}\text { - Críticas (Bryman, 1996) a este enfoque orientadas a señalar las dificultades en las medidas, } \\
\text { problemas para identificar la causalidad (estilo de liderazgo se relaciona con rendimientos de } \\
\text { empleados), ausencia de variables situacionales, entre otros. }\end{array}$ \\
\hline \multirow[t]{2}{*}{$\begin{array}{l}\text { Enfoques } \\
\text { contingentes: la } \\
\text { influencia de las } \\
\text { situaciones }\end{array}$} & $\begin{array}{l}\text { - Se denominan modelos contingentes o situacionales. } \\
\text { - La eficacia del liderazgo depende de las condiciones de la situación en que sucede. } \\
\text { - Teoría de la contingencia (Fieldler, 1967), relación líder-miembros, posición de poder del } \\
\text { líder, estructura de la tarea. } \\
\text { - Teoría de liderazgo situacional (Hersey y Blanchard, } 1969 \text { citados por Peiró, 1995), el modelo } \\
\text { predice una evolución en los estilos de liderazgo, desde decir hasta delegar, y parte de la } \\
\text { premisa del desarrollo o madurez de los subordinados. } \\
\text { - Teoría camino-meta (House, 1996, citado por Peiró, 1995), la eficacia del liderazgo } \\
\text { depende de tres variables, las conductas de los líderes (cuatro tipos de conducta: centrada } \\
\text { en la tarea, de apoyo, participativa y orientada al logro), los rasgos de los subordinados } \\
\text { (dependencia, autoritarismos, habilidad, locus de control) y determinadas variables } \\
\text { situacionales (estructura de la tarea, ambigüedad del rol, autonomía y ámbito del trabajo e } \\
\text { interdependencia de la tarea). } \\
\text { - Modelo de liderazgo participativo (Vroom y Yetton, 1973), se relaciona la conducta de } \\
\text { liderazgo y la participación para la toma de decisiones; también se le conoce como modelo } \\
\text { normativo (Vroom y Jago, 1978), analiza el estilo de decisión de los líderes (autocrático, } \\
\text { consultivo, grupal y delegativo) en función de situaciones. } \\
\text { - Teoría de los recursos cognitivos (Fiedler y García, 1987), la eficacia del liderazgo depende } \\
\text { de los recursos cognitivos del líder (inteligencia y experiencia) y las demandas de las } \\
\text { situaciones (complejidad de la tarea). } \\
\text { - Teoría de los sustitutos de liderazgo (Kerr y Jernier, 1978). }\end{array}$ \\
\hline & $\begin{array}{l}\text { - Críticas a los enfoques contingentes dado que han surgido listas interminables de factores } \\
\text { situacionales. Obtienen evidencia parcial o indirecta (Gil y Alcover, 2008). }\end{array}$ \\
\hline
\end{tabular}

Fuente: Aguilar (2017) 
La segunda clasificación sobre las teorías del liderazgo, Aguilar (2017) y Gil (2008), corresponde a los enfoques alternativos.

Tabla 2. Enfoques alternativos del liderazgo

$\begin{array}{cl}\text { Reanimar } & \text { - Frente a los problemas que suscitaron los modelos contingenciales, autores como Smith y } \\ \text { la teoría del } & \text { Peterson (1988, p. 47), con base en el modelo médico, proponen aplicar ciertos "remedios" } \\ \text { liderazgo } & \text { para reanimar la teoría del liderazgo. } \\ & \text { 1. Reemplazar las medidas del estilo del líder por medidas de recompensa y castigo. } \\ & \text { 2. Hacer distinciones entre subordinados (teoría del intercambio líder-seguidores, LMx), } \\ & \text { concepto de endogrupo y exogrupo (Graen y Uhl-Bien, 1995). } \\ & \text { 3. Reexaminar las bases de las percepciones de los subordinados respecto a los líderes } \\ & \text { (importantes las atribuciones que realizan los líderes). } \\ \text { 4. Reexaminar las bases de las percepciones de los subordinados respecto a los líderes (las } \\ \text { personas tienen sus propias creencias - teorías implícitas-. } \\ \text { 5. Revisar las circunstancias que determinan el liderazgo. } \\ \text { 6. Podemos señalar una propuesta más y es la hecha por Den Hartog y Koopman (2001), } \\ \text { quienes analizan el liderazgo a partir de las tácticas de poder e influencia. La aplicación } \\ \text { de los recursos de poder resulta de gran importancia para explicar el comportamiento de } \\ \text { los líderes (Yukl y Van Fleet, 1992). }\end{array}$

Fuente: Aguilar (2017)

En este segundo momento, de acuerdo con Smith y Peterson (1988), hay una tendencia a estudiar el liderazgo y retomar elementos de la psicología social, psicología cognitiva, psicología organizacional y de otras ciencias sociales; se le da mayor importancia a la forma como el líder y los seguidores perciben e interpretan las acciones del otro, y como esto genera un proceso de influencia; y, además, utilizan metodologías mixtas, experimentos de laboratorio, de campos y estadísticas cada vez más sofisticadas.

La tercera clasificación presenta tres temas importantes: el liderazgo estratégico, nuevamente los estudios sobre los rasgos y los nuevos liderazgos (Aguilar, 2017; Gil, 2008).

Tabla 3. Enfoques recientes de liderazgo

\section{Se caracteriza por:}

Liderazgo estratégico
- Preocupación por los líderes y directivos de niveles medio y superior.

- Dirigido a equipos de la alta dirección encargados de afrontar los nuevos retos de la globalización.

- Respuestas organizacionales frente a las condiciones del ambiente y se relaciona con un liderazgo para toda la empresa.

- Los líderes estratégicos ejercen una gran influencia, exagerada atribución a su poder; importante la cultura organizacional, los recursos disponibles, equipos ejecutivos, buscan consenso de grupo, una sola persona no puede hacer frente a todo, de ahí la necesidad de fortalecer los grupos (Yukl, 2002; Aditya, House y Kerr, 2000; Gil, 2008). 
Reaparece el interés por el estudio de los rasgos años ochenta.

Revitalización de - A través de metaanálisis se confirma la importancia de rasgos, inteligencia, masculinidad, los estudios de dominancia, en el aumento del éxito del líder, aunque no lo garanticen (Aditya, House y rasgos Kerr, 2000; Yukl y Van Fleet, 2002).

- Surgen teorías que relacionan el liderazgo con las situaciones: la teoría de Mischel (1973) citado por Peiró (1995), distingue situaciones débiles y fuertes, en las que el líder debe mostrar sus tendencias disposicionales. La teoría de motivación de poder (McClelland, 1975, citado por Peiró, 1995) que es un antecedente del liderazgo carismático, y permite identificar un perfil de liderazgo eficaz, con determinados rasgos, como un alto nivel de motivación de poder (afiliación) con una alta preocupación por el uso moral del poder.

Nuevo liderazgo - Luego de los años ochenta surge un renovado interés por el liderazgo y esto da lugar a nuevas teorías.

- Surgen el liderazgo carismático y el liderazgo transformacional.

- El liderazgo carismático desarrollado por Weber (1929) y retomado luego por House y Aditya (1997) describe una forma de influencia basada en las percepciones que los seguidores tienen del líder y que se produce en momentos de crisis social.

- La teoría del autoconcepto (House y Aditya, 1997; Shamir, House y Arthur, 1993) explica el liderazgo carismático basándose en un conjunto de rasgos y conductas identificadas en los líderes que influyen en las actitudes y conductas de los seguidores.

- Se reconoce el "lado oscuro del liderazgo carismático", con numerosos ejemplos de líderes políticos y de sectas milenaristas (Gil, 2008).

- Se identifican otros tipos de carisma (Howell y House, 1992, citado por Aditya, House y Kerr, 2000): personalizado, el cual se caracteriza por ser autoagradecido, explotador y autoritario. Carisma socializado, es altruista, colectivista e igualitario (Bass, 1999).

- El desarrollo del liderazgo transformacional, que proviene de la diferencia entre liderazgo transaccional y transformador.

- El liderazgo transaccional implica un contrato implícito entre líderes y seguidores que establece un intercambio (el líder otorga recompensas, dinero, prestigio, etc.). El liderazgo transformacional eleva las aspiraciones de sus seguidores, las funde con las suyas propias y les estimula y motiva (Bass y Avolio, 1994; Gil, 2008).

- Bass $(1985 ; 1999)$ elabora la teoría de liderazgo transformacional a partir de la distinción transaccional-transformador. Esta propuesta resulta efectiva en todas las situaciones y culturas e incluye dimensiones como: carisma, motivación inspiracional, consideración individualizada y estimulación intelectual (Gil, 2008).

- Yukl (2002) cuestiona que este estilo de liderazgo sea una panacea que pueda resolver todos los problemas de las grandes organizaciones, la mayoría de las investigaciones han evidenciado que los cambios en las organizaciones no se deben tanto a los líderes carismáticos, como a los procesos transformacionales de liderazgo.

Fuente: Aguilar (2017)

La cuarta perspectiva (Aguilar, 2017; Gil, 2008) se refiere a temas actuales, que incluyen dirección y liderazgo, globalización y generación de nuevas tecnologías de la información, dado que han provocado grandes transformaciones en las organizaciones, y han hecho que se reestructuren funciones, áreas, roles y competencias en las empresas. Shamir y Howell (1999) consolida nuevos escenarios, alternativos de liderazgo: 1) liderazgo indispensable, de usar y tirar; corresponde a un acuerdo temporal, limitado en su objetivo y duración. 2) Liderazgo colectivo, compartido, distribuido o 
de los miembros (importante, ya que plantea que el liderazgo se distribuye entre los miembros que lo ejecutan, es decir, equipos autónomos). 3) El novedoso teleliderazgo, en el que el líder debe centrarse en desarrollar una comunicación más efectiva; se relaciona con la transmisión de información entre el líder y seguidores a través de las tecnologías de comunicación mediada y los sistemas de apoyo a la decisión grupal.

\section{Tabla 4. Temas y orientaciones actuales}

\begin{tabular}{|c|c|}
\hline $\begin{array}{l}\text { Liderazgo } \\
\text { distribuido o } \\
\text { compartido }\end{array}$ & $\begin{array}{l}\text { - Propuesto por autores como Aditya, House y Kerr (2000) y Bryman (1996), adopta } \\
\text { diferentes modalidades y contrasta un liderazgo carismático con enfoques de nuevos } \\
\text { liderazgos - liderazgo de personas heroicas, de alto nivel y está centrado más en las } \\
\text { personas que en los grupos-. } \\
\text { - Algunos ejemplos son liderazgo delegado, coliderazgo, liderazgo de los miembros, } \\
\text { superliderazgo (Manz y Sims, 1989), modelo de los equipos reales (Katzenbach y Smith, } \\
\text { 1993), modelo de liderazgo (Kouzes y Posner, 1995; 2002), procesos y habilidades de } \\
\text { liderazgo (Hosking, 1988). Estos modelos por lo general se proponen alrededor de una } \\
\text { idea común, y es hacer que los miembros del grupo sean capaces de liderarse a sí mismos } \\
\text { (Manz y Sims, 1989). }\end{array}$ \\
\hline $\begin{array}{l}\text { Gestión de la } \\
\text { diversidad }\end{array}$ & $\begin{array}{l}\text { - Esta perspectiva reconoce diversas fuerzas de trabajo y miembros en cuanto a raza, etnia, } \\
\text { edad, género, formación, nivel socioeconómico, entre otros, lo que implica importantes } \\
\text { beneficios, pero también, otros costos y muchos conflictos (Alcover, 2008). } \\
\text { - Los líderes tienen el reto de gestionar la diversidad y encontrar el balance adecuado en la } \\
\text { organización para promover una fuerte identidad y una cultura organizacional basada en } \\
\text { valores e identidad compartida (Gil, 2008). }\end{array}$ \\
\hline $\begin{array}{l}\text { Liderazgo y gestión } \\
\text { del conocimiento }\end{array}$ & $\begin{array}{l}\text { - De acuerdo con Davenport (2000) y Delgado y Castañeda (2011), la ventaja competitiva de } \\
\text { las organizaciones radica en la capacidad que tienen de aprender, así deberá gestionar su } \\
\text { capital intelectual, relacional, y desarrollar un clima organizacional que propicie compartir la } \\
\text { información en todos los niveles y áreas de la organización, y generar conocimiento. }\end{array}$ \\
\hline Liderazgo ético & $\begin{array}{l}\text { - Yukl (2002) se acerca a proponer unos criterios para evaluar el liderazgo ético, dado } \\
\text { que resulta importante conocer los esfuerzos que hacen los líderes para mostrar un } \\
\text { comportamiento ético y para erradicar las prácticas no éticas en las organizaciones. } \\
\text { Evaluarlo es complejo y requiere identificar valores, intenciones y la moral de los líderes } \\
\text { (Gil, 2008). }\end{array}$ \\
\hline $\begin{array}{c}\text { Liderazgo en } \\
\text { distintas culturas }\end{array}$ & $\begin{array}{l}\text { - Gil (2008) afirma que el significado que se les da a los líderes varía de acuerdo con el } \\
\text { contexto cultural, y que la mayoría de las teorías sobre el liderazgo surgen en Estados } \\
\text { Unidos, y los estudios reflejan el interés por valores individualistas, posturas alrededor de } \\
\text { la racionalidad, incentivos individuales, responsabilidades de los seguidores, motivación } \\
\text { hedonista, orientación a valores democráticos. } \\
\text { - Prepararse para los años siguientes, la globalización hace necesario que los líderes } \\
\text { entiendan los valores de cada cultura. } \\
\text { - Aquí surge el proyecto más extenso y ambicioso que estudia el liderazgo en diferentes } \\
\text { culturas, el proyecto Globe que se presenta más adelante (Gil Rico, 2000). }\end{array}$ \\
\hline
\end{tabular}

Fuente: Aguilar (2017) 


\section{Cultura}

Para la psicología del trabajo y las organizaciones y la psicología social, la cultura corresponde a uno de los factores más importantes de influencia sobre el comportamiento a través del intercambio de normas y valores por parte de un gran número de personas (Shiraev y Levy, 2010). Para este caso en particular, el interés de este trabajo es sobre el papel de la cultura en el liderazgo y del liderazgo en la cultura. La cultura, tal como la definen House, Wright y Aditya (1997), corresponde a una serie de procesos comunes compartidos, formas de pensar, sentir, reaccionar, significados e identidades, ambientes socialmente construidos y compartidos. De acuerdo con Contreras, Barbosa y Piñeros (2016), el líder es un elemento importante en este proceso pues depende de lo que las personas consideren es su rol ideal. El líder desempeña un papel determinante en el desarrollo de la cultura y la forma como las personas se comportan y transmiten dichos patrones de generación en generación.

Nader y Solano (2009) llevan a cabo una interesante revisión sobre los antecedentes y la relación entre liderazgo y cultura, en la que muestran que los primeros trabajos se encuentran reseñados en algunos libros de autores como Sackmann (1991), Schein (1992) y Deal y Kennedy (1982), desde los años ochenta, quienes mostraron relaciones entre la cultura organizacional, los valores y el liderazgo.

En la literatura científica se identifican dos corrientes o dos perspectivas, unos que apoyan y confirman esta relación y otros que consideran que las habilidades de los líderes no se ven influenciadas por la cultura. Nader y Solano (2009) muestran algunos autores (Adler, Doktor y Redding, 1986; Child y Tayeb, 1983; Levitt, 1983) que afirman que: "las prácticas culturales y el contexto organizacional no afectan las habilidades del liderazgo pues los atributos del líder son en su mayoría universales (éticos) y las acciones que lo hacen efectivo, trascienden el contexto" (p. 239). La segunda perspectiva que se tiene en cuenta en el desarrollo de este trabajo, y que es de gran impacto científico hoy por hoy, confirma que un líder es efectivo si es reconocido como tal y esto está en estrecha relación con los valores, las tradiciones culturales y las ideologías de los seguidores (House, Wright y Aditya, 1997; House y Javidan, 2002).

Tal como se observó en las teorías del liderazgo, al revisar la relación entre cultura y liderazgo surge la misma problemática. Siempre que se estudie el liderazgo no se pueden dejar de lado las variables del contexto y la situación donde surge este. Triandis (2004) deja en evidencia en sus trabajos transculturales la necesidad de conocer las acciones del líder que más se ajustan a las pautas y prácticas culturales vigentes en una organización. Las teorías y modelos del liderazgo son en extremo generales y 
caracterizan las acciones del liderazgo independientemente del contexto, ya sea el organizacional o el cultural más amplio (House, Javidan y Dorfman, 2001; Yukl, 2002).

En este trabajo se aborda la cultura organizacional y no la cultura social. De acuerdo con Schein (1992) y Trice y Beyer (1993), cultura y liderazgo están muy relacionados, dado que los líderes se pueden ver influenciados por las condiciones de la cultura en que se encuentran, y a la vez, un líder puede crear, modificar, cambiar, potenciar o incluso intercambiar varias culturas.

Molero (2002) afirma que el liderazgo es capaz de crear culturas cuando, por ejemplo, una persona que tiene un proyecto o una visión, crea una organización. De este modo, el proyecto de empresa, según Trice y Beyer (1993), es la "sustancia" de la cultura organizacional, siendo los creadores y dueños una parte muy importante de la cultura de la organización por toda la influencia que ejercen en ella.

Para el segundo caso, estos autores afirman que el liderazgo cambia culturas, cuando los líderes cambian a otros a través de sus conductas, son carismáticos o transformacionales y logran influir y producir cambios en las organizaciones. También puede esperarse que el líder no cambie la cultura, sino que la fortalezca, la preserve, con miras a mantener la identidad de la organización. Es importante reconocer en las organizaciones el surgimiento de subculturas, que pueden ser las áreas o unidades de una organización. De acuerdo con Molero (2002), una importante función de un líder será hacer que los individuos de cada grupo actúen de forma armónica orientados al cumplimiento de los objetivos de la organización y esto se constituye en un elemento de cultura.

$\mathrm{Al}$ revisar algunos antecedentes, modelos y teorías sobre la cultura organizacional se identificaron los siguientes. Autores como Allaire y Firsirotu (1984) llevaron a cabo una revisión sistemática e identificaron muchas teorías y las clasificaron en ocho escuelas: funcionalista, estructural funcionalista, ecológica, histórica, estructuralista, mutual, simbólica y cognitiva. De acuerdo con Martínez-Avella (2010), si se rastrean publicaciones y trabajos de corte empírico, se distinguen dos tipos de estudios sobre cultura organizacional: primero están los trabajos que identifican variables que definen la cultura organizacional y la relacionan con resultados en el ámbito organizacional; y segundo, los estudios entre culturas que buscan relacionar los rasgos de las culturas de los países con características de las culturas organizacionales.

Para el primer tipo se encuentran diferentes modelos sobre las características o rasgos que definen la cultura organizacional. Harrison (1972) es uno de los primeros autores que se encuentra en la literatura científica; él desarrolló una tipología con variables como orientación al poder, orientación al rol, a la tarea y a las personas; y 
con estos elementos describió los rasgos que definen la cultura de una organización. Cunha y Cooper (2002), diseñaron y aplicaron un cuestionario incluyendo variables como poder, rol, tarea y personas. Luego, O'Reilly, Chatman y Caldwell (1991) consideraron que los rasgos de la cultura están definidos por perfil en innovación, toma de riesgos, minuciosidad, orientación a resultados, orientación a las personas, orientación a los equipos, agresividad y estabilidad. Con esta misma orientación se identifican los trabajos de Denison y Mishra (1995), quienes dan mucha importancia a los rasgos dentro de la cultura como, por ejemplo, el involucramiento, la consistencia, la adaptabilidad y la misión.

Ahora bien, para el segundo tipo tenemos estudios entre culturas (crosscultural), el máximo autor reconocido como pionero es Hofstede (1980). Él identifica unos rasgos para comparar culturas organizacionales entre diferentes países; esto ha servido de base en múltiples estudios sobre comportamiento organizacional. Incluye variables como individualismo, distancia de poder, masculinidad, aversión a la incertidumbre; luego incorporó orientación al futuro; a través de sus trabajos se han podido organizar las diferencias culturales en patrones generalizados, y esto ha permitido llevar a cabo una investigación comparativa que ha servido de base para muchos estudios sobre cultura organizacional.

En la literatura también se observan una gran cantidad de controversias sobre su definición y contenido. Se encuentran aportes desde la psicología, la sociología, la antropología y, más recientemente, desde las ciencias administrativas (Gil y Alcover, 2008). Denison (1996), por su parte, ha aclarado el constructo de cultura organizacional y lo diferencia con el clima organizacional, puesto que en muchos textos se utilizan indistintamente. Cultura se refiere a la forma como se comporta la gente, los valores y las presunciones arraigadas y dados por supuesto; mientras que el clima organizacional hace énfasis a los factores ambientales percibidos conscientemente y sujetos al control organizacional que se traduce en normas y pautas de comportamiento. Denison (1996) y Schneider (2000) defienden la postura de que los dos constructos son complementarios.

Adicionalmente, Trice y Beyer (1993) manifiestan que la cultura incluye dos categorías. Una que se corresponde a los sistemas de creencias compartidas e interrelacionadas que tienen una alta carga emocional y que se denominan ideologías. La segunda corresponde a las formas culturales, y estas son los artefactos observables como símbolos, lenguaje, relatos y prácticas o acciones, mediante las cuales las personas de una cultura expresan, afirman y se comunican. Aquí toma mucho valor el lenguaje y todo lo que las personas transmiten a través de él, metáforas, dichos, jergas utilizadas, el argot, entre otros. 
Para Rousseau (1997) es importante señalar la participación de antropólogos y otros investigadores organizacionales en el momento de definir la cultura, teniendo en cuenta las coincidencias que tienen al definirla. Las culturas son:

\section{conjuntos de cogniciones compartidas por los miembros de una determinada unidad social, las cuales se adquieren a través del aprendizaje social y de procesos de socializa- ción que exponen a los individuos a diversos elementos culturales, como actividades e interacciones, informaciones comunicadas y artefactos materiales, que conforman las experiencias sociales al tiempo que dotan a sus miembros de valores compartidos, marcos de comprensión comunes y sistemas de creencias y de expectativas. (p. 515)}

Esto permite concluir que las culturas son dinámicas, pues cambian de forma permanente, y ejercen una serie de consecuencias sobre las personas con las que comparten. Trice y Beyer (1993) dejan en evidencia algunas consecuencias de la cultura y a través de algunos estudios que corresponden a temas como el manejo de incertidumbre colectiva, la creación de orden social, de continuidad, identidad y compromiso colectivo, fomento de etnocentrismo, entre otras.

Hay una distinción importante cuando se revisan estudios sobre cultura organizacional. De acuerdo con Smircich (1983), la diferencia entre lo que la organización es frente a la cultura como algo que una organización tiene. La primera clasificación, cultura como la organización es, recibe el nombre de enfoque "emic o simbólico"; aquí, la cultura es una metáfora, y debe captar su estructura mediante las descripciones que hacen los colaboradores de la organización; los estudios de este tipo están centrados en los significados construidos a partir de las formas culturales como, por ejemplo, rituales, símbolos, celebraciones o disposiciones del espacio físico en cada organización (Alcover, 2008).

La segunda apuesta hace referencia a la cultura como algo que la organización tiene y corresponde a elementos particulares de cada empresa como son lineamientos, las políticas, los principios, los valores y la historia; de tal forma que un observador puede reconocer fácilmente sus costumbres, símbolos, rituales, normas, entre otros; cuando se identifican estos artefactos en la cultura, se hace referencia al enfoque "etic" (Alcover, 2008). En esta misma perspectiva para Schein (1985), la cultura corresponde a las respuestas aprendidas por los colaboradores de la organización sobre los posibles problemas colectivos; es decir, la cultura es una forma de interpretar, percibir, pensar y sentir la relación de los trabajadores con los problemas. Es una forma de comportarse frente a la cotidianidad de la organización. Así, las normas los valores, los rituales e incluso el clima son mecanismos o manifestaciones de la cultura. 
De acuerdo con Alcover (2008), estas dos clasificaciones dan lugar a dos aproximaciones epistemológicas que se han utilizado para abordar el estudio de la cultura; primero, corresponden a una perspectiva interpretativa o simbólica de carácter sociocognitivo (las organizaciones son culturas, metáfora); y segundo, la postura funcionalista, de naturaleza objetivista (las organizaciones tienen culturas, y es variable), esta denominación fue propuesta por Sypher, Applegate y Sypher (1985) citado por Alcover (2008).

Otra propuesta la hace Martín (2002), quien propone ordenar las teorías sobre la cultura organizacional y las clasifica en tres: integración, diferenciación y fragmentación. La primera, integración, hace alusión a las manifestaciones consistentes y consensuadas por los miembros de la organización; y de esta manera, la cultura es aquello que resulta claro y unificado para todos los miembros. En segunda instancia, la diferenciación se refiere a las manifestaciones e interpretaciones inconsistentes; por ejemplo, en organizaciones, donde hay subculturas y surgen conflictos entre las áreas y/o grupos formales e informales. Y, tercero, fragmentación, en la que la relación con las manifestaciones culturales es ambigua, el consenso es transitorio y específico para cada problema; los términos claves para esta perspectiva son redes de ambigüedad, paradoja y contradicción.

Adicional a estos análisis, Peiró (1990) y Alcover (2008) en la definición de cultura organizacional incluyen sus contenidos, elementos y/o niveles de análisis. Y, nuevamente, de acuerdo con Peiró (1990), surgen tres niveles que sirven para intentar aclarar los contenidos culturales de las organizaciones: 1) nivel observable, en el que lo evidente corresponde a los productos/artefactos de la cultura: lenguajes, rituales, sanciones, normas, patrones de conducta, costumbres, clima, símbolos, artefactos, mitos, leyendas, espacio físico, vestido, dotación, entre otros. 2) Nivel apreciativo y valorativo: son los lineamientos de la organización como, por ejemplo, valores, filosofía, ideología, expectativas, actitudes, perspectivas, conocimientos, prioridades, significados, etc. 3) Nivel fundante: son los supuestos y creencias básicas, que no se hacen tan evidentes en las manifestaciones culturales, son elementos esenciales de la cultura entre sí.

Rousseau (1997), propone, también, una clasificación de los principales elementos de la cultura, que van desde los de menor accesibilidad y mayor subjetividad a los de mayor accesibilidad y mayor objetividad; estos son presunciones fundamentales, valores, normas de comportamiento, patrones de conducta y artefactos.

Cuando se revisa la literatura científica, se encuentran diversas discusiones sobre los diferentes abordajes para definir y describir la cultura en las organizaciones. Buscar un acuerdo en sus definiciones y conceptos resulta casi imposible; esto deja 
en evidencia la vulnerabilidad del tema frente a los que tratan de deslegitimar la investigación en este campo (Alcover, 2008).

Si esto ocurre con su definición, igual pasa con su medición. Frente a las mediciones de la cultura se encuentran las dimensiones que se han utilizado para abordar de forma empírica su estudio. Con base en los planteamientos de uno de los autores más representativos, Geert Hofstede (2001), una dimensión es un aspecto de una cultura que puede medirse con relación a otras culturas. Los intentos por definir dimensiones culturales provienen de estudios de antropólogos, sociólogos y psicólogos sociales; la que ha tenido mayor difusión y aceptación en las últimas tres décadas es la propuesta por Hofstede; es una investigación transcultural realizada entre organizaciones multinacionales pertenecientes a 50 países (Hofstede, 1980; 2001). Las dimensiones que incluyó Hofstede (1980), en el estudio fueron cuatro:

\begin{abstract}
1) distancia jerárquica o de poder, que mide la desigualdad social y relaciones con la autoridad; 2) colectivismo frente a individualismo, y mide relaciones entre individuo y grupo; 3) feminidad frente a masculinidad, mide implicaciones sociales de pertenecer a uno u otro género; 4) control de la incertidumbre, mide las formas de tratar la incertidumbre relacionadas con el control de la agresión y las expresiones de las emociones. (p. 48)
\end{abstract}

Unos años más tarde, Hofstede y Bond (1988) identificaron otra dimensión, orientación a largo plazo versus orientación a corto plazo, en la vida.

También se identificaron otros esfuerzos por utilizar dimensiones de la cultura nacional para la cultura organizacional, sin embargo, el mismo Hofstede (1991) señala que: "los resultados de las investigaciones realizadas sobre culturas nacionales han demostrado ser solo parcialmente útiles para comprender las culturas organizacionales" (pp. 54-55).

Posteriormente, en 1991, R. J. House concibió el programa de investigación Global Leadership and Organizational Behavior Effectiveness (Globe), el cual estudia las interrelaciones del liderazgo, la cultural societal y la cultura organizacional (House et al., 1999), con una muestra que ha llegado a más de 20.000 personas, más de 800 organizaciones y más de 60 culturas. La mayoría de las revisiones teóricas, epistemológicas y metodológicas alrededor de la cultura organizacional se dirigen indistintamente al proyecto Globe (Globe, 2016).

Se pueden buscar y reseñar otros trabajos sobre cultura organizacional, pero la relación que se pretende presentar y resaltar en este capítulo es el liderazgo y la cultura organizacional, y ambos conceptos están asociados a un enfoque cultural, en el que el 
liderazgo es el motor. De acuerdo con Alcover (2008), el líder es responsable de crear y transmitir los elementos de la cultura organizacional como la visión, la misión, los valores, las normas, etc., así como las prácticas de los procesos que se pretende establecer. Por ejemplo, el profesor Molero (2002) afirma que las relaciones entre cultura y liderazgo pueden verse desde tres perspectivas y niveles: culturas transnacionales, nacionales y subnacionales.

Tabla 5. Perspectivas y niveles de la cultura según Molero (2002)

\begin{tabular}{cc}
\hline Tipo de cultura & Características \\
\hline Culturas transnacionales & Compartidas por los miembros de diferentes países \\
Culturas nacionales & Las que comparten los miembros de un mismo país \\
Culturas subnacionales & Las que son compartidas por los miembros de un departamento, \\
& área o unidad dentro de una organización \\
\hline
\end{tabular}

Fuente: Aguilar (2017).

Lo que se ha logrado identificar es que los estudios y las investigaciones entre liderazgo y cultura se llevan a cabo en dos vías, una, cuando la cultura determina el tipo de liderazgo que surge, y dos, cuando el liderazgo determina la cultura. En la primera, Bass (1990), Triandis (1995) y Smith y Bond (1998), evidencian que esta perspectiva es en la que se han realizado la mayor cantidad de trabajos en los últimos años y, esto ha facilitado hacer comparaciones transculturales y/o transorganizacionales.

Para la segunda perspectiva, en la que el liderazgo determina la cultura, Schein (1985), afirma que: "cultura y liderazgo son dos caras de la misma moneda" (p. 2), lo más importante que hacen los líderes es crear y manejar las culturas. Así, cuando se revisa esta relación, resulta muy relevante tener en cuenta el tipo de cultura sobre la que se hace el análisis, y si se considera variable independiente o dependiente con respecto al liderazgo.

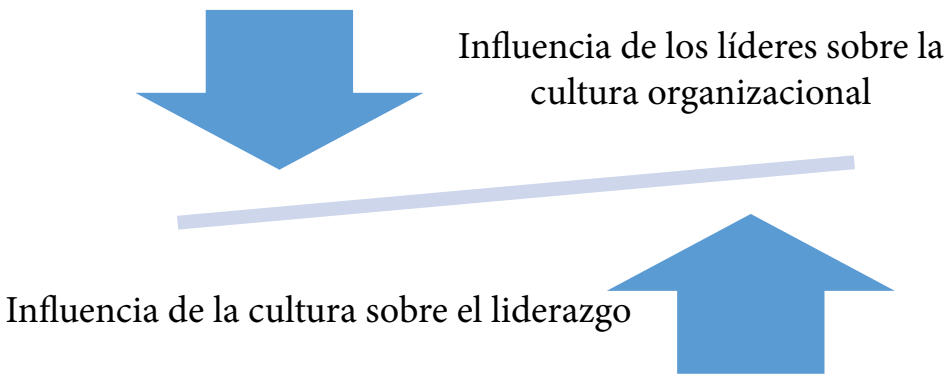

Figura 1. Relación entre cultura organizacional y liderazgo

Fuente: Aguilar (2017) 


\section{Conclusión}

Definitivamente, lo que resulta relevante es que la cultura influye en el liderazgo y el liderazgo influye en la cultura, esto no se puede negar. Sin embargo, todavía queda mucho por estudiar, investigar, explicar y entender. Se requieren más trabajos que analicen estas influencias y la forma en que las personas ejercen el liderazgo; investigaciones que expliquen cómo la cultura influye sobre el liderazgo en el contexto organizacional. Seguir explorando y estudiando estos temas ha sido una realidad, pero deben enriquecerse las investigaciones futuras desde una perspectiva del rol cambiante del líder de acuerdo con cada organización y a lo largo del tiempo, así como desarrollar metodologías más complejas e integrar otras variables psicológicas que son determinantes en los dos temas, y que han sido revisadas.

\section{Referencias}

Aditya, R. N., House, R. J. y Kerr, S. (2000). Theory and practice of leadership: Into the new millennium. En L. Cooper y E. Locke (eds.), Industrial and Organizational Psychology. Linking theory and practice (pp. 130-165). Blackwell Pub.

Adler. N. J., Doktor, R. y Redding, S. G. (1986). From the Atlantic to the Pacific century. Cross-cultural management reviewed. Journal of Management, 12, 295-318.

Aguilar Bustamante, M. C. (2017). Estudio comparativo del estilo de liderazgo y la cultura organizacional en asociaciones gremiales y directores de programas en psicología en Latinoamerica y España, con base en el proyecto Globe [tesis de doctorado Universidad de La Laguna].

Aguilar Bustamante, M. C. y Correa-Chica, A. (2017). Análisis de las variables asociadas al estudio del liderazgo: una revisión sistemática de la literatura. Universitas Psychologica, 16 (1), 1-13. http://dx.doi.org/10.11144/Javeriana.upsy16-1.avae

Allaire, Y. y Firsirotu, M. (1984). Theories of organizational culture. Organization Studies, 5(3), 193-226. doi: 10.1177/017084068400500301

Alcover, C. M. (2008). Las organizaciones en las sociedades actuales. En F. Gil y C. M. Alcover (coords.), Introducción a la psicología de las organizaciones (pp. 85-107). Alianza.

Anastácio-Barata, M. y Martí-Ripoll, M. (2015). El liderazgo en una perspectiva internacional: Un estudio comparativo entre líderes brasileños y españoles de acuerdo con el proyecto Globe. Revista de Psicología, 2(1), 35-49. http://periodicos.ufc.br/index.php/ psicologiaufc/article/view/1500

Antonakis, J., Cianciolo, A. T. y Sternberg, R. J. (2004). Leadership: Past, present, and future. En J. Antonakis, A. T. Cianciolo y R. J. Sternberg (eds.), The nature of leadership (pp. 3-15). Sage.

Bass, B. M. (1985). Leadership and performance beyond expectations. Free Press. 
Bass, B. M. (1990). Bass \& Stogdill's handbook of leadership: Theory, research, and managerial applications (3. ${ }^{\mathrm{a}}$ ed.). Free Press.

Bass, B. M. (1999). Two decades of research and development in transformational leadership. European Journal of Work and Organizational Psychology, 8(1), 9-32. http://dx.doi. org/10.1080/135943299398410

Bass, B. M. y Avolio, B. J. (1994). Improving organizational effectiveness through transformational leadership. Sage Publications.

Bligh, M.C. y Meindl, J.R. (2005). The cultural ecology of leadership: An analysis of popular leadership books. En D. M. Messick y R. M. Kramer (eds.), The psychology of leadership: New perspectives and research (pp. 11-51). Sage.

Bryman, A. (1996). Leaderships in organizations. En S. R. Clegg, C. Hardy y W. R. Nord (ed.). Handbook of Organizational Studies (pp. 276-292). Sage.

Child, J. D. y Tayeb, M. (1983). Theoretical perspectives in cross-national research. International Studies of Management and Organization, 23(4), 32-70.

Cunha, R. C., y Cooper, C. L. (1998). Privatization and the human factor. Journal of Applied Management Studies, 7, 201-210

Contreras, F., Barbosa, D., Juárez, F y Uribe, A. (2010). Efectos del liderazgo y del clima organizacional sobre el riesgo psicosocial, como criterio de responsabilidad social, en empresas colombianas del sector salud. Revista Argentina de Clínica Psicológica, 19(2), 173-182. http://www.redalyc.org/articulo.oa?id=281921801007

Contreras, F., Barbosa, D. y Piñeros, R. (2016). Liderazgo: antecedentes, tendencias y perspectivas de desarrollo. Editorial Universidad del Rosario.

Contreras, F. (2008). Liderazgo: perspectivas de desarrollo e investigación. International Journal of Psychological Research, 1(2) 64-72. http://www.redalyc.org/articulo. oa?id=299023508008 Contreras

Davenport, T. H. (2000). El trabajo del conocimiento y el futuro de la dirección. En W. Bennis, G. M. Spreitzer y T. G. Cummings (comps.), El futuro del liderazgo. (pp. 53-71). Deusto.

Deal, T. E. y Kennedy, A. A. (1982). Corporate cultures: The rites and rituals of corporate life. Penguin Books.

Delgado, L. y Castañeda, D. I. (2011). Relación entre capital psicológico y la conducta de compartir conocimiento en el contexto del aprendizaje organizacional. Acta Colombiana de Psicología, 14, 61-70. http://www.redalyc.org/articulo.oa?id=79822602006

Den Hartog, D. N. y Koopman, P. L. (2001). Leadership in organizations. En N. Anderson, D. S. Ones, H. Kepir-Sinangil y C. Viswesvaran, C. (eds.), International handbook of industrial, work and organizational psychology (vol. 2). Sage.

Denison, D. (1996). What is the difference between organizational culture and organizational climate? A native's point of view on a decade of paradigm wars. Academy of Management Review, 21, 619-654. doi: 10.5465/AMR.1996.9702100310 
Denison, D. y Mishra, A. (1995). Toward a theory of organizational culture and effectiveness. Organizational Science, 6(2), 204-223. http://www.trustiseverything.com/wp-content/ uploads/2012/07/denison-mishra-toward-a-theory-of-org-culture-and-effect-orgsci-1995.pdf

Dorfman, P. y Hanges, P. (2004). The identification of culturally endorsed leadership profiles. En R. J. House, P. J. Hanges, M. Javadin, P. W. Dorfman y V. Gupta. Culture, leadership and organizations: The Globe Study of 62 Societies (pp. 669-719). Sage.

Fiedler, F. E. (1967). A theory of leadership effectiveness. McGraw-Hill.

Fiedler, F. y García, J. (1987). New approaches to leadership, cognitive resources and organizational performance. John Wiley and Sons.

García-Rubiano, M., Aguilar Bustamante, M.C., Payan Wilson, E. y Forero, D. (2016). Investigación bibliométrica de los trabajos de grado sobre liderazgo en las facultades de psicología de la ciudad de Bogotá (Colombia). Universidad y Empresa, 17(28), 147-172. DOI: http://dx.doi.org/10.12804/rev.univ.empresa.28.2015.07

Gil, F. (2008). Dirección y liderazgo. En F. Gil y C. M. Alcover, Introducción a la psicología de las organizaciones (pp. 285-318). Alianza.

Gil, F. y Alcover, C. M. (2008). Introducción a la psicología de las organizaciones. Alianza.

Gil Rico, A. (2000). El programa de investigación Globe. Una estrecha relación entre cultura y liderazgo. Revista Reflexiones, 14, 30-92. http://uexternado2.metarevistas.org/index. php/sotavento/article/viewFile/1627/1466

Gil, F. y García Sáiz, M. (1993). Habilidades de dirección en las organizaciones. Eudema.

Gil, F. y Martí, M. (2011). Cultura y liderazgo. El proyecto Globe. En F. Molero y J. F. Morales (coords.), Liderazgo: hecho y ficción (pp. 197-220). Alianza.

Gil, F., Alcover, C., Rico, R. y Sánchez-Manzanares, M. (2011). Nuevas formas de liderazgo en equipos de trabajo. Papeles del Psicólogo, 32, 38-47. http://www.papelesdelpsicologo. es/pdf/1917.pdf

Globe (2016). Culture groups. Global leadership \& organizational behavior effectiveness. Autor. http://GLOBEproject.com/results/clusters/anglo?menu=list

Glynn, M. A. y De Jordy, R. (2010). Leadership through an organizational behavior lens: A look at the last half century of research. En N. Noria y R. Khurana (eds.), Handbook of Leadership Theory and Practice (pp. 119-157). Harvard Business Press.

Hanges, P. J. y Dickson, M. W. (2004). The development and validation of the Globe Culture and Leadership Scale. En M. Javidan, P. W. Dorfman y V. Gupta, Culture, leadership, and organizations. The Globe study of 62 societies (pp. 122-145). Sage.

Harrison, R. (1972). Understanding your organisation's character. Harvard Business Review, May-June, 119-128.

Hofstede, G. (1980). Culture's consequences: International differences in work related values. Sage. 
Hofstede, G. (2001). Culture's consequences: Comparing values, behaviors, institutions, and organizations across nations. Sage Publications.

Hofstede, G. y Bond, M. (1988). The Confucius connection: From cultural roots to economic growth. Organizational Dynamics, 16(4), 4-21.

Hosking, D. M. (1988). Organizing, leadership and skilful processes. Journal of Management Studies, 25, 147-166. doi: 10.1111/j.1467-6486.1988.tb00029.x

House, R. J. y Aditya, R. N. (1997). The social scientific study of leadership: Quo vadis?, Journal of Management, 23, 409-473. doi: 10.1177/014920639702300306

House R. J., Hanges P. J., Ruiz-Quintanilla, S. A., Dorfman, P. W., Javidan, M., Dickson, M., Gupta, V. y 170 co-authors. (1999). Cultural influences on leadership and organizations: Project Globe. En W. Mobley (ed.), Advances in global leadership, vol. 1. JAI Press.

House, R. J., Javidan M. y Dorfman, P. (2001). Project Globe: An Introduction. A p p li ed Psychology: An International Review, 50 (4), 489-505. doi: 10.1111/1464-0597.00070

House, R.J. y Javidan, M., (2002). Leadership and cultures around the world: findings from Globe. An introduction to the special issue. Journal of World Business, 37, 1-2. http:// ac.elscdn.com.ez.urosario.edu.co/S1090951601000682/1-s2.0-S1090951601000682main.pdf?_tid=1a35083a-24db-11e5-8714-00000aacb361\&acdnat $=1436296099$ _ df44908ac11cfb0b2a8de22809b34773

House, R. J., Wright, N. S., y Aditya, R. N. (1997). Cross-cultural research on Organizational leadership: A critical analysis and a proposed theory. En P. C. Earley y M. Erez (eds.), New perspectives in international industrial organizational psychology (pp. 535-625). New Lexington.

Katz, D. y Kahn, R. (1978). The social psychology of organizations. Wiley.

Katzenbach, J. R. y Smith, D. K. (1993). Sabiduría de los equipos. El desarrollo de la organización de alto rendimiento. Díaz de Santos.

Kerr, S. y Jermier, J. M. (1978). Substitutes for leadership: Their meaning and measurement. Organizational Behavior and Human Performance, 22, 375-403.

Kouzes, J. M., y Posner, B. Z. (1995). The leadership challenge: How to keep getting extraordinary things done in organizations. Jossey-Bass.

Kouzes, J. M., y Posner, B. J. (2002). Leadership challenge (3. a ed.). Jossey-Bass.

Levitt, T. (1983). The globalization of markets. Harvard Business Review, 83(3), 92-102.

Lord, R. y Maher, K. J. (1991). Leadership and information processing: Linking perceptions and performance. Unwin-Everyman.

Martín, J. (2002). Organizational culture, mapping the terrain. Sage.

Martínez Avella, M. (2010). Relaciones entre cultura y desempeño organizacional en una muestra de empresas colombianas: reflexiones sobre la utilización del modelo de Denison. Cuadernos de Administración, 23(40). http://revistas.javeriana.edu.co/index. php/cuadernos_admon/article/view/3625

Manz, C. C. y Sims, H. P. (1989). Superliderazgo. Paidós. 
Molero, F. (2002). Cultura y liderazgo. Una relación multifacética. Boletín de Psicología, 76, 53-75. http://www.uv.es/seoane/boletin/previos/N76-4.pdf

Molero, F. (2011). La investigación del liderazgo en psicología. En F. Molero y J. F. Morales (coords.), Liderazgo: hecho y ficción. (pp. 21-45). Alianza.

Molero, F. y Morales, J. F. (2011). Liderazgo: hecho y ficción. Alianza.

Moss, R. (2010). Leadership in a globalizing world. En N. Nohria y R. Khurana (eds.), Handbook of Leadership Theory and Practice (pp. 3-25). Harvard Business.

Nader, M. y Solano, A. (2009). Relación entre los estilos liderazgo, valores y cultura organizacional: un estudio con líderes civiles y militares. Anuario de Psicología, 40(2), 237-254. http://www.redalyc.org/pdf/970/97017660007.pdf

Ogliastri, E. (1999). Culture and organizational leadership in Colombia. En R. J. House y J. Chokkar, Cultures of the world, a Globe anthology of in-depth descriptions of the cultures of 14 countries. The Leadership Quarterly, 10(2), 219-256. doi https://doi.org/10.1016/ S1048-9843(99)00018-1

O’Reilly, C. A., Chatman, J., y Caldwell, D. F. (1991). People and organizational culture: A profile comparison approach to assessing person-organization fit. Academy of Management Journal, 34(3), 487-516. http://dx.doi.org/10.2307/256404

Peiró, J. M. (1990). Organizaciones: nuevas perspectivas psicosociológicas. PPU.

Peiró, J. M. (1995). Psicología de la organización (tomo II). UNED.

Rousseau, D. (1997). Organizational behavior in the new organizational era. Annual Review of Psychology, 48, 515-546. doi: 10.1146/annurev.psych.48.1.515

Sabucedo, J. M. y Morales, J. F. (2015). Psicología social. Editorial Médica Panamericana.

Schein, E. H. (1985). La cultura empresarial y el liderazgo. Plaza y Janés.

Schein, E. H. (1992). Organizational culture and leadership: A dynamic view (2. ${ }^{\mathrm{a}}$ ed.). Jossey-Bass.

Schilling, J. (2007). Leaders' romantic conceptions of the consequences of leadership. Applied Psychology, 56(4), 602-623. doi: http://dx.doi.org/10.1111/j.1464-0597.2007.00306.x

Schneider, B. (2000). The psychological life of organizations. En N. M. Askanasy, C. P. M. Wilderon y M. F. Peterson (eds.), Handbook of Organizational Culture and Climate (pp. xvii-xxi). Sage.

Shamir, B. y Howell, J. M. (1999). Organizational and contextual influences on the emergence and effectiveness of charismatic leadership. The Leadership Quarterly, 10(2), 257-283. http://dx.doi.org/10.1016/S1048-9843(99)00014-4

Shamir, B., House, R. J. y Arthur, M. B. (1993). Motivational effects of transformational leadership: A self-concept based theory. Organization Science, 4(4), 577-594.

Shiraev, E. B. y Levy, D. A. (2010). Cross-cultural psychology: Critical thinking and application (4. ${ }^{\mathrm{a}}$ ed.). Pearson/Allyn Bacon. 
Stogdill, R. M. (1974). Handbook of leadership: A survey of theory and research. Free Press. http://psycnet.apa.org/psycinfo/1974-22876-000

Smircich, L. (1983). Concepts of culture and organizational analysis. Administrative Science Quarterly, 28, 339-358. doi: 10.2307/2392246

Smith, P. B. y Bond, M. H. (1998). Social psychology across cultures. Prentice-Hall.

Smith, P. B. y Peterson, M. F. (1988). Leadership, organizations and culture: An event management approach. Sage.

Triandis, H. C. (1995). Individualism and collectivism. Westview Press.

Triandis, H. C. (2004). Foreword. En R. J. House, P. J. Hanges, M. Javidan, P. W. Dorfman y V. Gupta (eds.), Leadership, culture and organizations: The Globe study of 62 societies (pp. $\mathrm{xv}$-xix). Sage.

Trice, H. y Beyer, J. (1993). The cultures of work organization. Prentice Hall.

Vroom, V. H. y Jago, A. G. (1978). On the validity of the Vroom-Yetton model. Journal of Applied Psychology, 63, 151-162.

Vroom, V. y Yetton, P. W. (1973). Leadership and decision-making. University of Pittsburgh Press.

Yukl, G. (2002). Leadership in organizations. Prentice Hall Inc.

Yukl, G. y Van Fleet, D. D. (1992). Theory and Research on Leadership in Organizations. En M. D. Dunnette (ed.), Handbook of Industrial and Organizational Psychology. John Wiley \& Son. 



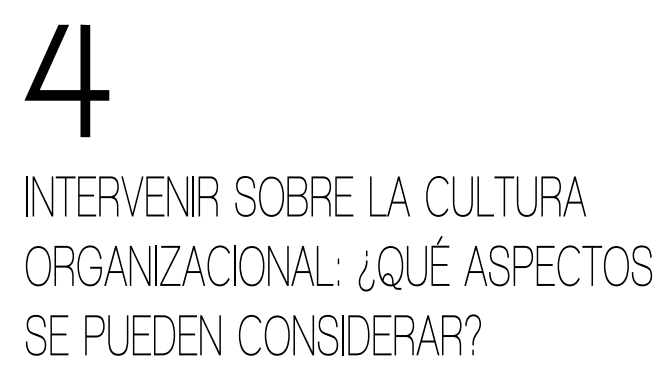

Verónica Andrade Jaramillo*

María Alejandra Gómez Vélez ${ }^{\star *}$

Universidad Pontificia Bolivariana

La cultura organizacional (co) es un macroconstructo que involucra una gran variedad de componentes y funciones organizacionales (Warner, 2014). Reyes y Moros (2018) señalan que tiene su origen en el estudio realizado en Hawthorne por Elton Mayo y otros investigadores de la Escuela de las Relaciones Humanas de la Administración, en el que buscaban identificar la influencia de las condiciones físicas y ambientales en el desempeño individual. Para Reyes y Moros (2018), la co se siguió desarrollando en los años setenta con Pettigrew, para ser entendida como un sistema de significados que tanto pública como colectivamente es aceptado para operar en un tiempo y por un grupo determinado. Los autores la definen como “... un sistema de significados compartidos por los miembros de la organización, los cuales son el resultado de una construcción social constituida a través de símbolos y como tal deben ser interpretados" (p. 205).

Cabe decir que el constructo cultura organizacional es clave en tiempos de cambios constantes, en un escenario global de incertidumbres y dinámicas variables, que obliga a ajustes constantes para poder adaptarse al contexto mundial y alcanzar los objetivos estratégicos, de allí que la cultura se considere el principal factor que hace que las organizaciones se introduzcan en procesos de cambio para adaptarse en un entorno que se caracteriza por la inestabilidad (Pérez-Vallejo, Vilariño-Corella y Ronda-Pupo, 2016).

Para De Ocampo, Fajardo y Suaza (2007) las organizaciones que cuenten con más de una década requieren modificar, o al menos revisar, sus modelos de gestión y cultura organizacional para favorecer la competitividad, contar con personas más 
capacitadas y que acompañen los procesos de cambio. De allí que explican que hay que potencializar a sus trabajadores, hacer un redireccionamiento estratégico, identificar sus procesos, diseñar sus perfiles y estructurar los cargos por procesos.

Los interesados en intervenir en las organizaciones hoy, sean administradores, profesionales en campo o académicos, reconocen que lograr cambios organizacionales, sean estos de poca o gran envergadura, deben al menos considerar la intervención en la cultura organizacional (Co) (Slack y Singh, 2018). Al tener este aspecto presente los interventores en co se enfrentan a los retos que ello implica, en particular por la ontología del fenómeno que se vuelve vida a través de la interacción de todos los miembros de la organización y que no se produce por obra de uno o unos pocos, llevando a que parte de su naturaleza sea además informal (Stavrinoudis y Kakarougkas, 2017; García, 2009).

Para intervenir en co corresponde lidiar con que en parte esta pueda ser gestionada, y en parte no, por su carácter multidimensional y multivariado, además de que en sí misma es una tarea extensa y complicada (Warner, 2014). Sin embargo, sigue siendo necesario hacerlo para contar con un mayor impacto en el logro de los objetivos buscados; de acuerdo con Denison y Mishra (1995) hay una relación directa entre la cultura organizacional y la efectividad organizacional.

Este capítulo tiene por objetivo aportar ideas alrededor de qué aspectos se pueden considerar para intervenir en la co. Lo anterior se deriva de revisar documentos de naturaleza conceptual y empírica, tanto de revistas científicas publicadas recientemente obtenidas a través de las bases de datos especializadas, como de libros considerados clásicos en el tema, que aportan a dicho propósito, procurando hacer el esfuerzo de inferir relaciones con variables o categorías que aparecen relacionadas con la co, aunque la intención de los autores revisados no fuera propiamente la intervención sino la descripción de su cambio por coyunturas acontecidas.

La información contenida en este capítulo puede ser de utilidad para todos aquellos interesados en considerar elementos de co para favorecer cambios necesarios para propósitos de supervivencia organizacional y bienestar de los trabajadores, o por qué no, conservar aspectos vitales para el funcionamiento organizacional que se pueden estar perdiendo con el afán de la consecución de objetivos productivos de corto plazo, y que en el largo pueden ser relevantes para que la organización no solo siga existiendo sino que se destaque; según Denison (2001) no hay cambio organizacional si no se gestiona el cambio cultural. De acuerdo con Slack y Singh (2018), antes de intervenir sobre la cultura, esta requiere ser entendida para facilitar su cambio y proporcionar elementos sobre cómo guiar la intervención, y de acuerdo con Denison y Mishra (1995), esta debe ser considerada un aspecto integral de los procesos de adaptación de las organizaciones. 
Para lo anterior, se parte de la premisa de que la cultura organizacional es gestionable o por lo menos lo es en parte, lo cual es una posición aceptada por algunos autores (Acosta, 2009; Furham, 2001; Schein, 2009; Pessôa y Trabasso, 2017). Sin embargo, también se encuentran autores que afirman que la cultura no es gestionable, al menos no en el sentido promovido por la literatura del management, ya que la co se considera el resultado de diversas variables y personas, lo que hace que intervenirla, al menos en su totalidad, sea prácticamente imposible (García, 2009). Se supone que lo gestionable son los aspectos formales de la cultura, y otros, de naturaleza más informal, que no responden a lógicas racionales, escapan a las posibilidades de intervención, o al menos a la intervención convencional.

Para pensar cómo intervenir sobre la co debe clarificarse qué se está entendiendo por esta. En el presente capítulo se reconocen los aportes de autores como Schein (2009), Hofstede (Hofstede y Minkov, 2010), y Cameron y Quinn (Ruiz y Naranjo; 2012), desarrollados con mayor detalle en el capítulo de Vesga en este mismo libro. Puede decirse de modo general, que la co corresponde a supuestos, patrones de pensamiento, o marcos de referencia mental que son construidos de manera colectiva, que van aprendiendo los nuevos miembros, y que sirven, además, de referente para relacionarse entre sí, para afrontar las vicisitudes del día a día en el marco organizacional, e incluso orientar las acciones presentes y futuras.

Entre los elementos centrales de la co (Furham, 2001; Hofstede, Hofstede y Minkov, 2010; Ruiz y Naranjo; 2012) se puede inferir que está embebida entre los miembros, que en ocasiones puede ser visible y/o consciente y en otras no, que se da fruto de su interacción a lo largo del tiempo, y que provee un marco de referencia para leer la realidad y relacionarse con ella. En esta medida, pensar en gestionar la co deberá considerar elementos de esta naturaleza que desbordan la lógica racional tradicional que respecto a procesos de management se tratan sobre el tema (García, 2009; Riascos, 2014).

\section{Intervenir la co implica intervenir la organización}

Para Piñero, Pacheco y Moreira (2018), el ambiente empresarial en el ámbito mundial está viviendo cambios significativos en la medida en que progresa la ciencia y la tecnología, lo que obliga a las organizaciones a moverse y adaptarse a los nuevos tiempos, porque si no lo hacen se "verán irremediablemente sumergidas en el fracaso" (p. 131). Tal como plantean Martínez-Bustos, Carrasco-Sagredo y Bull (2018), durante la existencia de la humanidad se puede observar que se incorporan nuevos métodos y tecnologías para facilitar y agilizar el trabajo organizacional, lo que produce cambios en la cultura y en lo que se entiende como un adecuado desempeño 
laboral. Estos movimientos generan, en diversos casos, resistencia a los cambios que han propuesto los directivos de empresas u organizaciones, razón por la cual en la academia se proponen modelos que respondan a los desafíos que urgen en la gestión administrativa y de las personas.

Intervenir en las organizaciones requiere la unión de lo teórico con lo práctico. Una intervención solo desde la técnica puede reducir la pertinencia de las acciones realizadas e impactar en menor medida el fenómeno intervenido. La intervención organizacional es "una práctica deliberada e intencional desde afuera, eminentemente transformadora de la realidad organizacional con el fin de mejorar y fortalecer su desempeño integral" (Pacheco, 2015, p. 22). Intervenir sobre la co es en sí mismo realizar una intervención organizacional; también se puede considerar que al realizar otras intervenciones organizacionales que no tienen su foco en la co, requiere a su vez trabajar sobre ella, como ya se mencionó.

Según el Diccionario de la lengua española (RAE, 2018) "intervenir", como verbo transitivo, significa tomar parte en un asunto; representa un hecho que sobreviene, ocurre, acontece. Intervenir proviene del latín intervenire, que se compone del prefijo latino inter, que se refiere a entre intervalo, y venire que significa venir, por lo que podría entenderse que la intervención es un hecho que ocurre entre un antes y un después. Pacheco (2015) indica que una intervención implica una transformación del estado de lo intervenido, entre el antes y el después, y que esta requiere estar sustentada teórica y metodológicamente, así como ser ordenada (planeada con base en objetivos determinados), y realizarse entendiendo la naturaleza de lo intervenido, en este caso, la organización y su cultura. Considerando que la intervención implica la consideración de un antes y un después, es vital conocer previamente el fenómeno, haberlo medido y caracterizado, para poder, más adelante, saber qué fue lo que realmente cambió.

La intervención organizacional remite al menos a cinco aspectos que deben clarificarse para llevarla a cabo: el objeto sobre el que recae la acción de intervención -que es la organización misma- y el fenómeno puntual a intervenir, el sujeto que realiza la acción (o los sujetos, quienes intervienen), los objetivos que persigue el sujeto interventor, los instrumentos que consideran para intervenir, y el proceso o la acción misma de intervenir (Pacheco, 2015). A estos cinco elementos se les debe agregar un sexto, que son las personas involucradas en el proceso de intervención - no siendo los que intervienen-; considerarlos parte del proceso de intervención es central, ya que las organizaciones de trabajo son y funcionan debido a las personas que trabajan en estas, y son las que hacen viable en el cotidiano los cambios promovidos por las intervenciones. 
De acuerdo con Pacheco (2015), para intervenir sobre una organización se requiere la consideración de la complejidad de la organización, que incluye al menos dos grandes aspectos relacionados con lo mencionado, el mundo de lo material y lo cuantitativo, que tiende a ser objetivo; y lo intangible, lo que no se ve ni se toca pero que crea realidades, es decir, las interpretaciones y significados que dan sentido a la realidad organizacional. Para este autor, dentro de lo intangible o lo que llama el inframundo organizacional, se encuentra la cultura.

Según Blake y Mouton, citados por Lagos (1994) pueden darse cinco tipos de intervenciones organizacionales, $\mathrm{o}$ en sus términos, relacionados con el desarrollo organizacional: la intervención basada en el cliente o aceptante, la intervención catalítica, la de confrontación, la prescriptiva y la intervención de principios, teorías y modelos. La intervención basada en el cliente o aceptante consiste en ayudarle a los involucrados en la intervención, a darse cuenta de posiciones o cuestiones subjetivas que impiden que los objetivos se consigan o el trabajo no funcione de la mejor manera. La intervención catalítica, por su parte, agrega algún aspecto para ayudar a que el intervenido vea la situación desde otra perspectiva, más allá de escucharlo y ayudarlo a identificar un posible bloqueo. La intervención de confrontación implica, a diferencia de las dos anteriores, considerar o intervenir sobre aspectos más profundos o personales de las personas relacionadas con la intervención para favorecer la movilización hacia el cambio.

La intervención prescriptiva implica que quienes intervienen indiquen qué deben hacer las personas intervenidas para modificar la situación o intervenir sobre el fenómeno, según sus consideraciones sin partir de las necesidades propias o las vivencias de los involucrados. Finalmente, la intervención basada en principios, teorías y modelos considera parámetros de naturaleza conceptual para entender los problemas organizacionales, procurar diagnosticarlos, y procurar intervenirlos según dichos referentes, aportando congruencia y contundencia respecto de la intervención realizada, comparada con la intervención pensada exclusivamente desde lo empírico del fenómeno. Se esperaría que una intervención contara, para mayor atino, con una buena mezcla entra las necesidades de los intervenidos (su realidad organizacional), sus propias capacidades para gestionarse y gestionar el cambio, el profesional que realiza la intervención y su experiencia, y por supuesto, un marco conceptual apropiado que ayude a comprender e intervenir sobre la realidad organizacional.

En el marco de la intervención organizacional de cualquier orden, la pregunta fundamental, además de qué se quiere intervenir, es para qué se quiere intervenir, y qué se supone que busca el cambio que se pretende promover. En el caso de la cultura organizacional en particular, la organización requiere preguntarse ¿cuál es el sentido 
de intervenir sobre esta, y a qué fines le sirve este cambio? De acuerdo con Driskill y Brenton (2011), las personas tienen distintos niveles de seguridad psicológica cuando se trata de asumir los cambios organizacionales, como un modo de protegerse de los cambios cuando son percibidos como riesgosos o desfavorables, lo que se refleja en lo que algunos autores del management llaman resistencia al cambio.

Para comprender las razones que llevan a que las personas se resistan a los cambios, en particular dentro de las organizaciones, Driskill y Brenton (2011) indican que cuando los cambios son percibidos como sustitución o evolución en lugar de como pérdida, pueden ser menos difíciles o no percibirse dificultades en el proceso del cambio. Es decir, si los trabajadores perciben que el cambio a realizarse con la intervención organizacional es cambiar una cuestión por otra (sustituir) que no modifica en ninguna o en gran medida las estructuras de significados que ya traían, puede ser menos problemático; o cuando el cambio se hace de modo gradual dando tiempo a que las personas se acostumbren paulatinamente a los nuevos modos de funcionamiento, se vaya transformando con el tiempo la estructura de significados (evolución) e incluso empiecen a percibir las ventajas del cambio.

Cuando los cambios son repentinos ya sea porque no pueden preverse, o se cuenta con poco tiempo para hacer un proceso de sensibilización y favorecer la participación de los trabajadores respecto de estos, cuestiones que reducen la resistencia al cambio, es probable que esta se dé por efectos de la percepción de pérdida. A los gestores del cambio o interventores les corresponde identificar qué es lo que se está perdiendo (lo que los trabajadores perciben que pierden), aceptar la importancia subjetiva de sus pérdidas, aceptar las reacciones aparentemente exageradas por parte de algunos miembros que puedan presentarlas, conocer/reconocer y aceptar las pérdidas de las personas de manera abierta y empática, estar abiertos a las quejas derivadas del proceso, y compensar en la medida de lo posible las pérdidas que las personas perciben (Bridges citado por Driskill y Brenton, 2011).

También es preciso tener en cuenta que la percepción de pérdidas no solo varía de una persona a otra, sino de un área a otra, y en la organización en general, por la existencia de culturas y subculturas, y diferencias de personalidad de los miembros que la integran, además de otros motivos como los encontrados por Martínez-Bustos et al. (2018), como son "la falta de motivación, mala retroalimentación y falta de capacitación del personal para comprender las implicaciones del cambio” (p. 97).

Pero, así como existen elementos que llevan a los integrantes de la organización a resistirse al cambio, propio de las intervenciones organizacionales, hay otros que lo facilitan, y le corresponde a quienes estén realizando la intervención identificar qué aspectos que ya son propios del funcionamiento organizacional, y de la cultura, o 
incluso de las subculturas, facilitan la gestión del cambio a implementarse. Se recomienda, en estos casos, considerar la inclusión de lo nuevo a través de ritos en los que se honre lo valioso del pasado o lo que se está dejando atrás, se marque con claridad el final de lo anterior y el inicio de lo nuevo, y se vaya introduciendo simbólicamente lo nuevo (Bridges citado por Driskill y Brenton, 2011). Lo anterior, complementado con un aspecto fundamental de la introducción de los cambios propios de las intervenciones, y es la reducción de la incertidumbre; entre mayor información clara se proporcione, que pueda permitirles a los miembros comprender el cambio, anticiparse y hacer parte de este, menor resistencia al cambio se presentará.

Además, intervenir de manera particular sobre co debe considerar la explicitación o el darse cuenta por parte de los directivos y de los responsables del proceso de intervención, de la noción que tienen sobre qué es lo que se interviene con miras hacia el cambio; es decir, si se intervendrá sobre el comportamiento de las personas y de la colectividad en general para cambiar sus representaciones, o apelar a modificar estas últimas en primera instancia (sus modos de percibir, las creencias, esquemas mentales, etc.) para que a su vez se reflejen en cambios de comportamientos (Warner, 2014), que reforzados a largo plazo se instaurarán como parte de la co.

La recomendación es que la intervención se trabaje desde las dos perspectivas, ya que pretender trabajar solo desde el cambio comportamental puede llevar a que se pierda o no se afiance el sentido del cambio, y pueda no perdurar, o a que se revierta en el corto plazo lo que ha sido ganado; y el intervenir solo las representaciones puede llevar a una escisión entre lo que las personas piensan o lo que se cree colectivamente, y lo que verdaderamente se hace en la práctica, promoviendo una distancia poco favorable entre el discurso oficial y las acciones efectivas llevadas a cabo.

\section{Dos caminos para pensar la intervención en cultura organizacional}

Para los que buscan intervenir en co, y quieran apoyar su iniciativa en la literatura especializada, además de hacerlo sobre su propia experiencia y las necesidades sentidas por los miembros de la organización, podrían considerar dos caminos, el primero, referido a identificar un modelo apropiado de intervención sobre cultura que sirva para su caso, relacionado por supuesto con el tipo de intervención basada en principios, teorías y modelos, propuesta por Blake y Mouton, o el segundo camino, identificar en experiencias empíricas llevadas a cabo y reportadas por académicos y practitioners, aspectos que hayan funcionado, sido valiosos, o que justamente por no ser considerados centrales a la co, no se lograron los resultados esperados. Para los que prefieren el primer camino se plantean dos modelos, uno que podría considerarse clásico, el de Denison y Mishra (1995), y otro contemporáneo, el planteado 
por Stavrinoudis y Kakarougkas (2017), los cuales pueden ser de utilidad e incluso complementarios.

El modelo de Denison y Mishra (1995) afirma que se requiere que la cultura organizacional cumpla unas hipótesis para garantizar el logro de los objetivos organizacionales propuestos. $\mathrm{O}$, en otros términos, que la intervención en co se realice en dirección a favorecer estas hipótesis, ya que según lo indica su estudio mixto (con 764 organizaciones en la medición cuantitativa y 5 en la cualitativa), estas tienen una estrecha relación con la efectividad organizacional. Las hipótesis son el involucramiento (involvement) o participación, la consistencia, la adaptabilidad y la misión.

La participación se refiere a que, si se involucra en gran medida a los trabajadores en la toma de decisiones y el funcionamiento organizacional, se logra modificar la co en dirección al cumplimiento de objetivos. La consistencia se refiere a que los equipos, y en general los miembros de la organización, compartan significados al respecto de los símbolos, temas de relevancia, modo de comunicarse, entre otros; incluso, se den subculturas. Para generar consistencia se requiere de niveles de conformidad individual más que la participación voluntaria (integración normativa). Los principios y los comportamientos promovidos deben ser consistentes entre ellos.

La hipótesis de la adaptabilidad se refiere a la capacidad de reestructurar la organización en función de responder a clientes internos, externos y demandas del entorno, esto a través de desarrollar normas y creencias que permitan estar vigilantes al ambiente y a buscar cambiar cuando se requiera. Y, por último, la misión, se refiere a ofrecer una dirección o un propósito al cual todos puedan aunarse para dar sentido a la acción que se realiza a través del trabajo; esta orienta hacia dónde van las prácticas organizacionales, y en general, el funcionamiento de la organización. Se espera que dicha misión desborde los objetivos económicos, aunque estén incluidos.

Para Denison y Mishra (1995), estas hipótesis, o también llamados rasgos culturales, se relacionan a su vez con la orientación hacia el medio, la integración interna, el cambio y la flexibilidad, y la estabilidad y dirección, aspectos clave para la competitividad organizacional. La adaptabilidad y la misión dan cuenta de cómo la organización se orienta hacia el entorno, la consistencia y el involucramiento, de cómo se logra la integración interna; la adaptabilidad y el involucramiento favorecen el cambio y la flexibilidad; y la misión y la consistencia son las que le dan estabilidad y dirección. Considerando este modelo, la intervención en co debe buscar el cumplimiento o el cultivo de estos cuatro rasgos considerando lo que se requiere mantener y lo que requiere cambiarse, así como la manera como responde al entorno y a su vez cómo mantiene la cohesión mientras lo hace. 
Si se observa detenidamente, estas cuatro hipótesis (la participación o involucramiento, la consistencia y la misión), requieren un posicionamiento ético por parte de los administradores/interventores, respecto a qué de la co se intervendrá, el por qué se hará y el cómo hacerlo, ya que estos aspectos finalmente están dirigidos a trabajadores que requieren que los cambios tengan algún sentido para su implementación y adopción permanente.

El anterior discernimiento va de la mano con lo propuesto por Riascos (2014), quien plantea que cuando se piensa en intervenir sobre co se debe reflexionar sobre qué noción de organización se tiene, de trabajador o persona que trabaja, qué se está entendiendo por co, y hasta dónde se pretende llegar con el cambio; pero más aún, la conciencia sobre el para qué, y a quién o quiénes les sirve dicha intervención, tanto en el corto como en el largo plazo, para desbordar las pretensiones que autores como Alvesson (1989) han manifestado como propias de este tipo de gestiones: manipulación del poder y condicionamiento de la subjetividad laboral, para el logro exclusivo de los objetivos organizacionales.

El modelo contemporáneo retomado para la presente reflexión es el de Stavrinoudis y Kakarougkas (2017), que procura ser integrador en su propuesta. Los autores proponen la consideración de dos dimensiones, la formal/revolucionaria, y la informal/ evolucionaria.

Respecto a la dimensión formal/revolucionaria, Stavrinoudis y Kakarougkas (2017) indican que para promover el cambio en la co se requiere considerar la intervención sobre las estructuras formales, que, aunque en inicio operan en una sola dirección (lo que la organización busca dirigido a los trabajadores), por partir de un paradigma racional que no cubre toda la realidad organizacional, en el camino, si son mantenidas y se realiza seguimiento, pueden llegar a operar en ambas direcciones. Al mirar los planteamientos de Lewin, los autores argumentan que el cambio cultural no se da si no ocurren nuevos comportamientos, valores y actitudes promovidos por cambios en los procesos y la estructura organizacional, lo que llaman revolución. La recomendación es que estos cambios revolucionarios se den en tiempos cortos para producir impactos largos - lo que los autores denominan trazos audacesrespecto a la gestión. Adicionalmente, resaltan que cuando se trata de lo formal se requiere una dirección explícita del cambio en el que los trabajadores se enteren de lo que se busca y qué papel desempeñan en ello, basada en tiempos específicos, y planes respecto al inicio y final de cada paso.

Sobre la dimensión informal/evolucionaria (Stavrinoudis y Kakarougkas, 2017), se parte de trabajar sobre cambios pequeños, locales y que se sostengan en el largo plazo para que logren incidencia, por lo que los denominan evolución, para que se vayan 
interiorizando en las rutinas. Los valores centrales para gestionar la dimensión informal son la innovación, el riesgo y el juicio de lo novedoso, que pueden ser trabajados sin una planificación estrictamente diseñada; por el contrario, se trata de seguir el ritmo de los modos clásicos de pensar y proceder de la co que quieren intervenirse e irlos cambiando poco a poco. Los autores indican que sobre esta dimensión se consideran la voluntad de participación, la orientación estratégica, la dominancia del estilo de gestión, y cómo los factores afectan las relaciones entre individuos y grupos. El modelo de Stavrinoudis y Kakarougkas (2017) podría ser complementado por el de Crossan, Lane y White (1999), que fue diseñado para pensar el aprendizaje organizacional ( $\mathrm{AO}$ ), pero que es pertinente si se considera que para que haya cambio cultural se requiere que la organización aprenda. En dicho modelo se plantean cuatro premisas de base; en primer lugar, el AO envuelve una tensión entre la asimilación de nuevo conocimiento (exploración) y el uso de lo aprendido (explotación). En segundo lugar, el AO es multinivel, lo que también ocurre con la co, tal como la proponen Stavrinoudis y Kakarougkas: se da desde lo individual, pasando por lo grupal, hasta llegar a lo organizacional, por lo que no puede pensarse un cambio de co si se hace solo a nivel organizacional (institucionalizado) sin contar con los individuos, y viceversa.

La tercera premisa del modelo de Crossan, Lane y White (1999) se refiere a que los tres niveles (individual, grupal y organizacional) están asociados a procesos psicológicos y sociales que son la base del modelo: intuición, interpretación, integración e institucionalización (las cuatro íes), que son el enganche y arman la estructura donde, desde la intuición que opera a nivel individual, los conocimientos, cambios y acciones suben hasta lo organizacional y se convierten en institucionales, y que a su vez bajan desde este nivel hasta lo individual pasando por el nivel grupal. Considerar los niveles puede aportar luces sobre la intervención del aspecto informal/evolucionario (Stavrinoudis y Kakarougkas, 2017).

Para intervenir tanto desde la revolución como desde la evolución (Stavrinoudis y Kakarougkas, 2017), resulta también conveniente considerar la comunicación como aspecto central de intervención en la co (Nosnik, 2005). A través de la comunicación organizacional debidamente gestionada, es decir, planeada, intencionada y unificada en toda la organización, y en dirección al cumplimiento de la estrategia, se promueven los valores organizacionales que se pretenden desarrollar o fortalecer, se crea o fortalece la identidad organizacional, se realiza sanción social explícita a los comportamientos y modos de relación no esperados, y se premian aquellos que sí van en dirección con lo que se quiere promover o modificar. Esta gestión de la comunicación resulta vital, tanto de modo formal como informal en el marco de intervenir la co. 
La gestión de la comunicación organizacional propuesta por Nosnik (2005), se relaciona con lo planteado por Martínez-Bustos, Carrasco-Sagredo y Bull (2018), respecto a que para gestionar el cambio en una cultura, partiendo del modelo de los tres pasos propuestos por Lewin, se requiere descongelar las prácticas antiguas - procurar no promoverlas o no usarlas-, desplazar y cambiar hacia una nueva dirección - a través de lo que se explicita, se premia o se privilegia-, y el recongelar los modos adoptados por la organización como más efectivos, es decir, favorecer que permanezcan las nuevas maneras que se buscó implementar.

De acuerdo con Driskill y Brenton (2011), respecto a la comunicación organizacional y la intervención en la co, se requiere comunicar una visión clara e inspiradora del cambio, y que además indique de manera concisa los pasos a seguir para implementarlo. En este camino, los autores sugieren que las directivas deben procurar relacionar los valores que ya existen y son compartidos, con los aspectos novedosos que se quieren introducir para el cambio cultural.

En relación con el segundo camino para pensar la intervención en co, se propone retomar aprendizajes derivados de investigaciones empíricas que buscaron ya sea describir la co, intervenirla, o la encontraron como aspecto subyacente en relación con otros temas que se estudiaron. A continuación, se menciona una serie de categorías que fueron halladas en el momento de realizar la revisión de antecedentes para la escritura de este capítulo. Entre las categorías encontradas están el papel del líder o el liderazgo que se ejerza, la formación o educación respecto a la co, los valores, la comunicación, la implementación de sistemas de gestión y la estructura organizacional.

Respecto al liderazgo, se encontró que promover el cambio de la co tiene relación con que a través de este se refuercen los aprendizajes (Yin et al., 2015), y como un promotor de la adopción de medidas relativas a la implementación de sistemas de gestión requeridos para que el trabajo funcione de mejor modo (Williams, Glisson, Hemmelgarn y Grenn, 2017). En su calidad de liderazgo transformacional, este tipo de liderazgo podría conducir a pequeñas organizaciones a aportar al desarrollo de un país y ser competitivas, siempre y cuando impliquen orientación empresarial (Widianto y Harsanto, 2017). Así mismo, el ejercicio del liderazgo por medio de procesos de coaching (Whetstone, 2017), conducen a generar consenso en la organización como el propósito común.

Para Dávalos (2015), los líderes son responsables de provocar y promover las condiciones favorables para implementar los cambios y reducir las resistencias; son quienes tienen un papel fundamental como agentes de cambio dentro de cualquier organización. 
En el estudio llevado a cabo en mineros por Salgado Roa, Lería Dulčić, Arcos, Pineda y González (2018), se identificó que cuando los trabajadores no confiaban en las capacidades de quienes debían implementar los cambios, es decir, sus jefes, presentaban una actitud de cinismo frente a ellos. Igualmente, encontraron que cuando gerentes y supervisores percibían como positivas sus capacidades para aportar al cambio, favorecían la comprensión y compromiso, y generaban disposición hacia el proceso de cambio organizacional por parte de los trabajadores.

Los procesos de aprendizaje promovidos por la formación y educación en el trabajo son también vitales para intervenir sobre co. Yin et al. (2015) encontraron que el entrenamiento es clave para dicho propósito si está acompañado de espacios para reflexionar sobre la propia acción, no simplemente la transmisión de información y conocimientos. La educación en el marco del trabajo también contribuye a favorecer modos de relación que respondan a contextos de trabajo saludables, considerando que se usen diferentes enfoques o caminos para lograrlo (Towne et al., 2015).

Respecto de los valores sobre los cuales se define la cultura organizacional, se encontró que estos aportan a la imagen que la organización tiene de sí, configuran el modo en que funciona y se relaciona con el entorno (Spencer y Salaban, 2017). Así mismo, llevan a la asunción o no de comportamientos éticos por parte de los trabajadores para realizar su labor (Rider et al., 2018), y al aumento de la probabilidad de rotación laboral voluntaria si entre estos valores no se promueve la gestión participativa, el trabajo en equipo y el reconocimiento (Shumba, Kielmann y Witter, 2017). Para Tang, Li y Zhang (2016) la orientación a procesos o personas, la apertura o cierre del sistema organizacional, el alto o bajo control, y la tendencia normativa o pragmática relativa al ejercicio de los valores, pueden influir en cómo se gestione la seguridad de la información.

Respecto a la comunicación, se encontró que se requiere cuidar los mensajes explícitos e implícitos que se envían a los miembros de la organización, que pueden favorecer o inhibir comportamientos esperados e inesperados relacionados con el cambio cultural promovido, como por ejemplo que se presenten comportamientos de acoso laboral en la organización (Porter, Day y Meglich, 2018).

Lo que es promovido y premiado explícitamente dentro de la co tiene mayor probabilidad de manifestarse o introducirse como parte de esta; entre los ejemplos se encuentran las investigaciones de Heinza y Heinze (2018), y Tang, Li y Zhang (2016). En el primero de los casos, si en la co se fomenta y se premia el uso de herramientas tecnológicas para la realización del trabajo, esta será una tendencia en crecimiento respecto a la extensión del uso individual de las herramientas. Para Tang, Li y Zhang (2016), manifestar y premiar abiertamente valores relativos al cuidado de la 
seguridad informática, hace que la actitud de los trabajadores frente a esta tienda a ser más favorable, y a que implementen comportamientos relativos a su cuidado.

La implementación y uso de programas de gestión de la calidad pueden aportar en la intervención sobre cultura organizacional para temas como promover el uso de herramientas tecnológicas requeridas para estar a la vanguardia (Tyagi, Cook, Olson y Belohlav, 2013), y favorecer la ejecución de parámetros que impulsen organizaciones que tiendan a comportamientos y prácticas saludables (Towne et al., 2015). Para Vesga (2013), la relación entre la co y los sistemas de gestión es relativa al modo en que se conciba la cultura, si es pensada como un elemento gestionable o no; en caso de serlo, propone pensar en los objetivos del sistema para realizar las modificaciones correspondientes sobre esta, de lo contrario sugiere ajustar el sistema al funcionamiento de la organización. El autor afirma que, así los estándares de los sistemas de gestión sean de naturaleza internacional, no pueden ser implementados de manera genérica, sin considerar la organización a la que llegan a aplicarse, ya que cada contexto (organización) es particular en su funcionamiento debido a la co que marca las diferencias entre unos contextos y otros, y no pueden ser desconocidas. El no tener presente estas particularidades, puede conducir al fracaso de la implementación del sistema.

Finalmente, la estructura organizacional presenta según las investigaciones revisadas, una relación importante con la intervención en la co. Las organizaciones con jerarquías marcadas y funcionamiento burocrático dificultan la probabilidad de cambiar (Slack y Singh, 2018), y pueden relacionarse con la presencia de conductas de acoso laboral, contrario a una estructura que favorezca las relaciones tipo clan y adhocráticas (Pilch y Turska, 2015). Así mismo, la estructura jerárquica se relaciona con la poca apertura hacia el cambio y la innovación (Naqushbandi, Kaur y Ma, 2015). Para Román, Bonilla y Patiño (2015), en algunos sectores contar con estructuras que en términos funcionales sean flexibles donde los límites en los cargos pueden ser borrosos y las personas trabajen en lógicas de multitarea, modifica la co y a su vez ayuda a que la organización pueda afrontar los cambios del mercado. La recomendación gira en torno a que la estrategia organizacional condicione la estructura y no al contrario, para que a su vez esta última incida sobre la co.

De acuerdo con Mintzberg (1980), la estructura organizacional se refiere a cómo se plantean las partes básicas de la organización y los mecanismos que esta usa para coordinar el trabajo y garantizar su funcionamiento. Entre las partes básicas de la estructura se encuentran quienes realizan el core de la operación, quienes tienen relación directa con la misión del negocio; los administradores de la organización que direccionan estratégicamente; la línea media o quienes conectan a los que realizan la 
operación con quienes planean el rumbo de la organización; la tecnoestructura, relativa a las técnicas para mantener y seguir diseñando el funcionamiento de la estructura; y el staff de apoyo, que son todos aquellos que contribuyen a la marcha general de la organización.

Los mecanismos, por su parte, requieren estar coordinados para que la estructura funcione; si bien cuando Mintzberg (1908) plantea los mecanismos no los asocia directamente con la co, sí lo hace con los valores de la organización y el papel que estos desempeñan respecto a cómo se coordinan, según lo indican Hofstede, Hofstede y Minkov (2010). Al revisar los mecanismos puede verse claramente su relación, ya que estos varían de un contexto a otro influidos por los modos de relación formales e informales que se generan en cada contexto y que son a su vez una expresión de la co. Entre los mecanismos se encuentran el modo de supervisión, la estandarización de los procesos, los estándares esperados, las habilidades y conocimientos esperados, la comunicación informal para el mutuo ajuste, la manera en que se entrena el personal, y la especialización de los puestos de trabajo, entre otros. La manera como se configura la estructura tiene una relación directa con la co; así, gestionar la cultura, en un nivel profundo, requiere por supuesto trabajar sobre la estructura organizacional. Para Piñero et al. (2018) las organizaciones son sistemas complejos, dinámicos y adaptativos, dado que están compuestas por personas, grupos y colectividades que hacen parte de una estructura, y que provocan diversos comportamientos que afectan el ambiente.

\section{Consideraciones finales}

La intervención en co debe considerar, en primer lugar que, al ser un fenómeno complejo compuesto por aspectos formales o expresivos, e informales y profundos, no puede gestionarse exclusivamente desde la implementación de procedimientos, medidas administrativas y políticas organizacionales (aunque sean indispensables), sino que también debe tener presentes aspectos de naturaleza relacional, cotidianos y simbólicos que estén siendo compartidos en la interacción por todos los miembros.

Lo anterior lleva a la segunda conclusión que es relativa a la temporalidad. La intervención en co implica medidas de corto y largo plazo. Las de corto, por supuesto, apoyadas en intervenciones de naturaleza formal, a través de la autoridad administrativa según el funcionamiento organizacional. A su vez, para que la intervención tenga éxito, se requiere tiempo para que los procesos maduren y se interioricen en las dinámicas cotidianas de la organización. Así, entonces, una intervención sobre co no puede hacerse pensando en la obtención de resultados inmediatos; para ver impacto se requiere constancia y mantenimiento de las medidas tomadas, hacerlas en 
las actividades más puntuales, y a través de la estructura organizacional, atravesando todos los niveles y áreas.

La intervención en co requiere para su favorecimiento una posición ética respecto a lo que se busca cambiar. Los miembros de la organización como unidad acostumbrada a ciertos modos de funcionamiento, no cambiarán solo porque así se solicite de manera formal, sino porque esto tenga un sentido y consecuencias favorables para sus propios intereses y bienestar. Implementar cambios culturales que consideren el beneficio de las partes, el mantenimiento de la organización en el tiempo y el bienestar de los trabajadores puede ser clave.

Además, intervenir en co se favorece cuando se consideran las pérdidas percibidas por parte de las personas involucradas en el cambio para reducir la resistencia, la comunicación clara y explícita sobre el cambio, los pasos para implementarlo, y se transmite un mensaje inspirador por parte de las directivas a quienes también se expliciten las ventajas del cambio, no solo para la organización sino también para los trabajadores.

Igualmente, según las investigaciones recientes revisadas, es relevante considerar ciertos temas como centrales para la intervención en la co, entre estos el liderazgo y su modo de ejercerlo, la manera en que funciona la estructura organizacional, la comunicación organizacional y los mensajes explícitos e implícitos que se envíen a los miembros, los valores promovidos tanto formal como informalmente, y las medidas que se tomen de manera decidida y continuada para generar cambios, acompañadas de procesos educativos en la organización.

Lo anterior se relaciona con los siguientes aspectos clave planteados por Hofstede, Hofstede y Minkov (2010), que se pueden tener en cuenta para favorecer la intervención en co:

- La gerencia o directivas deben encargarse de esta gestión, no puede ser delegada.

- Quienes realicen el proceso de intervención requieren tener poder y experticia.

- Puede iniciar con un mapa cultural de la organización.

- Hacer elecciones estratégicas donde se tenga presente si la cultura actual está asociada a la estrategia. De lo contrario, preguntarse si la estrategia puede ser adaptada. En caso de que no, preguntarse qué cambio de cultura se requiere, y si este es factible.

- Contar con personas para lograr el cambio cultural.

- Presupuestar los costos en dinero y en administración para gestionar el cambio. 
- Identificar si los beneficios esperados superan los costos presupuestados.

- Preguntarse por el lapso de tiempo realista en que se puede lograr el cambio que se busca.

- Identificar y asumir la existencia de diferentes subculturas que pueden requerir diferentes enfoques para la intervención.

- Crear una red de agentes de cambio en la organización que considere personas clave de todos los niveles jerárquicos, que a su vez serán seguidos por los demás.

- Diseñar los cambios estructurales necesarios como abrir y cerrar áreas o departamentos, fusionar o dividir áreas o tareas, modificar los roles y garantizar que estos estén relacionados con las capacidades o competencias.

- Diseñar procesos de cambio necesarios como crear o eliminar controles, procesos y canales de comunicación.

- Revisar no solo la entrada de los procesos sino también sus salidas o resultados.

- Revisar las políticas de personal, entre ellas las de contratación y promoción; verificar que el Área de Gestión Humana esté en capacidad de responder a las nuevas demandas con el cambio que se busca.

- Realizar rotación de cargos de manera oportuna si así se requiere.

- Garantizar que la capacitación y formación estén basadas en las propias necesidades percibidas por los trabajadores que se formarán, y no una imposición organizacional.

- Continuar con el monitoreo a través de la persistencia y atención sostenida, y repetir el diagnóstico de cultura periódicamente.

Por último, el cambio cultural implica persistencia (Hofstede, Hofstede y Minkov, 2010), por lo que el o los responsables del proceso de intervención requieren estar atentos a lo largo del tiempo. Se requiere que cada determinado periodo se mida nuevamente cómo está la $\mathrm{Co}$, con el propósito de mostrar cambios en función del diagnóstico inicial, y si es necesario, redireccionar las acciones respecto a los objetivos planteados; se trata de mantener los cambios con constancia y corregir cada vez que el proceso lo requiera para lograr intervenir en la co. 


\section{Referencias}

Acosta, C. A. (2009). Cómo administrar la cultura organizacional. En M. C. Aguilar y E. Rentería (eds.), Psicología del trabajo y de las organizaciones. Reflexiones y experiencias de investigación (pp. 297-308). Universidad Santo Tomás.

Alvesson, M. (1989). The culture perspective on organizations: Instrumental values and basic feature of culture. Scandinavian Journal of Management, 5(2), 123-136.

Crossan, M., Lane, H. y White, R. (1999). An organizational learning framework: From intuition to institution. Academy of Management Review, 24(3), 522-537.

Dávalos, R. M. F. (2015). La influencia del factor humano, el liderazgo y la cultura de las organizaciones en los procesos de implementación y gestión del cambio organizacional. Revista Internacional de Investigación en Ciencias Sociales, 11(1), 102-114.

Denison, D. R. (2001). Organizational culture: Can it be a key lever for driving organizational change? En C. L. Cooper, S. Cartwright y P. Ch. Earley (eds.), The International Handbook of Organizational Culture and Climate (pp. 347-372). John Wiley \& Sons.

Denison, D. R. y Mishra, A. K. (1995). Toward a theory of organizational culture and effectiveness. Organization Science, 6(2), 204-223.

De Ocampo, L. S. R., Fajardo, F. A. y Suaza, A. L. (2007). Cambio de cultura organizacional para empresas que requieren evolucionar hacia la competitividad. Scientia Ettechnica, $1(35), 327-332$.

Driskill, G. y Brenton, A. L. (2011). Organizational culture in action. A cultural analysis work book. Sage.

Furnham, A. (2001). Cultura y clima corporativos. En Psicología organizacional. El comportamiento del individuo en las organizaciones (pp. 575-625). Oxford University Press.

García, C. M. (2009). La cultura organizacional como una tecnología de control gerencial. En M. C. Aguilar y E. Rentería (eds.), Psicología del trabajo y de las organizaciones. Reflexiones y experiencias de investigación (pp. 275-295). Universidad Santo Tomás.

Heinza, K. y Heinze, J. (2018). Individual innovation adoption and the role of organizational culture. Review of Managerial Science, first online, 1-26, https://doi.org/10.1007/ s11846-018-0300-5

Hofstede, G., Hoftede, G. J. y Minkov, M. (2010). Cultures and organizations. Software of the mind. Intercultural cooperation and its importance for survival. McGraw-Hill.

Lagos, C. R. (1994). Desarrollo organizacional en Latinoamérica. Perspectivas, estrategias y experiencias de desarrollo organizacional e institucional para afrontar los desafíos del cambio. Instituto de Nutrición de Centroamérica y Panamá (Incap).

Martínez-Bustos, E., Carrasco-Sagredo, C. y Bull, M. T. (2018). Propuesta metodológica para implementar la primera fase del modelo de gestión del cambio organizacional de Lewin. Estudios Gerenciales, 34(146), 88-98. 
Mintzberg, H. (1980). Structure in 5's: A synthesis of the research on organization design. Management Science, 26(3), 322-341.

Naqushbandi, M., Kaur, S. y Ma, P. (2015). What organizational culture types enable and retard open innovation? QualQuant, 2123-2144.

Nosnik, A. (2005). Culturas organizacionales: Origen, consolidación y desarrollo. Netbiblo.

Pacheco, A. A. (2015). Intervención organizacional. Primeras aproximaciones conceptuales. Gestión y Estrategia, 48, 15-23.

Pérez-Vallejo, L. M., Vilariño-Corella, C. M. y Ronda-Pupo, G. A. (2016). El cambio organizacional como herramienta para coadyuvar la implementación de la estrategia. Ingeniería Industrial, 37(3), 286-294.

Pessôa, M. V. P. y Trabasso, L. G. (2017). The lean product development organizational culture. En The Lean Product Design and Development Journey. Springer International Publishing AG.

Pilch, I. y Turska, E. (2015). Relationships between Machiavellianism, organizational culture, and workplace bullying: Emotional abuse from the target's and the perpetrator's perspective. Journal of Business Ethics, 128, 83-93.

Piñero, H. R., Pacheco, A. M. y Moreira, P. Q. (2018). Clima y cultura organizacional y su relación con el cambio gerencial de organizaciones tradicionales a organizaciones inteligentes. Ciencias Sociales y Económicas, 2(1), 130-149.

Porter, T., Day, N. y Meglich, P. (2018). City of discontent? The influence of perceived organizational culture, LMX, and newcomer status on reported bullying in a municipal workplace. Employ Respons Rights, 30, 119-141

RAE (Real Academia Española) (2018). Diccionario de la lengua española, Intervención. http:// dle.rae.es/?id=LxNjz42

Reyes Hernández, J. y Moros Fernández, H. (2019). La cultura organizacional: principales desafíos teóricos y metodológicos para su estudio. Revista Estudios del Desarrollo Social: Cuba y América Latina, 7(1), 201-217.

Riascos, W. A. (2014). Contribuciones a la conceptualización de la cultura organizacional. En J. Orejuela (ed.), Psicología de las organizaciones y del trabajo. Apuestas de investigación (pp. 351-377). Editorial Bonaventuriana.

Rider, E., Giligan, M., Osterberg, L., Litzelman, D., Plews-Ogan, M., Well, A., Dunne, D., Hafier, J., May, N., Derse, A., Frankei, R. y Branch, W. (2018). Organizational culture of humanism. Journal of General Internal Medicine, 33(7), 1092-1099. https://doi. org/10.1007/S11606-018-4470-2

Román, O. H., Bonilla, L. F. y Patiño, C. A. (2015). Alineamiento entre estrategia, estructura y cultura. Nuevos paradigmas para lograr la competitividad en los superetes del Valle del Cauca. Editorial Bonaventuriana. 
Ruiz, Y. B. y Naranjo, J. C. (2012). La investigación sobre cultura organizacional en Colombia: una mirada desde la difusión en revistas científicas. Diversitas: Perspectivas en Psicología, 8(2), 285-307.

Salgado Roa, J., Lería Dulčić, F., Arcos, C., Pineda, A. y González, C. (2018). Actitud y resistencia al cambio organizacional en trabajadores mineros. Revista de Psicología, 36(1), 105-134.

Schein, E. (2009). The corporate culture survival guide. Jossey-Bass.

Shumba, C., Kielmann, K. y Witter, S. (2017). Health workers' perceptions of private-notfor-profit health facilities' organizational culture and its influence on retention in Uganda. BMC Health Services Research, 17, 809-820.

Slack, N. y Singh, G. (2018). Diagnosis of organizational culture in public sector undertakings undergoing reforms. Public Organization Review, 18, 361-380. doi: 10.1007/ s11115-017-0383-5

Spencer, S. y Salaban, I. (2017). Organizational culture in civic associations in Russia. Voluntas. International Journal of Voluntary and Nonprofit Organizations, 1-18. https:// doi.org/10.1007/s11266-017-9925-2

Stavrinoudis, T. y Kakarougkas, C. (2017). A theoretical model of weighting and evaluating the elements defining the change of organizational culture. En V. Katsoni, A. Upadhya, y A. Stratigea (eds.), Tourism, culture and heritage in a smart economy. Springer. doi: 10.1007/978-3-319-47732-9_16

Tang, M., Li, M. y Zhang, T. (2016). The impacts of organizational culture on information security culture: A case study. Information Technology and Management, 17, 179-186.

Towne, S., Anderson, K., Lee, M., Vollmer, D., Kellstedt, D., Pena, N. y Dry, M. (2015). Changing organizational culture: Using the CEO cancer gold standard policy initiative to promote health and wellness at a school of public health. BMC Public Health, 15, 853-861.

Tyagi, R., Cook, L., Olson, J. y Belohlav, J. (2013). Healthcare technologies, quality improvement programs and hospital organizational culture in Canadian hospitals. BMC Health Services Research, 13, 413-424.

Vesga, J. J. (2013). Cultura organizacional y sistemas de gestión de la calidad: una relación clave en la gestión de las instituciones de educación superior. Revista Guillermo de Ockham, 11(2), 89-100.

Warner, B. (2014). Organizational change. En B. Schneider y K. Barbera (eds.), The Oxford Handbook of Organizational Climate and Culture (pp. 457-483). Oxford University Press. 
Whetstone, J. T. (2017). Developing a virtuous organizational vulture. En A. J. Sison, G. Beabout, e I. Ferrero (eds.), Handbook of Virtue Ethics in Business and Management. Springer.

Widianto, S. y Harsanto, B. (2017). The impact of transformational leadership and organizational culture on firm performance in Indonesia smes En N. Muenjohn, A. McMurray (eds.), The Palgrave Handbook of Leadership in Transforming Asia (pp. 503-517), doi: 10.1057/978-1-137-57940-9_27

Williams, N., Glisson, C., Hemmelgarn A. y Grenn, P. (2017). Mechanisms of change in the ARC organizational Strategy: increasing mental health clinicians' EBP adoption through improved organizational culture and capacity. Administration and Policy in Mental Health, 44, 269-283.

Yin, E., Downing, N., Singer, S., Curry, L., Li, J., Krumholz, H. M. y Jiang, L. (2015). Organizational culture in cardiovascular care in Chinese hospitals: A descriptive cross-sectional study. BMC Health Services Research, 15, 2-10. 


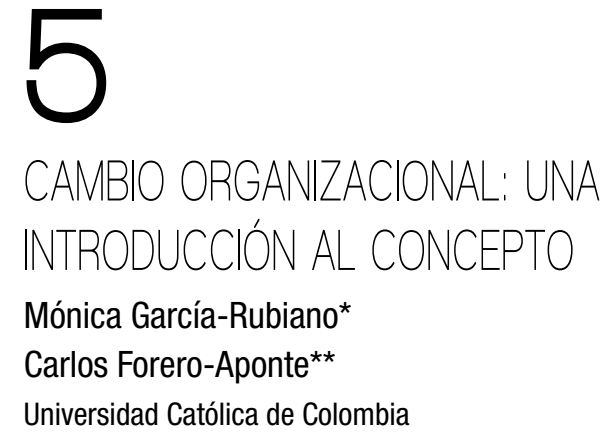

La variable cambio organizacional se tiene en cuenta en el macroproyecto que da lugar a este libro sobre cultura y cambio organizacional en el que se presentan los resultados de investigación al final de la obra.

Por tal razón, se consideró importante tener una mirada amplia sobre la temática, de manera que le permita al lector ampliar sus conocimientos y comprender la importancia de este concepto a la hora de realizar una propuesta de cambio en las organizaciones. En la primera parte de este capítulo se considerarán los antecedentes, los niveles de análisis y los factores que influyen en la resistencia al cambio: en la segunda parte se abordarán aspectos relacionados con la gestión del cambio, la resistencia y los modelos de resistencia.

\section{Antecedentes del concepto de cambio organizacional}

El concepto de cambio organizacional tiene sus cimientos en el modelo propuesto por Lewin en 1951, sobre análisis de las fuerzas; posteriormente, en 1967, Leavitt propone el modelo de análisis del sistema de Likert; en 1966 Katz y Kahn desarrollan la teoría de los sistemas abiertos; una década después, Weisbord propone el modelo de las Seis-Cajas; y entre 1981-1982 surge un modelo más completo, el de las 7S de McKinsey (García-Chacón, 2005). Por su parte, Burke realiza una comparación de diferentes modelos que datan de la década de 1960 hasta la de 1980, en la que explica su utilidad en relación con la comprensión del comportamiento organizacional,

mgarcia@ucatolica.edu.co

* https://orcid.org/0000-0002-7699-502X

** https://orcid.org/0000-0003-0132-4595 
clasificando e interpretando datos que proporcionen un lenguaje común en el momento de realizar un diagnóstico (Armenakis y Bedeian, 1999).

Entre los modelos que proporcionan una base firme y completa sobre el diagnóstico organizacional (basado en el cambio) se encuentra el modelo causal de BurkeLitwin, desarrollado en 1992, el cual permite predecir el desempeño tanto individual como organizacional, centrándose en el ciclo de las causas externas, las condiciones de la organización y los efectos resultantes de estas dos. El modelo está compuesto por doce variables organizacionales que se distribuyen a partir de dos dinámicas: la transformacional y la transaccional. En contraposición se encuentra el modelo de la transformación imprescindible de Vollman, el cual propone una matriz de 8 por 6 detallando las consideraciones potenciales a la hora del cambio organizacional y el esfuerzo que este implica. Ambos modelos son adecuados para hacer un óptimo diagnóstico organizacional ante un cambio, permitiendo planificar y evaluar el impacto de este sobre la organización (Armenakis y Bedeian, 1999).

De este modo, se evidencia que el cambio también es abordado por otras disciplinas como la psicología organizacional, la sociología y la economía, las cuales se dividen en diferentes corrientes de pensamiento, ofreciendo un enfoque estrecho, fragmentando la teoría respecto al cambio, centrándose en el comportamiento organizacional, por un lado, a partir del lugar de trabajo y los aspectos individuales de la organización y, por otro, en los aspectos performance-survival (González, 2010).

De acuerdo con lo expuesto se evidencia que las teorías del cambio se desarrollaron a partir de los efectos que se pueden producir dentro de la organización, y se concentraron en lo beneficioso, los aspectos individuales del trabajador y los aspectos del entorno, en otras palabras, se tratan de la capacidad de flexibilidad y adaptabilidad de la organización al cambio (González, 2010).

\section{Definiciones de cambio organizacional}

Liao y Lin Teo (2018) consideran el cambio como un proceso dinámico que se genera a través de la modificación de diferentes factores dentro de la organización que se abordan desde un solo enfoque teórico. Aunque en realidad este debe ser visto como un factor holístico que incluya y diferencie los modelos teóricos para permitir una menor resistencia y mayor aprobación a la nueva adquisición de información, según el modelo que se busca implementar. De tal manera, concluyen que el cambio es un proceso dinámico de transformación y adaptación que surge ante la necesidad de responder a las demandas del ambiente o de la misma organización, para mejorar su rentabilidad y competitividad, impulsando la innovación y habilidad para producir 
soluciones cada vez más rápidas a nivel estructural, cultural y de comportamiento organizacional.

Para Nesterkin (2013), el cambio responde a una necesidad que se presenta de acuerdo con la demanda competitiva del entorno, lo cual implica un proceso de modificación y transformación y adaptación de procesos organizacionales, que tienen impacto en la estructura y el clima de las organizaciones.

Por su parte, Petrou, Demerouti y Schaufeli (2016) definen el cambio como un fenómeno de adaptación y evaluación dinamizado por el contexto organizacional en donde el conocimiento que es adquirido por los empleados es fundamental, ya que el cambio repercute en la reconstrucción de las creencias y hábitos de los integrantes de la organización.

El cambio es, para Grimolizzi (2017), un conjunto de alteraciones, transformaciones o modificaciones que bien pueden ser estructurales o relacionadas con el comportamiento en la organización, las cuales tienen una relación e interactúan de manera conjunta gracias a la nueva estrategia a implementar con el fin de obtener los mejores resultados, por un lado, para la empresa como organización y, por otro lado, para quien la compone, es decir, para su estructura, sus procesos, la tecnología con la que cuenta y el personal.

\section{Tipos de cambio organizacional}

Weick y Quinn (1999) establecen dos tipos de cambio: el continuo, que se da de manera emergente y autoorganizado, lo que permite un proceso constante y evolutivo, pues es impulsado por la organización. Este proceso de cambio es enfocado al micronivel ya que busca con esto una adaptación de cada una de las partes que compone la estructura con el fin de que el cambio sea duradero en el tiempo (largo plazo) con un ajuste a los reconocimientos y replanteamientos de los modelos actuales. Por otra parte, el cambio episódico, se expresa en la organización como inerte, poco frecuente, discontinuo e intencional. Se caracteriza por una interrupción ocasional o divergencia del equilibrio. Tiende a ser dramático e impulsado desde el exterior; muestra una perspectiva enfocada en el macronivel, global y distante; con orientación a una adaptación a corto plazo; su proceso se centra en la inercia y busca un punto de influencia central; promueve sistemas rápidos del lenguaje, revolución, disparadores, coordinación, compromiso y puntualidad.

Liao y Lin Teo (2018) consideran los tipos de cambio: a) evolucionario, es un constructo determinado por las organizaciones cuando estas se ven permeadas por cambios leves que permiten un mejoramiento, adaptabilidad y ajuste a los cambios que son inminentes ambientalmente y afectan la industria, b) revolucionario, es entendido como todos aquellos cambios a gran escala y ágiles en la búsqueda de nuevas 
formas de eficiencia, por lo cual tiene bastante incidencia en la ejecución normal de tareas dentro de la organización, como la nueva implementación de procesos tecnológicos.

Por su parte, Nesterkin (2013) considera el cambio planeado, generado de manera intencional de un grupo de actores de la organización en donde se busca el desarrollo organizacional y se pone en evidencia en los momentos de transición de las organizaciones; por otro lado, estaría el cambio emergente o súbito, relacionado con una capacidad de respuesta rápida por parte de la organización ante eventos no planeados.

Otros tipos de cambio que considera el autor son: a) planeación, anticipación o proactivo, los cuales implican la toma de decisiones en relación con el aprovechamiento del tiempo; b) inercia o por imitación, que surgen por moda o tendencia gerencial; c) reacción o como respuesta a las circunstancias, esto se da en un momento determinado e inesperado, en el cual el tiempo o planeación no son suficientes ni están estructurados; y d) tensión final o por crisis, que surge cuando, después de un tiempo, la organización fue indiferente a la necesidad de cambio, no percibió a tiempo las demandas del mundo globalizado.

Majid et al. (2011) tienen en cuenta tres tipos de cambio: a) gradual, son las modificaciones que realiza la organización en el momento en el que está sucediendo el cambio, b) transición, la empresa realiza una transformación total de lo que existía, y c) transformacional, los cambios son radicales en aspectos como liderazgo, misión y cultura.

\section{Análisis multinivel del cambio}

La literatura del cambio organizativo está regulada por diferentes enfoques. Generalmente se tiende a fragmentar la teoría del cambio, siendo esta manipulada según el nivel u objeto de estudio, estos son: un micronivel, que incorpora todos aquellos atributos y características de los individuos (p. ej. raza/genero/estrato civil); un mesonivel, que incorpora las cualidades y conductas compartidas en los grupos (p. ej. valores/etnia/costumbres/hobbies) y un macronivel, que compone todos aquellos procesos, comportamientos y resultados en la organización (p. ej. cultura y clima). Es importante resaltar el primer componente de la organización, pues es allí donde debe centrarse la observación teórica y recae la mayoría de las consecuencias de dicha gestión. El cambio organizacional no surge del asilamiento, pues son las partes interesadas en generar la modificación que moldean la dirección y finalidad en el inicio, durante y en la resolución del proceso. Debe existir un microanálisis en la 
organización, en que los miembros y sus aspectos psicológicos sean de suma utilidad para que la evidencia real del cambio trascienda a un macronivel (González, 2010).

Dichas diferencias individuales y comportamentales son el componente principal de la convivencia dentro de la organización e influyen directamente en las competencias del grupo empresarial. Los comportamientos subestiman el impacto contextual que puede obstaculizar o mejorar la efectividad en el trabajador durante la época de cambio organizacional. Por tal motivo, no se debe prescindir de la cultura y las diferencias contextuales dentro y entre las organizaciones; así, la efectividad del cambio dependerá de la estructura organizacional estrechamente vinculada con la variable del clima laboral. Por ejemplo, la gente no trabaja de manera aislada, sino que trabaja con otros miembros de la organización, se involucra explícitamente con los recursos, las herramientas y los factores de organización que influyen significativamente en el rendimiento laboral durante y después del cambio. Buscar la efectividad y eficiencia laboral es una de las principales causas por las cuales se gestiona el cambio organizacional, pues dicha gestión proporciona un conjunto de principios rectores para la normalización del comportamiento en el trabajo, dando forma a la conducta de los empleados, como un marco de referencias que incluye tanto el clima laboral como las actividades propias de cada labor para el rendimiento en la productividad; por lo tanto, la gestión del cambio organizacional decide el camino de las compañías, integrando sus recursos, la tecnología, las habilidades humanas, los valores, las políticas, la filosofía, las estrategias administrativas, etc., en busca del progreso (Prieto et al., 2015).

Por otra parte, Neiva et al. (2015) afirman que, para llevar a cabo un análisis multinivel del cambio organizacional, se debe hacer hincapié en la necesidad de especificar las características del contexto donde surge el por qué y para qué del cambio organizacional, junto con la evaluación de los resultados. Puede considerarse un contexto específico, por ejemplo el uso de un nuevo programa de contabilidad, que es usado solo por una parte de los empleados, modificará directamente la actividad laboral del usuario del programa, pero al mismo tiempo, dicha actividad repercutirá positiva o negativamente dentro de la organización en un contexto mucho más amplio, es decir, con el uso del programa se agilizó la realización de órdenes de compra, por tal motivo se tiene la materia de forma más rápida, lo que promueve un ahorro de tiempo para generar un producto final del cliente. La complejidad de las organizaciones y su contenido cultural hacen del cambio un proceso muchas veces engorroso y lento, pero que es algo inherente a las organizaciones por su misma finalidad, la cual esta direccionada específicamente en la modificación de alguna o varias circunstancias 
presentes dentro de la compañía, según sea el caso; por lo tanto, la composición psicosocial de una organización produce su dinámica.

Estos autores consideran siete atributos que describen la constitución variable del cambio organizacional: a) control: hace referencia a los cambios planificados; b) ámbito de aplicación: es la transición de la adaptación a la transformación; c) frecuencia: es la cantidad de cambio organizacional que está sucediendo o número de etapas para poner en práctica el cambio; d) tiempo: duración para implementar el cambio; e) velocidad: es el ritmo de las acciones; f) objetivos: es lo que se quiere conseguir; g) estilo de liderazgo: es definido por el grado de participación de los empleados y puede variar en función de la cooperación y la participación de los niveles.

\section{Factores que influyen en el cambio organizacional}

El cambio es generado por diferentes factores del individuo o de la empresa, los cuales influyen en cada integrante de la organización, lo que crea percepciones, reacciones o emociones que afectan el desempeño laboral y/o empresarial.

Uno de los factores que influyen en el cambio organizacional es el aprendizaje, por medio de este el empleado logra entender cuáles son las políticas, valores, estrategias, objetivos y demás conocimientos de la organización; además de poder tener un espacio para la formación de la ejecución de actividades en la misma organización, con el fin entender lo que hay e identificar si se debe producir un cambio (Liao y Lin Teo, 2018).

También se encuentra la identidad institucional la cual se refiere a aquel sentido de pertenencia del individuo sobre su organización, por lo cual, si el individuo no tiene el suficiente sentido de pertenencia, no se esforzará por realizar un cambio o adaptarse a otro en dicha organización (González, 2010).

Otro factor de influencia es la resistencia, la cual hace referencia a una respuesta inmediata hacia el cambio organizacional, se considera como una barrera para el cambio organizacional, la cual impide que este se desarrolle, lo que lleva a generar tensión, baja satisfacción con la vida y el trabajo; y a veces hasta el fracaso total del cambio de organización propuesto. Por lo tanto, si el individuo (empleado) se resiste al cambio es muy poco probable que se lleve a cabo, ya que no se satisfacen sus vertientes laborales como trabajador (Tavakoli, 2010).

Por otra parte, se encuentra el liderazgo (patrón que lidera la acción que se pretende realizar), mediante el cual el cambio organizacional puede desarrollarse eficazmente, debido a que si se lidera el objetivo de cambio y los roles establecidos están claros para cada uno de los individuos (empleados), el afrontamiento y el desarrollo 
del cambio serán óptimos. Además, el liderazgo también es entendido como aquel comportamiento que se enfoca a un cambio específico, basado en la proyección, el empoderamiento, y la cooperación de la adaptación subjetiva, centrándose en la promoción de la iniciativa al cambio y las acciones que presionan a la consolidación del cambio (Ferrer, 2015).

Además de los factores mencionados se encuentra la actitud, la cual se ve reflejada en el comportamiento de las personas de acuerdo con las experiencias previas, por ende, los empleados de una organización presentan diferentes actitudes relacionadas con el cambio que se genera en la empresa influyendo en la eficacia de su labor y hasta en el mismo éxito o fracaso del cambio (Van der Smissen et al., 2013).

Por otra parte, existen dos tipos de fuerzas que influyen en el cambio de la organización, debido a diferentes factores: a) endógenas, se generan dentro de la organización, b) exógenas, son aspectos externos a la organización de orden social, político, económico que generan cambio dentro de la organización (Giaever y Helleso, 2010).

\section{Gestión del cambio organizacional}

En la gestión del cambio se debe tener en cuenta el tipo de cambio que se está presentando, considerar cómo afecta el entorno de laboral, la estructura, la cultura (Grama y Todericiu, 2016).

Zimmerman (2000) considera de gran importancia involucrar los equipos de trabajo en los procesos de cambio, los cuales deben ser creados con objetivos específicos para responder a las diferentes necesidades del cambio y así poder cubrir todas las áreas de la organización. De igual forma, se debe tener claro quién va a ser la persona que gestione el cambio en la organización para que el proceso tenga una cabeza que responda y a quien los equipos puedan reportar, estos aspectos pueden garantizar un cambio de manera exitosa.

Para que las organizaciones se preparen para el cambio se deben considerar varios aspectos como la actitud, la capacidad de innovación, las nuevas tecnologías de tal manera que se pueda ver reflejado en el incremento del rendimiento organizacional y preparando la organización para futuros cambios (Ferreira, Cardoso, y Braun, 2018).

\section{Teorías del cambio organizacional}

En relación con el cambio organizacional hay diversas teorías, una de ellas es la teoría institucional del cambio que plantea que este debe ser entendido como el producto de la pérdida de la institucionalización de la organización como fuente de discontinuidad 
y nueva información, que desalinea las actividades anteriormente institucionalizadas. Esto se genera por medio de una serie de pasos que incluyen nuevas políticas, empleados, conocimientos, entre otros, permitiendo cambios y logrando modificar las prácticas sociales y normativas de la empresa (Liao y Lin Teo, 2018).

En este sentido, se entiende que lo institucional es una de las barreras que se debe tener en cuenta para que se permita el cambio organizacional, debido a que es una de las fuentes que produce resistencia. Este aspecto genera la paradoja del cambio institucional, la cual se considera el punto de equilibrio entre lo que ya está establecido y la posible resistencia al cambio que se puede gestar. Para responder a esta paradoja, los autores plantean dos teorías: a) estructuralista, señala que las organizaciones son de carácter similar en cuanto a todo lo relacionado a su estructura, siendo así que generar un cambio político o tecnológico es un factor resistente o limitante; y b) agencia al cambio, considera a las organizaciones como instituciones que por medio de la diversidad permiten la ejecución de iniciativas diferentes (Liao y Lin Teo, 2018).

Por otra parte, González (2010) propone la teoría del cambio organizacional integrado, la cual plantea que la división de las áreas del conocimiento y las diferentes visiones metodológicas para explicar el cambio son limitantes que llegan a romper el ideal de la organización, generando obstrucción o resistencia al cambio. Esto se debe a que, al presentarse la división en el momento de abordar el cambio, no hay claridad en la comprensión y en el camino que se va a tomar para llegar. Es así como la psicología, la sociología y la economía deben encaminarse a una explicación no como áreas del conocimiento independientes, sino unificando los aportes de cada una para representar la explicación del cambio. En este orden de ideas, las teorías también deben enfocarse en los procesos de influencia multidireccionales, partiendo de lo micro de cada una para llegar a un macro general que permita comprender mejor el cambio.

Zapata y Mirabal (2011) plantean que uno de los aspectos fundamentales que se debe tener en cuenta en el momento de pensar en realizar un cambio organizacional es el ambiente en el que se desarrolla la empresa, pues es un determinante del comportamiento de los empleados. Por lo tanto, proponen la teoría de las contingencias, la cual plantea que cuando en una organización se genera un desajuste y se dejan en evidencian limitaciones que son impuestas por el ambiente, se presenta un nivel de contingencias alto que puede expresarse como un bajo desempeño, el cual se genera por la disminución de la satisfacción del empleado. $Y$ es en ese momento que se deben interpretar las situaciones como el factor detonante o punto de partida, que indica a la organización el inicio de un proceso de cambio y ajuste que se adapte al nivel de contingencias presentado, para así poder brindar mejores condiciones de trabajo 
a los empleados y de igual manera aumentar su nivel de satisfacción y desempeño en la organización.

Es así como esta teoría ayuda a definir las variables estructurales de la organización, relacionando y alineando diferentes variables con los factores de contingencia incidentes en el proceso de cambio, teniendo como finalidad la búsqueda de mayor eficiencia al generar un cambio dentro de la organización (Zapata y Mirabal, 2011).

Por último, Zapata y Mirabal (2011) exponen la teoría de la dependencia de recursos, la cual postula que para garantizar el cambio en una organización se debe tener en cuenta que la empresa no puede por sí sola aportar a su crecimiento o supervivencia, por ende, requiere de terceros que puedan llegar a suministrar esos servicios que la empresa no puede producir, volviéndola más propensa al ambiente y sus contingencias. Esto implica, en el momento del cambio, la disposición de este, puesto que es la empresa la que tiene un cierto grado de dependencia en cuanto a su propia capacidad de adaptación y a su vez al grado de urgencia con el que requiere los recursos. Dadas estas condiciones las empresas se enfrentan a las siguientes opciones: a) adaptarse a las condiciones del ambiente; b) participar activamente en la creación y control del entorno; c) enfrentarse al entorno buscando un equilibrio entre los puntos señalados.

\section{Acción para las transformaciones organizacionales}

Los cambios que se realizan en las organizaciones deben tener un propósito claro, de tal manera que la organización se beneficie a partir de estos. Mintzberg y Westley (1992) consideran tres aspectos a tener en cuenta: a) planear los procedimientos, contar con la cultura y la estrategia de la organización, b) liderazgo visionario, en el que el líder jalone los cambios, y c) aprendizaje inductivo, los cambios se desarrollan en cualquier nivel de la organización, pero su objetivo final es permear e impactar a toda la empresa.

Para González (2010) el liderazgo y la identidad de la organización son un puente sobre el cambio organizacional el cual lleva a diferentes teorías desde perspectivas como las psicológicas, sociológicas y económicas que hoy en día se presentan en todas las organizaciones; otra opinión que refuerza este comentario es la de Ferreira et al. (2018), quien indica que en la actualidad se han presentado eventuales cambios organizacionales que están diseñados para mejorar el rendimiento de la organización mediante la adaptación al medio ambiente y la preparación para los cambios futuros que, a su vez, pueden tomar una variedad de formas, incluyendo cambios en la estructura organizacional, los procesos sociales, el medio ambiente y las personas. 
En muchas ocasiones, a pesar de optar por uno u otro modelo y seguir los pasos correctamente, las reformas organizacionales pueden causar o generar en los empleados o colaboradores la resistencia al cambio lo cual influye en el desenvolvimiento y funcionamiento de la organización y así mismo en los resultados (Zuinaga de Mazzei, 2014).

\section{Resistencia al cambio}

Están relacionadas con la naturaleza de la composición humana en grupos sociales. Es un fenómeno social que tiene un carácter psicológico de las resistencias de los individuos. La resistencia será una decisión intraindividual que por sus mismas condiciones y en contacto con otras personas se convertirá en una especie de factor de atracción que interviene en las relaciones intragrupales, modificando directa o indirectamente el comportamiento de los individuos frente al cambio organizacional (Zuinaga de Mazzei, 2014).

La resistencia al cambio es definida como todas aquellas oposiciones tanto cognitivas como comportamentales dentro de una organización ante el cambio que se pretende realizar, independientemente de que este sea de índole evolucionaria o revolucionaria (Dolan, García y Auerbach 2003).

Zuinaga de Mazzei (2014) explica que las primeras actitudes que presentan los empleados son rabia y enfado, y de cierta manera es esperado o predecible, lo importante en esta instancia es reconocer la realidad de la situación y tomar medidas pertinentes para evitar dificultades en el clima organizacional y la productividad.

La resistencia al cambio es algo inevitable en las organizaciones, la manera como se maneje el cambio va a generar que se genere resistencia en mayor o menor medida. Algunos aspectos que generan resistencia son: a) inadecuada comunicación, b) conformidad con el statu quo, c) percepción perdida de estatus en la organización (Trader-Leigh, 2002). Desde esta perspectiva, Cinite y Duxbury (2018) señalan que las personas cuya actitud es negativa frente al cambio tienden a desasistirse más a este.

Barahona y Prowesk (2008) identifican algunas fuerzas que generan resistencia como la cultura, intereses a nivel personal que priman sobre los objetivos de la organización. Los autores señalan que, si estas fuerzas se abordan oportunamente, el cambio tendrá mayor posibilidad de éxito (Grama y Todericiu, 2016).

Para Rabelo et al. (2004) la resistencia se puede identificar a partir de aspectos como las creencias de las personas sobre el proceso de cambio generado por aprendizajes previos, lo que despierta una reacción cognitiva inadecuada con relación a este. 
Por otro lado, Jansson (2013) sostiene que la resistencia no necesariamente es negativa ya que, desde otro punto de vista, esta es reflexiva y permite ser un activo valioso para la organización y propiamente para el cambio, debido a que puede generar escrutinio y contraargumentación por parte de los individuos y, de esta manera, evaluar, considerar y, de ser el caso, emprender reestructuraciones al cambio que se pretende realizar.

\section{Modelos de resistencia}

Hay diversos modelos que indican las razones por las cuales las personas se resisten al cambio, uno de ellos es el de Robbins y Judge (2006), quienes consideran que cuando las personas perciben que deben incorporar nuevas normas o pierden estatus en la organización se sienten vulneradas y, por ende, generan resistencia, además, el sentimiento de incertidumbre también ayuda a que las personas manifiesten malestar ante un cambio (Cinite y Duxbury, 2018).

Autores como Dick, Ciampa y Liang (2018) consideran que la resistencia se presenta dependiendo de la perspectiva de las personas que se pueden relacionar con los aspectos éticos con los que se haya generado el cambio, las nuevas reglas que se presenten, la evaluación que realicen las personas frente a dichos cambios y sus resultados finales.

Otra perspectiva que se tiene sobre la resistencia es la planteada por Erwin y Garman (2010), quienes consideran la importancia de permitir a los colaboradores crecer en la organización, lo cual implica flexibilidad para el empleado, por otra parte, es importante considerar los recursos de la organización reflejada en la adquisición de tecnología de punta que le permita ser más competitiva y responder de manera adecuada a las demandas de los cambios.

\section{Dinámicas y efectos del cambio en las organizaciones}

Para Pettigrew, Goodman y Cameron (2001), enfrentar los cambios, sus dinámicas y efectos en el tiempo es un aspecto clave, ya que permite realizar un reconocimiento del quehacer cotidiano de las organizaciones proporcionándoles un marco sobre el rol y las actividades que desarrollan los trabajadores dentro de la organización. Estos aspectos implican gestionar el cambio, de tal manera que se haga una mirada multidimensional y la temporalidad de desarrollo, además de que se pueda responder adecuadamente a las consecuencias del cambio, tanto entre las personas como con la organización (Whelan-Berry et al., 2003). 
Un ejemplo de cambio exitoso es el del Hospital Público de La Florida en Chile, que ha planeado su proceso de cambio, partiendo del diseño del proyecto y su desarrollo, a dos centros de salud y su culminación con la propuesta de sistemas y modelos innovadores de atención para la población (Díaz Canepa, Arancibia y Drobny, 2015).

También es importante tener en cuenta que no todos los cambios llegan a feliz término a causa del manejo inapropiado, ya que se debe contar con los integrantes de la organización, y estructurarlos sistemáticamente, tener buena comunicación, hacer seguimiento permanente, antes, durante y después, ya que la organización no puede permitir que el cambio se reverse. Considerar a las personas dentro de este proceso de cambio es clave en la medida en que las personas puedan entenderlo y se sientan parte de él, esto ayuda a que el proceso fluya. Esto no significa que no se vaya a presentar resistencia, sin embargo, se puede reducir la intensidad si el proceso se desarrolla de manera adecuada. El seguimiento es crucial en estos procesos, no es posible dejarlos a la deriva sin ningún tipo de supervisión y planteamiento de indicadores, puesto que así se puede ayudar a gestionar el cambio y a determinar cuáles aspectos pueden mejorar (García y Forero, 2018).

Díaz Capena (2016) señala la importancia de la articulación de los elementos técnicos, subjetivos, pragmáticos y contextuales; él presupone tener en cuenta tres aspectos: a) participación inminente de las personas en la organización que se ven afectadas por el proceso de cambio y desarrollo de estrategias que direccionen el proceso; b) coherencia entre los recursos que la organización ha dispuesto para el proceso vs. las exigencias que se pueden realizar desde las diferentes áreas para operar el cambio; y c) equilibrio entre continuidad, asimilación y apropiación de las nuevas prácticas. Estos aspectos son los que ayudan a mantener el proceso de cambio y garantizan la efectividad de este.

\section{Conclusiones}

El cambio organizacional es un aspecto constante en las organizaciones, estas deben responder adecuadamente a las exigencias del ambiente interno o externo, de tal manera que puedan ser competitivas. El modo como las organizaciones afrontan los cambios es lo que marca la diferencia para que sean exitosas, por lo tanto, se deben considerar diversos temas para el logro de este objetivo.

Tener una mirada holística de la organización en todos sus niveles (individuo, grupo y organización), entender que hay muchas variables que se asocian a este y funcionan como un engranaje permite que se pueda ejecutar el cambio. Lo anterior procede siempre y cuando se considere el talento humano, es importante que las 
organizaciones tengan en cuenta la particularidad de las personas y cómo estas pueden ayudar en la transición o la obstaculización del cambio. En la medida en que los colaboradores entiendan el proceso de cambio es mucho más probable que este se ejecute de forma adecuada.

\section{Referencias}

Armenakis, A. y Bedeian, A. (1999). Organizational change: A Review of Theory and Research in the 1990s. Journal of Management, 3(25), 293-315.

Barohona, J. A. y Prowesk, K. (2008). Percepción de los factores de riesgo en una entidad financiera fusionada. Pensamiento Psicológico, 4 (11), 183-198.

Cinite, I. y Duxbury, L. (2018). Measuring the behavioral properties of commitment and resistance to organizational change. The Journal of Applied Behavioral Science, 54(2), 1-27. https://doi.org/10.1177/0021886318757997

Díaz Canepa, C. (2016). Gestión del cambio en las organizaciones: efectos sobre la actividad y las personas. Laboreal, 12 (2), 2-35. doi: 10.4000/laboreal.2314

Díaz Canepa, C., Arancibia D. y Drobny, T. (2015). Informe técnico GCo-abril. Informe interno Equipo Gestión del Cambio, Hospital de la Florida, Santiago de Chile.

Dick, R., Ciampa, V. y Liang, S. (2018). Shared identity in organizational stress and change. Current Opinion in Psychology, 23, 20-25. https://doi.org/10.1016/j.copsyc.2017.11.005

Dolan, S. J., García, S. y Auerbach, A. (2003). Understanding a and managing chaos in organizations. International Journal of Management, 20(1), 23-35. https://www.researchgate. net/publication/265748021_Understanding_and_managing_chaos_in_organisations

Ferreira, A., Cardoso, C. y Braun, T. (2018). The mediating effects of ego-resilience in the relationship between organizational support and resistance to change. Baltic Journal of Management, 13(1), 104-124. https://doi.org/10.1108/BJM-06-2017-0171

Ferrer, R. (2015). La influencia del factor humano, el liderazgo y la cultura de las organizaciones en los procesos de implementación y gestión del cambio organizacional. Revista de Investigación en Ciencias Sociales, 11(1), 102-114. http://dx.doi.org/10.18004/riics.2015. julio.102-114

García- Chacón, G. (2005). Herramienta para el diagnóstico de la resistencia al cambio durante el desarrollo de proyectos mayores. Estudios Gerenciales, 21(96), 57-106. http:// www.scielo.org.co/pdf/eg/v21n96/v21n96a03.pdf

García, M. y Forero, C. (2018). Estrés laboral y contrato psicológico como elementos relacionales del cambio organizacional. Revista Diversitas Perspectivas en Psicología, 1(14), 149-162. doi: $10.15332 / 22563067$

Giaever, F. y Helleso, R. (2010). Negative experiences of organizational change from an emotions perspective: A qualitative study of the Norwegian nursing sector. Nordic Psychology, 62(1): 37-52. http://dx.doi.org/10.1027/1901-2276/a000004 
González, J. (2010). Diversity Change in Organizations: A Systemic, Multilevel, and Nonlinear Process. The Journal of Applied Behavioral Science, 46(2), 197-219. doi: $10.1177 / 0021886310367943$

Grama, B. y Todericiu, R. (2016). Change, resistance to change and organizational cynicism. Studies in Business and Economics, 11(3), 47-54. doi:10.1515/sbe-2016-0034

Grimolizzi, C. (2017). Organizational change: Effect of motivational interviewing on readiness to change. Journal of Change Management, 17, 54-69. http://dx.doi.org/10.1080/14 697017.2017.1349162

Jansson, N. (2013). Organizational change as practice: A critical analysis. Journal of Organizational Change Management, 26(6), 1003-1019. doi: 2117/10.1108/ JOCM-09-2012-0152

Liao, L. y Lin Teo, A. (2018). Organizational Change Perspective on People Management in BIM Implementation in Building Projects. Journal of Management in Engineering, 34(3), 1-13. https://doi.org/10.1061/(ASCE)ME.1943-5479.0000604

Majid, A., Abdullan, M. T., Yasir, M. y Tabassum, N. (2011). Organizational inertia and change portfolio: An analysis of the organizational environment in developing countries. African Journal of Business Management, 5, 383-388.

Mintzberg, H. y Westley, F. (1992). Cycles of organizational change. Journal Strategic Manegement, 12(52), 39-59. doi: 10.1002/smj.4250130905

Neiva, E., Odelius, C. y Ramos, L. (2015). The organizational change process: Its influence on competences learned on the job. BAR, Brazilian Administration Review, 12, (4), 324-347. doi: 10.1590/1807-7692bar2015140082.

Nesterkin, D. A. (2013). Organizational change and psychological reactance. Journal of Organizational Change Management, 26(3), 573-594. doi: 10.1108/09534811311328588

Pettigrew, A., Goodman, R. y Cameron, K. (2001). Studying organizational change and development challenges for future research. Academy of Management Journal, 44, 4, 697-713.

Petrou, P., Demerouti, E. y Schaufeli, W. (2016). Crafting the change: The role of employee job crafting behaviors for successful organizational change. Journal of Management, 44(5): 1766-1792. https://dx.doi.org/10.1177/0149206315624961

Prieto, R., Emonet, P., García, J. y González, D. (2015). Cambio organizacional como estrategia de gestión en las empresas mixtas del sector petrolero. Revista de Ciencias Sociales, 11(3), 386-402. doi:10.31876/rcs.v21i3.25739

Rabelo, E., Ros, M. y Torres da paz, M. (2004). Validación de una escala de actitudes ante el cambio organizacional. Revista de Psicología del Trabajo y de las Organizaciones, 20 (1), 9-30.

Robbins, P. y Judge, T. (2006). Organizational behavior. Prentice Hall.

Tavakoli, M. (2010). A positive approach to stress, resistance, and organizational change. Procedia Social and Behavioral Sciences, 5, 1794-1798. 
Trader-Leigh, K. E (2002). Case study: Identifying resistance in managing change. Journal of Organizational Change Management, 15(2), 138-155.

Van der Smissen, S., Schalk, R. y Freese, C. (2013). Organizational change and the psychological contract: How change influences the perceived fulfillment of obligations. Journal of Organizational Change Management, 26(6), 1071-1090.

Weick, K. y Quinn, R. (1999). Organizational change and development. Journal Psychology, 50(1), 361-386. doi: 10.1146/annurev.psych.50.1.361

Whelan-Berry, K. S., Gordon, Judith R. y Hinings, C. R. (2003). Strengthening organizational change processes: Recommendations and implications from a multilevel analysis. The Journal of Applied Behavioral Science, 39, 2, 186-207.

Yeh-Yun Lin, C. (1998). Success factors of small and medium sized enterprises in Taiwan: An analysis of cases. Journal of Small Business Management, 36, (4), 43-56.

Zapata, G. y Mirabal, A. (2011). El cambio en la organización: un estudio teórico desde la perspectiva de control externo. Estudios Gerenciales, 27(119), 79-98.

Zuinaga de Mazzei, S. (2014). Resistencia al cambio organizacional en una pequeña y mediana empresa (PyME) del sector industrial. Telos, 16 (2), 226-242.

Zimmemann, A. (2000). El cambio organizacional. En Gestión para el cambio organizacional: caminos y herramientas (pp. 73-126). Abya-Yala. 



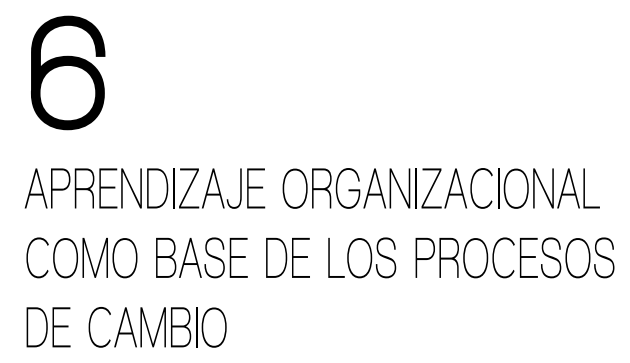

María Alejandra Gómez Vélez*

Verónica Andrade Jaramillo**

Universidad Pontificia Bolivariana

\section{Introducción}

El aprendizaje organizacional (AO) es cimiento para lograr cambios en las organizaciones (Elliott, 2020), al menos cuando se pretende que sean profundos y duraderos, llamados por Argyris (2001) como de doble bucle, y que son tan necesarios en los entornos turbulentos como los que la humanidad atraviesa hoy por cuenta de la pandemia generada por el Covid-19 (Avgar et al., 2020; International Organisation of Employers e International Trade Union Confederation, 2020). La incertidumbre bien gestionada puede conducir a la creatividad colectiva o a la innovación, siempre y cuando los sistemas de gestión de los recursos humanos en las organizaciones las favorezcan (Jeong y Shin, 2017; Jyoti, Chahal y Ranl, 2017).

Este capítulo tiene como propósito retomar aspectos esenciales del aprendizaje tanto desde lo organizacional, como desde lo individual, aportados por diversos autores para comprender cómo promover el cambio en las organizaciones de trabajo. Se parte de la importancia de comprender la complejidad del cambio como consecuencia esencialmente de un sistema en el que se aprende y se comparten modelos mentales, creencias, valores, incertidumbres, tecnología, información, etc., y que tiene por visión el concretar objetivos que le permitan a la organización sobrevivir, crecer, desarrollarse y lograr utilidades, a través de innovación, procesos eficientes, liderazgo, desarrollo de personas y una cultura organizacional fortalecida.

El aprendizaje organizacional, y las denominadas organizaciones inteligentes, constituyen un campo de práctica profesional y de investigación que interesa a directivos, consultores 
y profesionales, enfocado en la transformación de las organizaciones. Para Yeung et al. (1999, p. 10) "en un contexto organizacional, aprendizaje significa que el conocimiento ha sido transferido a través de los aprendizajes individuales a otras personas, unidades y funciones". Ahumada (2002, p. 144) indica que el AO "es un proceso mediante el cual se incorporan nuevas distinciones, que traen como consecuencia un cambio en la lógica dominante de la organización [...] que implica una apertura o modificación del margen de posibilidades viables y/o significativas del decidir organizacional".

De acuerdo con Swicringa y Wierdsma (1995), el aprendizaje organizacional se trata de un cambio en el comportamiento organizacional que es reflejo de un aprendizaje colectivo, lo que de acuerdo con Senge (1995) implica poner el conocimiento al alcance de toda la organización. Para Andrade (2008), el AO es "la capacidad de la organización para generar e implementar conocimiento de manera constante y fluida, involucrando a todos los niveles, e inmersa en los distintos procesos organizativos" (p. 23). Se puede decir, de acuerdo con Willems et al. (2018) que el Ao se refleja "como un cambio en la comprensión compartida del problema a abordar, que también se puede ver en las estrategias desarrolladas posteriormente" (p. 1090).

El aprendizaje organizacional requiere ser entendido como un elemento clave dentro de las organizaciones por ser dinamizador del comportamiento organizacional en sus tres niveles: individual, grupal y organizacional (Crossan, Lane y White, 1999). Y además de ser multidimensional, y estar articulado a diversos aspectos de la organización, incluyendo el sector al que pertenezca (Shukla, Kumar y Dubey, 2018; Willems, Busscher, Van den Brink y Arts, 2018), es fundamental reconocer que influye en la forma en que los trabajadores perciben el cambio (García-Rubiano y ForeroAponte, 2016), se desempeñan (Perlo y De la Riestra, 2005; Weinzimmer y Esken, 2017), y por tanto, aportan al logro de los objetivos organizacionales.

Para Angulo (2017), al estar el escenario empresarial caracterizado por la incertidumbre, la complejidad y el constante cambio, el conocimiento logra un protagonismo vital porque posibilita un desarrollo en las organizaciones que finalmente se convierte en fuente de riqueza. Para Nonaka y Takeuchi (1999), es el conocimiento el que brinda una ventaja competitiva sostenible para las organizaciones, y según Garzón y Fisher (2008), es vital para la toma de decisiones, productividad, innovación y estrategia; es decir, que el conocimiento es un factor clave que añade valor a las organizaciones. ¿Cómo lograr entonces que este sea parte de la vida cotidiana dentro de ellas?

\section{Los cambios, una realidad ineludible}

Los cambios son inexorables incluso allí donde la tradición tiene mayor arraigo, por lo que no queda otra opción que medir las consecuencias de las transformaciones y 
dar respuesta a ellas (Ordóñez, 2010), ya que las organizaciones se encuentran en un escenario que las presiona, exige cambios y ajustes continuos, relativos a la apertura a mercados globales, a la tecnología cambiante y al surgimiento de conocimientos que permiten hacerse competitivos para responder con eficiencia y con capacidad de adaptación, en un entorno voluble (Montealegre y Calderón, 2007). Ordóñez (2010) sugiere identificar las cualidades del cambio para tratar de afrontarlo de mejor manera; entre estas destaca la velocidad, la dirección y su nivel de trascendencia.

Para Ordóñez (2010), los cambios presentan diversos ritmos (velocidad), algunos llevan décadas y, otros, años en instaurarse en las generaciones venideras; sin embargo, destaca que en tiempos de crisis la innovación aumenta su velocidad. Respecto a la dirección, el autor afirma que las transformaciones son multidireccionales, ya tienen un origen impredecible al igual que sus impactos. Las fuentes de los cambios son diversas, como por ejemplo, los provenientes de la competencia, de un organismo del Estado, de la acción de un otro.

Acosta (2002) señala que el cambio también se produce por el desarrollo de nuevos productos y servicios, las nuevas directrices administrativas, las exigencias del entorno, las dificultades financieras, los ajustes en el mercado, las alianzas estratégicas, las innovaciones en tecnología, las transformaciones en el entorno social, político y económico, las políticas mundiales, el papel del Estado, la competencia global y las catástrofes naturales.

Para Ramírez Arango (2007), los tiempos de crisis son también motivo de cambio y pueden ser de oportunidad. Estos requieren un esfuerzo ante los retos que se presentan, y su dificultad depende de la oportunidad que se tenga de convertir las amenazas y problemas en oportunidades. Según Elliott (2020), las crisis que implican austeridad son una buena fuente de aprendizaje organizacional profundo; sin embargo, puede ocurrir que, en medio de la contingencia, las organizaciones opten por aprendizajes superficiales, de corto plazo y de impacto principalmente individual, más que organizacional.

Sobre la cualidad de trascendencia del cambio planteada por Ordóñez (2010), respecto a si este es estructural o coyuntural, el autor afirma que es difícil prever los efectos que ocasionará un cambio y discernir las profundidades que conlleva una transformación, ya que sus efectos no son siempre predecibles, incluso pueden pasar inadvertidos en un primer momento. Agrega que las modificaciones no siempre son estructurales y los efectos definitivos, provocando solo cambios momentáneos, los que Argyris (2003) llamaría de bucle simple. Lo complejo aquí es poder detectar si se trata de un cambio estructural en el momento oportuno, para tomar las decisiones que se ameritan a tiempo. 
Para Martínez Villaverde (2006), si bien los cambios llevan a vivir momentos de mucha incertidumbre para las organizaciones, que implican buscar personal cada vez más cualificado, herramientas de trabajo que simplifiquen las tareas diarias y la gestión de la información, también las obliga a alcanzar una cultura organizacional más innovadora.

\section{Tres modelos clásicos para comprender el aprendizaje organizacional}

Los inicios del constructo "Organizaciones que aprenden" pueden rastrearse en Peter Senge, a partir de su libro La quinta disciplina, que el autor retoma en obras posteriores (Senge, 1992, 1995). Este momento marca el inicio de un interés por comprender la naturaleza compleja del aprendizaje organizacional, las dificultades que lo limitan, las posibilidades de innovar y las de afrontar los cambios que se generan de forma continua en el contexto organizacional.

A partir de este momento se crean modelos para explicar cómo ocurre el AO; algunos de ellos ya considerados clásicos siguen vigentes para la comprensión actual del fenómeno. Entre estos pueden destacarse los aportes de Senge (1992), Nonaka y Takeuchi (1995) y Crossan, Lane y White (1999), entre otros. Para Basten y Haamann (2018), las teorías y modelos disponibles en la actualidad sobre AO refieren tres tendencias cuyos elementos esenciales pueden rastrearse en los modelos clásicos de los autores mencionados: centrarse en las personas, aquellos que de manera individual gestionan o favorecen que el conocimiento se dé y se incorpore en toda la organización; fijarse en los procesos, concentrarse en lo que realizan los equipos de trabajo, la formación de comunidades de práctica y cómo estas resuelven problemas, el análisis sobre situaciones de manera transversal, y la formación requerida por parte de los trabajadores para afrontar las situaciones. Y, por último, considerar el uso de la tecnología tanto para almacenar información, como para favorecer la interacción a través de la virtualidad.

Senge (1992) señala que las organizaciones son inteligentes cuando aprenden, es decir, que lo son cuando cuentan con la capacidad de aprender de su propia experiencia para poder convertir lo aprendido en una fuente de ventaja competitiva y admitir que todas las prácticas organizacionales son susceptibles de mejora, incluidas las que han sido exitosas. Para lograr una organización inteligente esta requiere orientarse a formar a sus integrantes en cinco disciplinas según lo indica Senge: dominio personal, modelos mentales, visión compartida, aprendizaje en equipo y pensamiento sistémico.

El dominio personal (Senge, 1992) se refiere al crecimiento y el aprendizaje a través del que las personas buscan expandir continuamente su aptitud para crear los 
resultados que quieren en su vida. Trasciende las competencias y las habilidades, y requiere además crecimiento espiritual para vivir la vida de una forma creativa y no solo reactiva. Cuando este dominio se integra como actividad a la vida se clarifica continuamente lo que es importante para sí, siendo un proceso que dura toda la vida: " $[. .$.$] consiste en aprender a generar y sostener la tensión creativa en nuestras vidas"$ (p. 182), estar de cara a la realidad actual y actuar en función de la visión y de la dirección deseada por uno mismo.

Senge (1992) denomina la segunda disciplina modelos mentales, los cuales se refieren a "profundas imágenes internas acerca del funcionamiento del mundo, imágenes que nos limitan a modos familiares de pensar y actuar [...] en la mente llevamos imágenes, supuestos e historias" (p. 222). Los modelos mentales se traducen en generalizaciones que moldean las acciones; su poder afecta la forma en que se ve el mundo, y son de naturaleza tácita, por lo que cambiarlos se hace más difícil. De acuerdo con Willems, Busscher, Van den Brink y Arts (2018), estos esquemas mentales pueden verse reflejados en los enfoques que usan los administradores para gestionar las organizaciones cotidianamente.

De acuerdo con Senge (1982), para modificar los modelos mentales se requiere llevar estos supuestos básicos a la superficie, aquellos supuestos compartidos por quienes toman las decisiones en la organización; y lo segundo, desarrollar aptitudes de aprendizaje para entender el contexto empresarial y desarrollar un aprendizaje interpersonal que posibilite reflexionar e indagar. Cuando esto sucede [...] la gente de todos los niveles deja aflorar sus modelos mentales y los desafía antes que las circunstancias externas impongan nuevos razonamientos (p. 238). Este proceso, según Covey (2003), trae detrás la noción de cambio de paradigma usada por Thomas Kuhn, que implica rupturas con las tradiciones, con los habituales modos de pensar y con los antiguos paradigmas en los que "alguien finalmente 've' de otro modo" (p. 20) y, por tanto, puede actuar diferente.

La tercera disciplina es la visión compartida (Senge, 1992) que responde a la pregunta ¿qué deseamos crear? Es una imagen que convoca a la gente y crean por ello un vínculo común que embebe a la organización y da pie a la cohesión a través de una aspiración común. La visión compartida crece a partir de las visiones individuales y se hacen compartidas cuando se dan conversaciones permanentes en las que las personas pueden expresar sus sueños y aprender a escuchar los sueños de los demás.

La cuarta disciplina que Senge (1992) formula para que una organización sea inteligente es el aprendizaje en equipo. Este consiste en el proceso de alinearse para crear los resultados que los integrantes del equipo desean. Para lograrlo se requiere plantear la necesidad de pensar agudamente en torno a los problemas complejos, 
aprovechando el potencial de todos integrantes como si fueran uno solo; así mismo, se necesita de una acción innovadora y a la vez coordinada, en la que cada integrante sea consciente de los demás y se comporte de tal forma que se complementen.

Por último, el aprendizaje en equipo requiere de la participación de los miembros en otros equipos de los cuales se aprenda y a los que se aporte lo aprendido. Para Jeong y Shin (2017) "cuando se alienta a los empleados a participar en interacciones sociales, habrá más variaciones, combinaciones y validaciones de ideas para una mayor creatividad organizacional" (p. 910).

La quinta disciplina es la piedra angular de la propuesta de Senge (1992), y se refiere al pensamiento sistémico que integra a las otras cuatro disciplinas mencionadas. Señala el autor que esta es una disciplina para ver totalidades, patrones e interrelaciones en vez de observar imágenes instantáneas o desconectadas. Es un conjunto de principios generales retomados de diversas ciencias y/o profesiones como la física, las ciencias sociales, la ingeniería y la administración de empresas.

Senge (1992) argumenta que el pensamiento sistémico es una disciplina que contribuye a ver las estructuras que subyacen a las situaciones complejas, y que también aporta para comprender los cambios de alto y bajo apalancamiento. Se trata de un cambio de enfoque, ver las totalidades en vez de las partes. Para Senge, la práctica del pensamiento sistémico se inicia con la comprensión del concepto de retroalimentación o feedback, porque permite ver cómo los actos se pueden reforzar o contrarrestarse. De lo que se trata es de aprender a identificar los tipos de estructuras que son recurrentes, ver los patrones más profundos que subyacen a los acontecimientos para intervenir de manera más atinada en los fenómenos.

Por su parte, Nonaka y Takeuchi (1995) proponen el modelo de conversión del conocimiento dentro del proceso de aprendizaje organizacional. De acuerdo con los autores existen dos tipos de conocimiento, el tácito y el explícito; según indican, gran parte del conocimiento organizacional se encuentra en el nivel tácito. Este se refiere al conocimiento que tiene el individuo, pero al que no tiene acceso por medio del lenguaje por lo que usarlo y gestionarlo se hace difícil. El conocimiento tácito puede ser de naturaleza técnica (saber hacer) y cognoscitiva (la representación que se tenga de ese saber, creencias y percepciones arraigadas no necesariamente conscientes, similares a los modelos mentales en Senge [1992]). Por su parte, el conocimiento explícito se puede expresar a través del lenguaje, puede escribirse, formularse y, por lo tanto, intercambiarse y gestionarse; es este tipo de conocimiento que se consigna en los procedimientos, instructivos y manuales, entre otros documentos organizacionales. 
Según el modelo de Nonaka y Takeuchi (1995), el conocimiento puede convertirse o transformarse de cuatro maneras; conocerlas ayuda a gestionarlo para favorecer el aprendizaje organizacional. En primer lugar, se convierte (intercambiar en este caso) de conocimiento tácito a conocimiento tácito, es decir, lo que se conoce como el proceso de socialización. En segundo lugar, puede convertirse de conocimiento tácito a conocimiento explícito, denominado exteriorización para favorecer que sea gestionable racionalmente. La tercera manera es el conocimiento que va de explícito a explícito, llamado combinación. Finalmente, la cuarta forma de conversión del conocimiento es la interiorización que implica que el conocimiento pase de ser explícito a ser tácito, es decir, que el individuo lo aprenda haciéndolo parte de sí. Según Basten y Haamann (2018), la interiorización es un proceso que tiende a estar descuidado en las organizaciones. Para que todos los mecanismos de conversión se den, se requiere conocimiento, sin embargo, solo los de socialización y de interiorización implican la existencia de otra persona distinta de quien tiene el conocimiento para que ocurra.

El modelo propuesto por Crossan, Lane y White (1999) es conocido como el modelo de las cuatro íes, que además plantea cuatro premisas de base. Primero, parte de que el AO envuelve una tensión entre la asimilación de nuevo conocimiento (exploración) y el uso de lo ya aprendido (explotación). Segundo, se asume que el Ao es multinivel: se da desde lo individual, pasando por lo grupal, hasta llegar a lo organizacional, y viceversa. La tercera premisa se refiere a que los tres niveles de AO (individual, grupal y organizacional), están asociados a procesos psicológicos y sociales que son la base del modelo: intuición, interpretación, integración e institucionalización (las cuatro íes), y que están relacionados entre sí.

Por último, en el modelo se considera que la cognición afecta la acción y viceversa: No pueden separarse, ya que el conocimiento es importante para el éxito de la organización, y, de acuerdo con Argyris (2003), esta es la mayor evidencia de aprendizaje, la acción eficaz. El modelo de Crossan, Lane y White (1999) ha contado con complementos propuestos por Zietsma, Winn, Branzei y Vertinski (2002), al agregar dos elementos más, el atender en el nivel individual, y el experimentar en el nivel grupal. Por su parte, Castañeda y Pérez (2005) plantean otros cambios a partir de la teoría cognoscitiva social de Bandura entre los cuales incluyen otros dos elementos: las capacidades humanas - refiriéndose a la capacidad simbólica, previsiva, vicaria y autorreflexiva-, y los procesos individuales que regulan el aprendizaje - la atención, retención, producción y motivación - que pasan a ser grupales a través de la socialización.

Entre los aspectos que se destacan de los modelos presentados se encuentra la interrelación entre los niveles de la organización (individuo, grupo y organización en su 
nivel institucional como tal), el carácter sistémico de los niveles y los componentes, la importancia de la construcción del conocimiento a través de esquemas compartidos que da cuenta de cómo el conocimiento se transforma, y que este pase de ser individual a tener impacto organizacional.

Senge, Smith, Kruschwitz, Laur y Schley (2009) explican que hay tres capacidades básicas de aprendizaje que deben desarrollarse continuamente en las organizaciones y en los individuos, porque son las que brindan una mayor promesa de lograr un cambio sistémico y son ver los sistemas, colaborar a través de fronteras y crear futuros deseados. Añaden que se deben desarrollar juntas porque sin una orientación a la creatividad no se logra un compromiso sobre las visiones de largo plazo, las metas y los resultados deseados. Sin destrezas para colaborar, las personas no logran aprender a desarrollar la inteligencia de los sistemas colectivos, que son los que enfrentan los problemas complejos. Y sin la capacidad de ver los sistemas, las personas y las organizaciones se enfocarán solo en una parte en vez de lograr una comprensión compartida y una visión más grande.

\section{Barreras y facilitadores del aprendizaje}

Cortés Ramírez y Pérez Zapata (2008) exponen que el aprendizaje organizacional requiere comprenderse en su rol estratégico en la dirección de organizaciones y como un elemento previo a la gestión del conocimiento, porque primero se presenta el proceso de aprendizaje y después de generado el conocimiento se gestiona. Para esto es vital considerar las barreras que inhiben el aprendizaje, las cuales pueden servir para sensibilizar y ser intervenidas en las organizaciones con el fin de reflexionar y mejorar la disposición y apertura a los nuevos aprendizajes. Los autores hacen una síntesis de algunas barreras que se exponen en la tabla 1. 
María Alejandra Gómez Vélez, Verónica Andrade Jaramillo

Tabla 1. Barreras para el aprendizaje en las organizaciones

\begin{tabular}{|c|c|c|}
\hline Autor(s) & Barrera & Descripción \\
\hline \multirow{7}{*}{ Senge (1993) } & Yo soy mi puesto & $\begin{array}{l}\text { Hace referencia a cuando los integrantes de una organización se } \\
\text { enfocan en sus propias tareas sin sentirse comprometidos o interesados } \\
\text { con el efecto de sus acciones en otras partes de la organización. No } \\
\text { tener una visión sistémica dificulta el intercambio entre sus integrantes } \\
\text { para que se pueda dar el aprendizaje organizacional. }\end{array}$ \\
\hline & El enemigo externo & $\begin{array}{l}\text { Es frecuente ubicar la culpa de los errores propios en los demás y no } \\
\text { reconocerlos. Esto impide su mudanza y la autorreflexión sobre las } \\
\text { propias acciones, lo cual dificulta el aprendizaje. }\end{array}$ \\
\hline & $\begin{array}{l}\text { La ilusión de hacerse } \\
\text { cargo }\end{array}$ & $\begin{array}{l}\text { Hace referencia a que considerar que responder con agresividad a } \\
\text { las dificultades es proactivo. Esto bloquea el aprendizaje porque la } \\
\text { agresividad puede estar disfrazando la reactividad y una postura } \\
\text { defensiva. }\end{array}$ \\
\hline & $\begin{array}{c}\text { La fijación en los } \\
\text { hechos }\end{array}$ & $\begin{array}{l}\text { Esta barrera ilustra que la atención se puede estar dando solo a lo } \\
\text { inmediato, sin ir más allá de las dificultades evidentes, por lo que se } \\
\text { da un desconocimiento de procesos ocultos que, en el largo plazo, se } \\
\text { traducen en causa de nuevas dificultades. Dicha limitación pone a la } \\
\text { organización en una postura de reactividad que no le permite adoptar } \\
\text { soluciones creativas y comportamientos proactivos ante los problemas. }\end{array}$ \\
\hline & $\begin{array}{l}\text { La parábola de la } \\
\text { rana hervida }\end{array}$ & $\begin{array}{l}\text { Esta parábola representa la incapacidad de ver cambios lentos y } \\
\text { graduales, y estar solo receptivo a los cambios rápidos y agitados. Esta } \\
\text { incapacidad le impide a la organización adoptar las medidas requeridas } \\
\text { para ajustarse y cuando se percata de los cambios ya se le hace } \\
\text { imposible adaptarse, por ser demasiado tarde. }\end{array}$ \\
\hline & $\begin{array}{l}\text { La ilusión de que } \\
\text { se aprende con la } \\
\text { experiencia }\end{array}$ & $\begin{array}{l}\text { Es frecuente que en muchas organizaciones opinen que se aprende } \\
\text { mejor de la experiencia, sin tener en cuenta que no siempre es } \\
\text { posible experimentar directamente las consecuencias de situaciones } \\
\text { o decisiones que pueden tener consecuencias a muy largo plazo. Esta } \\
\text { presunción dificulta la capacidad que necesita la organización de } \\
\text { aprendizaje. }\end{array}$ \\
\hline & $\begin{array}{l}\text { El mito del equipo } \\
\text { administrativo }\end{array}$ & $\begin{array}{l}\text { Hace referencia a la creencia que consiste en concebir al equipo } \\
\text { directivo como personas con todas las capacidades para resolver todos } \\
\text { los tipos de problemas que se presentan en la organización, y es más } \\
\text { fructífero reconocer las propias limitaciones con la finalidad de hacer } \\
\text { frente a los problemas que se plantean y poder aprender de ellos. }\end{array}$ \\
\hline \multirow{2}{*}{$\begin{array}{l}\text { March y Leavitt } \\
\text { citados por } \\
\text { Argyris (1999) }\end{array}$} & $\begin{array}{l}\text { El aprendizaje } \\
\text { supersticioso }\end{array}$ & $\begin{array}{l}\text { Este se refiere a creer que ciertas rutinas o maneras de actuar son las } \\
\text { que permiten alcanzar los resultados deseados, sin que por ello se tenga } \\
\text { ninguna evidencia de que es cierto, pueden incluso existir pruebas de lo } \\
\text { contrario. Esta creencia imposibilita la revisión de tales rutinas e impide } \\
\text { el aprendizaje de la organización. }\end{array}$ \\
\hline & $\begin{array}{l}\text { Las trampas de } \\
\text { competencia }\end{array}$ & $\begin{array}{l}\text { Las personas se muestran resistentes a cambiar las rutinas que dominan, } \\
\text { y a verse en la situación de tener que realizar un esfuerzo para un nuevo } \\
\text { aprendizaje de otras. El tener un alto grado de competencia puede } \\
\text { dificultar un nuevo aprendizaje. }\end{array}$ \\
\hline
\end{tabular}


Aprendizaje organizacional como base de los procesos de cambio

\begin{tabular}{|c|c|c|}
\hline Autor(s) & Barrera & Descripción \\
\hline \multirow[b]{2}{*}{$\begin{array}{c}\text { Geranmayeh } \\
\text { (1992) }\end{array}$} & $\begin{array}{l}\text { El mito de la } \\
\text { infalibilidad }\end{array}$ & $\begin{array}{l}\text { Esta es una la idea que hace referencia a que los directivos no cometen } \\
\text { errores, y que promueve a que no se realicen cuestionamientos a sus } \\
\text { decisiones y acciones, lo que lleva a equivocaciones y, frena el impulso } \\
\text { del aprendizaje y mejoramiento de las organizaciones. }\end{array}$ \\
\hline & Matar al mensajero & $\begin{array}{l}\text { La barrera reside en sancionar a quien da las malas noticias. Es así que } \\
\text { se logra que las personas eviten narrar los fracasos o errores, y esto } \\
\text { lleva a que no se logren identificar las causas, para plantear cambios. } \\
\text { Se constriñe el cuestionamiento y el compartir de las acciones que han } \\
\text { podido posibilitar un aprendizaje. }\end{array}$ \\
\hline \multirow{4}{*}{ Argyris (1993) } & $\begin{array}{l}\text { La incompetencia } \\
\text { calificada }\end{array}$ & $\begin{array}{l}\text { Con frecuencia las personas cometen errores sin ser conscientes de } \\
\text { ellos, no los cuestionan y tampoco son capaces de descubrir qué los ha } \\
\text { llevado a la equivocación. Es así que, en dichos casos, las personas son } \\
\text { incompetentes por aplicar competentemente lo que creen que está bien. }\end{array}$ \\
\hline & $\begin{array}{l}\text { Las rutinas } \\
\text { defensivas }\end{array}$ & $\begin{array}{l}\text { Estas consisten en acciones o prácticas que no les permiten a las } \\
\text { personas o a partes de la organización experimentar miedo o confusión } \\
\text { por lo que no están dispuestos a nuevos modos de proceder. Esto lo } \\
\text { hacen para protegerse de los efectos de situaciones amenazadoras. }\end{array}$ \\
\hline & EI autoengaño & $\begin{array}{l}\text { Hacer el trabajo mal de una manera adecuada (incompetencia } \\
\text { calificada), manteniendo rutinas defensivas, se relaciona con el hecho } \\
\text { de engañarse a sí mismo, al negarse a las inconsistencias derivadas de } \\
\text { las propias acciones. Esto lleva a que culpen a otras personas de ser } \\
\text { las causantes de los equívocos. De este modo, el aprendizaje, tanto } \\
\text { individual como organizativo, no se ve favorecido por no aceptar la } \\
\text { posibilidad de mejorar las propias acciones e inconsistencias. }\end{array}$ \\
\hline & $\begin{array}{l}\text { El malestar } \\
\text { organizativo }\end{array}$ & $\begin{array}{l}\text { Esto sucede cuando el autoengaño es una práctica extendida en la } \\
\text { organización, se crea un clima de malestar generalizado. Si bien la gente } \\
\text { no se siente bien, al mismo tiempo, es incapaz de cambiar la situación } \\
\text { que se presenta en la organización y que se caracteriza por: 1) criticar } \\
\text { a la organización, pero sin aceptar la responsabilidad de corregir los } \\
\text { errores; 2) acentuar lo negativo, minimizando lo positivo; } 3 \text { ) aceptar los } \\
\text { valores que se sabe que son irrealizables, pero actuando como si no lo } \\
\text { fueran. }\end{array}$ \\
\hline \multirow{2}{*}{$\begin{array}{l}\text { Probst y } \\
\text { Büchel (1995) } \\
\text { identificaron } \\
\text { las mismas } \\
\text { barreras que } \\
\text { Argyris (1999) } \\
\text { y agregaron dos } \\
\text { más }\end{array}$} & $\begin{array}{l}\text { Los privilegios y } \\
\text { tabúes }\end{array}$ & $\begin{array}{l}\text { Los privilegios que tienen algunos miembros de la organización pueden } \\
\text { constituir factores de bloqueo del aprendizaje, porque algunos de } \\
\text { ellos manifiestan resistencia para abandonar sus privilegios. De forma } \\
\text { similar, los tabúes en la organización pueden traducirse en resistencia } \\
\text { al aprendizaje. Como ejemplo, se pueden observar algunas normas que } \\
\text { no son cuestionadas por el sentimiento de amenaza e inseguridad que } \\
\text { genera en muchas personas, por lo que no se favorece el aprendizaje de } \\
\text { normas o patrones nuevos de comportamiento. }\end{array}$ \\
\hline & $\begin{array}{l}\text { La patología de la } \\
\text { información }\end{array}$ & $\begin{array}{l}\text { Un tratamiento deficiente de la información puede conducir a la toma } \\
\text { de decisiones equivocadas, o bien, a la adopción de comportamientos } \\
\text { que no son apropiados, por el hecho de no contar con una base de } \\
\text { conocimiento suficiente o más preciso de la realidad. Con cierta } \\
\text { frecuencia, los bloqueos al aprendizaje se derivan de la falta de } \\
\text { capacidad para manejar la información. }\end{array}$ \\
\hline
\end{tabular}




\begin{tabular}{|c|c|c|}
\hline Autor(s) & Barrera & Descripción \\
\hline $\begin{array}{c}\text { Lounamaa y } \\
\text { March (1987) }\end{array}$ & $\begin{array}{l}\text { El dilema del } \\
\text { aprendizaje }\end{array}$ & $\begin{array}{l}\text { Consiste en pensar que resolver problemas de corto plazo solucionará } \\
\text { los de largo plazo sin proyectar estratégicamente las acciones al futuro. }\end{array}$ \\
\hline \multirow{3}{*}{$\begin{array}{c}\text { Watkins y } \\
\text { Marsick (1993) }\end{array}$} & $\begin{array}{l}\text { La incapacidad } \\
\text { aprendida }\end{array}$ & $\begin{array}{l}\text { Hace referencia a las situaciones que se caracterizan por la total } \\
\text { pasividad y desmotivación de los individuos ante las oportunidades de } \\
\text { aprendizaje. Esto sucede con frecuencia cuando durante mucho tiempo } \\
\text { los individuos han sido acostumbrados a no tomar iniciativas propias, } \\
\text { o incluso han sido reiteradamente recompensados por no asumir } \\
\text { responsabilidades o castigados por tomarlas. }\end{array}$ \\
\hline & La visión de túnel & $\begin{array}{l}\text { Se identifica con la propia incapacidad para verse a sí mismo o ver una } \\
\text { situación desde un punto de vista sistémico y actuar en consecuencia. } \\
\text { Las personas son conscientes de su propia perspectiva, pero no de la } \\
\text { complejidad de la situación en su conjunto. }\end{array}$ \\
\hline & $\begin{array}{l}\text { El aprendizaje } \\
\text { truncado }\end{array}$ & $\begin{array}{l}\text { Esto sucede en situaciones en las que el proceso de aprendizaje } \\
\text { es interrumpido o solo parcialmente implantando. Ocurre en } \\
\text { organizaciones que no han asumido su necesidad real de aprender y } \\
\text { realizan operaciones de "maquillaje" que incorporan pequeños cambios, } \\
\text { pero sin llegar a implicarse de forma profunda para cambiar en lo } \\
\text { que requieren hacer de forma radical. Esta forma imposibilita que el } \\
\text { proceso de aprendizaje se logre al más alto nivel. }\end{array}$ \\
\hline $\begin{array}{l}\text { Van de Ven y } \\
\text { Polley citados por } \\
\text { Argyris (1999) }\end{array}$ & Suavizar la verdad & $\begin{array}{l}\text { Es cuando los implicados en el proceso presentan unas proyecciones } \\
\text { más optimistas de lo real, con el objetivo de no enfrentar } \\
\text { cuestionamientos que obstaculicen el proceso en curso, conduciendo } \\
\text { a situaciones que limitan el aprendizaje por seguir desconociendo la } \\
\text { situación real y dejarse orientar por percepciones erróneas. }\end{array}$ \\
\hline
\end{tabular}

Fuente: adaptado de Pérez Zapata y Cortés Ramírez (2007)

Para mencionar algunos facilitadores del aprendizaje, se consideró apropiado retomar las propuestas de autores como Gagné (1985), Vall (1996) y Driscoll (2002), respecto al aprendizaje desde el nivel individual, y algunos elementos del modelo de generación y generalización de ideas con impacto de Yeung, Ulrich, Nason y Von Glinow (1999) que aportan aspectos para facilitar el aprendizaje organizacional propiamente dicho.

Gagné (1985), centrado en el enfoque cognoscitivo del aprendizaje, ha aportado a la comprensión sobre la manera en que se recibe, se procesa y se estructura la información en el sistema de la memoria de las personas, lo que lleva finalmente al aprendizaje, a través de cinco fases (véase tabla 2). Esta explicación sobre el aprendizaje es un modelo híbrido del conductismo y el cognoscitivismo que se propone para entender cómo se aprende y cómo se pueden tomar decisiones cuando se van a realizar las acciones para la formación y modificación del comportamiento o el desarrollo de habilidades. 
Tabla 2. Fases del proceso de aprendizaje de Robert Gagné

\begin{tabular}{cl}
\hline Fases & \multicolumn{1}{c}{ Descripción } \\
\hline Motivación & $\begin{array}{l}\text { Es la fase inicial que consiste en crear una expectativa que mueva al aprendizaje; esta } \\
\text { expectativa puede tener un origen externo o interno. }\end{array}$ \\
\hline Comprensión & $\begin{array}{l}\text { Se denomina así a la atención de quien aprende sobre lo que es importante, y consiste } \\
\text { en el proceso de percepción de aquellos aspectos que ha escogido y que le interesa } \\
\text { aprender. }\end{array}$ \\
\hline Adquisición y retención & $\begin{array}{l}\text { Marca la transición del no-aprendizaje al aprendizaje. Se refiere a lo que la persona ha } \\
\text { decidido almacenar como información importante para sí. }\end{array}$ \\
\hline Recuerdo y transferencia & $\begin{array}{l}\text { Estas son las fases del perfeccionamiento del aprendizaje. El recuerdo hace viable } \\
\text { que la información se recupere y la transferencia posibilita que se pueda generalizar } \\
\text { lo que se ha aprendido y se pueda transmitir la información aprendida a diversos } \\
\text { contextos y otros intereses. }\end{array}$ \\
\hline Respuesta y & $\begin{array}{l}\text { La fase de respuesta concierne al momento del desempeño, que se establece como } \\
\text { un parámetro vital del aprendizaje. La retroalimentación reside en el proceso } \\
\text { de confrontación entre las expectativas y lo alcanzado en el aprendizaje. Así el } \\
\text { aprendizaje se verifica, afirma, corrige y avanza. }\end{array}$ \\
\hline
\end{tabular}

Fuente: adaptado de Gottberg de Noguera, Noguera Altuve y Noguera Gottberg (2012)

El enfoque cognoscitivo piensa el aprendizaje como un proceso activo que logra modificar el sistema cognoscitivo de las personas con el objetivo de generar un cambio en el comportamiento o en sus habilidades. De lo que se trata es de crear formas nuevas para el aprendizaje que se enfoque en quien aprende, al permitir mayor libertad y participación, estimulando el recuerdo, proporcionando retroalimentación y favoreciendo el aprendizaje. Esto, aplicado al marco de las organizaciones, implicaría el involucramiento en los procesos en los que se pretende aO donde se pongan en juego las capacidades y se cuente con retroalimentación.

Para Vaill (1996), en el ritmo actual de cambio y turbulencia, se necesita un proceso de aprendizaje que incorpore múltiples aspectos del ser como lo cultural, lo emocional, lo recreativo y lo espiritual. Para ello, sugiere considerar siete maneras diferentes de aprender, lo que resultan modos de ser respecto al aprendizaje: el aprendizaje autodirigido, el creativo, el expresivo, el aprendizaje donde se siente aprendiendo, el aprendizaje en línea, el continuo y el reflexivo.

El primero es el aprendizaje autodirigido, que está en contraste con el adoctrinamiento masivo, rígido y estructurado. Una autodirección sistemática es crucial para comprender los problemas que deben abordarse y que el aprendizaje aporta en el proceso de resolverlos. Este primer aspecto plantea la entrada a los otros seis procesos formativos, que son clave. Este tipo de aprendizaje puede relacionarse con la primera disciplina de Senge (1992), el dominio personal. 
Un segundo modo de aprender es el aprendizaje creativo, entendido como un proceso de aprendizaje exploratorio e inventivo que se permite nuevos caminos para hacer las cosas. La tercera manera es el aprendizaje expresivo, que se refiere a la experimentación en contexto pudiendo mostrar las capacidades con las que se cuenta. Vaill (1996) argumenta que en la experimentación real hay un encuentro con la complejidad, dado que no se sabe lo que va a suceder y se tiene la posibilidad de mirar cómo las diferentes partes de los procesos de aprendizaje se relacionan entre sí y con el todo. El cuarto modo de aprendizaje es sentirse aprendiendo; este valida sentimientos como la curiosidad, la paciencia, el coraje, la incertidumbre, la autoestima y el sentido de control que surgen en el proceso de aprendizaje, y así, se reconoce que hacen parte de la experiencia, además por colocar en duda una falsa dicotomía entre lo cognitivo y lo afectivo respecto al hecho de aprender.

El quinto modo es el aprendizaje en línea referido a que no requiere estar circunscrito a espacios exclusivamente formales o institucionalizados. En la actualidad, el aprendizaje se produce a través de comunidades de práctica, redes personales, y por medio de la realización de las tareas laborales en los puestos de trabajo.

Por su parte, el aprendizaje continuo (Vaill, 1996) se refiere a que aprender es un proceso continuo de toda la vida, que ocurre constantemente en medio del trabajo y las demás dimensiones de la vida por lo que todas estas pueden aportar a ello. Y, por último, el aprendizaje reflexivo, que significa pensar en el propio proceso de aprendizaje (Vaill, 1996), qué se aprende, cómo se aprende, qué se quiere aprender, qué no se conoce, etc.

Vaill (1996) sustenta que el aprendizaje debe lograr constituirse como una forma de ser, como un conjunto permanente de actitudes y acciones que las personas y los colectivos utilizan para tratar de mantenerse al tanto de las circunstancias y situaciones sorpresivas, novedosas, caóticas, inevitables y recurrentes. En esta medida, las necesidades y los modelos de aprendizaje organizacional estarían orientados a reflejar cada vez más la importancia de innovar, aprender y reinventarse continuamente, y evitar la sanción sobre la manifestación del error derivado de la creatividad y la experimentación.

La tolerancia al error puede promoverse al vincular la evaluación del desempeño, la gestión de la información y la retroalimentación al trabajo, porque permite dar cuenta del proceso y reduce situaciones intempestivas (Edwards, 2017), dando confianza para trabajar de manera creativa. De acuerdo con Weinzimmer y Esken (2017) tolerar el error y usarlo para aprender a nivel organizacional, favorece el desempeño organizacional por lo que es recomendable tratar de gestionar dentro de la cultura organizacional que esto ocurra. 
Para Driscoll (2002), por su parte, aprender se produce como resultado de la experiencia de quien aprende y de su interacción con el mundo. Este resultado puede ser perdurable y se obtiene a través de las experiencias e interacciones con información o con otras personas. El autor realiza la pregunta acerca de cómo las personas aprenden, y para responderla plantea cuatro principios generales que dan un marco que facilita el proceso de instrucción: se aprende en contexto, se requiere acción -involucrarse-, se desarrolla de manera social y es un proceso reflexivo derivado de la retroalimentación.

El primer principio que plantea Driscoll (2002) es que el aprendizaje ocurre en contexto, es decir que, sin un contexto apropiado, la comprensión y el aprendizaje son difíciles, y es poco probable que se tenga éxito. Señala que cuando las personas están aprendiendo tratarán de darle sentido a cualquier cosa que no les resulte familiar, y para hacerlo van a recurrir a experiencias y conocimientos previos. Sin un contexto apropiado los significados que construyen pueden ser diferentes de lo que se pretende aprendan.

Acerca del segundo principio, señala Driscoll (2002) que el aprendizaje es activo, haciendo énfasis en la importancia de involucrar mentalmente a quienes están en las actividades de aprendizaje con la finalidad de que se generen conexiones entre lo que ya saben y lo que se les pide que aprendan para poder, paulatinamente, ir construyendo el significado a partir de sus experiencias, y se conviertan en participantes activos en el proceso de construcción del conocimiento. Este enfoque del aprendizaje pasa de cubrir el contenido de lo que se quiere enseñar a que quienes están aprendiendo trabajen con sus ideas.

El tercer principio señala que el aprendizaje es social, es decir que aprender equivale a aumentar la participación y la contribución en las prácticas de una comunidad social. Significa que una visión social del aprendizaje centra la atención en establecer conexiones entre los aprendices y la comunidad en general. Así, la construcción de conocimiento, el aprendizaje y la tutoría se vuelven primordiales porque se concibe a los aprendices bajo la tutela de compañeros o instructores más experimentados (Driscoll, 2002).

El cuarto y último principio consiste en que el aprendizaje es reflexivo. Driscoll (2002) plantea que el aprendizaje se facilita cuando los aprendices obtienen retroalimentación sobre su pensamiento, ya sea que provenga de sí mismo o de otros, porque esto les brinda la oportunidad de revisión y observación, lo que conduce a alcanzar niveles más altos de aprendizaje y de entendimientos más profundos. 
Sobre los aspectos que facilitan el aprendizaje en el nivel organizacional propiamente, se pueden retomar las dos primeras dimensiones del modelo para la capacidad del AO de Yeung, Ulrich, Nason y Von Glinow (1999), generación y generalización de ideas; la tercera dimensión se refiere a incapacidades para aprender, que ya fueron trabajadas iniciando este apartado. La generación de ideas se refiere a modos que pueden promoverse para que se produzca nuevo conocimiento, para luego ser expandido y absorbido por toda la organización. Lo anterior, mediado además por las características de la cultura organizacional (Yeung et al., 1999; Edwards, 2017; Basten y Haamann, 2018).

Dentro de los modos para generar ideas, o lo que los autores llaman estilos de aprendizaje, se encuentran la experimentación, la adquisición de competencias, la referenciación o benchmarking, y el mejoramiento continuo. La experimentación se refiere a que los trabajadores de la organización se atreven a buscar nuevos caminos para llevar a cabo las actividades y conseguir las metas; está relacionada con organizaciones innovadoras, y para que se dé este estilo se requiere contar con los sistemas de recompensa, comunicación, recursos económicos de la organización, e incluso la misma práctica gerencial y una cultura organizacional que la favorezca.

La adquisición de competencias se refiere a que la organización adquiera competencias nuevas según sus necesidades, a través del desarrollo de estas por parte de los individuos y grupos que se encuentran dentro, o con la contratación de personas que las hayan desarrollado, asociadas siempre a la planeación estratégica, buscando conectar lo que se quiere que la organización aprenda para el cambio que se está buscando hacer.

Las organizaciones que tienen el estilo de aprendizaje de referenciación dan evidencia de aprender de otras organizaciones, implementar nuevos procesos y productos solo hasta que han sido completamente probados, aprender de los desarrollos, conocimientos y actividades específicas llevadas a cabo por otras organizaciones, y referenciarse con las organizaciones consideradas competencia.

Por último, el estilo de aprendizaje continuo se encuentra en las organizaciones que priorizan los sistemas de gestión, que se destacan por la revisión y seguimiento a todos los procesos organizacionales; procuran mejorar las maneras de realizar el trabajo hasta que sea óptimo y medirse a sí mismos con base en su desempeño anterior. Identificar el o los estilos de aprendizaje de la organización y promoverlos de manera sistemática ayudará a que la generación de ideas sea una constante.

Para generalizar las ideas, es decir, lograr que lleguen a toda la organización y tengan impacto en ella desde el AO, Yeung et al. (1999) recomiendan considerar cinco 
principios: reconocer la existencia de límite o fronteras para la organización, anclar las ideas a la estrategia, pensar de manera contingente, concatenar las ideas e impactar. La existencia de límites se refiere a reconocer los límites de distinta naturaleza que pueden favorecer o no que el conocimiento se generalice en la organización, entre ellos está el tiempo, la jerarquía, la división entre las áreas, el nivel de conexión y relaciones de la organización con el entorno y los límites geográficos.

Anclar las ideas a la estrategia se trata de que las ideas que se generen apunten a fomentar la estrategia organizacional para que tengan impacto, si no, sencillamente serán buenas ideas, pero transitorias, con poco efecto. El pensamiento contingente consiste en considerar el contexto en el que se encuentra embebida la organización en el momento, durante y después de la implementación de las nuevas ideas. Este tipo de pensamiento facilita la adaptación de la organización al medio cambiante, implica imaginar escenarios posibles de acuerdo con las decisiones que se lleven a cabo para tomar las medidas necesarias para su funcionamiento. Este principio es similar al pensamiento sistémico que propone Senge (1992) como quinta disciplina.

Concatenar las ideas se relaciona con que las capacidades más importantes de la organización vayan más allá de experimentos aislados, tratando de implementar medidas conectadas entre sí basadas en necesidades organizacionales, que cobren sentido a través del seguimiento y la relación con el funcionamiento de la organización.

Por último, el impacto se refiere al hecho de llevar el conocimiento a la acción, aplicar las ideas novedosas o renovadas que la organización desarrolló u obtuvo a través de su particular estilo de aprendizaje. Para ello se requieren modificaciones en distintos niveles que los autores listan principalmente desde aspectos formales como los sistemas de recompensa, entrenamiento, capacitación, evaluaciones de desempeño, medios de comunicación de la información y tecnología que sea necesaria de acuerdo con lo requerido. Para Edwards (2017), entre más rígidas sean las estructuras organizacionales, menos se promoverá el aprendizaje organizacional, por lo que promover su flexibilización para que funcionen distinto puede ser la clave (Willems, Busscher, Van den Brink y Arts, 2018).

Además de los aspectos formales, para lograr que el conocimiento generado se vuelva de carácter organizacional y beneficie a la organización, se hace vital considerar aspectos de naturaleza informal como son las relaciones de poder asociadas a las jerarquías (Collien, 2018), ya que pueden reproducir estructuras de dominación en el nivel micro o individual, que favorecen o desfavorecen el proceso de AO. En este mismo sentido, Valentine (2017) destaca la importancia del rol de quienes dirigen o administran las organizaciones para estos efectos, ya que si ellos cuentan con claridad sobre hacia dónde se dirige la organización, qué necesita cambiar y por tanto qué 
requiere aprender, pueden reconfigurar su manera de gestionar y dirigir, e impactar positivamente en la dirección deseada.

\section{Algunas conclusiones}

Para favorecer cambios organizacionales profundos y duraderos que les permitan a las organizaciones mantenerse motivados en tiempos de incertidumbre como los actuales, es necesario gestionar la capacidad de estas para aprender, considerando no solo aspectos del nivel organizacional propiamente, sino también del nivel grupal y del individual. El aprendizaje organizacional implica que el conocimiento y la experticia de naturaleza individual pase a ser de dominio organizacional e impacte toda la organización en función de sus objetivos estratégicos. En este proceso no solo se beneficia la organización, sino también las personas que aprenden en su interior, ya que siguen en desarrollo y pueden ver directamente las implicaciones de su hacer a través de un trabajo cualificado.

Los tiempos de crisis, gestionados adecuadamente y acompañados por la gestión de los recursos humanos, son una excelente oportunidad para la creatividad y la innovación, lo que puede marcar la diferencia para una organización respecto a su permanencia o visibilización en el mercado. Es fundamental reconocer que el aprendizaje organizacional es un proceso que hace posible el cambio, en el que la adaptación a la incertidumbre hace efectivo el desarrollo de renovadas capacidades orientadas al mejoramiento organizacional y brinda el ambiente para la creación de nuevas oportunidades.

Se trata de promover organizaciones inteligentes que reconozcan la urgencia de incentivar un modo de pensamiento sistémico para alentar y fortalecer unas relaciones que son necesariamente interdependientes; buscar formas de aprendizaje enfocadas en quien o quienes aprenden, permitir una mayor autonomía y participación, en las que se promueva la retroalimentación asertiva y se estimule el aprendizaje.

Lo anterior, considerando que las personas aprenden cuando le encuentran sentido a lo que están aprendiendo y logran vincularlo con conocimientos anteriores, se involucran activamente en el proceso, cuentan con retroalimentación sobre lo interiorizado, pueden pensar de manera creativa sin ser sancionados, se potencian los espacios formales e informales para el aprendizaje, se valoran todas las dimensiones de la vida además del trabajo como fuentes de aprendizaje y crecimiento personal, se promueve la interacción con otros, dentro y fuera del trabajo como fuente de creación y espacio de compartir conocimiento, y se tiene la oportunidad de reflexionar sobre sus propios procesos de aprendizaje a través de la retroalimentación. 
Se podría decir que la capacidad de las organizaciones para aprender está determinada por la forma en que construyen ventajas competitivas que persistan en el tiempo, y para ello requieren propiciar un ambiente en el que converjan las competencias individuales que multipliquen el conocimiento, la visión compartida que alienta la acción colectiva, la renovación de los modelos mentales que se recrean ante los nuevos conceptos, el trabajo colaborativo que produce las sinergias que multiplican las opciones, el pensamiento sistémico que va más allá de lo superficial e identifica lo estructural, y el liderazgo que se renueva en posturas más enfocadas al desarrollo. Solo así se hace realidad el aprendizaje organizacional que permita a las organizaciones redefinirse en los momentos de crisis y disponerse continuamente para el cambio y la innovación.

\section{Referencias}

Acosta, C. (2002). Cuatro preguntas para iniciarse. Revista Colombiana de Psicología, 11, 9-24.

Ahumada, L. (2002). El aprendizaje organizacional desde una perspectiva evolutiva y constructivista de la organización. Revista de Psicología, XI(1),139-148.

Andrade, V. (2008). Aprendizaje Organizacional en un ingenio azucarero del Valle del Cauca, reconocido y autopercibido como exitoso [trabajo de grado de maestría Universidad del Valle].

Angulo, R. (2017). Gestión del conocimiento y aprendizaje organizacional: una visión integral. Informes Psicológicos, 17(1), 53-70.

Argyris, C. (2001). Sobre el aprendizaje organizacional. Oxford University Press.

Argyris, C. (2003). A life full of learning. Organization Studies, 24(7), 1178-1192.

Avgar, A., Eaton, A., Kolins, R. y Seth, A. (2020). Paying the price for a broken healthcare system: Rethinking employment, labor, and work in a post-pandemic world. Work and Occupations, 47(3), 1-13. https://doi.org/10.1177/0730888420923126

Basten, D. y Haamann, T. (2018). Approaches for organizational learning: A literature review. Sage Open, jul.-sep., 1-20. doi.org/10.1177/2158244018794224

Castañeda, D. y Pérez, A. (2005). ¿Como se produce el aprendizaje individual en el aprendizaje organizacional? Revista Interamericana de Psicología Ocupacional, 24, 1-15.

Collien, I. (2018). Critical-reflexive-political: Dismantling the reproduction of dominance in organisational learning processes, Management Learning, 49(2), 131 -149.

Cortés Ramírez, J. y Pérez Zapata, J. (2008). El aprendizaje organizacional: reflexión desde la investigación aplicada en el grupo de estudios empresariales. Cuadernos de Administración, (39), 29-36. http://www.redalyc.org/pdf/2250/225020360003.pdf

Covey, S. (2003). Los 7 hábitos de la gente altamente efectiva: la revolución ética en la vicia cotidiana y en la empresa. Paidós.

Crossan, M., Lane, H. y White, R. (1999). An Organizacional Learning framework: From intuition to institution. Academy of Management Review, 24(3), 522-537. 
Driscoll, M. P. (2002). How people learn (and what technology might have to do with it). ERIC Digest, 1, 8. https://files.eric.ed.gov/fulltext/ED470032.pdf

Edwards, M. (2017). An organizational learning framework for patient safety. American Journal of Medical Quality, 32(2), 148-155. https://doi.org/10.1177/1062860616632295

Elliott, I. (2020). Organisational learning and change in a public sector context. Teaching Public Administration, 38(3), 270-283. https://doi.org/10.1177/0144739420903783

Gagné, R. (1985). Las condiciones del aprendizaje. 4. ${ }^{\text {a }}$ edición. McGraw-Hill.

García-Rubiano, M. y Forero-Aponte, C. (2016). Calidad de vida laboral y la disposición al cambio organizacional en funcionarios de empresas de la ciudad de Bogotá-Colombia. Acta Colombiana de Psicología, 19 (1), 79-90. http://www.scielo.org.co/pdf/acp/v19n1/ es_v19n1a05.pdf

Garzón, M. y Fisher, A. (2008). Modelo teórico de aprendizaje organizacional. Revista Científica Pensamiento y Gestión (24), 195-224.

Gottberg de Noguera, E. Noguera Altuve, G. y Noguera Gottberg, M. (2012). El aprendizaje visto desde la perspectiva ecléctica de Robert Gagné y el uso de las nuevas tecnologías en educación superior. Universidades (53), 50-56.

International Organisation of Employers e International Trade Union Confederation. (2020). Joint statement on Covid-19. https://www.ilo.org/wcmsp5/groups/public/---ed_dialogue/---actrav/documents/genericdocument/wcms_739522.pdf

Jeong, I. y Shin, S. (2017). High-performance work practices and organizational creativity during organizational change: A collective learning perspective. Journal of Management, 45(3), 909 -925. https://doi.org/10.1177/0149206316685156

Jyoti, J., Chahal, H. y Ranl, A. (2017). Role of organizational learning and innovation in between high-performance HR practices and business performance: A study of telecommunication sector. Vision, 21(3), 259-273. https://doi.org/10.1177/0972262917716766

Martínez Villaverde, L. (2006). Gestión del cambio y la innovación en la empresa. Un modelo para la innovación empresarial. Ideas Propias Editorial.

Montealegre, J. y Calderón, G. (2007). Relationships between attitude towards change organisational culture: A study of medium - and large - scale clothing industry companies in Ibagué, Colombia. Innovar, 17(29), 49-70.

Nonaka, I. y Takeuchi, H. (1995). The knowledge-creating company: How Japanese companies create the dynamics of innovation. Oxford University Press.

Nonaka, I. y Takeuchi, H. (1999). La organización creadora de conocimiento. Cómo las compañias japonesas crean la dinámica de la innovación. Oxford University Press.

Ordóñez, R. (2010). Cambio, creatividad e innovación. Desafíos y respuestas. Granica.

Pérez Zapata, J. y Cortés Ramírez, J. A. (2007). Barreras para el aprendizaje organizacional: estudio de casos. Pensamiento \& Gestión, 22, 256-282.

Perlo, C. L. y De la Riestra, M. del R. (2005). Enfoques y perspectivas del aprendizaje organizacional. Acerca de las posibilidades de concebir la organización como entidades 
que aprenden. XII Jornadas de Investigación y Primer Encuentro de Investigadores en Psicología del Mercosur. Facultad de Psicología-Universidad de Buenos Aires, Buenos Aires.

Ramírez Arango, J. S. (2007). El liderazgo del cambio en periodos de crisis. Panorama.

Senge, P. (1992). La quinta disciplina. El arte y la práctica de la organización abierta al aprendizaje. Ediciones Juan Granica.

Senge, P. (1995). La quinta disciplina: cómo impulsar el aprendizaje en la organización inteligente. Ediciones Granica.

Senge, P., Smith, B., Kruschwitz, N., Laur, J. y Schley, S. (2009). La revolución necesaria. Cómo individuos y organizaciones trabajan por un mundo sostenible. Norma.

Swicringa, J. y Wierdsma, A. (1995). La organización que aprende. Adison-Wesley Iberoamericana.

Shukla, A., Kumar, S. y Dubey, A. (2018). Determinants of organizational learning in a firm: An empirical analysis of Indian IT industry. Global Business Review, 21(3) 1-14. https:// doi.org/10.1177/0972150918779162

Vaill, P. B. (1996). Learning as a way of being: strategies for survival in a world of permanent white water. CA, Jossey-Blass Inc.

Valentine, M. (2017). Renegotiating spheres of obligation: The role of hierarchy in organizational learning. Administrative Science Quarterly, 63(3), 570-606, https://doi. org/10.1177/0001839217718547

Weinzimmer, L. y Esken, C. (2017). Learning from mistakes: How mistake tolerance positively affects organizational learning and performance. The Journal of Applied Behavioral Science, 53(3) 322-348. https://doi.org/10.1177/0021886316688658

Willems, J., Busscher, T., Van den Brink, M. y Arts, J. (2018). Anticipating water infrastructure renewal: A framing perspective on organizational learning in public agencies. Environment and Planning, Politics and Space, 36(6), 1088-1108. https://doi. org/10.1177/2399654417733993

Yeung, A., Ulrich, D., Nason, S. y Von Glinow, M. A. (1999). Organizational learning, capability, generating and generalizing ideas with impact. Oxford University Press.

Zietsma, C., Winn, M., Branzei, O. y Vertinsky, I. (2002). The war of the woods: Facilitators and impediments of organizational learning processes. British Journal of Management, 13, 61-74. 


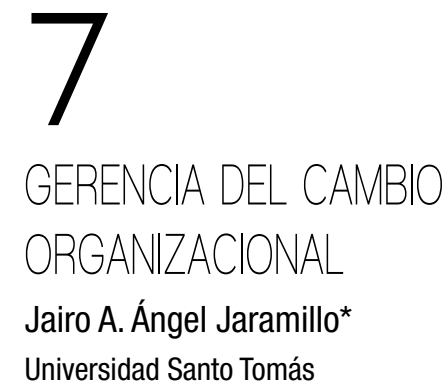

Como es ampliamente conocido, el cambio es la única constante que existe en muchas de las situaciones de la vida; en la naturaleza, en los seres vivos y, por supuesto, en nosotros los humanos. Esta constante de cambio se manifiesta claramente en las instituciones, concebidas como "un acuerdo deliberado de personas para llevar a cabo un propósito específico", que se comporta como un

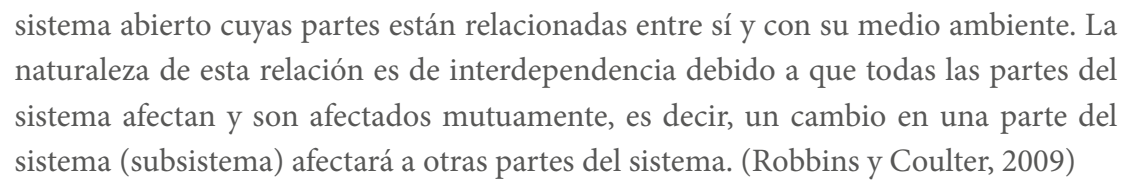

Con base en lo anterior, el presente capítulo busca ofrecer una visión panorámica sobre la gerencia del cambio organizacional, como tendencia de estudio, que pueden constituirlo en sí mismo como una disciplina con objeto de estudio propio, con teorías explicativas e investigaciones alrededor del cambio organizacional y su manejo, desde la psicología y la administración, principalmente.

De esta forma, el capítulo contará con una breve introducción al tema y posteriormente con la exposición de 23 modelos de gerencia del cambio organizacional, que complementan el capítulo 5 de este libro, en el que se presenta una mirada amplia sobre el cambio organizacional, el cual se traduce en las estrategias específicas de implementación de cambio (gerencia del cambio), expuestos en este capítulo. Este es un tema de alto interés, en parte por las tendencias del conocimiento que propone

jairoangel@usantotomas.edu.co

${ }^{*}$ https://orcid.org/0000-0002-7340-9371 
un determinado campo de "moda", pero más importante, debido a que es uno de los planteamientos que mejor engloba conceptos efectivos de la psicología organizacional y de la administración en función de un efectivo mejoramiento de la organización.

Una de las dos grandes fuentes teóricas que sustentan la gerencia del cambio surge de la administración, tal como lo desarrolla el primer capítulo del libro, que nace en la relación de convivencia entre los seres humanos con sus semejantes y buscando satisfacer sus necesidades de alimentación, vivienda, seguridad, vestido, etc., ha creado grupos que conforman comunidades, las cuales necesitan organizarse para optimizar los recursos y capacidades de sus integrantes (Pinto, 2012).

En este marco, Robins (2009) clasifica las organizaciones desde cuatro enfoques: el clásico, que enfatiza en la racionalidad y la eficiencia (Taylor, Fayol y Weber); el cuantitativo, que se basa en la aplicación de la estadística, como los encaminados a la calidad (Deming); el conductual (más relacionado con la psicología) que estudia el comportamiento organizacional (Owen, Munsterberg, Follett y Barnard) y el contemporáneo, que integra administración y psicología en un marco sistémico, atendiendo tanto el interior de la organización, como su entorno, junto con una mirada del enfoque de contingencias o situacional que no acepta reglas universales, sino respuestas a contextos específicos (Segredo, 2016). Similar clasificación ofrece Kreps, con base en su diseño de organización, agrupándolas en explotador autoritario, benévolo, consultivo y participativo (Kreps, 1995).

El segundo gran pilar de la gerencia del cambio se encuentra en la psicología, particularmente en la psicología organizacional y del trabajo (РОт), que busca ubicar el acople organización-individuo, para que ambos se beneficien a partir de expectativas y metas comunes; es decir el ajuste entre las condiciones de las organizaciones (trabajos) y las características de las personas (Borman, Klimoski e Ilgen, 2003). Este ajuste está influenciado por factores originados en la interacción dinámica entre las personas y la organización, así como por las fuerzas evolutivas a las que están sometidos ambos (Schneider, 1987 citado por Borman, Klimoski e Ilgen, 2003), en concordancia con Pineda (2017), citado en el primer capítulo del presente libro.

Según Robbins y Coulter (2009), la comprensión del comportamiento organizacional (co) aborda el estudio de la administración centrándose en los recursos humanos de la organización, ocupándose de las acciones (conductas) de las personas en el trabajo, denominándolo co y dando origen a la administración de los recursos humanos y a amplios estudios sobre motivación, liderazgo, confianza, trabajo en equipo y manejo de conflictos. En este enfoque se ve la gente como el activo más importante de las organizaciones y en consecuencia debe ser administrada, desarrollando técnicas de selección, programas de motivación, manejo del clima organizacional, etc. En la figura 1 se resumen las ideas más importantes de estos primeros defensores. 
En la óptica de la gerencia, y derivada de la disciplina de la administración, aparece el estudio del comportamiento organizacional que se centra en los recursos humanos de la organización, ocupándose de las acciones (conductas) de las personas en el trabajo, denominándolo también co, a lo cual Robbins y Coulter (2009) indican que da origen a la administración de los recursos humanos y a amplios estudios sobre motivación, liderazgo, confianza, trabajo en equipo y manejo de conflictos. En este enfoque se ve la gente como el activo más importante de las organizaciones y en consecuencia debe ser administrada, desarrollando técnicas de selección, programas de motivación, manejo del clima organizacional, etc. En la siguiente figura se resumen las ideas más importantes de estos primeros defensores del co:

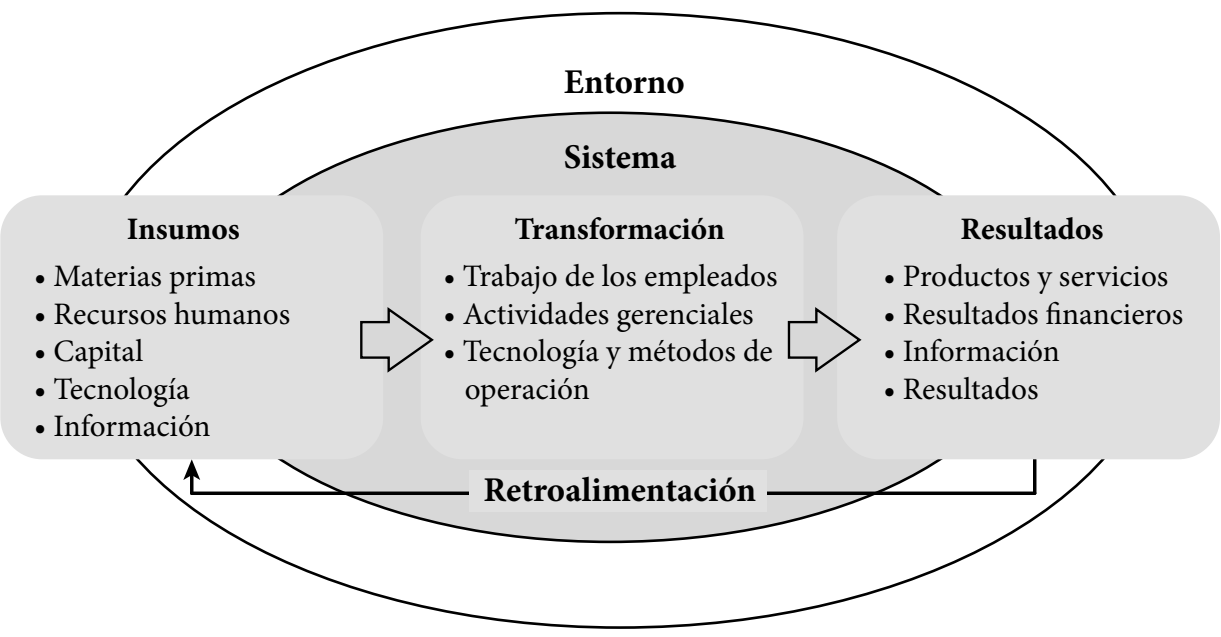

Figura 1. Organización como sistema abierto

Fuente: Robbins y Coulter (2009)

En este punto, hablar de gerencia es hablar de creación de valor, comprendido como el principio de animación de la gestión moderna y su principal responsabilidad, e implica un cambio importante en la mentalidad de la administración de los recursos que entran a la organización (entradas) para administrar el rendimiento (resultados), y que refleja una visión de qué es el rendimiento y cómo actúan las organizaciones (Magretta, 2012). Crear valor es el deber primordial de la administración, ya que subraya el cambio de gestión de recursos a la gestión de resultados o desempeño de la organización. El valor es lo que se obtiene a cambio de lo que se paga y puede verse desde diferentes ópticas.

Desde la década de 1960, dos escuelas de pensamiento sobre administración competían entre sí: la escuela de planificación que se basó en procedimientos formales, 
formación formal, análisis formal y una gran dosis de cuantificación y su hipótesis subyacente era que una estrategia podía ser conjunta y trabajar de la misma manera que una máquina, lo cual condujo a la creación de departamentos de planificación estratégica en las organizaciones, que reportan directamente al gerente general, cuya función era aprobar el plan de los planificadores (Burnes, 2004).

Existen diferentes posiciones teóricas para explicar la base sobre la cual se desenvolvió el desarrollo organizacional (DO) $)^{1}$, las cuales se pueden agrupar en tres grandes categorías: el enfoque individual (teoría del cambio de Maslow y la teoría de los dos factores de Herzberg), el enfoque de grupos-T (Lewin, Argyris y Bion) y el enfoque total de sistemas (Likert, Lorenzo y Lorsch y Levinson) que trasciende hasta el día de hoy y se practica en todo el mundo, con variadas metodologías de intervención en respuesta a la globalización y la tecnología de la información (Dotse, Okyireh y Kumako, 2015; McGill, 1974).

\section{Gerencia del cambio}

French (1999) define la gerencia del cambio como "un sistema de cambio planeado, soportado en el conocimiento de la ciencia del comportamiento, que apunta a procesos humanos y sociales de las organizaciones (específicamente los sistemas de creencias de individuos, grupos de trabajo, o cultura), con la intención de fortalecer la capacidad de adaptación y renovación de las organizaciones" (French, 1999), mientras que Burnes (2004) indica que la gerencia del cambio no es una disciplina con límites rígidos y claramente definidos, sino que la teoría y la práctica de la gestión del cambio se basan en una serie de disciplinas y tradiciones de las ciencias sociales, que se convierte en una de sus fortalezas. Sus bases directas están en tres escuelas de pensamiento (Burnes, 2004):

La escuela individual agrupa de una parte a los gestálticos que argumentan que el comportamiento es producto del medio ambiente y de la razón, por lo cual su aprendizaje es un proceso de ganar o cambiar las percepciones, perspectivas, expectativas o patrones de pensamiento, junto con los conductistas, que sostienen que las acciones humanas son condicionadas por sus consecuencias esperadas, lo cual produce una visión de un individuo en interacción con su entorno. Esta combinación de motivadores extrínsecos e intrínsecos enfatiza la necesidad de ambas formas de estímulos para influir en el comportamiento humano. En consecuencia, se generan aplicaciones, como la escuela de excelencia-cultura, que recomienda el uso de incentivos

\footnotetext{
1 El tema de desarrollo organizacional es sumamente amplio. Para quienes deseen profundizar, el libro Organization development and change, (2014) de Thomas G. Cummings (University of Southern California) y Christopher G. Worley (University of Southern California Pepperdine University) es una completa y excelente fuente.
} 
individuales fuertes (estímulos externos) y discusión, participación y debate (reflexión interna) con el fin de llevar a la organización al cambio (Burnes, 2004).

La escuela de dinámica de grupo es la más ampliamente trabajada, originada en la obra de Kurt Lewin, en la que el cambio organizacional se realiza a través de equipos o grupos de trabajo en lugar de individuos, ya que en las organizaciones las personas trabajan en grupos y su comportamiento debe ser visto, modificado o cambiado a la luz de estos, en los que que prevalecen prácticas y normas propias que afectan el comportamiento individual. Esto es producto de la interacción entre la intensidad y la valencia (positivo o negativo) de las fuerzas del grupo que afectan a la persona, por lo cual un grupo nunca está en un "estado de equilibrio constante", sino en un continuo proceso de adaptación. Para lograr el cambio, por lo tanto, es inútil concentrarse en el cambio del comportamiento de los individuos, sino que debe ser a nivel de grupo y deben concentrarse en influir y cambiar las normas, roles y valores.

La escuela de sistemas abiertos. Luego de los enfoques grupal e individual, en este punto la referencia es la organización en su totalidad. En esta escuela se ven las organizaciones compuestas por un número de subsistemas interconectados y cualquier cambio en una parte del sistema tendrá un impacto en otras partes del sistema y a su vez en su rendimiento general. En este enfoque el cambio se basa en un método para describir y evaluar estos subsistemas, para determinar cómo deben cambiarse para mejorar el funcionamiento general de la organización. Además, la escuela no solo ve a las organizaciones como sistemas aislados, sino como sistemas abiertos, que interactúan con su entorno y abiertos internamente a los distintos subsistemas que interactúan entre sí. El objetivo del enfoque de sistemas abiertos es estructurar las funciones de un negocio de tal manera que, a través de líneas de coordinación claramente definidas se persigan colectivamente los objetivos generales de la empresa. El énfasis es lograr la sinergia global, en lugar de optimizar el rendimiento de cualquier parte individual.

Por otro lado, desde un punto de vista más sistémico, Miller (citado por Burnes, 2004) habla de cuatro grandes subsistemas: metas y valores organizacionales, técnico, psicosocial y gestión (gerencia). La escuela de sistemas abiertos se ocupa de comprender a las organizaciones desde una perspectiva holística más que una particularista; su enfoque de cambio está guiado por tres premisas: 1) los subsistemas son interdependientes; 2) la formación, como mecanismo para el cambio, es improbable que tenga éxito por sí sola, ya que se concentra en el individuo y no en el nivel organizacional; 3) para tener éxito, las organizaciones tienen que aprovechar y dirigir la energía y el talento de su fuerza de trabajo, eliminando los obstáculos que impiden esto, con cambios en las normas, sistemas de recompensa y estructuras de trabajo. 
Estas tres orientaciones dan un sustento epistemológico a la gerencia del cambio y a su vez orientan la forma en que la organización desarrolla su estrategia (ya introducida antes), con base en un modelo de gestión del cambio (se desarrollan en el siguiente punto). Por esta razón, y como se ha subrayado en varios apartes del capítulo, la estrategia organizacional es el eje orientador del proceso de cambio organizacional y por lo tanto el que marca el modelo a implementar en una determinada organización.

\title{
Enfoques en la gerencia del cambio
}

En 1986 Morgan ideó una forma para clasificar

\begin{abstract}
la vida organizacional basada en metáforas que nos llevan a ver y comprender las organizaciones en un modo distinto, aunque parcial. Las metáforas se emplean normalmente como un recurso para embellecer el discurso, pero su importancia va mucho más allá. El empleo de la metáfora implica un "modo de pensar" y un "modo de ver" que traspasa el cómo comprendemos nuestro mundo en general. (Morgan, 1991)
\end{abstract}

La metáfora permite estirar nuestro pensamiento y profundizar nuestra comprensión, lo que nos permite ver las cosas de nuevas maneras y actuar en consecuencia, aunque también crea distorsiones (Bejinariu, Jitarel, Sarca y Mocan, 2017; Paul, 2015).

Las ocho metáforas propuestas por Morgan son que las organizaciones se comportan como: 1) máquinas; 2) organismos; 3) cerebros; 4) culturas; 5) sistemas políticos; 6) prisiones psíquicas; 7) flujo y transformación y 8) instrumentos de dominación (Morgan, 1991).

Cameron (2015), en su libro Making sense of change management, selecciona cuatro de las metáforas organizacionales de Morgan para explorar el rango de supuestos que existe acerca de cómo funciona el cambio organizacional, que son las cuatro más utilizadas por los gerentes, escritores y consultores, y que proporcionan las perspectivas más útiles del proceso de cambio organizacional (Cameron y Green, 2015; Bejinariu, Jitarel, Sarca y Mocan, 2017).

Tabla 1. Cuatro enfoques diferentes para el proceso de cambio

\begin{tabular}{clcl}
\hline Metáfora & \multicolumn{1}{c}{ Cómo se aborda el cambio } & Responsable & \multicolumn{1}{c}{ Guía/principios } \\
\hline & $\begin{array}{l}\text { Los altos directivos definen objetivos y } \\
\text { escala temporal. Asesoría en técnicas. El } \\
\text { programa de cambio se desenrolla de arriba } \\
\text { abajo. El entrenamiento se da a la brecha del } \\
\text { comportamiento del puente. }\end{array}$ & Sénior/ & El cambio debe ser conducido. \\
gencia & & $\begin{array}{l}\text { La resistencia puede ser manejada. } \\
\text { Los destinos definidos al inicio del } \\
\text { proceso definen la dirección. }\end{array}$ \\
\hline
\end{tabular}


Jairo A. Ángel Jaramillo

\begin{tabular}{|c|c|c|c|}
\hline Metáfora & Cómo se aborda el cambio & Responsable & Guía/principios \\
\hline 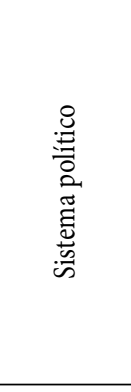 & $\begin{array}{l}\text { Un grupo poderoso de individuos construye } \\
\text { una nueva coalición con nuevos principios } \\
\text { rectores. Hay debates, maniobras y } \\
\text { negociaciones que eventualmente conducen a la } \\
\text { nueva coalición, ya sea ganando o perdiendo. } \\
\text { El cambio se produce a medida que nuevas } \\
\text { personas están en el poder con nuevas } \\
\text { opiniones y nuevas formas de asignar recursos } \\
\text { escasos. Los que los rodean se posicionan para } \\
\text { ser ganadores en lugar de perdedores. }\end{array}$ & $\begin{array}{l}\text { Aquellos con } \\
\text { poder }\end{array}$ & $\begin{array}{l}\text { Habrá ganadores y perdedores. } \\
\text { El cambio requiere nuevas } \\
\text { coaliciones y nuevas negociaciones. }\end{array}$ \\
\hline 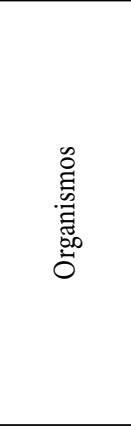 & $\begin{array}{l}\text { Primero hay una fase de investigación en la } \\
\text { que los datos se reúnen en la cuestión relevante } \\
\text { (cliente retroalimentación, encuesta de } \\
\text { empleados, etc.) A continuación, los datos se } \\
\text { presentan a los responsables de hacer cambios. } \\
\text { Hay discusión sobre lo que significan los datos, } \\
\text { y entonces lo que hay que hacer. Una solución } \\
\text { es colaborativa, diseñada y movida hacia, con } \\
\text { la máxima participación. Se da capacitación } \\
\text { y apoyo a los que necesitan hacer cambios } \\
\text { significativos. }\end{array}$ & $\begin{array}{c}\text { Gerentes } \\
\text { de recursos } \\
\text { humanos }\end{array}$ & $\begin{array}{l}\text { Debe haber participación y una } \\
\text { conciencia de la necesidad de } \\
\text { cambio. El cambio es colaboración } \\
\text { diseñado como una respuesta a } \\
\text { cambios en el ambiente. La gente } \\
\text { necesita ser apoyada a través del } \\
\text { cambio. }\end{array}$ \\
\hline 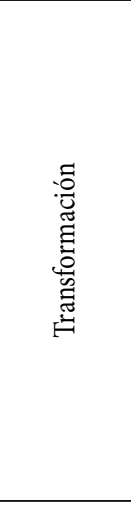 & $\begin{array}{l}\text { La chispa inicial de cambio es un tema } \\
\text { emergente. Este es un tema que está } \\
\text { comenzando a aparecer en la agenda de todos. } \\
\text { Alguien con autoridad toma la iniciativa de } \\
\text { crear un foro de discusión, el cual inicialmente } \\
\text { es bastante desestructurado, caracterizado por } \\
\text { preguntas como ¿podría ser?, ¿por qué has de } \\
\text { venir?, ¿cuál es el verdadero problema?, ¿cómo } \\
\text { nos gustaría que las cosas sean?. La discusión } \\
\text { implica cualquiera que tenga la energía para } \\
\text { interesarse. Un plan para manejar el problema } \\
\text { emerge de una serie de discusiones. Más } \\
\text { personas son traídas a la red. }\end{array}$ & $\begin{array}{l}\text { Alguien con } \\
\text { autoridad } \\
\text { para actuar }\end{array}$ & $\begin{array}{l}\text { Los cambios no pueden ser } \\
\text { administrados, emergen. El } \\
\text { conflicto y la tensión dan lugar a } \\
\text { cambiar. Los administradores son } \\
\text { parte del proceso. Su trabajo es } \\
\text { resaltar brechas y contradicciones. }\end{array}$ \\
\hline
\end{tabular}

Fuente: Cameron y Green (2015)

\section{Modelos de gerencia del cambio}

El cambio es una constante y los gerentes que lo anticipan y reaccionan rápida y responsablemente, salen adelante; sin embargo, los líderes organizacionales que anticipan e inventan el futuro son aún más exitosos porque inventan el juego en su industria, las demás organizaciones son seguidores que se adaptan al cambio y, finalmente, están las organizaciones que no sobreviven. 
Hay muchos modelos que se pueden utilizar para realizar el cambio organizacional exitoso, como veremos más adelante, y es sumamente importante que los líderes organizacionales identifiquen y utilicen un modelo que ayude a su organización a sobrevivir en el futuro.

Algunos autores se refieren a cambio organizacional, indistintamente de transformación organizacional y desarrollo organizacional; sin embargo, existen diferencias alrededor de los siguientes puntos: (1) la naturaleza simultánea de los cambios; (2) la velocidad en la que ocurren los diferentes tipos de cambio; (3) la complejidad de los cambios, (4) la inmediata comunicación e impacto de los cambios en todo el mundo; y (5) la necesidad de individuos como líderes de organizaciones (Cummings y Worley, 2014). Por lo tanto, es necesario definir el cambio y la transformación organizacional en términos del grado en que el cambio organizacional se produce, así como su rapidez. La transformación organizacional es un movimiento radical que desarrolla nuevas visiones, misiones, valores, metas, estrategias y estructuras que reflejan un cambio continuo, al punto que se convierte en un proceso en curso y la norma. Mientras que cambios esporádicos o constantes, como mejoramiento continuo, calidad total o seis sigma, son parte de iniciativas de mejora o de desarrollo organizacional, basadas en varios modelos de cambio.

Teniendo en cuenta la clasificación de Cao (2003) sobre cambio, podemos clasificar los enfoques de cambio en las mismas cuatro categorías: en el cambio procesal los enfoques típicos pueden incluir la gestión de la calidad total (сст [control de calidad total]) y reingeniería de procesos de negocio (вPR [business process re-engineering]), los cuales son valiosos para mejorar el proceso organizacional, pero carecen de poder tratar adecuadamente con otros tipos de cambio organizacional. Los enfoques estructurales pueden ser teoría de contingencias y economía de costos; el primero argumenta que la estructura organizativa y el rendimiento están supeditados a las variables situacionales que enfrenta, como ambientales, tecnológicos o de tamaño; se basan en que si las variables clave de una organización pueden determinarse, el cambio organizacional puede ser manejado eficazmente; mientras que la economía de costos exclusivamente busca causas originarias en los mercados, centrándose en mejorar la eficiencia y la efectividad de las partes más tangibles de una organización. En los enfoques culturales están el de cultura unitaria y gestión de la diversidad cultural que dirigen la atención hacia el lado humano en lugar que a los procesos, estructuras, mercados o tecnologías; muestran la importancia y la posibilidad de la cultura en crear y formar organizaciones por influenciar valores y creencias, las negativas potenciales están en desarrollar en un proceso de control 
ideológico. Los enfoques políticos ayudan a entender las acciones organizacionales en las que el poder desempeña un papel clave en abordar diversos intereses; desde esta perspectiva la eficiencia y la efectividad son siempre políticas y se corre el riesgo de que las personas se comporten políticamente para sus propios intereses personales, resultando en cinismo y desconfianza (Cao, Clarke y Cao, 2003; Fitzgerald et al., 2005).

A continuación, se presentan los principales modelos de gerencia de cambio organizacional.

\section{Modelos de cambio de Lewin (1947)}

Kurt Lewin, interesado en la psicología social y el tema de las relaciones interpersonales, fue uno de los primeros y más prolíficos investigadores en la psicología; sus planteamientos respecto al tema del cambio organizacional, así como en la investigación empírica del liderazgo se citan en el capítulo 3 del presente libro. Lewin plantea que el co se puede ubicar bajo tres grandes descripciones (Burnes, 2007):

- Teoría investigación/acción

- Teoría de campo

- Modelo de cambio de los tres pasos

Lewin (1947, citado por Burnes, 2004) argumentó que el statu quo necesita ser desestabilizado antes de que el viejo comportamiento pueda ser descartado y un nuevo comportamiento sea adoptado con éxito. Basándose en su teoría de campo, Lewin reconoció que el statu quo se producía cuando las fuerzas de cambio y las fuerzas de estabilidad eran iguales y para lograr el cambio, se debe aumentar la fuerza de la primera y reducir la de la última (Burnes, 2004). Lewin creía que el cambio se producía cuando las fuerzas que apoyaban un sistema de comportamiento estable se modificaban y que mientras ambos grupos de fuerzas sean aproximadamente iguales, el sistema está en un estado de "equilibrio cuasiestacionario" y para modificar este estado la organización debe fortalecer un grupo de fuerzas o el otro; Lewin sugería que la alteración de fuerzas de estabilidad elegida fuera la de las favorables al mantenimiento del statu quo, que probablemente generaría menos resistencia al cambio que el fortalecimiento de las fuerzas procambio (Schein, 1988; Tripon y Dodu, 2005; Armstrong, 2006; Gallos, 2006; Pryor, Taneja y Hump, 2008; Robbins y Coulter, 2009; D’Ortenzio, 2012; Cummings y Worley, 2014; Cameron y Green, 2015; Hayes, 2018). 


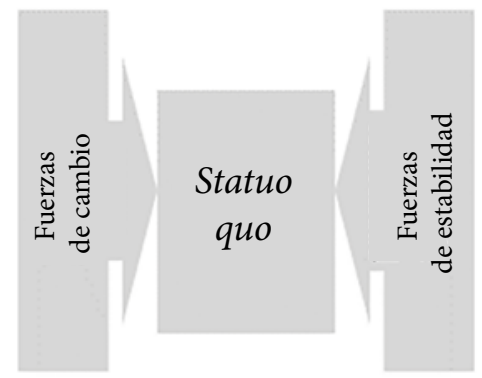

Figura 2. Manteniendo el statu quo

Fuente: Burnes (2004)

De esta forma, Lewin llega al planteamiento de su modelo de cambio planeado en tres pasos, como se muestra en la siguiente figura:

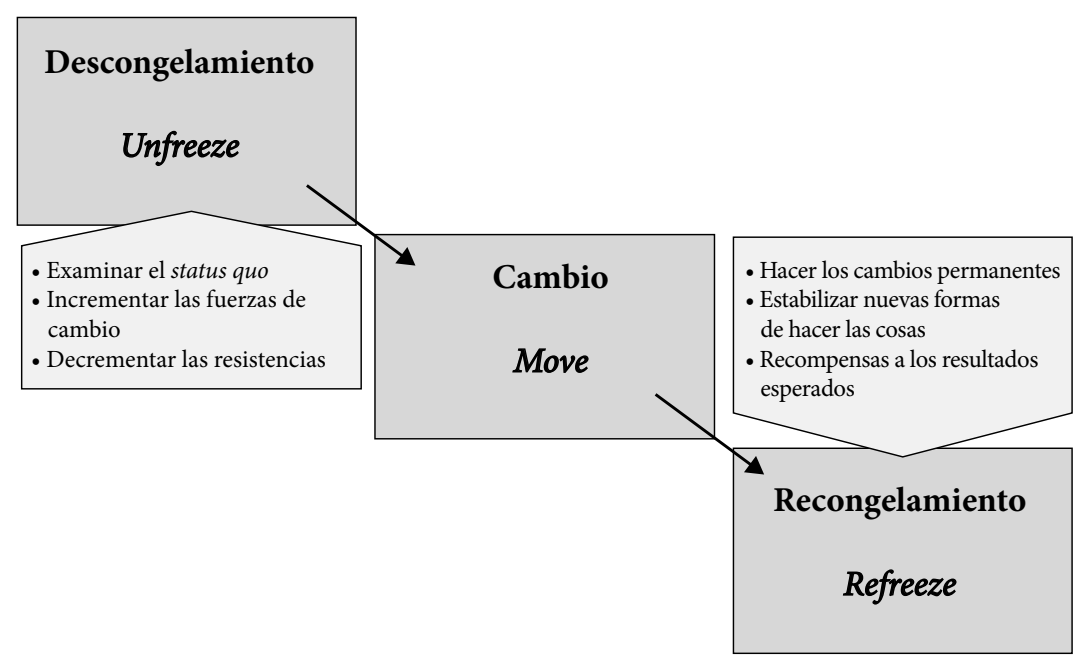

Figura 3. Modelo de los tres pasos de Lewin

Fuente: Cameron y Green (2015)

El proceso de cambio se despliega en tres etapas: 1) descongelamiento, que se refiere a minimizar las fuerzas que mantienen el sistema en el nivel actual, que se puede hacer mediante la introducción en el sistema de información que mostraría la presencia de ciertas discrepancias entre el comportamiento deseado por los empleados y el comportamiento real. 2) Cambio, se trata de modificar el comportamiento de la organización para alcanzar otro nivel en el plan; es el desarrollo de nuevos comportamientos, 
valores y actitudes a través del cambio de estructuras y procesos organizacionales. 3) Recongelamiento, que se refiere a estabilizar la nueva etapa en la que se encuentra la organización, reforzar los elementos recién introducidos y se puede lograr mediante cultura organizacional, normas, políticas y estructuras (Burnes, 2004; Tripon y Dodu, 2005; Burnes, 2007; Cameron y Green, 2015; Hayes, 2018).

\section{Modelo de cambio de Lippitt, Watson y Westley (1958)}

Varios autores han desarrollado diferentes modelos a partir de los planteamientos de Lewin y su modelo de los tres pasos. Uno de esto modelos es el planteado por Lippitt, Watson y Westley (1958), el cual ha tenido muy poca difusión, tal vez por su gran parecido al de Lewin. Según Pryor, Taneja y Hump (2008), estos autores extienden y cambian la terminología de Lewin, ampliando los pasos de tres a cinco, con acciones después de la fase de descongelamiento, siguiendo con establecer una relación de lo cambiado (fase 4) y lograr una relación terminal como fase 5.

Para Kritsonis (2005), Lippitt, Watson y Westley crearon una teoría de siete pasos que se centra en el papel del agente de cambio, antes que en la evolución del propio cambio, en el cual la información se intercambia continuamente durante todo el proceso. Los siete pasos son:

1. Diagnosticar el problema.

2. Evaluar la motivación y la capacidad de cambio.

3. Evaluar los recursos y la motivación del agente de cambio. Esto incluye el cambio, el compromiso del agente con el cambio, el poder y la resistencia.

4. Elegir objetos de cambio progresivo. En este paso se desarrollan planes de acción y se establecen estrategias.

5. El papel de los agentes de cambio debe seleccionarse y entenderse claramente por todas las partes para que las expectativas sean claras; los roles pueden ser dinamizador, facilitador y experto.

6. Mantener el cambio mediante comunicación, retroalimentación y coordinación de grupos.

7. Eliminar gradualmente la relación de ayuda, en el momento en que el cambio pasa a formar parte de la cultura organizacional.

Los autores plantean que los cambios son más propensos a ser estables si se propagan a sistemas vecinos o a subpartes del sistema inmediatamente afectado. 
Plan de cambio de Beckhard (1969)

Richard Beckhard es uno de los más destacados teóricos del Do y desarrolló varios planes de entrenamiento para diferentes empresas; su modelo es poco conocido y hace un puente inicial entre el do y la gerencia del cambio.

El planteamiento de Beckhard (1969, citado por Tripon y Dodu, 2005) habla de Do, definiéndolo como un esfuerzo que es (1) y (2) a nivel de la organización, (3) comienza desde la parte superior de la jerarquía organizacional, para (4) mejorar la efectividad de la organización a través de las intervenciones (5) previstas en procesos organizacionales, utilizando los conocimientos de las ciencias de la conducta.

A este modelo debemos la incorporación del efecto casaca en la implementación de modelos de cambio.

Su énfasis se encuentra en la etapa de diagnóstico, enfocado en dos áreas principalmente:

1. Componentes sistémicos: el sistema o el medio ambiente externo, el sistema de organización tomado en su conjunto, los subsistemas como elementos que componen el sistema de organización.

2. Procesos intrasistémicos: objetivos, toma de decisiones, planificación, comunicación, colaboración entre grupos, equipos o subunidades y resolución de conflictos (Tripon y Dodu, 2005).

Modelo de las diez claves de Pendlebury, Grouard y Meston (1998)

Estos científicos han presentado diez factores clave que pueden adaptarse a cualquier situación de cambio en particular. Puede ser necesario implementar todas las claves, bien sea simultáneamente o de forma separada en el proceso de cambio. Las diez claves son las siguientes (Essays, 2013):
1. Definir la visión
2. Movilizar
3. Catálisis
4. Dirigir
6. Obtener participación
9. Entrenar
5. Entregar
7. Manejar las emociones
10. Comunicarse activamente
8. Manejar el poder

Este modelo parte de que el cambio es de hecho perjudicial para las organizaciones, pero aún más, es bastante perjudicial para el individuo; de hecho, el efecto del cambio en los individuos es sustancial en muchos aspectos, por lo cual genera una dimensión emocional traducida en la resistencia, la cual debe ser manejada a lo largo del acontecimiento del cambio. 
El proceso de cambio puede conllevar algunas emociones contundentes dentro de las organizaciones, de hecho, varios autores argumentan que cada acontecimiento del cambio provocará algún tipo de resistencia que se manifiesta en emociones tales como la depresión, la manía, la irritabilidad, el miedo, la cólera, la negación, la evitación, los pensamientos perturbadores u obsesivos; el cambio puede interferir tanto que incluso las personas no afectadas directamente por una iniciativa de cambio pueden verse afectadas por culpa de quienes sí participan en el proceso (Shodhganga, 2012).

\section{Modelo de cambio de Thurley (1979)}

En diferentes revisiones teóricas se menciona el modelo de cambio introducido por Thurley (Shodhganga, 2012; Brisson-Banks, 2010), el cual describe cinco estrategias para gestionar el cambio basadas en la acción; cada una de las estrategias tiene ventajas y desventajas para cada una de las partes involucradas. El punto de partida principal es reconocer la necesidad de un cambio en una organización.

1. Directiva: se refiere a la obligación de cambio en situaciones de crisis o cuando otros métodos han fallado. Esto se hace por el ejercicio del poder directivo sin consulta y el cambio se lleva a cabo rápidamente, sin tener en cuenta las opiniones o los sentimientos de los involucrados.

2. Negociado: este enfoque reconoce que el poder se comparte entre empleador y empleado y ese cambio implica la negociación, compromiso y acuerdo antes de ser ejecutado. Se reconoce que los afectados tienen derecho a transmitir sus opiniones sobre el plan de cambio.

3. Corazones y mentes: hay cambios en las actitudes, valores y creencias de toda la fuerza laboral. Este enfoque busca el compromiso y una visión compartida, pero no implica participación. Adquiere un positivo compromiso con los cambios, pero tarda más en funcionar.

4. Analítico: es un enfoque teórico que avanza sucesivamente desde el análisis de la situación, a través del establecimiento de objetivos, el anteproyecto del proceso de cambio, la estimación de los resultados y la determinación de los objetivos para la etapa subsecuente en el proceso.

5. Basado en la acción: esta estrategia asume una plena contribución de todos los implicados y afectados por los cambios esperados, ya que a menudo los modelos de cambio pasan por alto el cambio que se requiere que ocurra dentro de los individuos en la organización durante el proceso de cambio real, por lo cual se sugiere incluir el elemento humano en el proceso de cambio. 
Cada una de estas estrategias puede ser usada independientemente o en combinación de la manera más apropiada para una organización. Puede haber situaciones que requieran métodos de una estrategia mezclada con métodos de una estrategia diferente para apoyar un modelo exitoso para un negocio en particular. Lockitt (2004, citado por Brisson-Banks, 2010) señala cómo "la habilidad de la gestión efectiva del cambio es reconocer qué estrategias emplear, cuándo, dónde y cómo usarlas para ser más eficaces", lo que puede hacer alguien de recursos humanos, de la gerencia o un agente contratado (Brisson-Banks, 2010).

\section{Modelo de doce pasos de Nadler (1980)}

En la revisión teórica realizada en Essays (2013) se presenta el modelo de Nadler, quien ha desarrollado un trabajo de marco de gestión de doce pasos de acción que es útil para los gerentes y ejecutivos, que es factible en todos los niveles de jerarquía durante el proceso de cambio. Esto es inmensamente útil para liderar y gestionar el cambio en cada rincón de la organización. Los doce pasos de acción son los siguientes:

1. Obtener apoyo de grupos claves

2. Obtener líderes para modelar el comportamiento de cambio

3. Usar símbolos y lenguaje

4. Definir áreas de estabilidad

5. Ubicar el descontento superficial con las condiciones actuales

6. Promover la participación en el cambio
7. Comportamientos de recompensa que apoyan el cambio

8. Desenganche de lo antiguo

9. Desarrollar y comunicar claramente la imagen del futuro

10.Utilizar varios puntos de apalancamiento

11.Desarrollar acuerdos de gestión de la transición

12.Crear comentarios

El modelo de Nadler centra su atención en el rol del gerente, puntualmente recomienda a los directivos, independientemente de sus limitaciones personales y profesionales para adaptarse, cuatro pasos para discernir si entran en un cambio nuevo y por consiguiente responde en corcondancia:

1. Reconocimiento. Evidencias de que su estilo de liderazgo y su enfoque ya no funcionan. Puede asumir varias formas, como notar que las personas no responden como lo hicieron antes a sus discursos, o que sus iniciativas vacilan, o que choca con su equipo, sintiéndose fatigado y emocionalmente desenganchado de su trabajo. 
2. Aceptación. Algunos líderes ven el fracaso como el resultado de la negligencia o errores de otros y creen que el pobre desempeño simplemente pide redoblar el coraje y la persistencia, pero tales creencias son a menudo autoengañosas e incluso delirantes; por lo tanto, es importante que los líderes tengan más puntos de vista (directores seleccionados o consultores externos).

3. Análisis y comprensión. Una vez se es consciente del punto anterior, y que requiere un nuevo tipo de liderazgo, debe determinar las implicaciones para su liderazgo con una mirada objetiva.

4. Decisión y acción. Hay varias estrategias, como cambio personal, dar un paso atrás, ajustar su enfoque, todo lo cual requiere una rara capacidad para reflexionar sobre su propio comportamiento y una gran voluntad (Nadler, 2007).

Igualmente, para el equipo de dirección realiza algunas recomendaciones (Nadler, 2004), las cuales son: 1) composición equilibrada y diversa del equipo; 2) equipo ejecutivo comprometido; 3) el gerente como líder de proceso; 4) cultura abierta y constructiva y 5) responsabilidad de la junta directiva.

\section{Extensión del modelo de cambio de Lewin por Schein (1980)}

La teoría de Schein (1988) es una extensión de la teoría de cambio de Lewin, en la cual discute los tres pasos del modelo de Lewin como tres etapas del cambio y describe más las maneras de descongelar una organización, de moverla del estatus actual a un estado futuro y de congelar los cambios.

Indica que para descongelar el trabajo y para que las personas de la organización abracen el cambio, deben experimentar una necesidad de cambio, es decir, la insatisfacción con el statu quo. Luego, una vez que se introduce la necesidad de cambio y el cambio deseado, la gente verá la brecha entre lo que existe y lo que existirá; debido a la culpa y/o ansiedad, la gente estará motivada para reducir la brecha y lograr el cambio deseado y para ser productivo y eficiente, para efectivamente lograr el cambio requerido, la gente debe sentirse psicológicamente segura y entender que mudar/ cambiar no les causará humillación, castigo o pérdida de autoestima.

La segunda etapa de Lewin, "moviéndose o cambiando", la llama "reestructuración cognitiva", cuyo propósito es ayudar a la gente a ver y responder a las cosas de manera diferente en el futuro; plantea que para que esta fase sea eficaz, la gente debe identificarse con nuevos modelos de conducta para la reestructuración cognitiva y además deben adquirir información nueva y relevante que pueda ayudarles a avanzar con los cambios necesarios. 
La tercera etapa, recongelación, la divide en dos partes que son relaciones del yo y con otros; para que el cambio sea permanente, la gente debe hacer un compromiso de cambio personalmente para hacer las cosas de una forma cómoda con ellos mismos, e igualmente deben velar por que sus respectivas actitudes y comportamientos estén alineados con el sistema y las relaciones con otros; esto son los comportamientos que deben ser "congelados", es decir, cambiados permanentemente (Schein, 1988; Pryor, Taneja y Hump, 2008; Shodhganga, 2012).

\section{Modelo de procesamiento de cambio continuo (1982)}

Otra de las metodologías reseñadas en las revisiones literarias (Shodhganga, 2012), es el modelo de cambio continuo, el cual tiene relación con las teorías de liderazgo asociadas a procesos de cambio, planteando que el cambio se desarrolla a partir de la alta dirección y desde donde debe mantenerse continuo. Incorpora conceptos de Lewin sobre la fase de implementación, en la que la gerencia percibe tendencias de cambio, las cuales evalúa en su proceso habitual de toma de decisiones de la organización. A partir de esto, la alta dirección define sus objetivos en términos de cómo espera que sean los nuevos procesos o salidas después del cambio, para generar y evaluar las alternativas de cambio y finalmente seleccionar la opción más aceptable. Tichy y Ulrich (1984, citados por Shodhganga, 2012) plantean que para iniciar el proceso la organización puede solicitar ayuda de un agente de cambio, quien será el responsable de administrar el esfuerzo de cambio, e incluso ayudar a la gerencia a definir el problema o la necesidad de cambio, hasta la generación y evaluación de posibles planes de acción.

El proceso se implementa bajo la dirección y gestión del agente de cambio, siguiendo los pasos planteados por Lewin de descongelamiento, cambio y recongelamiento y, en el paso final, la evaluación y el control, el agente de cambio y la administración evalúan el grado en que el cambio está teniendo el efecto deseado. Como el agente de cambio se sumerge en la definición y la solución del problema con los miembros de la organización, se convierte en un "colaborador" de y durante todo el proceso, aporta nuevas ideas y puntos de vista que ayudan a los miembros a abordar los viejos problemas de maneras innovadora. Ackerman (1982, citado por Shodhganga, 2012) dice que la transición es el proceso de planificación, organización y aplicación del cambio, desde el desmontaje del estado actual hasta la realización del estado futuro completamente funcional dentro de la organización. Una vez que el cambio se produce, la organización no está en el estado anterior ni en el nuevo, pero los negocios deben continuar, por lo cual la gestión de la transición debe garantizar que el negocio continúe y por lo tanto iniciar antes de que ocurra el cambio. 
Los cambios deben ser comunicados a todos los involucrados, incluyendo empleados, clientes y proveedores, quienes desempeñan un importante papel en la gestión de la transición.

La siguiente figura muestra el modelo de procesamiento de cambio continuo (Ukpata y Olukotun, 2008):

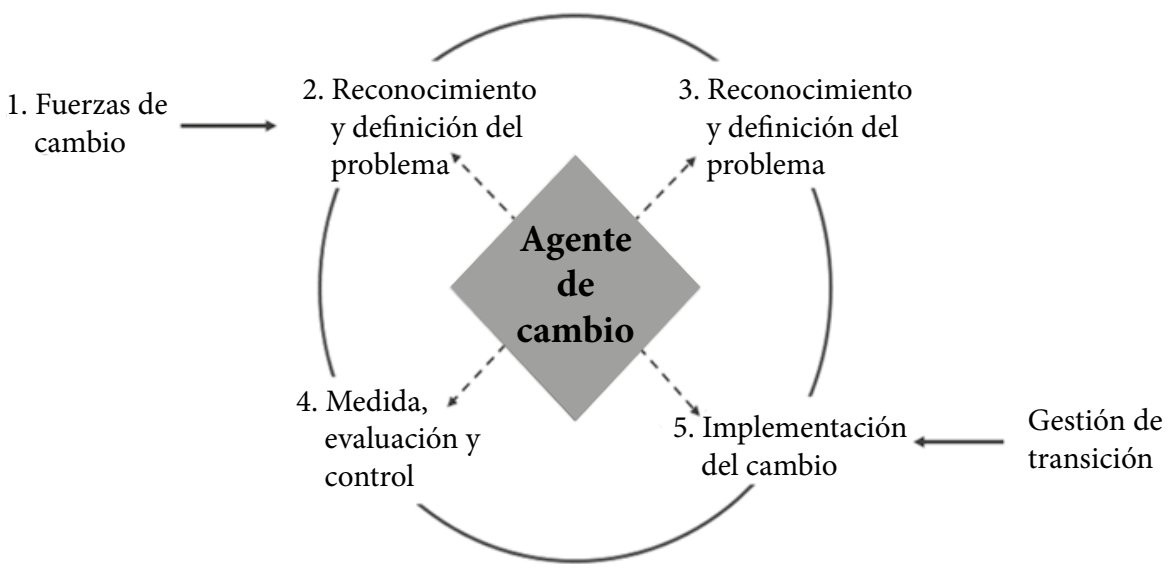

Figura 4. Modelo de procesamiento de cambio continuo

Fuente: Ukpata y Olukotun (2008)

Modelo de cambio planificado de Bullock y Batten (1985)

Dentro de los modelos clasificados en la metáfora de "máquina" se encuentra el modelo de cambio planificado de Bullock y Batten, reseñado por Cameron y Green (2015). Los cuatro pasos planteados son los siguientes:

1. Exploración: implica verificar la necesidad de cambio, y adquirir los recursos específicos (como la pericia) necesarios para que el cambio siga adelante.

2. Planeación es una actividad que involucra a los tomadores de decisiones clave; se completa con un diagnóstico y se concretan acciones que se secuencian en el plan de cambio, el cual es avalado por la dirección antes de pasar a la fase de acción.

3. Acción es la fase en que se completan las actividades según el plan, con mecanismos de retroalimentación que permiten cierta replanificación si las cosas se salen de control.

4. Integración es la fase final que se inicia una vez que el plan de cambio ha sido totalmente accionado. La integración implica alinear el cambio con otras áreas en 
la organización y formalizarlo de alguna manera a través de mecanismos como políticas, recompensas, etc.

Este modelo asume que el cambio se puede definir y adelantar de una manera planificada; simplifica el proceso de cambio al aislar una parte de la organización con el fin de hacer cambios necesarios, por ejemplo, el desarrollo de liderazgo, habilidades en la gestión media, o reorganizar el equipo de ventas para dar más energía del motor a las cuentas de ventas dominantes. Este enfoque funciona bien con cuestiones aisladas, pero poco cuando las organizaciones se enfrentan a un cambio complejo e incognoscible que puede requerir que los involucrados discutan la situación actual y posibles futuros (Cameron y Green, 2015).

Complementariamente Paul (2015) indica que el modelo de cambio planeado de Bullock y Batten describe cuatro etapas del cambio planeado. En primer lugar, hay una exploración que significa determinar la necesidad de cambio, así como la adquisición de los recursos necesarios para el cambio (por ejemplo, la pericia). En la siguiente etapa de la planificación, los responsables de la toma de decisiones clave vienen con un plan de cambio que representa una secuencia de acciones necesarias. En la etapa de acción, las acciones se completan de acuerdo con el plan realizado. Esta etapa también implica mecanismos de retroalimentación, permitiendo algún tipo de replanificación en caso de que las cosas salgan mal. Una vez que el plan de cambio ha sido completamente accionado, la cuarta y última etapa de la integración comienza. Aquí, el cambio se alinea con otras áreas de la organización. Además, el cambio se formaliza a través de políticas y recompensas (Paul, 2015).

\section{Modelo de cambio de Carnall (1990)}

Colin Carnall (1990, citado por Cameron y Green, 2015), planteó un modelo que reúne una serie de perspectivas sobre el cambio. Dice que la gestión eficaz de cambio depende del nivel de habilidad de gestión en las siguientes áreas:

- Gestión eficaz de las transiciones

- Tratar con las culturas organizacionales

- Gestión de la política organizacional

La gestión de transiciones implica que el gerente ayude a la gente a aprender a medida que cambia y crea un ambiente de apertura y de toma de riesgos. Respecto a las culturas organizacionales, el gerente examina la actual y comienza a desarrollar "una cultura más adaptable", que favorezca un mejor flujo de información, más apertura y mayor autonomía local. Sobre la política organizacional, el gerente puede entender 
y reconocer diferentes facciones y diferentes agendas; desarrolla habilidades en la utilización y reconocimiento de diversas tácticas políticas como la construcción de coaliciones, el uso de expertos externos y el control de la agenda.

La figura 5 muestra la relación de las tres áreas durante el proceso de transición.

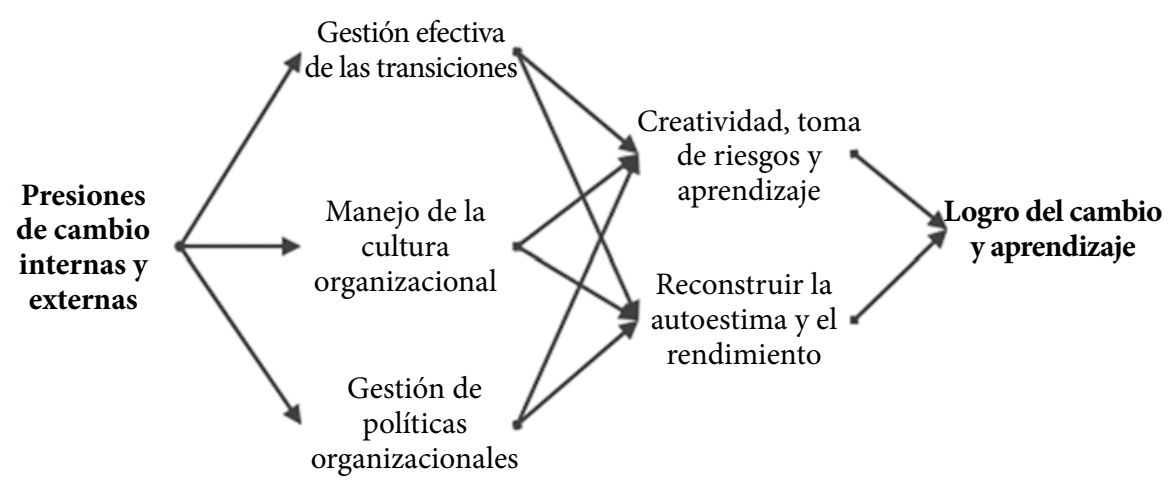

Figura 5. Gestión de la transición de Carnall

Fuente: Cameron y Green (2015)

Carnall puntualiza que solo mediante la síntesis de la gestión de la transición, el tratamiento de las culturas organizacionales y manejo de la política organizacional constructivamente se puede crear el medio ambiente en el que se puede lograr la creatividad, la toma de riesgos y la reconstrucción de la autoestima (Carnall, 2018).

\section{Modelo de cambio basado en la transición de Bridges (1991)}

Bridges (1991, citado por Cameron y Green, 2015) hace una distinción clara entre el cambio planeado y la transición. La transición, el más complejo, se centra en mejorar nuestra comprensión de lo que sucede durante la transición y de cómo podemos manejar este proceso más eficazmente. Separa los cambios funcionales mecánicos del proceso humano natural de llegar a ser emocionalmente consciente del cambio. Transición se trata de dejar ir el pasado y tomar nuevos comportamientos o formas de pensar.

Bridges también proporciona una lista de actividades útiles a ser atendidas durante cada fase, y plantea el cambio en tres fases: final, zona neutral y nuevo principio (Bridges y Mitchell, 2000)

1. Final: antes de que pueda comenzar algo nuevo, tienes que terminar lo anterior; es necesario identificar quién pierde qué y esperar una abierta reacción de cuando se reconocen las pérdidas. Se debe repetir la información sobre lo que es cambiar y dar tiempo para que se implante. Se requiere puntualizar los finales. 
2. Zona neutral: en esta etapa la gente se siente desorientada. La motivación cae y la ansiedad sube. El consenso puede descomponerse a medida que las actitudes se polarizan o también puede ser un tiempo bastante creativo. El trabajo del gerente es asegurar que la gente reconozca la zona neutral y tratarla como parte del proceso. Pueden ser necesarias estructuras temporales y equipos más pequeños.

3. Nuevo comienzo: los comienzos deben ser nutridos cuidadosamente; no pueden planificarse o predecirse, pero pueden ser alentados, apoyados y reforzados. Bridges y Mitchell (2000) sugieren que la gente necesita cuatro elementos clave para ayudarles a hacer un nuevo principio: 1) el propósito detrás del cambio, 2) la imagen de cómo se verá y se sentirá esta nueva organización, 3) un paso a paso del plan para llegar allí y 4) un puesto para estar en el resultado.

Bridges y Mitchell (2000) plantean que un requisito para casi cualquier ejecutivo sénior es entender el proceso de transición, sin embargo, cuando la organización está en transición es que los propios líderes necesitan ayuda. Están tan inmersos en el cambio que pueden no recordar que ellos mismos tomaron tiempo para llegar a un acuerdo con el cambio necesario y que sus seguidores necesitarán al menos el mismo tiempo para hacerlo; en ocasiones, piensan que alguien no acepta el cambio, por lo que creen que sus seguidores son ignorantes, rígidos, o directamente hostiles a la nueva dirección y los directivos no ven que se trata de una transición y no necesariamente del cambio mismo lo que retiene a la gente y amenaza con hacer el cambio inalcanzable.

De esta forma, se genera lo que Bridges llama el efecto maratón, que consiste en que entre más alto está el líder en la organización más rápidamente tiende a moverse a través del proceso del cambio, ya que puede ver la meta antes que como lo muestra la figura 6 .

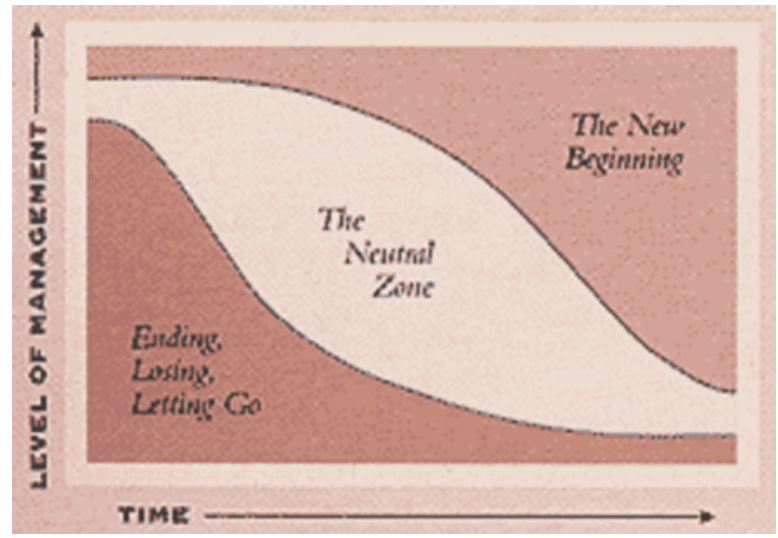

Figura 6. Efecto maratón

Fuente: Bridges y Mitchell (2000) 
El inicio se alcanza cuando la gente siente que puede hacer el compromiso emocional de hacer algo de una manera nueva. Bridges puntualiza que la zona neutral es más larga y los finales son más prolongados, especialmente para quienes están más alejados de la gerencia, lo cual puede generar impaciencia de los gerentes, quienes emocionalmente ya están en el nuevo comienzo, mientras que su gente parece retrasarse, aparentemente atrapados en un final.

Modelo de cambio de Mintzberg y Quinn (1991)

Según Mintzberg y Quinn (1991, citados por D’Ortenzio, 2012), hay cuatro grandes rúbricas situacionales que tienen un papel importante en la determinación del grado en que una organización puede implementar cambios. Estas incluyen factores como:

1. Edad de la organización

2. Tamaño de la organización

3. Sistemas técnicos
4. Medio ambiente

5. Naturaleza del control

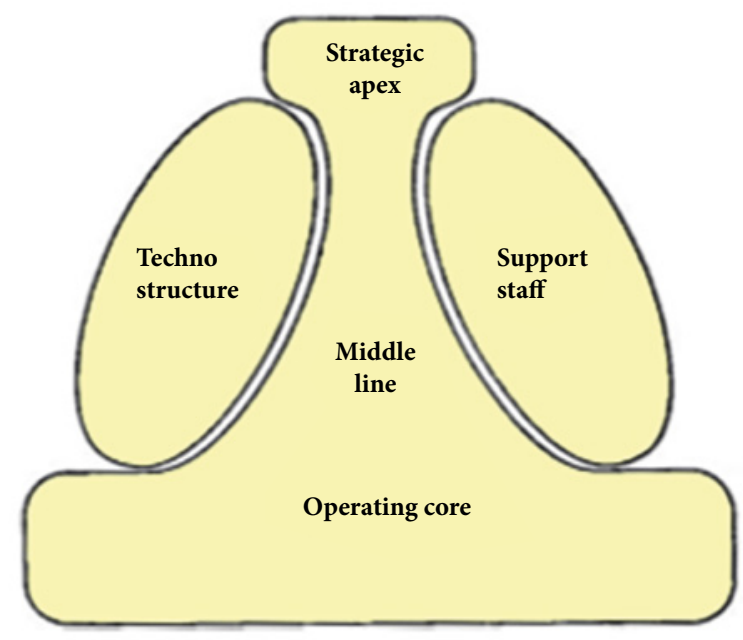

Figura 7. Los cinco componentes básicos de una organización

Fuente: D'Ortenzio (2012)

La edad y el tamaño de la organización son indicadores importantes de su capacidad de aceptar e implementar el cambio. El sistema técnico, que son los instrumentos utilizados en el núcleo operativo para producir sus salidas, también puede limitar la capacidad de una organización para cambiar, ya que influye sobre la estructura organizativa de tres maneras: organizaciones altamente reguladas dominadas por sus sistemas técnicos tienden a mostrar más estructuras burocráticas; organizaciones 
con sistemas técnicos altamente complejos delegan la toma de decisiones a personal profesional o cualificado con respecto a la gestión de los conocimientos técnicos; finalmente, organizaciones con sistemas técnicos automatizados que adoptan estructuras más orgánicas y que son caracterizados por la fluidez y la flexibilidad, para acomodarse a circunstancias particulares. El medio ambiente son las características del contexto exterior de la organización, en relación con los mercados, el clima político, las condiciones económicas, etc. Organizaciones ubicadas en entornos dinámicos tienden a adoptar estructuras más orgánicas; organizaciones en entornos complejos adoptan estructuras más descentralizadas; organizaciones ubicadas en mercados diversificados adoptan estructuras divisionales basadas en el mercado y organizaciones en ambientes hostiles adoptan estructuras centralizadas. Finalmente, el ejercicio del poder ya sea interna o externamente, influye por que cuanto mayor sea el control externo de la organización, más centralizada y formalizada su estructura; coaliciones externas divididas dan lugar a coaliciones internas politizadas y viceversa (Mintzberg y Quinn, 1997)².

Mintzberg descubrió que, aunque las capacidades individuales de los empleados hacen una contribución significativa en la implementación de un rol en la organización, es la organización la responsable de la creación de ese rol. También es importante señalar que antes de implementar iniciativas de cambio en la organización, los iniciadores de cambios deben prestar una atención cuidadosa a la estructura de la organización actual (D’Ortenzio, 2012).

\section{Modelo de Burke y Litwin (1992)}

Burke y Litwin (1992) plantean que el cambio de la organización es una clase de caos con gran número de variables cambiando al mismo tiempo; el cambio en el entorno y la resistencia de los sistemas humanos crea una confluencia de procesos que son extremadamente difíciles de predecir y casi imposibles de controlar. Sin embargo, existen patrones (constantes) con vínculos entre las clases de eventos que se han demostrado en la literatura y se pueden ver en organizaciones reales. Para construir un modelo debemos explorar dos líneas de pensamiento importantes: entender a fondo cómo funcionan las organizaciones (lo que lleva a qué) y en segundo lugar entender cómo las organizaciones podrían ser cambiadas deliberadamente (Burke y Litwin, 1992).

\footnotetext{
2 El modelo se encuentra más ampliamente descrito en el capítulo 8 del presente libro, que señala una investigación sobre cultura organizacional y su relación con el cambio organizacional en una entidad de educación superior, donde se tuvo en cuenta este modelo para el desarrollo de la investigación.
} 
Burke-Litwin (citados por Bejinariu, Jitarel, Sarca y Mocan, 2017) presentan la relación causal específica entre las principales variables organizacionales, considerando una distinción entre la dinámica transaccional y transformacional de una organización. La figura 8 resume el modelo Burke-Litwin, que sigue los principios del enfoque sistémico presentado por Katz y Kahn (1978), el modelo considera el ambiente externo, las entradas y termina con el desempeño individual y organizacional, y termina de nuevo con el medio ambiente, con una retroalimentación; los factores de la mitad dan la información específica sobre los mecanismos por los cuales opera la organización (Bejinariu, Jitarel, Sarca y Mocan, 2017).

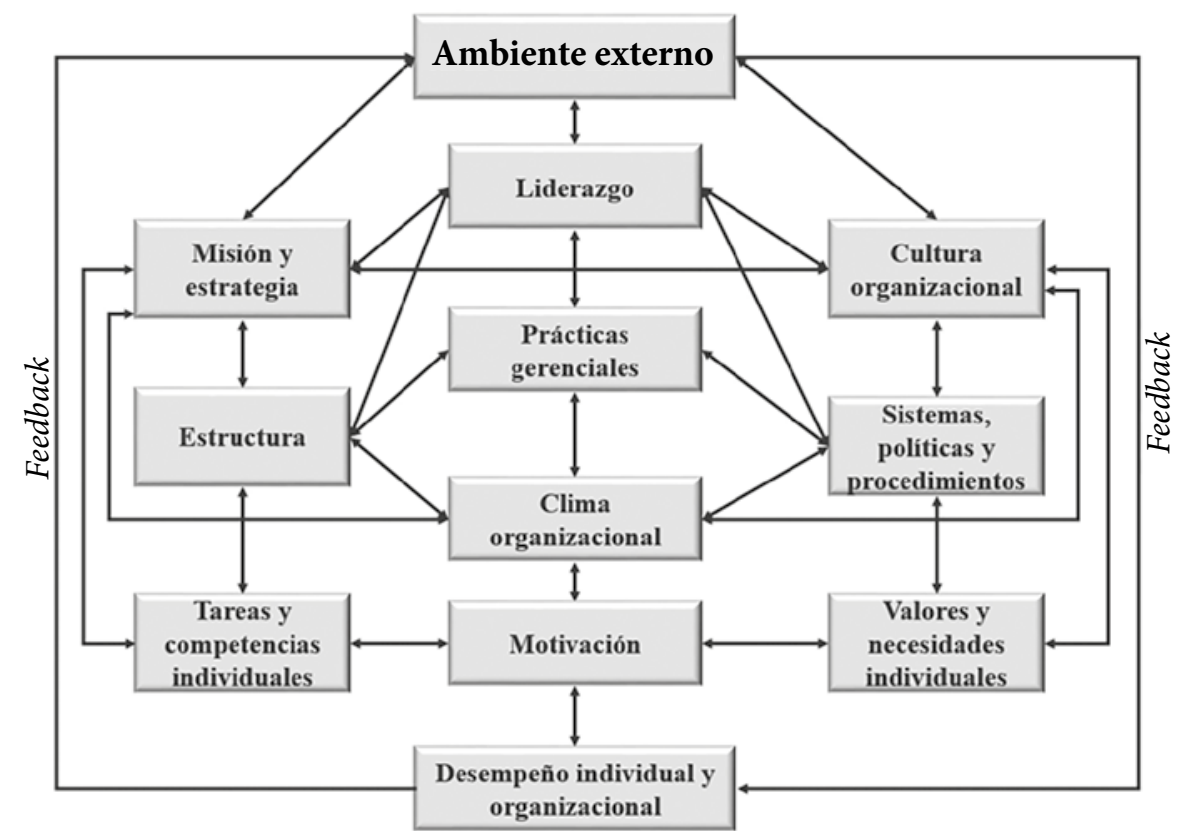

Figura 8. Modelo de rendimiento organizacional y cambio

Fuente: Burke y Litwin (1992)

Diez mandamientos de Kanter, Stein y Jick (1992)

Inicialmente Kanter solo, y posteriormente Kanter, Stein y Jick, realizaron una maravillosa investigación sobre el cambio de organización y propusieron diez mandamientos sobre cómo planificar un proceso de cambio (Essays, 2013). Ellos son del grupo de autores que ofrecen una orientación práctica a las organizaciones y gerentes (Todnem, 2005). 
1. Analizar la necesidad de cambio

2. Crear una visión compartida

3. Separar del pasado

4. Crear un sentido de urgencia

5. Apoyar un papel líder fuerte
6. Alinear patrocinio político

7. Elaborar un plan de implementación

8. Desarrollar estructuras habilitadoras

9. Comunicar e involucrar a las personas

10. Reforzar e institucionalizar el cambio

Kanter et al. (1992 citado por Burnes, 2004) creen que la estructura de una organización puede ser cambiada relativamente rápido a través de un "golpe audaz", pero que el cambio cultural solo se puede lograr por una "marcha larga" requiriendo una amplia participación con el tiempo y un cambio cultural.

\section{Modelo de contingencia de cambio de Dunphy y Stance (1993)}

La postura de Dumping y Doug desarrolló el mejor enfoque de contingencia de cambio, según Essay, (2013); ellos argumentan que el estilo de cambio y la magnitud del cambio deben coincidir con las necesidades de la organización, como se aprecia en la figura 9:

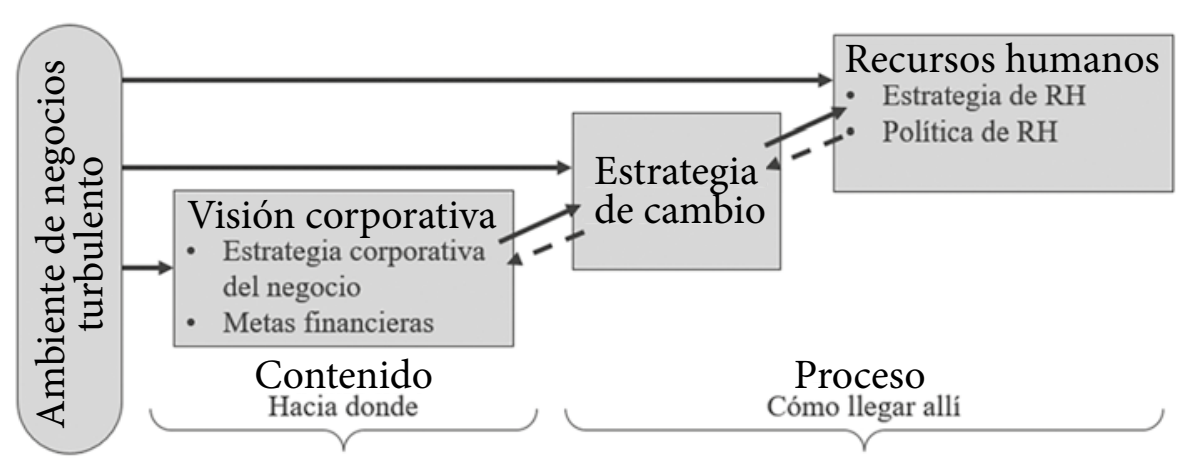

Figura 9. Estrategia de negocios y relación con los procesos de gerencia

Fuente: Essays (2013)

A partir de sus investigaciones desarrollaron un modelo de cambio organizacional situacional basado en los diferentes grados de cambio del ambiente, en el cual las gerencias eligen pragmáticamente con base en la situación en lugar de modelos universalistas; las estrategias se ubican para mantener la organización y ajustarse al entorno, a partir de lo cual crean su matriz de estrategias de cambio, a partir de cuatro tipos de estrategias, de forma similar que otros modelos (Huy, 2007). La base fundamental está en los estilos de la gestión del cambio (liderazgos), en combinación con la 
dimensión del cambio que se emprende (intensidad o alcance). Estas categorías se parecían en la siguiente figura (Dunphy y Stace, 1992)

En la figura 10 se sobreponen los porcentajes de respuestas organizacionales obtenidas durante su investigación, por parte de las organizaciones de la muestra, a partir de una autoclasificación del gerente mediante escalas que midieron características del estilo del cambio en dos periodos de tiempo.

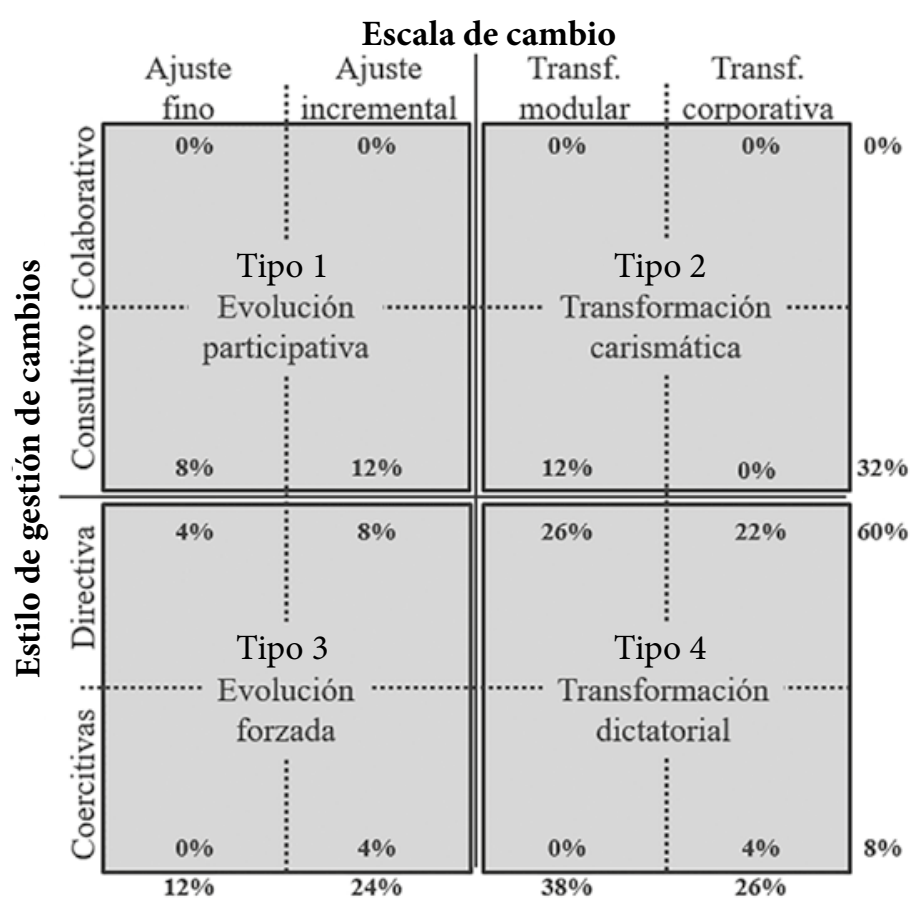

Figura 10. Matriz de posiciones de cambio

Fuente: Dunphy y Stace (1992)

El cambio tipo 1 (evolución participativa) se conoce como transiciones de desarrollo y se refiere a situaciones en las que existe un cambio constante como resultado de la organización que se adapta a los cambios externos y ambientales; el principal estilo de liderazgo es consultivo, en el que el líder actúa en la capacidad de un coach con el objetivo de obtener el compromiso voluntario y compartido de los miembros de la organización a la necesidad de una mejora continua. 
La transformación tipo 2 (carismática) se caracteriza porque los empleados aceptan que la organización está fuera de su entorno y que hay una necesidad de cambio radical y revolucionario; el líder ayuda a crear una nueva identidad y un cambio de paradigma en la forma en que la organización lleva a cabo sus operaciones y es capaz de operar simbólicamente para obtener el compromiso emocional del personal a nuevas direcciones.

En la transición tipo 3 (evolución forzada) conocida como focalizada en tareas, el estilo de gestión del cambio es directivo, con el líder de cambio actuando como capitán buscando el cumplimiento de los miembros de la organización, para redefinir cómo opera la entidad en áreas específicas; el liderazgo directivo significa que el cambio global es impulsado desde arriba y puede traducirse en un enfoque más consultivo por parte de los gerentes que operan más abajo en la organización quienes están obligados a implementar los cambios.

El cambio tipo 4 (transformación dictatorial) es conocido como recambio y está dirigido a cambios totales de marco; los líderes de cambio participan como comandantes utilizando sus posiciones de poder para forzar los cambios requeridos en la organización. Se asocia con un modelo taylorista con enfoques paternalistas para la gestión del cambio (Essays, 2013).

Los ejemplos de diferentes cambios corporativos son abundantes y una estrategia de cambio exitosa en una organización no lo es en otra. Lo importante es que la estrategia debe estar integrada a las necesidades de negocio de la organización, la cual debe ser capaz de enfrentar la cantidad de cambios estructurales, sistémicos y culturales necesarios, dentro de un determinado tiempo (Dunphy y Stace, 1992).

A partir de la matriz de posiciones de cambio, Dunphy y Stace (1992) plantean las estrategias gerenciales relacionadas especialmente con la estrategia de negocio y con la gestión de recursos humanos, como se aprecia en la figura 11:

Las estrategias de negocio son defensoras (producir a bajo costo, productos de alta calidad y estabilidad en mercados monopolistas), el prospectivo (un innovador de productos en mercados cambiantes), el analizador (es una con costos controlados en algunas áreas e innovación de productos en otras), y el reactivo (para negocios inviables, con reacciones incoherentes a las crisis ambientales).

Las estrategias de recursos humanos son orientadas a tareas y son conocidas también como estructurales (implica unidad de negocio), trabajo en equipo, rediseño de habilidades funcionales, entrenamiento y énfasis relativo en unidades de negocio más que corporativas. Están orientadas a soluciones estructurales, definición de roles, desarrollo de habilidades técnicas y poca participación de los empleados en la 
planificación personal, profesional o corporativa; el segundo tipo es de desarrollo (fuerte énfasis en desarrollo organizacional en áreas como la humana, planes de carrera y cultura organizacional y comunicación organizacional); la tercera, denominada de cambio (relacionada con la redefinición del negocio y la transformación organizacional, definiendo sistemas de recursos humanos y políticas con esquemas de abierto reclutamiento de niveles ejecutivos) y finalmente la estrategia paternalista (se asocia con menor desempeño organizacional con políticas tradicionales de recursos humanos, roles centralistas, procedimientos, control de personal).

\section{Modelo de Kotter (1996)}

Las bases del modelo de Kotter (1980, citado por Hayes, 2018) es la teoría de sistemas abiertos a partir de la cual desarrolla un modelo integrado de dinámica organizacional, que compromete siete elementos clave en el proceso organizacional y seis elementos estructurales, como lo muestra la figura 12.

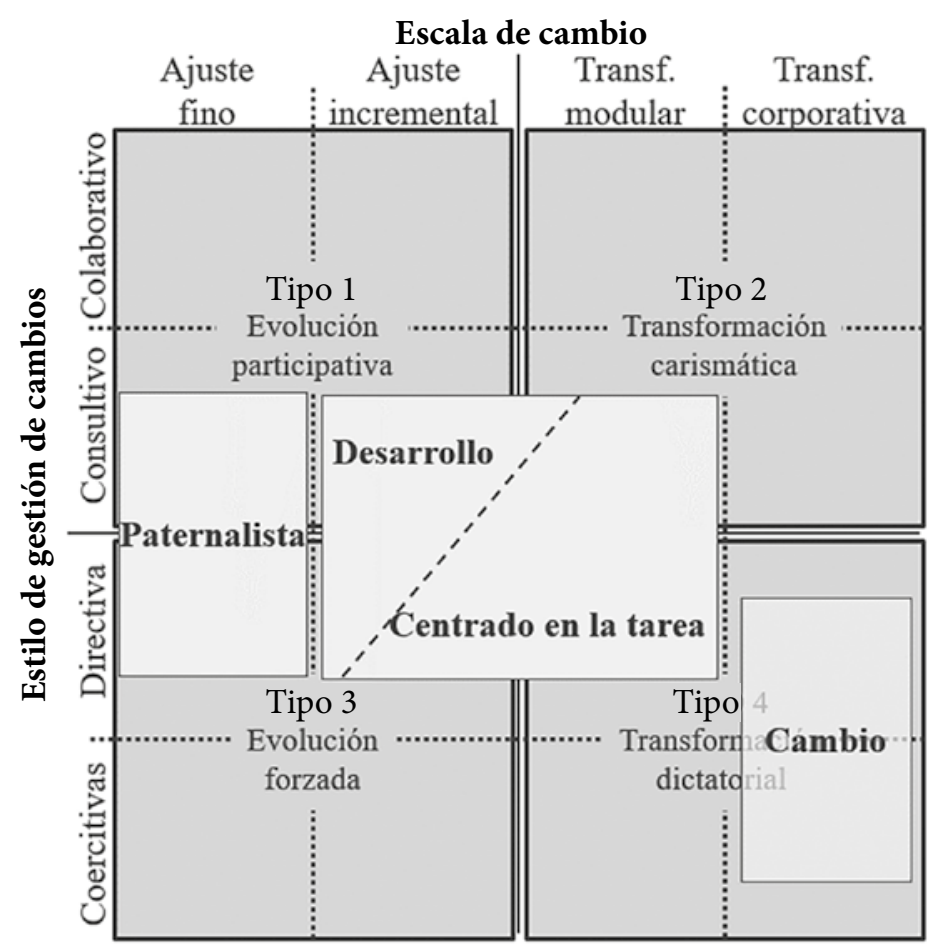

Figura 11. Matriz de cambio y estrategia de recursos humanos

Fuente: Dunphy y Stace (1992) 


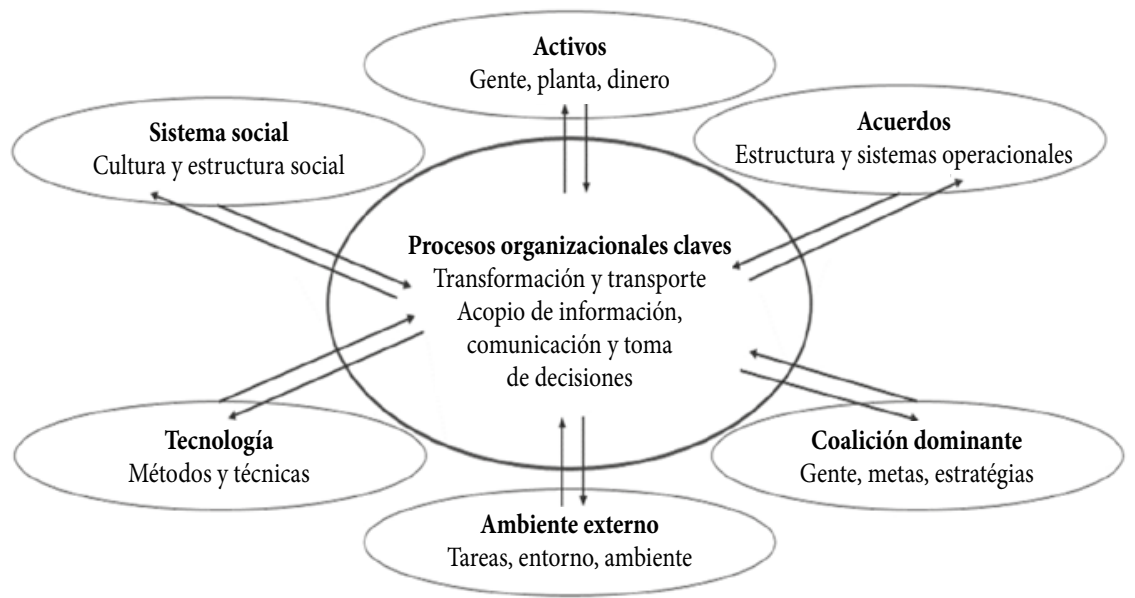

Figura 12. Modelo integrativo de dinámica organizacional de Kotter

Fuente: Hayes (2018)

Kotter (1996, 1998, citado por Pryor, Taneja y Hump, 2008) desarrolló un modelo que debe ser utilizado en el nivel estratégico de la organización para cambiar su visión y posteriormente transformar la organización. Los estudios que utilizan este modelo han demostrado que el proceso de cambio pasa por un conjunto de fases, cada una de las cuales dura una cierta cantidad de tiempo y los errores en cualquier fase pueden impactar el éxito del cambio.

El modelo de Kotter se basa en ocho pasos que se muestran en la figura 13.

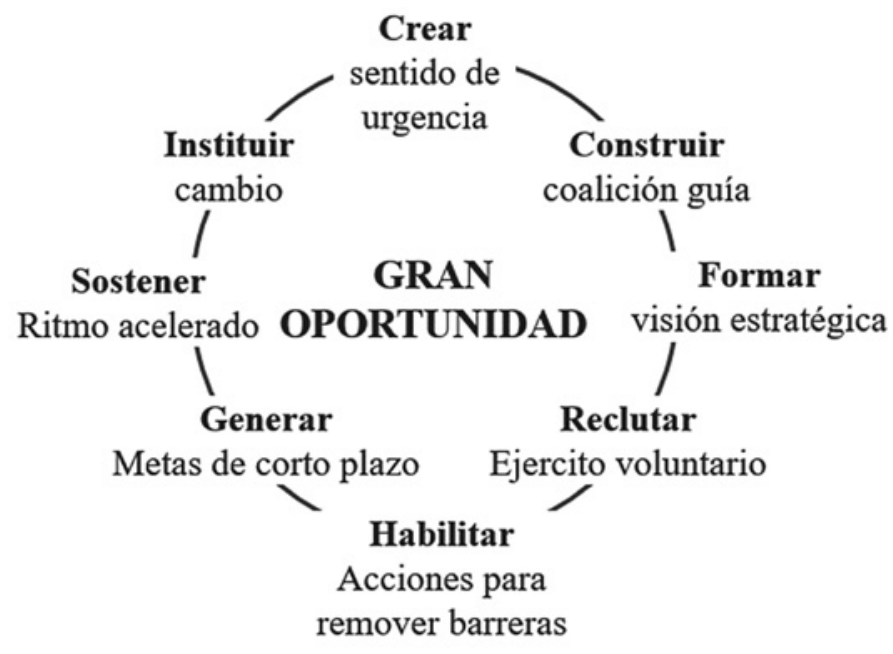

Figura 13. Modelo de ocho pasos de Kotter 
Estos son: (1) la gente prefiere el statu quo ya que el cambio significa incertidumbre sobre el futuro y la incertidumbre incomoda a la gente, además, la gente tiende a desconfiar de cosas que son inciertas, por eso evita el cambio; para animar a las personas al cambio, debe crear un sentido de urgencia. (2) Este paso es similar a las intervenciones en el tratamiento farmacológico, se puede tratar de luchar contra la resistencia al cambio, pero la gente debe hacerlo por sí misma; para contrarrestar la resistencia una opción es formar una poderosa coalición de directivos para trabajar con las personas más resistentes. (3) Aunque no es imposible hacer las cosas sin un plan de acción definido, es mucho más simple (y se obtiene más cooperación) si hay un plan claro, ya que desde el statu quo es más cómodo para la mayoría de la gente revertir a "como de costumbre" y no permitir fluir los cambios si no hay un plan; la creación de una visión y las estrategias para lograrla, ayudarán a acelerar el cambio. (4) Si la gente no sabe que el cambio viene o ha ocurrido, es más probable que se resistan al cambio; por ejemplo, si un compañero de trabajo dice “¿qué te pasa?, esa no es la forma en que estamos haciendo eso ya"; ese comentario hace claro que hay cambios en el lugar de trabajo y que de alguna manera no se ha enterado, probablemente porque la gerencia no pudo comunicar la visión a través de la organización. (5) Recordando una vez más que la gente tiende a preferir el statu quo y que están preocupados por las nuevas experiencias, deben ser alentados o inspirados a cambiar; además, si se quiere que hagan algo nuevo, probablemente se obtendrá más cooperación de ellos si se les enseña cómo y les proporcionan las herramientas necesarias para hacer las cosas de la nueva manera; esto empodera otros a actuar en la visión mediante la eliminación de las barreras al cambio y fomentar el riesgo de tomar iniciativa de resolución de problemas. (6) Este paso parece ser una extensión del paso cinco; la gente debe ser recompensada cuando se aleja de los comportamientos antiguos y hace algo que es nuevo y deseable; básicamente es un refuerzo positivo; este es el paso donde planean, crean y recompensan "victorias" a corto plazo, que mueven a la organización hacia el nuevo cambio de visión. (7) En este paso la resistencia debe estar disminuyendo, pero todavía es necesario observar las acciones, nutrir el cambio y hacer los ajustes necesarios para el cambio. (8) Cuando se trata de trabajar, nunca se puede decir a alguien lo suficiente sobre todas las buenas razones por las que las cosas que ellos hacen llevan la compañía al éxito; de lo contrario, algunas personas tenderán a comportarse como si no tuvieran ninguna razón para hacer algo diferente de lo que hacían antes; por lo tanto, para hacer los cambios más permanentes, usted debe reforzarlos demostrando la relación entre los nuevos comportamientos y cambio organizacional del éxito (Cameron y Green, 2015; Pryor, Taneja y Hump, 2008). 


\section{Modelo de Ghoshal y Barlett (1997)}

Ghoshal y Barlett (Essays, 2013) defienden la importancia de la secuenciación e implementación de las actividades en un proceso de cambio. Las fases de cambio interrelacionadas son:

1. Racionalización: agilizar las operaciones de la empresa.

2. Revitalización: aprovechamiento de recursos y vinculación de oportunidades en toda la organización.

3. Regeneración: gestión de las operaciones y tensiones de las unidades de negocio, al mismo tiempo que colabora en otras partes de la organización para lograr el rendimiento.

Afirman que, si bien el cambio se presenta a menudo como difícil y desordenado, no hay nada místico en el proceso de lograr el cambio con estrategias efectivas tras el proceso secuencial de racionalización, revitalización y regeneración.

Ellos plantean un nuevo modelo de organización a partir de nuevos roles de administración, para lo cual primero hay que reconocer los elementos principales del marco organizacional postransformacional de sus jerarquías tradicionales basadas en la autoridad; la tendencia fue a que las empresas replanteaban su antiguo enfoque de dividir la organización de arriba abajo en grupos, sectores y divisiones y, en su lugar, construían de abajo hacia arriba en una base de pequeñas unidades operativas de primera línea. La segunda característica común en el modelo organizacional emergente son los procesos integrativos entre unidades, que están diseñados para romper las relaciones aisladas orientadas verticalmente que han dominado la jerarquía clásica basada en la autoridad. Finalmente, en la organización emergente, estos cambios en la estructura y los procesos antiguos fueron apoyados por un fuerte compromiso con el empoderamiento genuino, una filosofía que representaba un desafío formidable a la cultura basada en la autoridad en la mayoría de las jerarquías clásicas (Bartlett y Ghoshal, 1997).

Entre las muchas tareas y responsabilidades de los niveles directivos, ellos identifican tres que eran fundamentales en su papel como emprendedores en lugar de solo ejecutores.

\section{Modelo sistémico de Senge et al. (1999)}

Es un modelo de cambio sostenible de ideas y conceptos. Primero plantea las bases con la teoría de las empresas que aprenden, en la V disciplina, en 1991, y más 
adelante desarrollando un claro modelo de cambio en el libro La danza del cambio en 1999, que busca ayudar a quienes se preocupan por construir nuevos tipos de organizaciones para entender los desafíos futuros. Su teoría se basa en la observación de que muchas iniciativas de cambio fallan, planteando que se debe pensar menos como gerentes y más como biólogos, con una miríada de procesos de equilibrio o fuerzas de la homeostasis que actúan para preservar el statu quo en cualquier organización. (Cameron y Green, 2015).

Senge et al. (citados por Cameron y Green, 2015) dicen que las iniciativas de cambio se enfrentarán a cuestiones incrustadas en nuestro sistema de gestión prevaleciente, lo que incluye a gerentes comprometidos con el cambio, siempre que no les afecte a ellos o a tópicos riesgosos de los cuales no se debe hablar, o con el arraigado hábito de atacar síntomas e ignorar las causas profundas del sistema. Sus pautas son:

- Empezar pequeño

- Crecer constantemente

- No planear todo

- Esperar desafíos

Senge utiliza los principios de los sistemas medioambientales para ilustrar cómo operan las organizaciones y para mejorar la comprensión de cómo operan las fuerzas en juego.

Su enfoque es diferente al de la gran mayoría de modelos de cambio, que se centran en las etapas tempranas, tales como la creación de una visión, la planificación, la búsqueda de energía para avanzar y decidir en los primeros pasos. Su modelo se fija en cuestiones a largo plazo que mantengan y renueven el cambio organizacional, para lo cual plantea: primero, iniciar; segundo, sostener, y tercero, rediseñar y replantear el cambio.

Senge dice que los desafíos clave al iniciar el cambio son las fuerzas de equilibrio que surgen cuando cualquier grupo de personas comienza a hacer las cosas de manera diferente, tales como " $¡$ no tenemos tiempo para estas cosas!" (quienes trabajan en iniciativas de cambio necesitarán tiempo extra fuera del día a día para dedicarse a los esfuerzos de cambio), "no tenemos ayuda" (la gente necesitará coaching y apoyo para desarrollar nuevas capacidades), "estas cosas son irrelevantes" (a menos que la gente esté convencida de la necesidad, no va a suceder), "no aplican lo que dicen" (la gente busca el refuerzo de los nuevos valores o nuevos comportamientos por parte de la gerencia). Si estos aspectos no funcionan bien, habrá resistencia al progreso. 
Los empleados se van a sumar si los desafíos de mantener el cambio por parte del grupo piloto (los que empiezan el cambio) son exitosos y el cambio empieza a tocar el resto de la organización, mientras se topa con desafíos como: "esto es pura basura" (incomodidad sentida por individuos cuando se sienten expuestos o temerosos de los cambios y se expresa como "estas cosas cuestan más de lo que vale la pena"), o "esto no está funcionando" (quienes están fuera del grupo piloto, y algunos de los que están dentro de este, pueden estar impacientes por resultados positivos, mientras que las formas tradicionales de medir el éxito no siempre aplican, y puede terminar dando un visión sesgada del progreso), o "nosotros tenemos la razón y ellos no entienden" (el grupo piloto se siente evangelista del cambio y genera una reacción de los “forasteros") , o “iquién está a cargo de estas cosas?” (conflictos que pueden surgir entre los grupos pilotos exitosos, que empiezan a querer hacer más y el resto de la organización), o "seguimos reinventando la rueda" (el reto de difundir el conocimiento, de nuevas ideas y procesos es duro, especialmente para los más distantes que no reciben buena calidad de información), finalmente, “¿a dónde vamos y para qué estamos aquí?" (poner a participar a las personas en torno a cuestiones profundas de propósito y estrategia está lleno de desafíos porque abre la puerta al sagrado interior de la alta dirección, tradicionalmente cerrado) (Cameron y Green, 2015).

\section{Modelo de cambio de Anderson y Anderson (2001)}

El modelo de cambio Anderson y Anderson es totalmente completo diseñado para abordar todo tipo de cambios organizativos y que también capte la naturaleza cíclica del cambio organizacional (D’Ortenzio, 2012; Anderson y Anderson, 2001, p. 13). Este modelo consta de tres áreas: contenido (áreas organizativas y técnicas que necesitan cambio); gente (la mentalidad, cambios conductuales y culturales necesarios para la entrega del cambio propuesto) y proceso (acciones necesarias para planificar, diseñar e implementar el cambio propuesto). Los tres procesos deben realizarse de forma integrada y unificada.

A partir de la tesis de doctorado de D’Ortenzio (2012), de los planteamientos de (Juneja, 2018)y de los propios autores (Anderson y Anderson, 2018), se resumen las nueve fases planteadas por Anderson y Anderson en su modelo de cambio de la siguiente forma: 


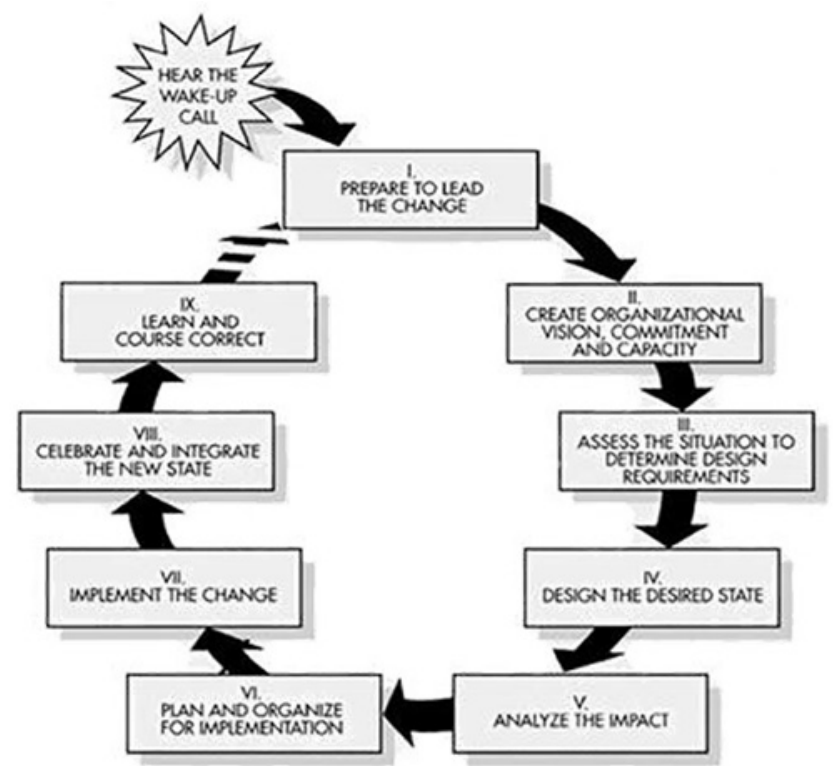

Figura 14. Modelo Anderson y Anderson de cambio

Fuente: D’Ortenzio (2012)

Fase I: prepárese para liderar el cambio; las iniciativas de cambio son resultado de una "llamada de alerta" que lleva al consenso de que hay una necesidad de cambio en la organización y se convierte en imperativo. En esta fase se deben clarificar los roles, determinar las razones del cambio (resultados deseados), evaluar la disponibilidad y capacidad de la organización para implementar el cambio, fortalecer la capacidad de los iniciadores de cambio, diseñar enfoques, procesos, condiciones y estructuras óptimas para el logro exitoso del cambio y, finalmente, clarificar la estrategia general de cambio.

Fase II: crear visión organizativa, compromiso y capacidad, se refiere principalmente a la construcción de la comprensión de toda la organización, el compromiso, el impulso y la capacidad de triunfar en la transformación. En esta fase se motiva a todos los empleados a aceptar el cambio, se utilizan técnicas de comunicación que profundizan la comprensión de la necesidad de cambio.

Fase III: evaluar la situación para determinar los requisitos de diseño, emerge la información que define qué significa el éxito y lo que la organización ya tiene en su lugar que apoya este éxito. En esta fase se crean expectativas claras, se crean escenarios de diseño que puedan afectar el cambio. 
Fase IV: diseñar el estado deseado, el papel de los iniciadores del cambio es diseñar el soluciones organizacionales y culturales que permitirán lograr el éxito de la "visión". Para lograr esta "visión", los iniciadores de cambios deben crear los procesos y estructuras que faciliten el logro del estado deseado, decidir cómo los cuatro niveles de diseño (visión, estratégico, gerencial y operacional) serán administrados.

Fase v: analizar el impacto, se centra en un análisis de la magnitud del impacto que tendrá en el futuro el diseño del estado esperado sobre la organización existente y asegurar que el estado deseado funcione eficazmente como estado integrado.

Fase vi: planificar y organizar la implementación, se refiere principalmente a identificar las acciones necesarias para implementar el estado deseado y desarrollar el plan maestro, para lo cual se requiere que los iniciadores cambien para crear procesos, que identifiquen las acciones que se deben desarrollar en un plan maestro de implementación.

Fase vir: llevar a cabo el plan maestro de ejecución para lograr el estado deseado e implementar cualquier cambio requerido de acuerdo con las necesidades de la organización en su estado actual. En esta fase debe asegurarse el plan maestro de implementación con atención a la resistencia y reacciones de los empleados.

Fase viII: celebrar e integrar el nuevo estado, celebrar el hito de alcanzar el estado deseado, que sirve para integrar a los empleados y apoyarlos para dominar las nuevas mentalidades, comportamientos, destrezas y prácticas; las celebraciones pueden tomar formas como comunicaciones públicas por la gerencia, boletines de edición especial, una fiesta o cena, recompensas como bonificaciones, cartas de agradecimiento, etc.

Fase Ix: aprender y cursar correctamente, esta fase final también es importante ya que requiere que la organización tenga lo siguiente en su lugar:

1. Mecanismos para la mejora continua del nuevo estado.

2. Estrategias de evaluación y aprendizaje de la estrategia y el proceso de cambio diseñado e implementado.

3. La iniciación de acciones destinadas a mejorar la disponibilidad y capacidad de la organización para facilitar los cambios futuros con éxito.

4. El cierre del proceso de cambio mediante el desmantelamiento de infraestructuras temporales y condiciones que no atienden las necesidades de la "nueva" organización. 
Proceso de respuestas complejas de Stacey y Shaw (2001)

Más que un modelo, esta es una escuela, cuyos mayores representantes son Ralph Stacey (2001) y Patricia Shaw (2002), y su orientación plantea el cambio como un nuevo orden de las cosas que emerge naturalmente de una comunicación clara, del conflicto y la tensión. Además, plantean que el gerente no está fuera del sistema, lo controla o planea alterarlo, siendo parte de todo el entorno (Cameron y Green, 2015)

Patricia Shaw (2003) en su libro Cambio de conversaciones en las organizaciones aborda cuestiones tradicionales sobre cómo manejar el cambio y cómo participamos en las maneras en que las cosas cambian con el tiempo, en la paradoja de que nuestra interacción, no importa lo considerada o apasionada que sea, siempre está evolucionando de maneras que no podemos controlar o predecir a largo plazo, sin importar qué tan sofisticadas sean nuestras herramientas de planificación (Stacey, Griffin y Shaw, 2002).

Ralph Stacey y Patricia Shaw escriben sobre complejidad y cambio; los gerentes e incluso consultores encuentran este tipo de lectura difícil porque en principio se aleja de la racionalidad tradicional, en contraste, quienes trabajan en entornos complejos, encuentran que estas ideas y su noción del cambio refleja sus propias experiencias de tratar de manejar el cambio.

Desde esta teoría, Cameron y Green (2015) extraen algunas "reglas" básicas para aquellos que trabajan con procesos de cambio complejos. En un cambio complejo, el papel del líder es:

- Decidir qué negocio es el de la organización y llevar a los demás a estar allí.

- Asegurar que existe un alto nivel de conectividad entre las diferentes partes de la organización, fomentando la retroalimentación y optimizando el flujo de información, permitiendo el aprendizaje.

- Focalizar la atención de las personas en las importantes diferencias entre lo actual y el rendimiento deseado, entre el estilo de trabajo y entre el pasado y los resultados actuales.

Stacey, Griffin y Shaw (2002) plantean cinco maneras de entender la estabilidad y el cambio, dentro del marco de las ciencias de la complejidad en las organizaciones humanas, basado en las cinco diferentes nociones de la teleología (Stacey, Griffin y Shaw, 2002):

- Ley natural, en la que los conceptos de autoorganización y la emergencia no tiene ninguna característica y no hay cambio, más que el movimiento a la perfección. 
- Racionalista, que tampoco tiene implicaciones particulares para la autoorganización y el cambio y que es la consecuencia de la elección humana.

- Formativa, que implica una forma de autoorganización que reproduce formas sin ninguna transformación significativa.

- Transformativa, que implica una forma de autoorganización paradójica, caracterizada tanto por la continuidad como por la transformación.

- Adaptativa, lo que implica un cambio basado en la búsqueda competitiva, con una débil forma de autoorganización confinada a procesos de selección. El cambio es el movimiento hacia un estado estable de adaptación al medio ambiente.

Modelo de cambio de Mento, Jones y Dimdorfer (2002)

En su revisión, Pryor, Taneja y Hump (2008) mencionan el modelo de Mento, Jones y Dimdorfer, planteado en 2002, quienes recomiendan doce pasos para liderar el cambio transformacional, basados en la investigación de otros modelos de cambio y actualizado en sus experiencias de finales de los años noventa.

Los doce pasos se basan e incluyen algunos de los planteados por Jick en su modelo de cambio (Mento, Jones y Dirndorfe, 2002):

1. La idea y su concepto (que necesita ser cambiado).

2. Definir la iniciativa de cambio (analizar la organización y sus necesidades de cambio; similar al primer paso de Jick).

3. Evaluar el clima para el cambio (comprender las funciones de la organización y su entorno).

4. Desarrollar un plan de cambio (incluir metas específicas y detallar responsabilidades; similar al paso siete de Jick).

5. Encontrar y cultivar un "patrocinador" (influenciadores que deben estar comprometidos con el proceso de cambio).

6. Preparar al público objetivo, destinatarios del cambio (identificar resistencias).

7. Crear el ajuste cultural, hacer que el cambio dure (acciones concretas y planes a largo plazo).

8. Desarrollar y elegir un equipo líder de cambio (un líder inspirador que anime a los empleados a asumir la misión organizacional). 
9. Crear pequeños triunfos para la motivación (premiar los logros).

10. Comunicar el cambio constante y estratégicamente (incrementar la comprensión y el compromiso con el proceso de cambio).

11. Medir el progreso del esfuerzo de cambio (implementar programas de medición y seguimiento).

12. Integrar las lecciones aprendidas (evaluación continua de los aprendizajes logrados durante el proceso de cambio).

Modelo de cambio de Jick (2003)

El modelo de Jick (2003) está orientado más hacia un nivel táctico de cambio, por lo tanto, puede ser utilizado como una receta para guiar e iniciar el cambio o para evaluar el cambio que ya está ocurriendo en una organización. Este modelo se puede utilizar para demostrar que el cambio es un proceso en curso y que las preguntas formuladas en cada paso deben estar en curso y a menudo se solapan (Mento, Jones y Dirndorfe, 2002; Pryor, Taneja y Hump, 2008).

Jick plantea que no existe fórmula fácil para acelerar el cambio y lograr que las personas rompan hábitos, pero propone tres áreas que ofrecen mayores oportunidades para acelerar el cambio y reducir los cuellos de botella: 1) acelerar la comprensión y el compromiso de las personas con el cambio. 2) Acelerar los aspectos de la acción y de los experimentos del cambio. 3) Enfatizar el momento para acelerar y para mantener la velocidad (Jick, 1995). Para su modelo plantea nueve pasos y se basa en las experiencias de General Electric y Xerox.

1. Analizar la necesidad organizativa de cambio.

2. Crear una visión compartida y una dirección común separada del pasado.

3. Crear un sentido de urgencia.

4. Apoyar un papel líder fuerte.

5. Alinear patrocinio político.

6. Elaborar un plan de implementación.

7. Desarrollar estructuras habilitadoras.

8. Comunicar, involucrar a la gente y ser honesto.

9. Reforzar e institucionalizar el cambio. 


\section{El modelo ADKAR (2006)}

El modelo ADKAR desarrollado por Prosci Research, una compañía líder en el desarrollo de investigación organizacional proporciona un marco para la comprensión y administración del cambio individual, porque se producen cambios importantes a nivel individual y las organizaciones tienen que considerar primero los cambios de todo su personal. El nombre del modelo ADKAR es un acrónimo y se deriva de los cinco elementos a observar que se cumplen el objetivo del cambio Hiatt (2006, citado por Bejinariu, Jitarel, Sarca y Mocan, 2017):

Awareness change process $\rightarrow$ Proceso de cambio de conciencia;

Desire to engage in change $\rightarrow$ Deseo de participar en el cambio;

Knowledge necessary changes $\rightarrow$ Conocimiento de los cambios necesarios;

Ability to implement change $\rightarrow$ Capacidad para implementar cambios;

Reinforcement the change made $\rightarrow$ Reforzamiento del cambio realizado.

El ADKAR se puede utilizar para crear un plan de acción para el desarrollo profesional y personal mientras se implementa cambios, para desarrollar un plan de manejo para el cambio de organizaciones de recursos humanos y para diagnosticar la resistencia al cambio.

Es fácilmente comprensible y eficaz, se aplica para identificar las brechas que llevaron a defectos en la implementación de un proceso de cambio y puede destacar áreas de mejora el éxito del cambio. La implementación del modelo subyacente de ADKAR sigue siendo cuestionado porque establece acciones prioritarias, de acuerdo con los resultados (Bejinariu, Jitarel, Sarca y Mocan, 2017).

La gestión del cambio en el plano personal y organizacional requiere un nuevo pensamiento, modelos para el cambio y nuevos marcos y herramientas para permitir la implementación fluida del cambio deseado. El modelo Prosci ADKAR es un marco valioso para los líderes, gerentes de cambio y directores de proyectos para liderar eficazmente una amplia variedad de cambios. Más que teorías, son conceptos que conducen a un cambio exitoso con consejos prácticos y sobre cómo implementar estos conceptos (Prosci, 2014).

\section{Trabajo de Huy sobre la gestión del cambio (2007)}

El modelo Huy en realidad es una contribución a la teoría del cambio planificado (véase modelo de procesamiento de cambio continuo) enfocándose en dos 
construcciones que han sido subexploradas: el tiempo y el contenido del cambio, los cuales se interrelacionan con frecuencia en la práctica del cambio planificado, porque algunos elementos organizativos generalmente pueden cambiarse más rápidamente que otros. Los modelos de dirección en este modelo son (Huy, 2001):

Comandante: la intervención de cambio dominante es de corto periodo de tiempo, abrupta y rápida. El cambio suele ser implementado por altos directivos que exigen el cumplimiento de los miembros de la organización. Los cambios pueden incluir reducciones, externalización y desinversiones. Ingeniero: este modelo está orientado hacia una perspectiva de cambio relativamente rápida y a medio plazo, a menudo asistido por analistas de diseño laboral, que ayudan a cambiar los sistemas operativos y de trabajo. El agente de cambio actúa como un catalizador en este proceso. Docente: este modelo adopta una perspectiva de cambio organizacional más gradual y a largo plazo. Asistido por consultores de procesos externos, quienes enseñan a analizar las prácticas de trabajo y comportamientos para revelar nuevas formas de hacerlo. Socializador: esta intervención es también es gradual y a largo plazo. Considera que el cambio se desarrolla a través del aprendizaje experimental participativo basado en procesos organizacionales democráticos automonitoreados (Huy, 2001; Essays, 2013).

El enfoque dominante puede conducir al resentimiento y raramente produce un cambio de comportamiento duradero; el enfoque docente es muy individualista y no puede estar alineado con los objetivos estratégicos corporativos; el enfoque de ingeniería puede no fomentar la colaboración y la propagación del cambio a través de las unidades de negocio y el enfoque socializador puede conducir a una mayor concentración en los grupos de trabajo individuales en lugar de la manera de operar como parte de un colectivo más grande y corporativo (Essays, 2013).

En la tabla 2 se pueden ver los tipos de modelos (Huy, 2001):

Tabla 2. Cambio de contenido y cambio asociado a tipos de intervención ideales

\begin{tabular}{|c|c|c|}
\hline \multirow{2}{*}{ Contenido de tangibilidad } & \multicolumn{2}{|c|}{ Énfasis de cambio en la literatura } \\
\hline & Cambio episódico & Cambio continuo \\
\hline Tangible (teoría E) & $\begin{array}{c}\text { Estructuras formales } \\
\text { Comandante }\end{array}$ & $\begin{array}{c}\text { Procesos de trabajo } \\
\text { Ingeniería }\end{array}$ \\
\hline Intangible (teoría O) & $\begin{array}{l}\text { Creencias } \\
\text { Docente }\end{array}$ & $\begin{array}{c}\text { Relaciones sociales } \\
\text { socializador }\end{array}$ \\
\hline
\end{tabular}




\section{Conclusiones}

Después de haber discutido el tema de la gerencia del cambio, y de transitar por veintitrés diferentes modelos, se pueden apreciar más similitudes que diferencias entre estos. Unos plantean más etapas que otros, no porque sean diferentes significativamente, sino más bien porque para algunos es más importante particularizar y para otros es preferible ser abarcadores. Finalmente, son cuatro los pasos básicos para la gerencia del cambio: diagnóstico, planeación, intervención y evaluación, los cuales, en coincidencia de todos los autores, deben ser adaptados a cada organización, como lo indica la lógica.

Por esta razón, cabe cuestionarse si el proceso de adaptación no impide hablar de modelos e incluso de metodologías de conducción del proceso de cambio, y más bien se centra en la capacidad profesional de quien asesora el cambio, en saber analizar las organizaciones para lograr detectar los hechos más significativos y plantear para estas alternativas particularizadas a cada contexto organizacional.

\section{Referencias}

Amagoh, F. (2008). Perspectives on organizational change: Systems and complexity theories. The Innovation Journal: The Public Sector Innovation Journal, 13(3), 1-14.

Anderson, L. A. y Anderson, D. (2018). Building your change strategy: How to ensure that your effort is on the right track. www.beingfirst.com www.changeleadersnetwork.com/ blog : www.changeleadersnetwork.com/blog

Anderson, N., Ones, D. S., Sinangil, H. K. y Viswersvaran, C. (2001). Handbook of industrial, work \& organizational psychology: Volume 1: Personnel psychology. Sage.

Armstrong, M. (2006). A handbook of human resource management practice. Kogan Page Publishers.

Arnold, J. y Randall, R. (2005). Work psychology: Understanding human behaviour in the workplace. Pearson Education.

Bartlett, C. A. y Ghoshal, S. (1997). The myth of the generic manager: New personal competencies for new management roles. California Management Review, 40(1), 92-116.

Bejinariu, A. C., Jitarel, A., Sarca, I. y Mocan, A. (2017). Organizational change managementconcepts definitions and approaches inventory. Management challenges in a network economy (pp. 321-330). Lublin.

Borman, W. C., Klimoski, R. J. y Ilgen, D. R. (2003). Stability and change in industrial and organizational psychology. Handbook of Psychology. John Wiley y Sons, Inc.

Bridges, W. y Mitchell, S. (2000). Leading transition: A new model for change. Leader to Leader, 16(3), 30-36. 
Brisson-Banks, C. V. (2010). Managing change and transitions: a comparison of different models and their commonalities. Library Management, 31(4), 241-252.

Burke, W. W. y Litwin, G. H. (1992). A causal model of organizational performance and change. Journal of Management, 18(3), 523-545.

Burnes, B. (2004). Managing change: A strategic approach to organisational dynamics. Pearson Education.

Burnes, B. (2007). Kurt Lewin and the Harwood Studies. Journal of Applied Behavioral Science, 43(2), 213-231.

Cameron, E. y Green, M. (2015). Making sense of change management: A complete guide to the models, tools and techniques of organizational change. Kogan Page Publishers.

Cao, G., Clarke, S. y Cao, B. L. (2003). Diversity management in organizational change: Towards a systemic framework. Systems Research and Behavioral Science, 20(3), 231-242.

Carnall, C. (2018). Managing change. Routledge.

Cummings, T. G. y Worley, C. G. (2014). Organization development and change. Cengage Learning.

D’Ortenzio, C. (2012). Understanding change and change management processes: A case study. [tesis de doctorado University of Canberra] http://www.canberra.edu.au/researchrepository/file/81c02a90-6a15-91ae-c7a2-ff44c96d60b2/1/full_text.pdf

Díaz, L. (1999). Psicología del trabajo y las organizaciones: concepto, historia y método. Departamento de Psicología Cognitiva, Social y Organizacional Universidad de La Laguna.

Dotse, J. E., Okyireh, M. A. y Kumako, S. K. (2015). Evolution of organizational development and implications for management of Ghanaian organizations. European Journal of Business and Management, 54-56.

Essays, U. (2013). UK Essays. Literature Review on Organisational Change Management Essay. https://www.ukessays.com/essays/management/literature-review-on-organisational-change-management-essay.php?vref=1

Fayol, H. (1916). General principles of management. Classics of Organization Theory.

Fitzgerald, L., Ketley, D., Buchanan, D., Gollop, R., Jones, J. L., Lamon, S. S., . . Whitby, E. (2005). No going back: A review of the literature on sustaining organizational change. International Journal of Management Reviews, 73(3), 189-205.

French, W. L. (1999). Organization development: Behavioral science interventions for organization improvement. Prentice Hall.

Gallos, J. V. (2006). Organization development. John Wiley \& Sons.

Hayes, J. (2018). The theory and practice of change management. Palgrave Macmillan.

Huy, Q. N. (2001). Time, temporal capability, and planned change. Academy of Management Review, 26(4), 601-623. 
Jick, T. D. (1995). Accelerating Change for competitive advantage. Organizational Dynamics, 24(1), 77-82.

Juneja, P. (2018). Management Study Guide. https://www.managementstudyguide.com/

Kerber, K. y Buono, A. F. (2005). Rethinking organizational change: Reframing the challenge of change management. Organization Development Journal, 23(3), 23.

Kotter, J. (2018). 8 steps for accelerate change in your organization. https://www.kotterinc. $\mathrm{com} /$ research-and-perspectives/8-steps-accelerating-change-ebook-confirmation

Kozlowski, S. W. (2012). The Oxford handbook of organizational psychology. Oxford University Press, Inc.

Kreps, G. (1995). Comunicación en las organizaciones. Addison-Wesley Iberoamericana.

Kritsonis, A. (2005). Comparison of change theories. International Journal of Scholarly Academic Intellectual Diversity, 8(1), 1-7.

Magretta, J. (2012). What management is. Simon and Schuster.

McGill, M. E. (1974). The evolution of organization development. Public Administration Review, 34(2), 98-105.

McGuire, D. y Hutchings, K. (2006). A Machiavellian analysis of organizational change. Journal of Organizational Change Management, 19(2), 192-209.

McKendall, M. (1993). The tyranny of change: Organizational development revisited. Journal of Business Ethics, 12(2), 93-104.

Mento, A. J., Jones, R. M. y Dirndorfe, W. (2002). A change management process: Grounded in both theory and practice. Journal of Change Management, 3(1), 45-59.

Mintzberg, H. y Quinn, J. B. (1997). El proceso estratégico: conceptos, contextos y casos. Pearson Educación.

Morgan, G. (1991). Imágenes de la organización. Alfaomega.

Nadler, D. A. (2004). What's the board's role in strategy development?: Engaging the board in corporate strategy. Strategy \& Leadership, 32(5), 25-33.

Nadler, D. A. (2007). The CEO's second act. Harvard Business Review, 85(1), 66.

Paul, M. L. (2015). The future of organizational change management [Bachelor's thesis]. Twente Netherlands.

Pinto, C. (2012). Desarrollo organizacional. Red Tercer Milenio.

Prosci. (2014). Best practices in change management. Prosci Inc.

Pryor, M. G., Taneja, S. y Hump, J. (2008). Challenges facing change management theories and research. Delhi Business Review, 9(1), 1-20.

Quattrone, P. y Hopper, T. (2001). What does organizational change mean? Speculations on a taken for granted category. Management accounting research. Management Accounting Research, 12(4), 403-435.

Robbins, S. y Coulter, M. (2009). Administración (10 ed.). Pearson. 
Romero, J., Matamoros, S. y Campo, C. A. (2013). Sobre el cambio organizacional. Una revisión bibliográfica. Innovar, 23(50), 35-52.

Schein, E. H. (1988). Organizational culture. American Psychological Association, 45(2), 109.

Segredo, A. M. (2016). Aproximación teórica a la evolución, teorías, enfoques y características que han sustentado el desarrollo de las organizaciones. Revista Cubana de Salud Pública (42), 585-595.

Shaw, P. (2003). Changing conversations in organizations: A complexity approach to change. Routledge.

Shodhganga. (2012). Change management from balanced scorecard perspective: Study of selected Indian organizations. http://shodhganga.inflibnet.ac.in/bitstream/10603/55622/12/12 chapter\%202.pdf

Society for Industrial and Organizational Psychology. (2018). Society for Industrial and Organizational Psychology. http://www.siop.org/visibilitybrochure/memberbrochure. aspx

Stace, D. A. y Dunphy, D. C. (1992). Translating business strategies into action: Managing strategic change. Strategic Change, 1(4), 203-216.

Stacey, R. D., Griffin, D. y Shaw, P. (2002). Complexity and management. Routledge.

Teece, D. J., Pisano, G. y Amy, S. (1997). Dynamic capabilities and strategic management. Strategic Management Journal, 18(7), 509-533.

Todnem, R. B. (2005). Organisational change management: A critical review. Journal of Change Management, 5(4), 369-380.

Tripon, C. y Dodu, M. (2005). Change management and organisation development. New York University Press.

Ukpata, S. L. y Olukotun, A. G. (2008). The effect of organizational development on the Nigerian economy. African Journal of Business Management, 2(5), 85.

Worley, C. G. y Feyerherm, A. E. (2003). Reflections on the future of organization development. The Journal of Applied Behavioral Science, 39(1), 97-115.

Young, M. (2009). A meta model of change. Journal of Organizational Change Management, 22(5), 524-548. 



\section{8 \\ TENDENCIAS DE LA CULTURA \\ Y CAMBIO ORGANIZACIONAL: \\ ESTUDIO DE CASO \\ Mónica García-Rubiano* \\ Juan Javier Vesga Rodríguez** \\ Carlos Forero-Aponte ${ }^{\star \star \star}$ \\ Universidad Católica de Colombia}

\section{Introducción}

La imagen corporativa en relación con el medio se evidencia en el informe de Deloitte (2018) sobre tendencias del capital humano, en donde se reportan alrededor de 11.000 cuestionarios aplicados a gerentes de 140 países y 150 líderes de empresas colombianas, el planteamiento realizado sugiere que el capital social cobra tanto importancia como el físico y el financiero. Estos aspectos están relacionados con la identidad corporativa y cómo se relaciona a su vez con la cultura y la gestión del cambio en la organización.

La cultura y la gestión del cambio han cobrado mucho interés para las personas que guían las organizaciones, los estudios realizados por Deloitte en 2017 se focalizaron en la relación de la cultura y el compromiso como elementos importantes del empleado; los resultados del estudio dejan en evidencia cómo la habilidad de las organizaciones para afrontar inconvenientes de compromiso y cultura tenían una reducción del $14 \%$ con respecto al año anterior, estos datos permiten entender la complejidad del ambiente en el ámbito laboral y dan cuenta de la importancia de desarrollar conocimiento válido que oriente a académicos y empresarios para que puedan abordar de una manera adecuada estos aspectos.

mgarcia@ucatolica.edu.co

* https://orcid.org/0000-0002-7699-502X

** https://orcid.org/0000-0003-2382-5104

*** https://orcid.org/0000-0003-0132-4595 


\section{Cultura organizacional}

Este constructo ha sido estudiado por diversas disciplinas como la sociología y la antropología. White (1964) señala que la cultura es producto de las características propias del contexto de la organización. Por su parte, Morgan (1998) considera que el estudio de la cultura se hizo más evidente después de la segunda guerra mundial.

Para Cameron y Quinn (2011) y Schein (1984) la cultura hace referencia al desarrollo de los aspectos tácitos dados por un grupo de personas y evidenciado en la organización a partir de procesos de innovación con miras al cumplimiento de los principios de la organización por parte de los miembros de esta. Y, por lo tanto, debe ser orientado a las personas que se integren a la organización como aspectos validados por esta y que se convierten en una guía de acción.

Los estudios sobre cultura muestran que el modelo de valores por competencias es uno de los más influyentes ya que se centró en la identificación de indicadores de efectividad organizacional (Quinn y Rohrbaugh, 1983), lo que llevó a la generación de grandes controversias.

\section{Modelo de valores en competencia}

Este modelo tiene como principal objetivo evaluar los valores dentro de la organización y preparar el cambio necesario para la organización (Cameron y Quinn, 2011), permitiendo diagnosticar la actuación de las personas en la organización en función de los valores y la manera como estos se pueden incorporar a los valores organizacionales. Este modelo considera dos ejes, el horizontal contrasta la orientación interna que se enfoca en beneficio de la organización y la orientación externa focalizada en el logro de los objetivos (Baray, 2009). El segundo eje es la vertical diferencia entre la flexibilidad y el control (Vargas, Sampieri, Álvarez y Vargas, 2012). La combinación de estos dos ejes da lugar a cuatro tipos de cultura.

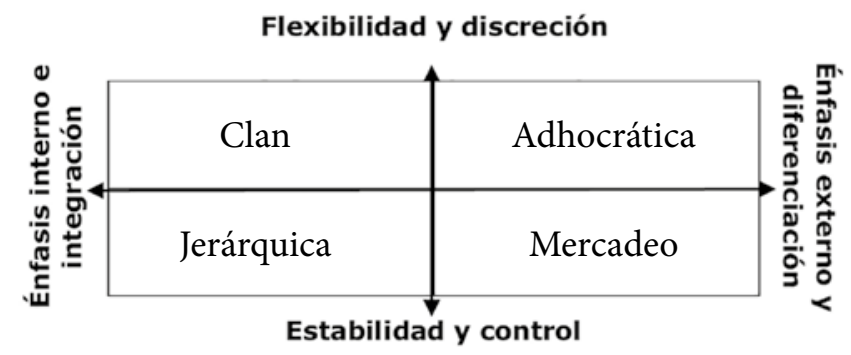

Figura 1. Cultura organizacional según el modelo de valores en competencias

Fuente: Cameron y Quinn (2006, p. 35) 
Cultura de clan: la cultura de clan se enmarca entre orientación interna y control flexible que interactúan entre sí de manera proporcional. Esta cultura se caracteriza por tener una dinámica familiar, en donde sus valores y objetivos son compartidos por las personas que trabajan en la empresa, se genera sentido de pertenencia, trabajo en equipo, lealtad y consenso (Quinn y Rohrbaugth, 1981; Cameron y Quinn, 2011).

Cultura adhocrática: la organización es un lugar dinámico, que promueve la innovación y creatividad, que permiten la generación de nuevos productos y servicios (Cameron y Quinn, 2011).

Cultura jerárquica: es característico de empresas estructuradas y formalizadas. Permite la estabilidad y el desempeño eficiente en términos de entregas confiables, programación exacta y bajo costo (Cameron y Quinn, 2011).

Cultura de mercadeo: se orienta a los resultados, por consiguiente, su énfasis es el éxito, ganar y mantener la reputación corporativa (Robbins, 2004).

\section{Cambio organizacional}

El concepto de cambio se ha transformado a lo largo del tiempo (Roskin, 1986). El cambio organizacional es la transformación a la cual está sujeta una organización y que puede causar diferente impacto a la cultura, es un proceso flexible, combinado y de doble entrada (Grant, Michelson, Oswick y Wailes, 2005). Los autores señalan que es un proceso multiperspectivo, que considera diversos aspectos como el comportamiento y las actitudes de las personas, así como los contextos en los que se puede desarrollar.

Finalmente, Jacobs, Witteloostuijn y Zeyse (2012) definen el cambio organizacional como un fenómeno notoriamente complejo, debido a que se pueden tener perspectivas muy diferentes a veces complementarias, pero también contradictorias, pues en ella se centran tres niveles a evaluar: uno micro, que se refiere a los individuos; uno meso, que se refiere a los grupos, y uno macro, que se refiere al entorno de la organización y de las poblaciones de las organizaciones.

En conclusión, el cambio organizacional se puede definir como esa transformación de los procesos y actividades desarrollados por el individuo en la organización, que generan un impacto sociocultural significativo para promover un adecuado desempeño laboral que incremente la satisfacción del individuo y del grupo logrando mayor rentabilidad en la organización. En el momento en que se presenta un cambio dentro de la organización, todos los integrantes reciben una información básica sobre los cambios que se planea implementar, en ese momento, se generan los primeros cuestionamientos y el análisis de cómo estos cambios pueden afectar su situación laboral 
actual, para que el cambio que se está presentando sea significativo, la organización debe tener la capacidad de implementarlo de tal forma que se puedan cumplir sin que esto afecte negativamente al trabajador (Amis y Ai“Ssaoui, 2013).

El cambio, en la perspectiva de los trabajadores, ha sido abordado principalmente desde las actitudes; sin embargo, la disposición ha sido propuesta como un factor clave que explica las respuestas a los eventos organizacionales tales como los cambios (Smollan, Matheny y Sayers, 2010). El abordaje disposicional implica la tendencia de las personas a sentir y actuar en relación con su contexto laboral, independientemente de la naturaleza y características de su trabajo (Weiss y Cropanzano, 1996).

En la investigación realizada por Villa, Pons y Obando (2018) se utilizó una metodología para diagnosticar el cambio y la cultura organizacional en el desarrollo de la gestión relacionada con la calidad en instituciones de educación superior. Los resultados evidencian barreras culturales que son propias de las instituciones, además, los planes de mejoramiento para la variable de índole social incrementaron el compromiso de los trabajadores con respecto a los procesos de acreditación.

Teniendo en cuenta lo anterior, la pregunta de investigación es ¿cuál es la asociación entre los aspectos de la cultura y el cambio organizacionales? Como objetivo general se establece identificar la asociación entre los aspectos de la cultura y el cambio organizacionales. Los objetivos específicos son: a) caracterizar la cultura organizacional y la disposición al cambio en las organizaciones participantes, y b) realizar el análisis de la relación entre los aspectos de la cultura y el cambio organizacionales.

\section{Diseño}

La investigación propuesta se enmarca en un estudio correlacional entre la cultura y el cambio organizacional (Ato, López y Benavente, 2013).

\section{Participantes}

La población participante fue de 212 empleados de una organización de educación superior, de los cuales 118 (55,7\%) son hombres y 94 (44,3\%) mujeres, cuyas edades oscilan entre los 22 y 83 años; la antigüedad de los empleados en la organización está entre los 6 meses y 41 años. El máximo nivel de estudios alcanzado es de posgrado $132(62,35 \%)$, seguido por técnico/tecnológico $39(18,4 \%)$, pregrado $30(14,2 \%)$ y secundaria 11 (5,2\%); el estado civil que predomina es casados 112 (52,8\%), solteros 58 $(27,4 \%)$, en unión libre (12,7\%), separados o divorciados $15(7,1 \%)$; en cuanto al tipo de contratación, el 54,7\% (116) es a término indefinido, el $42 \%$ (89) a término fijo, el $1,9 \%$ (4) con prestación de servicios, y el 1,4\% (3) por obra labor. 


\section{Instrumentos}

Para la variable criterio - disposición al cambio organizacional- se empleó el cuestionario diseñado por García y Forero (2016). El instrumento está constituido por tres macrodimensiones: a) individual, b) grupal y c) organizacional, y siete subdimensiones que componen las macrodimensiones: a) aceptación, b) motivación, c) comunicación, d) liderazgo, e) conocimiento, f) clima y g) cultura.

Para medir la orientación de la cultura organizacional se utilizó el instrumento diseñado por Cameron y Quinn (2006), el Organizational Culture Assessment Instrument (OCAI), el cual está constituido por seis dimensiones: a) características dominantes, b) liderazgo organizacional, c) administración de personal, d) unión de la organización, e) énfasis estratégico y f) criterio de éxito. Las dimensiones identifican cuatro tipos de cultura organizacional: 1) clan, 2) adhocracia, 3) mercado y 4) jerarquía.

\section{Procedimiento}

Las fases en las que se desarrolló esta investigación fueron revisión literatura, aplicación, instrumentos y análisis de resultados.

\section{Resultados}

\section{Estadísticos descriptivos de las variables}

En la tabla 1 se presentan los descriptivos de los instrumentos de cultura y cambio organizacional. Con relación a la prueba de disposición al cambio, las respuestas de las personas muestran unas medias de la prueba entre 5,20 y 4,97, y las desviaciones están entre 1,02 y 0,87 , lo que muestra homogeneidad en las respuestas y una adecuada disposición al cambio por parte de los participantes.

En relación con la orientación de la cultura organizacional la tendencia está entre la cultura jerárquica y la cultura de clan; en la primera predomina el control y la eficiencia, y prevalece la formalización y la estructura del lugar de trabajo; en la segunda predomina la participación y el compromiso que en un sentido figurativo es como una familia, donde la base es el trabajo en equipo, el compromiso organizacional y el involucramiento del empleado. 
Tabla 1. Descriptivos de las variables objeto de estudio

\begin{tabular}{|c|c|c|c|c|}
\hline & Mínimo & Máximo & Media & $\begin{array}{l}\text { Desviación } \\
\text { estándar }\end{array}$ \\
\hline \multicolumn{5}{|l|}{ Cambio organizacional } \\
\hline Dimensión individual & 2,12 & 6,00 & 4,7139 & 0,83381 \\
\hline Motivación & 1,00 & 6,00 & 4,4473 & 1,03030 \\
\hline Aceptación & 2,50 & 6,00 & 5,2028 & 0,68074 \\
\hline Dimensión grupal & 2,71 & 6,00 & 4,6776 & 0,73232 \\
\hline Comunicación & 2,29 & 6,00 & 4,5067 & 0,82450 \\
\hline Liderazgo & 2,14 & 6,00 & 4,8484 & 0,75453 \\
\hline $\begin{array}{c}\text { Dimensión } \\
\text { organizacional }\end{array}$ & 2,31 & 6,00 & 4,8709 & 0,69249 \\
\hline Clima & 1,20 & 6,00 & 4,9726 & 0,77631 \\
\hline Conocimiento & 1,25 & 6,00 & 4,6073 & 0,87079 \\
\hline Cultura & 1,00 & 6,00 & 4,9488 & 0,83362 \\
\hline \multicolumn{5}{|l|}{ Cultura organizacional } \\
\hline $\begin{array}{c}\text { Características } \\
\text { dominantes }\end{array}$ & 8,00 & 36,00 & 27,3632 & 5,63799 \\
\hline $\begin{array}{c}\text { Liderazgo } \\
\text { organizacional }\end{array}$ & 4,00 & 36,00 & 27,9104 & 6,03359 \\
\hline $\begin{array}{l}\text { Administración de los } \\
\text { empleados }\end{array}$ & 4,00 & 36,00 & 26,3113 & 5,71165 \\
\hline $\begin{array}{c}\text { Cohesión } \\
\text { organizacional }\end{array}$ & 8,00 & 36,00 & 27,7736 & 5,49068 \\
\hline Énfasis estratégico & 6,00 & 36,00 & 27,6887 & 5,99741 \\
\hline Criterio de éxito & 6,00 & 36,00 & 25,3208 & 6,06528 \\
\hline Clan & 7,00 & 54,00 & 41,5519 & 8,61566 \\
\hline Adhocrática & 7,00 & 54,00 & 39,1085 & 8,85226 \\
\hline De mercado & 12,00 & 54,00 & 39,6887 & 8,42796 \\
\hline Jerárquica & 12,00 & 54,00 & 42,0189 & 7,55326 \\
\hline
\end{tabular}

\section{Correlaciones de las variables}

En las tablas 2 y 3 se muestran las correlaciones entre las dimensiones de la cultura, tipos de cultura organizacional y disposición al cambio, lo que deja en evidencia tanto en las dimensiones como en los tipos de cultura correlaciones significativas al 0,01 con respecto a la disposición al cambio.

A pesar de presentarse correlaciones significativas entre todas las variables de disposición al cambio y cultura organizacional, es importante evaluar la fuerza de la asociación, de acuerdo con Coe y Merino (2003), ya que en este tipo de evaluaciones no resulta conveniente emplear la expresión tamaño del efecto, dado que no se trata de una evaluación de relaciones de causalidad. 


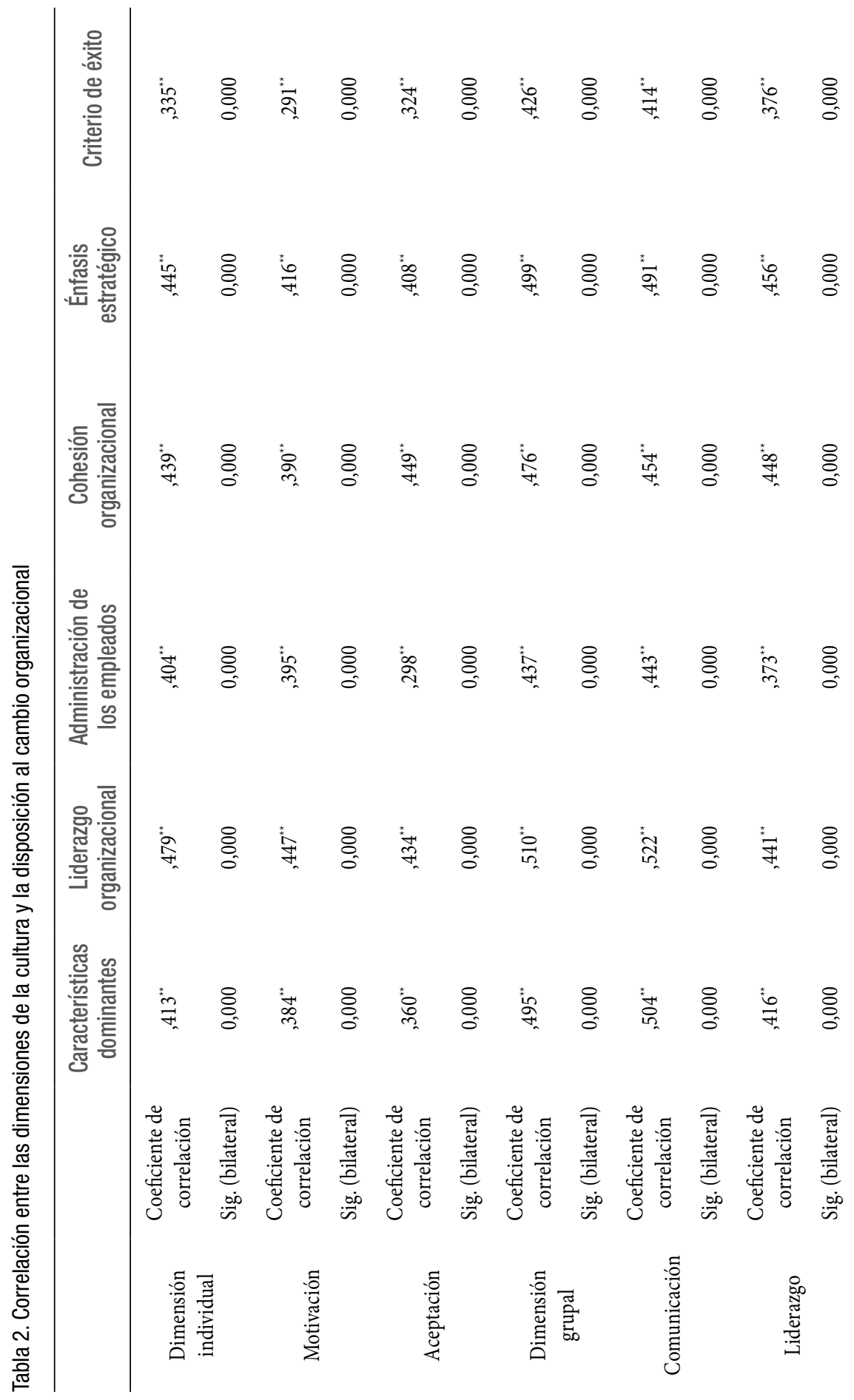


Tendencias de la cultura y cambio organizacional: estudio de caso

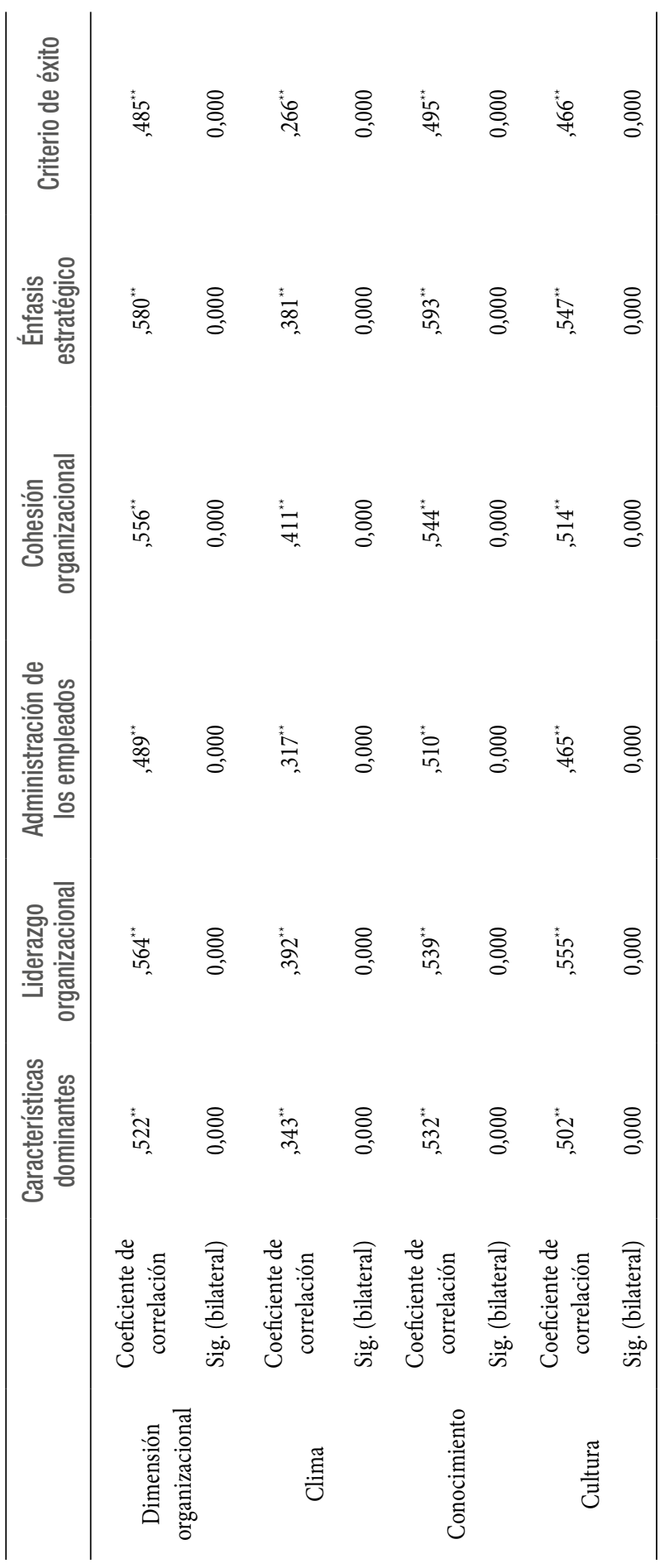


Tabla 3. Correlación entre los tipos de la cultura y la disposición al cambio organizacional

\begin{tabular}{|c|c|c|c|c|c|}
\hline & & Clan & Adhocrática & De mercado & Jerárquica \\
\hline \multirow[t]{2}{*}{ Dimensión individual } & $\begin{array}{l}\text { Coeficiente de } \\
\text { correlación }\end{array}$ &, $508^{* *}$ & $394^{* *}$ &, $362^{* *}$ &, $496^{* *}$ \\
\hline & Sig. (bilateral) & 0,000 & 0,000 & 0,000 & 0,000 \\
\hline \multirow[t]{2}{*}{ Motivación } & $\begin{array}{l}\text { Coeficiente de } \\
\text { correlación }\end{array}$ &, $487^{* *}$ &, $369^{* *}$ &, $310^{* *}$ &, $461^{* *}$ \\
\hline & Sig. (bilateral) & 0,000 & 0,000 & 0,000 & 0,000 \\
\hline \multirow[t]{2}{*}{ Aceptación } & $\begin{array}{l}\text { Coeficiente de } \\
\text { correlación }\end{array}$ &, $427^{* *}$ & $345^{* *}$ &, $368^{* *}$ &, $440^{* *}$ \\
\hline & Sig. (bilateral) & 0,000 & 0,000 & 0,000 & 0,000 \\
\hline \multirow[t]{2}{*}{ Dimensión grupal } & $\begin{array}{l}\text { Coeficiente de } \\
\text { correlación }\end{array}$ &, $580^{* *}$ & $468^{* *}$ &, $424^{* *}$ &, $517^{* *}$ \\
\hline & Sig. (bilateral) & 0,000 & 0,000 & 0,000 & 0,000 \\
\hline \multirow{2}{*}{ Comunicación } & $\begin{array}{l}\text { Coeficiente de } \\
\text { correlación }\end{array}$ &, $580^{* *}$ &, $472^{* *}$ &, $412^{* *}$ &, $511^{* *}$ \\
\hline & Sig. (bilateral) & 0,000 & 0,000 & 0,000 & 0,000 \\
\hline \multirow{4}{*}{ Dimensión organizacional } & $\begin{array}{l}\text { Coeficiente de } \\
\text { correlación }\end{array}$ &, $509^{* *}$ &, $406^{* *}$ & $381^{* *}$ &, $466^{* *}$ \\
\hline & Sig. (bilateral) & 0,000 & 0,000 & 0,000 & 0,000 \\
\hline & $\begin{array}{l}\text { Coeficiente de } \\
\text { correlación }\end{array}$ & $622^{* *}$ &, $537^{* *}$ & $498^{* *}$ &, $580^{* *}$ \\
\hline & Sig. (bilateral) & 0,000 & 0,000 & 0,000 & 0,000 \\
\hline \multirow[t]{2}{*}{ Clima } & $\begin{array}{l}\text { Coeficiente de } \\
\text { correlación }\end{array}$ & $459^{* *}$ &, $319^{* *}$ &, $311^{* *}$ &, $395^{* *}$ \\
\hline & Sig. (bilateral) & 0,000 & 0,000 & 0,000 & 0,000 \\
\hline \multirow{3}{*}{ Conocimiento } & $\begin{array}{l}\text { Coeficiente de } \\
\text { correlación }\end{array}$ & $618^{* *}$ &, $561^{* *}$ &, $509^{* *}$ &, $576^{* *}$ \\
\hline & Sig. (bilateral) & 0,000 & 0,000 & 0,000 & 0,000 \\
\hline & $\mathrm{N}$ & 212 & 212 & 212 & 212 \\
\hline \multirow[t]{2}{*}{ Cultura } & $\begin{array}{l}\text { Coeficiente de } \\
\text { correlación }\end{array}$ &, $568^{* *}$ &, $527^{* *}$ &, $472^{* *}$ &, $549^{* *}$ \\
\hline & Sig. (bilateral) & 0,000 & 0,000 & 0,000 & 0,000 \\
\hline
\end{tabular}

\section{Discusión}

La investigación pone en evidencia la relación entre cambio y cultura organizacional, acordes con el planteamiento de Pettigrew (1979), quien afirma que la cultura hace referencia a los significados aceptados de manera pública y colectiva. Así mismo, se relaciona con la postura de Cameron y Quinn (2006), en cuanto estos resaltan 
aspectos internos (personas) como externos (grupo y organización) que permiten identificar diferentes tipos de cultura.

Los resultados de esta investigación son coherentes con el estudio realizado por Haffar, Al-Karaghouli y Ghoneim (2012), quienes examinaron la influencia de los cuatro tipos de cultura organizacional de la estructura de valores en competencia, en el nivel de preparación individual para el cambio e identificar la cultura y las características de esas organizaciones; los resultados de los análisis indicaron que existe mayor correlación entre los componentes de la preparación individual para el cambio y los tipos de cultura adhocrática; la investigación tuvo como fin brindar una percepción holística en cambio de centrarse en el impacto de los tipos de cultura organizacional en la preparación individual para el cambio.

Schein (2004) señala que la cultura es un patrón de suposiciones aprendidas, compartidas y utilizadas para resolver problemas externos e internos y lograr una adecuada integración del grupo de trabajo, por lo que es pertinente lograr una cultura capaz de afrontar cambios en las organizaciones que permita estar a la vanguardia de la innovación.

\section{Conclusiones}

Se puede concluir que lo más importante en el momento de realizar un cambio organizacional es conocer la cultura, los comportamientos de los individuos y de los grupos inmersos en ella, su rendimiento y aprendizaje dentro de la organización, para identificar qué debe cambiarse y cuál sería la mejor estrategia para lograrlo evitando la resistencia al cambio (Cameron y Quinn, 2011).

En futuras investigaciones es recomendable considerar el incremento del alcance psicométrico y explicativo de los cuestionarios empleados, así como la población a la cual se aplican los instrumentos.

\section{Referencias}

Amis, J. M. y Ai“'Ssaoui, R. (2013). Readiness for change: An institutional perspective. Journal of Change Management, 13(1), 69-95. doi: 10.1080/14697017.2013.768435

Ato, M., López, J. J. y Benavente, A. (2013). Un sistema de clasificación de los diseños de investigación en psicología. Anales de Psicología, 29 (3), 1038-1059.

Baray, H. L. A. (2009). Análisis de la orientación al mercado y la cultura organizacional de las pequeñas empresas de la industria de artes gráficas local. Revista Internacional Administracion y Finanzas, 2 (1), 19-30.

Cameron, K. y Quinn, R. (2006). Diagnosing and changing organizational culture. Jossey-Bass. 
Cameron, K. S. y Quinn, R. E. (2011). Diagnosing and changing organizational culture: Based on the competing values framework. John Wiley \& Sons.

Deloitte. (2017). Deloitte global human capital trends. Reescribiendo las reglas para la era digital. https://www2.deloitte.com/gt/es/pages/human-capital/articles/introduction-human-capital-trends-2017.html

Deloitte. (2018). El auge de la empresa social: estudio “Tendencias globales de capital humano 2018". Resumen ejecutivo. Deloitte insights. https://www2.deloitte.com/co/ es.html?icid=site_selector_co

Erwin, D. y Garman, A. (2010). Resistance to organizational change: linking research and practice. Leadership \& Organization Development Journal, 31(1), 39-56. http://dx.doi. org/10.1108/01437731011010371

Grant, D., Michelson, G., Oswick, C. y Wailes, N. (2005). Guest editorial: Discourse and organizational change. Journal of Organizational Change Management, Bradford, 18 (1), 6-15. doi: 10.1108/09534810510579814

Haffar, M., Al-Karaghouli, W. y Ghoneim, A. (2014). An empirical investigation of the influence of organizational culture on individual readiness for change in Syrian manufacturing organizations. Journal of Organizational Change Management, 27 (1), 5-22. doi:10.1108/JOCM-04-2012-0046

Jacobs, G. A., Witteloostuijn, A. y Zeyse, J. (2012). A theoretical framework of organizational change. Journal of Organizational Change Management, 26 (5), 772-792.

Morgan, G. (1998). Imágenes de la organización. Alfaomega.

Pettigrew, A. M. (1979). On studying organizational cultures. Administrative Science Quarterly, 24(4), 570-581. https://pdfs.semanticscholar.org/98d7/c9a0199985eb79d828a9060f9530c593ab18.pdf

Quinn, R. E. y Rohrbaugh, J. (1981). A competing values approach to organizational effectiveness. Public Productivity Review, 5 (2), 122-140.

Quinn, R. y Rohrbaugh, J. (1983). A spatial model of effectiveness criteria: Toward a competing values approach to organizational analysis. Management Science, 29, 363-377. $10.1287 /$ mnsc.29.3.363

Quinn, R. E., Bright, D., Faerman, S. R., Thompson, M. P. y McGrath, M. R. (2014). Becoming a master manager: A competing values approach. John Wiley \& Sons.

Robbins, S. (2004). Comportamiento organizacional. Pearson/Prentice Hall.

Roskin, R. (1986). Corporate culture revolution: The managment development imperative. Journal of Managerial Psychology, 1(2), 3-9.

Schein, E. H. (1984). Culture as an environmental context for careers. Journal of Organizational Behavior, 5(1), 71-81.

Schein, E. (2004). Organizational cultures. Jossey Bass. 
Smollan, R., Matheny, J. y Sayers, J. (2010). Personality, affect and organisational change: A qualitative study. En N. Ashkanasy, W. Zerbe y C. Härtel, Research on Emotion in Organizations (vol. 6, pp. 85-112). Emerald Group.

Vargas, M. D., Sampieri, R., Álvarez, B. E. y Vargas, H. C. (2012). Diagnóstico de la cultura organizacional en universidades tecnológicas bajo el Modelo de Valores en Competencia. Estudios en Ciencias Sociales y Administrativas de la Universidad de Celaya, 2, 9-29.

Villa, E., Pons, R. y Obando, M. (2018). Aplicación de una metodología de diagnóstico del cambio de la cultura organizacional en instituciones de educación superior. Espacios, 39 (30), 16-24.

Weiss, H. y Cropanzano, R. (1996). Affective events theory: A theoretical discussion of the structure, cause and consequences of affective experiences at work. Research in Organizational Behavior, 18, 1-74.

White, L. A. (1964). La ciencia de la cultura: un estudio sobre el hombre y la civilización. Paidós. 


\section{REFLEXIONES FINALES}

Juan Javier Vesga $R$.

Universidad El Bosque

El análisis y comprensión de todo fenómeno humano o social implica dos niveles: uno teórico y otro empírico; el primero intenta siempre describir y explicar el segundo, mientras que este último se refiere a la vivencia concreta que experimentan los individuos y grupos en un contexto determinado. En este sentido, la comprensión y la explicación científicas de un determinado fenómeno o situación están constituidas por los niveles teórico y empírico, siendo el primero constructos ideales y el segundo datos observables (Cortada de Kohan, 1999).

En este orden de ideas, el cambio y la cultura organizacional son, a la vez, fenómenos que constituyen realidades de las organizaciones y que experimentan los individuos y grupos que pertenecen a ellas, y constructos teóricos que intentan describir y explicar estos fenómenos empíricos.

Como hechos concretos, el cambio y la cultura organizacional son fenómenos que forman parte de las vivencias de los individuos y los grupos en la cotidianeidad de la experiencia de trabajo y que impactan de diferentes maneras el desempeño y efectividad en el desarrollo de las tareas y el alcance de los objetivos en las organizaciones. Sin embargo, estos fenómenos no ocurren ni se experimentan de manera aislada, sino que ellos a su vez están insertos en un contexto laboral más amplio constituido por una diversidad de variables organizacionales que conforman la dinámica que caracteriza a cada organización.

En consecuencia, la configuración de culturas organizacionales y la experiencia o necesidad de cambio en las organizaciones ha variado a lo largo del tiempo en la medida en que los contextos sociales, políticos, económicos o tecnológicos han cambiado en la historia, particularmente, a partir de las grandes transformaciones laborales 
derivadas de la primera revolución industrial, hasta el presente en que el mundo experimenta la denominada cuarta revolución industrial, aunque cultura y cambio organizacionales, como constructos teóricos, no hayan sido objeto de estudio y teorización desde el comienzo de estas revoluciones.

En lo que respecta al presente estado de cosas, la cuarta revolución industrial o industria 4.0 implica la convergencia de los procesos de producción industrial junto con las tecnologías de información y comunicación, lo que produce una fusión entre los mundos físico y virtual (Hermann, Pentek y Otto, 2016), que facilita almacenar una inmensa cantidad de información, poder procesarla y trabajar con ella en muy poco tiempo, así como la interacción de la tecnología en la acción, conocimiento y comprensión de fenómenos a escala molecular o subatómica y a escala macro como los sistemas solares y galaxias, lo cual representa importantes desarrollos tecnológicos producto de esta interacción sinérgica, como los sistemas fisicocibernéticos, la nanotecnología, la fusión entre lo físico, lo digital y lo biológico, entre otros (Skilton y Hovsepian, 2018).

En este contexto, las culturas organizacionales pasan de estar limitadas a una región geográfica para convertirse en culturas transnacionales, ya que la conformación y gestión de las organizaciones trasciende fácilmente las fronteras políticas o físicas de un país, integrando diversas nacionalidades. Así mismo, las tecnologías actuales facilitan la interacción en la distancia entre seres humanos y entre estos y las máquinas, lo cual genera nuevas concepciones de la acción social y las relaciones humanas.

En relación con la gestión del cambio, este se ha dado de manera vertiginosa y en gran magnitud, ya que los seres humanos han experimentado en un lapso de dos décadas radicales transformaciones tecnológicas que han impulsado el avance industrial y empresarial como no ocurrió en todo un siglo.

En este orden de ideas, en el nivel de lo teórico, el campo de la psicología organizacional enfrenta importantes desafíos para la investigación y el desarrollo de conceptos y teorías que permitan explicar, comprender, predecir e intervenir en el cambio organizacional y la gestión de la cultura en el actual escenario de trabajo. Algunos de los temas que emergen como prioritarios en el contexto de la cuarta revolución industrial son los siguientes.

Los procesos de comunicación interpersonal trascienden la esfera de la presencialidad inmediata para desarrollarse a través de interacciones en la distancia con mediación de las tecnologías de comunicación. Aunado a la comunicación, la formación de equipos de trabajo y el trabajo en equipo, también se ven impactados por la realización de reuniones con presencialidad en acceso remoto. Esto imprime 
unas dinámicas deferentes en la interacción social que demanda de las personas la habilidad para mantener los vínculos humanos que integren a cada persona a sus equipos de trabajo.

El liderazgo en las organizaciones en el contexto de las industrias 4.0 exige otorgar un mayor nivel de autonomía a las personas y a los equipos de trabajo y estos a su vez deben actuar responsablemente para corresponder con confianza a la autonomía asignada. En este sentido, el liderazgo debe evolucionar de un direccionamiento centrado en los colectivos a uno centrado en los equipos particulares y los individuos.

Finalmente, cobran gran importancia la flexibilidad en la gestión, la capacidad de adaptabilidad permanente, la rapidez de la respuesta a los cambios y la capacidad de trabajar en equipos con un enfoque más plural y diverso, en el que se construyen equipos multifuncionales e interdisciplinares que trabajan por medio de redes virtuales más flexibles y horizontales con una orientación hacia los procesos más que hacia las funciones (Martínez-González, Selva y Crespo, 2019).

\section{Referencias}

Cortada de Kohan, N. (1999). Teorías psicométricas y construcción de tests. Lugar.

Hermann, M., Pentek, T. y Otto, B. (2016). Design Principles for Industrie 4.0 Scenarios. 49th Hawaii International Conference on System Sciences, 3927-39367. doi:10.1109/ HICSS.2016.488

Martínez-González, M., Selva, C. y Crespo, J. L. (2019). La evolución de las competencias de RRHH en organizaciones inmersas en la cuarta revolución industrial. Quaderns de Psicologia, 21(1). doi:10.5565/rev/qpsicologia.1471

Skilton, M. y Hovsepian, F. (2018). The 4th industrial revolution. Responding to the impact of artificial intelligence on business. Palgrave Macmillan. 
Editado por la Universidad Católica de Colombia en diciembre de 2020, en tipografía Minion Pro, tamaño 11 pts.

Publicación digital Hipertexto Ltda.

Bogotá, D. C., Colombia 


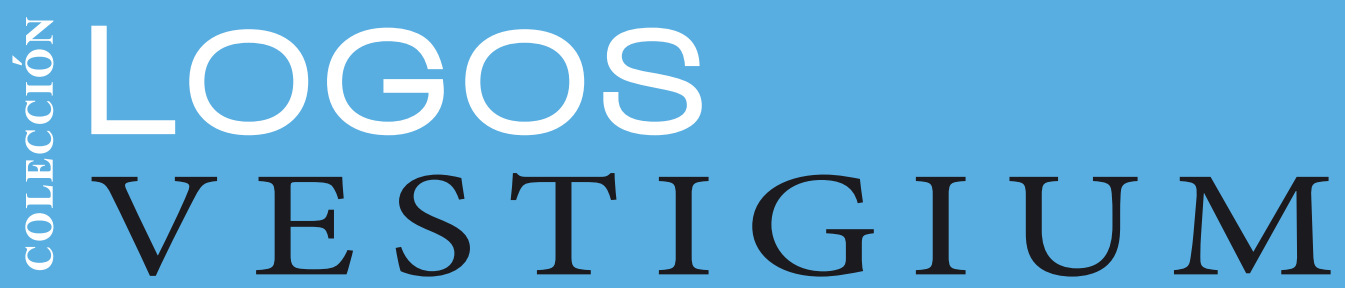

Cultura organizacional

y cambio:

reflexiones y discusiones desde la psicologia organizacional
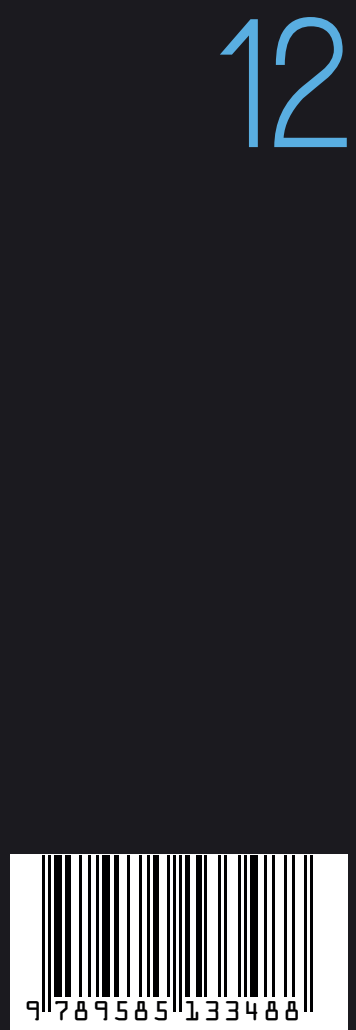

La cultura organizacional es uno de los ejes centrales y transversales de las organizaciones; las orientaciones de cultura en las organizaciones se ven reflejados en la manera de actuar de sus miembros y, por ende, en la forma como se aceptan los diversos cambios que se presentan tanto a nivel interno como externo. La estrategia de las organizaciones para responder a estos cambios implica que sean más competitivas en un ambiente permeado por la cultura.

En ese orden de ideas, las culturas cuyas características son fuertes son más difíciles de permear y en las que, por lo tanto, será más difícil implementar de manera exitosa los cambios, mientras que las culturas que tienen una cultura dúctil, propician los cambios y sus miembros tienen una disposición y actitud más favorables. 